\title{
Enhanced Durability of Desulfurization Sorbents for Fluidized-Bed Applications
}

\section{Topical Report}

\author{
R.P. Gupta \\ S.K. Gangwal
}

Work Performed Under Contract No.: DE-AC21-88MC25006

\author{
For \\ U.S. Department of Energy \\ Office of Fossil Energy \\ Morgantown Energy Technology Center \\ P.O. Box 880 \\ Morgantown, West Virginia 26507-0880
}

By
Research Triangle Institute
P.O. Box 12194
Research Triangle Park, North Carolina 27709

November 1992 


\begin{abstract}
Advanced integrated gasification combined cycle (IGCC) power systems require the development of high-temperature desulfurization sorbents capable of removing hydrogen sulfide $\left(\mathrm{H}_{2} \mathrm{~S}\right)$ from coal gasifier gas down to low parts per million (ppm) levels. In a previous investigation (base period of this project), a granulation method was demonstrated for preparing zinc ferrite sorbents with enhanced iong-term chemical reactivity and mechanical strength for fluidized-bed applications. Fluidized-bed hot gas desulfurization reactors offer significant potential advantages in IGCC systems because of their ability to control the highly exothermic regeneration involved. However, fluidized-bed reactors require a durable attrition-resistant sorbent in the 100 to $300 \mu \mathrm{m}$ diameter size range. Zinc ferrites prepared by the granulation technique exhibited superior performance (attrition resistance and long-term chemical reactivity) over those prepared by other techniques including spray drying, impregnation, and crushing and screening of durable extrudates. However, zinc ferrite was found to be limited to a maximum temperature of about $550^{\circ} \mathrm{C}$ beyond which it tended to lose its mechanical strength due to excessive reduction and iron carbide formation.
\end{abstract}

To extend the operating temperature range and further improve the durability of fluidizable sorbents, zinc titanate, another leading regenerable sorbent, was selected for development in the later part of this project. A number of zinc titanate formulations were prepared in the 50 to 300 $\mu \mathrm{m}$ range using granulation and spray drying methods. Important sorbent preparation variables investigated included zinc to titanium ratio, binder type, binder amount, and various chemical additives such as cobalt and molybdenum. A number of sorbents selected on the basis of screening tests were subjected to bench-scale testing for 10 cycles at high temperature, high pressure (HTHP) conditions using the reactor system designed and constructed during the base program. This reactor system is capable of operation either as a $2.0 \mathrm{in.}$ or $3.0 \mathrm{in}$. I.D. bubbling bed and is rated up to $20 \mathrm{~atm}$ operation at $871^{\circ} \mathrm{C}$. Bench-scale testing variables included sorbent type, temperature $\left(550\right.$ to $\left.750^{\circ} \mathrm{C}\right)$, gas type (KRW or Texaco gasifier gas), steam content of coal gas, and fluidizing gas velocity (6 to $15 \mathrm{~cm} / \mathrm{s})$. The sorbents prepared by spray drying showed poor performance in terms of attrition resistance and che nical reactivity. On the other hand, the granulation method proved to be very successful. For example, a highly attritionresistarit zinc titanate formulation, $Z T-4$, prepared by granulation exhibited virtually no zinc loss and demonstrated a constant high reactivity and sulfur capacity over 10 cycles, i.e., approximately a 60 percent capacity utilization, with Texaco gas at $750^{\circ} \mathrm{C}, 15 \mathrm{~cm} / \mathrm{s}$ fluidizing velocity and 15 atm pressure. The commercial potential of the granulation method for zinc titanate manufacture was demonstrated by preparing two $80 \mathrm{lb}$ batches of sorbent with zinc to titanium mol ratios of 0.8 and 1.5 .

In addition, a number of reactor design issues, including kinetics of sulfidation and regeneration, zinc vaporization, sulfate formation, etc., were addressed in this study. Furthermore, a simple mathematical model based on a single parameter was evaluated which adequately described the performance of the semi-batch reactor used in this study. Finally, a conceptual design was evaluated for a continuous hot-gas desulfurization system inivolving two fluidized-bed reactors. 


\section{ACKNOWLEDGMENTS}

This research was sponsored by the Morgantown Energy Technology Center (METC) of the U.S. Department of Energy (DOE) under Contract No. DE-AC21-88MC25006. Valuable guidance and suggestions provided by Mr. Suresh $\mathrm{C}$. Jain of METC as Contracting Officer's Representative (COR) are gratefully acknowledged. Helpful discussions were also held with Drs. Tom Grindley, Tom Dorchak, and L. Gasper-Galvin of METC, Dr. Douglas P. Harrison of Louisiana State University, Dr. Raul Ayala of General Electric (GE), Messrs. Tom Leininger and Ken Wolfenberger of Texaco, Inc., and Dr. R. Datta of Virginia Polytechnic Institute and State University. United Catalysts, Inc. (UCI), and DuPont prepared and supplied several spray-dried sorbent formulations. $\mathrm{UCl}$ also provided two baseline zinc titanate formulations. Dr. John Renton of West Virginia University conducted all the $x$-ray diffraction (XRD) and scanning electron microscope (SEM) analyses. Mr. Peter Grohse and Dr. David Binstock performed the inductively coupled plasma (ICP) zinc and titanium analyses. Dr. William J. McMichael provided useful suggestions in carrying out the modeling of the semi-batch fluidized-bed reactor, as well as on a number of other issues addressed in this report. Technical assistance from Gary Howe, Gary Folsom, Teresa Paar, Dan Ward, Chris Fuller, E.W. Johnson, Mike Taylor, Mark Janello, Sue Pauley, Linda Gaydosh, and Jan Shirley is gratefully acknowledged. 


\section{TABLE OF CONTENTS}

Chapter

Page

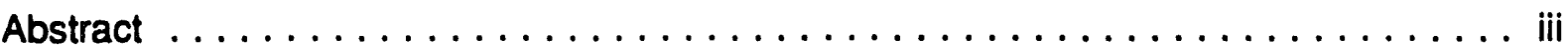

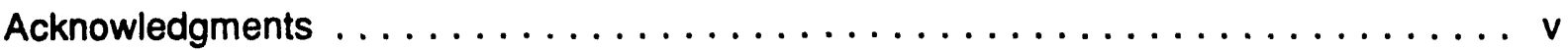

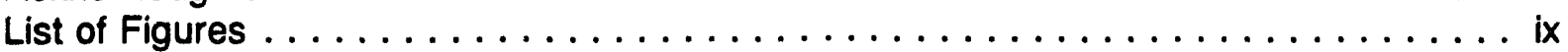

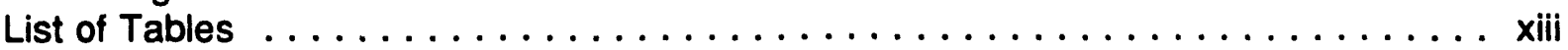

Executive Summary .........................

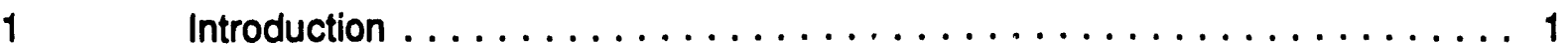

1.1 Contract Objectives $\ldots \ldots \ldots \ldots \ldots \ldots \ldots \ldots \ldots \ldots \ldots$

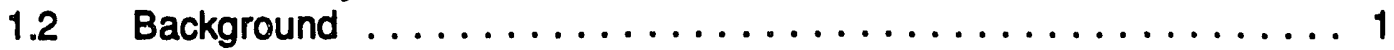

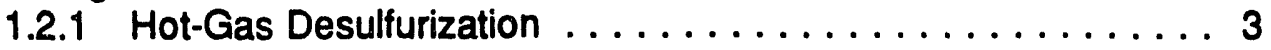

1.2 .2 Zinc Ferrite ..................... 5

1.2.3 Copper-based Sorbents $\ldots \ldots \ldots \ldots \ldots \ldots \ldots \ldots \ldots \ldots$

1.2.4 Zinc Titanate Sorbents . . . . . . . . . . . . 7

2 Zinc Titanate: A Review of Chemical and Ceramic Aspects . . . . . . . 9

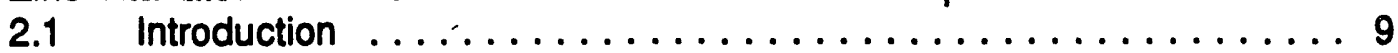

2.2 Use of Zinc Titanate Compounds . . . . . . . . . . . . . 9

2.3 Zinc Titanate Preparation .................... 13

$3 \quad$ Bench-Scale Sorbent Test Facility $\ldots \ldots \ldots \ldots \ldots \ldots \ldots \ldots \ldots$

3.1 Description of Bench Unit . . . . . . . . . . . . . . 17

3.1.1 Gas Delivery System ... . . . . . . . . . . . 17

3.1.2 Reactor Assembly . . . . . . . . . . . . . . . 19

3.1.3 Data Acquisition and Process Control ............ 20

3.1.4 Outlet Gas Analysis System . . . . . . . . . . 21

3.1.5 Reactor Off-gas Venting System . . . . . . . . . 22

3.2 Cold Flow Model . . . . . . . . . . . . . . . . . . . . 22

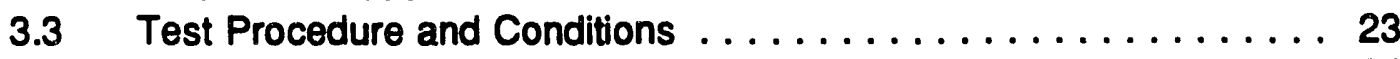

3.41 -in.-I.D. Quartz Reactor System . . . . . . . . . . . . . . 24

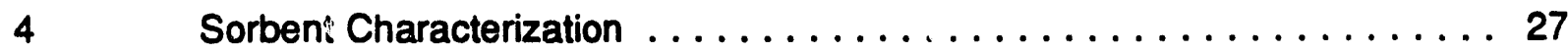

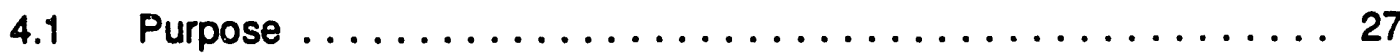

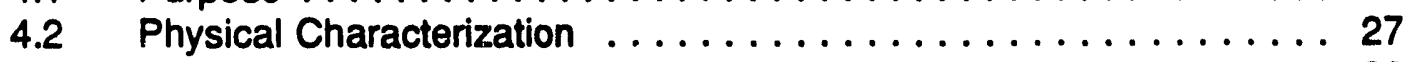

4.2.1 Particle Size Distribution . . . . . . . . . . . . . 28

4.2.2 BET Surface Area . . . . . . . . . . . . . . 28

4.2.3 Pore Size Distribution . . . . . . . . . . . . . 28

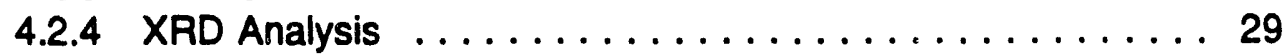

4.2 .5 SEM/EDS Analysis . . . . . . . . . . . . . . 30

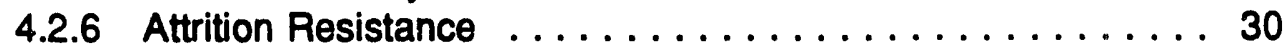

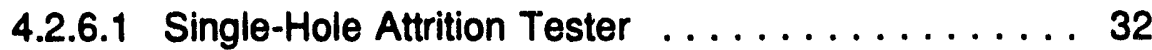

4.2.6.2 Three-Hole Attrition Tester . . . . . . . . . 33

4.3 Chemical Characterization .................. 35

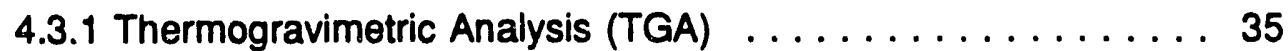

4.3.2 Determination of Zinc and Titanium Contents . . . . . . . 38 
TABLE OF CONTENTS (cont.)

Chapter

Page

Sorbent Preparation and Screening $\ldots \ldots \ldots \ldots \ldots \ldots \ldots$

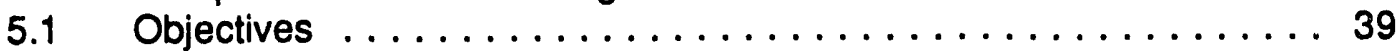

5.2 Sorbent Preparation Techniques Investigated ............. 39

5.2 .1 UCl's Technique .................... 40

5.2 .2 Spray Drying $\ldots \ldots \ldots \ldots \ldots \ldots \ldots \ldots \ldots \ldots \ldots \ldots \ldots \ldots \ldots$

5.2.2.1 UCl's Effort .................... 41

5.2.2.2 Spray-dried Formulations Produced by DuPont . . . 44

5.2 .3 Granulation ..................... 46

5.3 Sorbent Screening $\ldots \ldots \ldots \ldots \ldots \ldots \ldots \ldots \ldots \ldots \ldots \ldots$

5.3.1 Screening of First Series of Sorbents . . . . . . . . 46

5.3.2 Effect of Calcination Time on the Sorbent Performance . . . 52

5.3.3 Screening of Second Series of Sorbents . . . . . . . . 54

5.4 Preparation of a Large Batch . . . . . . . . . . . . . 56

$6 \quad$ Bench-Scale Testing of Zinc Titanate Sorbents $\ldots \ldots \ldots \ldots \ldots \ldots$

6.1 Objective ......................... 59

6.2 Run No. 1-10-Cycle Testing of L-3758 Sorbent . . . . . . . . . 62

6.3 Run No. 2-10-Cycie Testing of ZT-5 in KRW-Gas (20\% Steam) . . 62

6.4 Run No. 3-10-Cycle Testing of ZT-5 in KRW-Gas (5\% Steam) . . 64

6.5 Run No. 4-10-Cycle Testing of ZT-5 in Texaco Gas . . . . . . . . 64

6.6 Run No. 5-10-Cycle Testing of ZT-2 in Texaco Gas . . . . . . . . . 66

6.7 Run No. 6-10-Cycle Testing of ZT-2 in KRW-Gas (5\% Steam) . . 67

6.8 Run No. 7-10-Cycle Testing of ZT-7 in Texaco Gas . . . . . . . . 68

6.9 Run No. 8-10-Cycle Testing of ZT-4 in Texaco Gas at $650^{\circ} \mathrm{C}$. . . . 69

6.10 Run No. 9-10-Cycle Testing of ZT-4 in Texaco Gas at $750^{\circ} \mathrm{C} \ldots . .70$

6.11 Run No. 10-10-Cycle Testing of ZT-4 Under High Velocity

Conditions .......................... 72

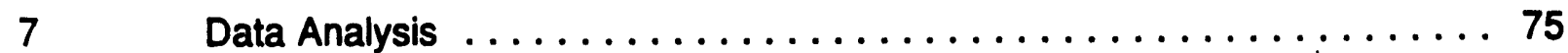

$7.1 \quad$ Parametric Studies ...................... 75

7.1.1 Method of Sorbent Preparation ............. 75

7.1 .2 Effect of Sulfidation Temperature $\ldots \ldots \ldots \ldots \ldots \ldots \ldots$

7.1.3 Effect of Superficial Gas Velocity ............ 81

7.1 .4 Effect of Binders .................... 81

7.1.5 Effect of Gas Composition ................ 82

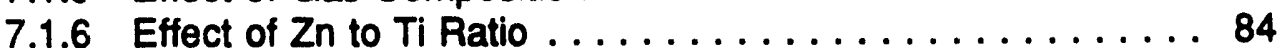

7.2 Address Reactor Design Issues . . . . . . . . . . . . . 84

7.2 .1 Sulfidation Kinetics . . . . . . . . . . . . . . . 84

7.2.2 Sorbent Regeneration ................. 90

7.2.2.1 Experimental Results . . . . . . . . . . . 90

7.2.2.2 Analysis of Temperature Rise ............ 92

7.2.2.3 Comments on Regeneration Kinetics .........996

7.2.2.4 Comments on Sulfate Formation ........... 98 
TABLE OF CONTENTS (cont.)

Chapter

Page

7.2.3 Extent of Zinc Vaporization ................ 98

7.2.3.1 Thermodynamic Allalysis . . . . . . . . . . . . 98

7.2.3.2 Experimental Results ............... 100

7.2.4 Effect of Sulfidation on Sorbent Attrition .......... 101

7.2.5 Extent of Shift Reaction ................. 106

7.2.6 Conceptual Commercial Systems . . . . . . . . . 108

$8 \quad$ Mathematical Modeling $\ldots \ldots \ldots \ldots \ldots \ldots \ldots \ldots \ldots \ldots \ldots \ldots \ldots$

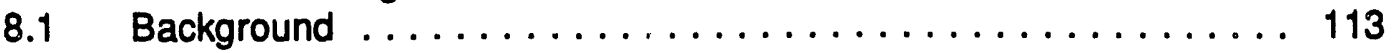

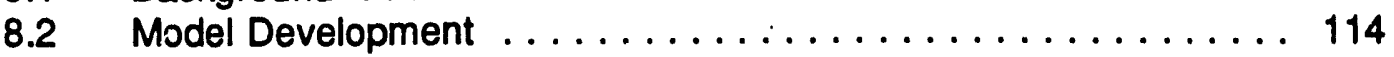

8.3 Comparison with Experimental Data $\ldots \ldots \ldots \ldots \ldots \ldots \ldots .120$

8.4 Possible Improvements to Model . ............... 123

9 Conclusions and Recommendations $\ldots \ldots \ldots \ldots \ldots \ldots \ldots \ldots \ldots$

$10 \quad$ References $\ldots \ldots \ldots \ldots \ldots \ldots \ldots \ldots \ldots \ldots \ldots \ldots \ldots \ldots . \ldots \ldots$

List of Acronyms . ............................ 133

List of Symbols ............................... 137

\section{Appendix}

A Samples of Pore Size Distribution Reports Generated by

Micromeritics Autopore 922011 Mercury Porosimeter ............ A-1

B A Sample X-Ray Diffraction Report and Scanning Electron

Micrographs for a Zinc Titanate Specimen Done by

West Virginia University ........................ B-1

C $\mathrm{H}_{2} \mathrm{~S}$ Breakthrough Curves for Runs 1 to $10 \ldots \ldots \ldots \ldots \ldots \ldots \ldots \ldots \ldots$

D Cos Breakthrough Curves for Runs 1 to $10 \ldots \ldots \ldots \ldots \ldots \ldots$ D-1

E Sulfur Capacities Curves for Runs 1 to $10 \ldots \ldots \ldots \ldots \ldots \ldots$ E-1

F Particle Size Distribution of Fresh and Reacted Sorberits for

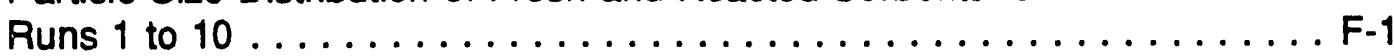




\section{LIST OF FIGURES}

Number

Page

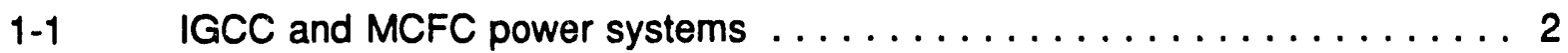

1-2 Calculation of equilibrium $\mathrm{H}_{2} \mathrm{~S}$ concentrations for $\mathrm{ZnO} \ldots \ldots \ldots \ldots \ldots$

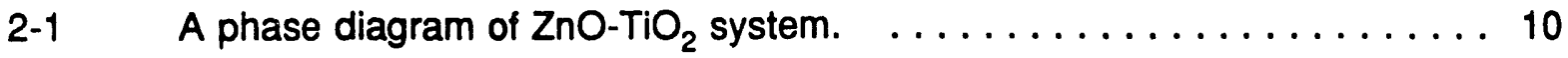

3-1 Bench-scale fluid-bed sorbent test facility $\ldots \ldots \ldots \ldots \ldots \ldots \ldots \ldots$

3-2 Sulifidation gas preheater $\ldots \ldots \ldots \ldots \ldots \ldots \ldots \ldots \ldots \ldots \ldots \ldots \ldots \ldots$

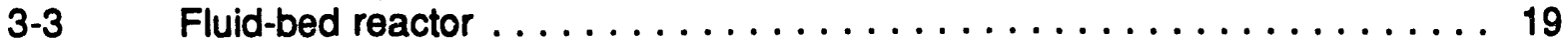

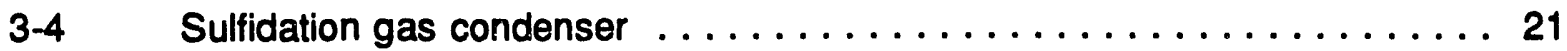

3-5 Schematic of GC sampling system for bench unit $\ldots \ldots \ldots \ldots \ldots \ldots 22$

3-6 High-pressure fluid-bed cold-flow see-through reactor model . . . . . . . 23

3-7 Bench-scale experimental test setup for 1-in.-ID quartz reactor . . . . . . 25

4-1 Bragg reflection positions for zinc titanate samples $\ldots \ldots \ldots \ldots \ldots \ldots \ldots$

4-2 Schematic of a single-hole attrition tester $\ldots \ldots \ldots \ldots \ldots \ldots \ldots \ldots \ldots$

4-3 Schematic of a three-hole attrition tester ................ 34

4-4 RTI's atmospheric pressure TGA system $\ldots \ldots \ldots \ldots \ldots \ldots \ldots \ldots$

5-1 Effect of sorbent loss on electricity cost $\ldots \ldots \ldots \ldots \ldots \ldots \ldots \ldots$

5-2 Particle size distribution of spray-dried formulations supplied by UCl $\ldots .42$

5-3 TGA reactivity of spray-dried $\mathrm{ZT}$ sorbents $\ldots \ldots \ldots \ldots \ldots \ldots \ldots \ldots$

5-4 Attrition behavior of spray-dried sorbents $\ldots \ldots \ldots \ldots \ldots \ldots \ldots \ldots \ldots 44$

5-5 TGA reactivity profile of DuPont $Z T$ formulation in Texaco gas . . . . . . . 45

5-6 TGA reactivities of various zinc titanate formulations in a TGR at

$5500^{\circ} \mathrm{C}$ in the Texaco gas .................... 48

5-7 Sulfur capacities of various zinc titanate formulations in a TGR

at $550^{\circ} \mathrm{C}$ in the Texaco gas $\ldots \ldots \ldots \ldots \ldots \ldots \ldots . \ldots . \ldots 4$

5-8 Attrition tendency of various zinc titanate formulations measured

in the three-hole attrition tester . . . . . . . . . . . . . . . 50

5-9 TGA reactivities of ZT-5 and ZT-2 formulations as a function of

calcination time ....................... 53

5-10 TGA reactivities of second series of 2 T-formulations $\ldots \ldots \ldots \ldots \ldots$

6-1 TGA reactivities of fresh and reacted $Z T-7$ sorbent $\ldots \ldots \ldots \ldots$

7-1 A comparison of breakthrough curves during first cycle for L-7

(zinc ferrite), L-3758 (UCI zinc titanate) and ZT-5 (RTI zinc titanate) . . . . 76

$7-2 \quad$ Sulfur capacities of various sorbents $\ldots \ldots \ldots \ldots \ldots \ldots \ldots \ldots$

7-3 Zinc reduction profiles for $L-3758$ and $Z T-5$ in KRW reducing gas $\left(20 \%\right.$ steam) at $650^{\circ} \mathrm{C} \ldots \ldots \ldots \ldots \ldots 77$

7-4 Attrition rates of various sorbents measured in

three-hole attrition tester (15 slpm) ...................... .... . . . .

7-5 Conversion of ZT-5 at various temperatures in Texaco gas in a TGR .... 79

7-6 ZT-4 breakthrough curves at 650 and $750^{\circ} \mathrm{C}$ in Texaco gas . . . . . . 80

7-7 Sulfur capacities of $\mathrm{ZT}-4$ at 650 and $750^{\circ} \mathrm{C} \ldots \ldots \ldots \ldots$ 


\section{LIST OF FIGURES (cont.)}

Number

Page

7-8 Breakthrough behavior of $\mathrm{ZT}-4$ at $750^{\circ} \mathrm{C}$ at low and high superficial velocities $\ldots \ldots \ldots \ldots \ldots \ldots \ldots \ldots \ldots \ldots$

7-9 Sulfur capacities of ZT-5 sorbent in various coal gases $\ldots \ldots \ldots \ldots$. . 83

7-10 Sulfur capacities of ZT-2 sorbent in various coal gases $\ldots \ldots \ldots \ldots \ldots$

7-11 TGA reactivities of $Z T-2$ sorbent at various temperatures in Texaco gas . . . . . . . . . . . . . . . 85

$7-12$

$7-13$ Arrhenius plot for $Z T-2$ and $Z T-5 \ldots \ldots \ldots \ldots \ldots \ldots$. . . . . . 88

Regeneration temperature profile for $Z T-4$ in Texaco gas . . . . . . . . . 91

Zinc loss as a function of time in KRW reducing gas

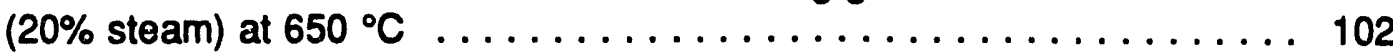

7-15 Zinc loss as a function of time in KRW reducing gas

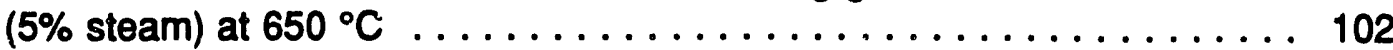

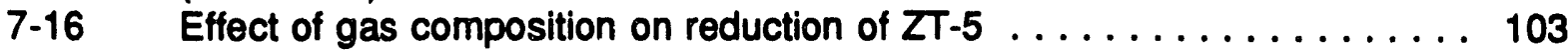

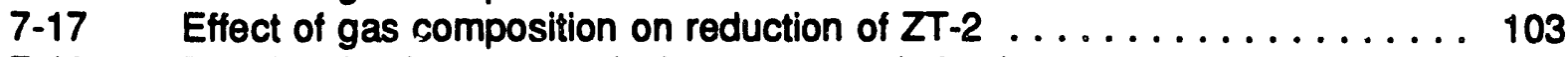

7-18 Relationship between reducing power and zinc loss

as measured by weight loss rate in a TGA at $1 \mathrm{~atm}, 650^{\circ} \mathrm{C}$

in the presence of various $\mathrm{H}_{2} \mathrm{~S}$-free coal gas compositions . . . . . . . . . 104

7-19 Fluid-bed absorber with fluid-bed regenerator both operating

in a bubbling fluidized-bed mode ... . . . . . . . . . . . . . . . . . 109

7-20 Schematic of a conceptual fluid-bed hot-gas desulfurization system employing a riser for sulfider and a bubbling fluid bed

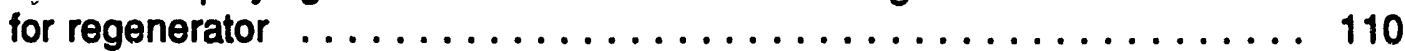

7-21 Continuous fluid-bed hot-gas desulfurization system employing

a circulating fluid-bed sulfider, a bubbling-bed regenerator

and DSRP for downstream $\mathrm{SO}_{2}$ treatment $\ldots \ldots \ldots \ldots \ldots \ldots \ldots$

8-1 Schematic of semi-batch fluidized-bed reactor . . . . . . . . . . . . . . . 114

8-2 ZnO conversion as a function of dimensionless time $\left(\mathrm{t}^{*}\right)$ for

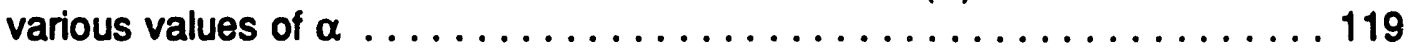

8-3 Fraction of $\mathrm{H}_{2} \mathrm{~S}$ unreacted as a function of dimensionless time $\left(\mathrm{t}^{*}\right)$

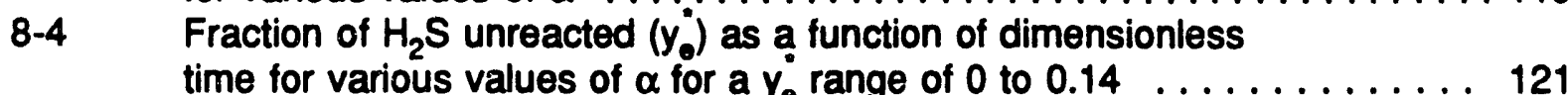

8-5 Dimensionless parameter, $\alpha$, as a function of dimensionless time for

8-6 A comparison of experimental data (Run No. 9) with model

8-7 A comparison of experimental data (Run No. 10) for high velocity

case with model predictions $(k=8.5$ and 9$) \ldots \ldots \ldots 123$ 


\section{LIST OF TABLES}

Number

Page

2-1 U.S. Patents Issued to Phillips Petroleum on

Zinc Titanate Catalyst ..................... 11

4-1 Composition of TGA Test Gases $\ldots \ldots \ldots \ldots \ldots \ldots \ldots \ldots$

5-1 Chemical Composition and Structural Properties of Various

5-2 Spray-dried Sorbent Formulations $\ldots \ldots \ldots \ldots \ldots \ldots \ldots \ldots \ldots \ldots \ldots \ldots$

5-3 Series of Zinc Titanate Sorbents Prepared Using the

Granulation Technique . . . . . . . . . . . . . . . . . . . . . 47

5-4 Comparison of TGA Sulfur Capacities and Other Structural

Properties for First ZT Series . . . . . . . . . . . . . . . 49

5-5 Attrition Parameters of Various Zinc Titanate Sorbents $\ldots \ldots \ldots \ldots \ldots$

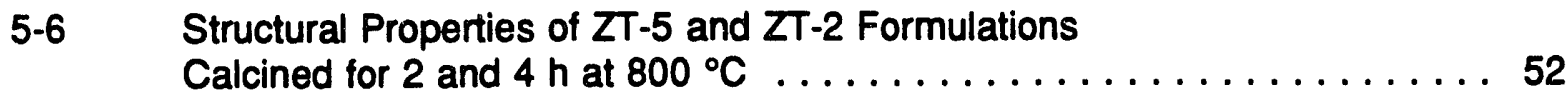

5-7 Physical and Structural Characterization of Second Series

5-8 Physical and Chemical Properties of ZT-5 and ZT-2 Zinc

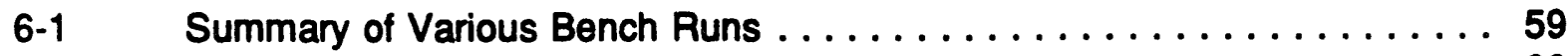

$6-2 \quad$ Bench-scale Test Conditions ...................... 60

6-3 Composition of Various Simulated Sulfidation Gases (vol \%) . . . . . . . . 60

6-4 Regeneration Conditions for Zinc Titanate Tests . . . . . . . . . . . 61

6-5 Structural Properties of Fresh and Reacted L-3758

Formulation (Run \#1) . . . . . . . . . . . . . . . 63

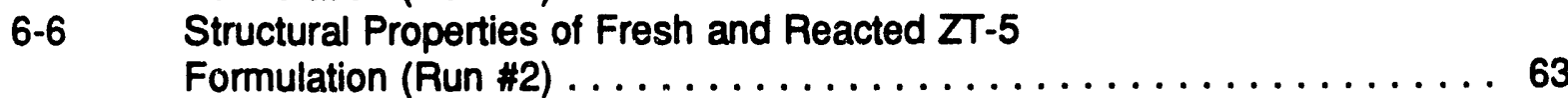

6-7 Structural Properties of Fresh and Reacted ZT-5

6-8 Structural Properties of Fresh and Reacted ZT-5

Formulation (Run \#4) . . . . . . . . . . . . . . . . 65

6-9 Structural Properties of Fresh and Reacted ZT-2

Formulation (Run \#5) . . . . . . . . . . . . . . . 66

6-10 Struc'ural Properties of Fresh and Reacted $\mathrm{ZT}-2$

6-11 Structural Properties of Fresh and Reacted ZT-7

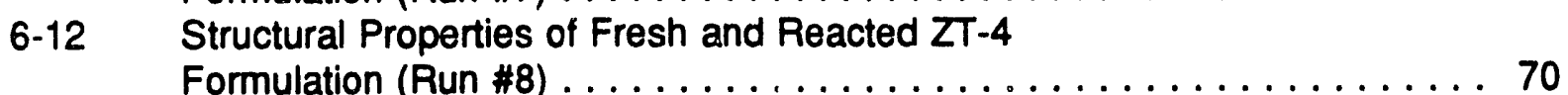

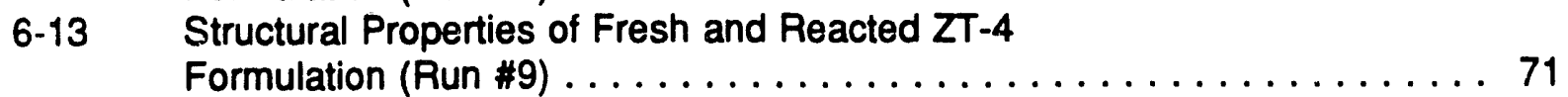




\section{LIST OF TABLES (cont.)}

Number

Page

6-14 Attrition Behavior of Fresh, Reacted, and Sulfided ZT-4 . . . . . . . . . 72

6-15 Structural Properties of Fresh and Reacted ZT-4

Formulation (Run \#10) .................... 73

7-1 Sulfider Sorbent Requirement for a 100-MW Texaco Plant . . . . . . . . . 90

7-2 Comparison of Measured $\mathrm{SO}_{2}$ with Stoichiometric $\mathrm{SO}_{2}$

During Quasi Steady-State Period of Regeneration (vol \%) . . . . . . . . 92

7-3 Specific Heats of Solids of Interests ................. 93

7-4 Estimated Adiabatic Temperature Rise as a Function of

Sorbent Circulation Rate (100 MW Electric KRW Gas,

$3 \%$ Sulfur Coal . . . . . . . . . . . . . . . . . . . . . . . 94

7-5 Adiabatic (Maximum) Gas Temperature Rise in a

Batch Regenerator ........................... 95

7-6 Comparison of Experimental and Adiabatic Temperature

Rise $\left({ }^{\circ} \mathrm{C}\right)$ Versus Time Data for Batch Reactor . . . . . . . . . . . . . 96

7-7 Thermodynamic Equilibrium Constants for Reactions

(7-21), (7-22), and (7-23) . . . . . . . . . . . . . . . 99

7-8 Equilibrium Zinc Vapor Concentration in Texaco Coal Gas

Leaving the Sulfider (mol/100 mol gas) . . . . . . . . . . . . . . . . . 99

7-9 Equilibrium (Maximum Potential) Zinc Loss from a 400-MW Texaco

Coal Gas IGCC Plant (18\% Steam Coal Gas) at 23.8 atm Operating

Pressure ............................... 100

7-10 Attrition Behavior of Fresh, Reacted, and Sulfided Sorbent . . . . . . . . 104

7-11 Attrition Loss as a Function of Extent of Sulfidation ... . . . . . . . . 105

7-12 Hardgrove Grindability Index (HGI) for Various Materials . . . . . . . . 106

7-13 Theoretical Extent of Shift Reaction .................. 106

7-14 Calculations of CO Conversion via Shift Reaction ............ 107

7-15 Comparison of Shift Activity in Fixed and Fluid Beds of Zinc

Titanate (Ratio of Experimental CO Conversion to Maximum

Theoretical Fractional Conversion) .................... 108 


\section{EXECUTIVE SUMMARY}

The U.S. Department of Energy/Morgantown Energy Technology Center (DOE/METC) is actively pursuing the development of hot-gas desulfurization systems for application to advanced IGCC and integrated gasification fuel cell (IGFC) power plants. Zinc ferrite and zinc titanate are currently the leading mixed-metal oxide desulfurization sorbent candidates. Both of these sorbents have high sulfur capacities and can remove hydrogen sulfide $\left(\mathrm{H}_{2} \mathrm{~S}\right)$ from coal gasifier gas down to a few ppm. They can be easily regenerated with inert-diluted air for multicycle operation.

Early testing of zinc ferrite and zinc titanate was conducted in fixed-bed reactor systems using cylindrical extrudates prepared by mixing the individual oxides, extrusion using a suitable binder, and calcination. However, the highly exothermic regeneration involved imposes some operational problems (e.g., sorbent spalling) on the efficient operation of a fixed-bed system. These problems are not as serious in moving-and fluidized-bed reactor systems that are currently being developed with DOE/METC sponsorship at GE and the Research Triangle institute (RTI), respectively.

Provided that suitable sorbents can be developed, fluidized-bed reactors offer several potential advantages over fixed-bed reactors. These advantages include good gas-solid contact, ability to continuously add or remove sorbent, excellent temperature control of the highly exothermic regeneration, use of small particles leading to faster overall kinetics, and nearly continuous steady-state operation. However, highly attrition-resistant sorbents with good sulfur capacity which are capable of withstanding stresses induced by rapid temperature swings, chemical transformations, and fluidization and transport are required before fluidized beds can be employed successfully.

In a previous investigation (base period of this project, Tasks 1 through 6), a granulation method was developed and demonstrated for preparing zinc ferrite sorbents with enhanced longterm chemical reactivity and mechanical strength. Zinc ferrite prepared by granulation exhibited superior performance in terms of attrition resistance and long-term chemical reactivity over those prepared by other techniques including spray drying, impregnation, and crushing and screening of durable extrudates. Despite superior performance of formulations prepared by granulation, zinc ferrite was generally found to be limited to a maximum temperature of about $550^{\circ} \mathrm{C}$ beyond which it tended to lose its mechanical strength due to excessive reduction and iron carbide formation, particularly under highly reducing conditions.

The work in Tasks 7,8 , and 10 of this project, described herein, was aimed to develop the second leading regenerable sorbent, zinc titanate, suitable for fluidized-bed reactors. Selection of zinc titanate for development is based on the fact that in fixed-bed tests it has shown higher durability than zinc ferrite, and also it has the potential to extend the operating temperature range of hot-gas desulfurization systems up to $760^{\circ} \mathrm{C}\left(1,400^{\circ} \mathrm{F}\right)$, and can withstand highly reducing fuel gas compositions.

A number of zinc titanate formulations were prepared in the 50 to $300 \mu \mathrm{m}$ dia particle size range using granulation and spray drying methods. Sorbent formulations prepared by spray drying by both United Catalysts, Inc. (UCI) and DuPont exhibited poor overall performance as measured by attrition resistance and chemical reactivity. On the other hand, the granulation 
method proved to be very successful. A number of sorbent formulations prepared using this technique exhibited excellent durability, attrition resistance, and sulfur capacity during multicycle testing. Important sorbent preparation variables during granulation included zinc to titanium ratio, binder type, binder amount, and various chemical additives such as cobalt and molybdenum.

Three promising sorbent formulations designated at $\mathrm{ZT}-2, \mathrm{ZT}-5$, and $\mathrm{ZT}-4$ were identified using screening tests. ZT-2 and ZT-5 were prepared with 2 percent binder using zinc to titanium mol ratios of 0.8 and 1.5, respectively. ZT-4 was prepared with 5 percent binder and a zinc to titanium ratio of 1.5. The screening tests included determination of particle size distribution, pore size distribution, BET surface area, chemical reactivity in a thermogravimetric reactor (TGR) and, most importantly, the attrition resistance. $Z T-4$ sorbent was found to have the best overall performance tested in terms of attrition resistance, long-term chemical reactivity, and sulfur capacity.

Ten HTHP runs were carried out, each involving 10 sulfidation-regeneration cycles in the bench-scale unit designed and constructed in the base program. This unit is capable of operation at up to $871^{\circ} \mathrm{C}$ at $20 \mathrm{~atm}$. Bench-scale testing variables included sorbent type, temperature (550 to $750^{\circ} \mathrm{C}$ ), gas type (KRW or Texaco gasifier gas), steam content of coal gas, and fluidizing gas velocity $(6$ to $15 \mathrm{~cm} / \mathrm{s})$. In all the 10 multicycle tests, the sulfur capacity for zinc titanate sorbents at breakthrough remained fairly constant over 10 cycles at about 40 to 60 percent of their theoretical capacity, unlike zinc ferrite sorbents. The attrition resistance of 10-cycle regenerated material was significantly better than the fresh sorbent in all the runs.

It was found that ZT-4 did not undergo a measurable zinc loss over 10 cycles of bench-scale testing at temperatures as high as $750^{\circ} \mathrm{C}$ and superficial fluidizing velocities up to $15 \mathrm{~cm} / \mathrm{s}\left(\mathrm{U} / \mathrm{U}_{\mathrm{m} f}\right.$ $>8$ ) in the presence of Texaco gasifier gas.

During bench-scale testing, it was demonstrated that sulfided sorbent can be completely regenerated with 1 to 5 percent $\mathrm{O}_{2}$ in $\mathrm{N}_{2}$. Sulfate formation was not found to occur at $760^{\circ} \mathrm{C}$ and 1.5 $\mathrm{MPa}$. The inlet temperature could be controlled to reach the required $760^{\circ} \mathrm{C}$ with any of the oxygen contents tested. Also, regeneration of the zinc titanate sorbent demonstrated stoichiometric formation of an $\mathrm{SO}_{2}$ containing off-gas with potentially no oxygen according to $\mathrm{ZnS}$ $+(3 / 2) \mathrm{O}_{2} \rightarrow \mathrm{ZnO}+\mathrm{SO}_{2}$. A quasi-steady-state generation of $\mathrm{SO}_{2}$-containing off-gas was demonstrated indicating that a nearly constant steady-state $\mathrm{SO}_{2}$ content in the regeneration offgas of a commercial fluidized-bed system can be obtained. The constancy of $\mathrm{SO}_{2}$ concentration is believed to be essential for economical processing downstream to elemental sulfur or sulfuric acid.

The sulfidation reaction was found to be controlled by intrinsic chemical reaction rather than extemal or pore diffusion. The apparent activation energy for the sulfidation reaction ranged from 15 to $20 \mathrm{kcal} / \mathrm{mol}$ depending on the sorbent composition, indicating that significant reduction in size of the desulfurization system can be achieved by increasing the operating temperature. A simple mathematical model which assumed well-mixed solid phase and plug flow of gas made a reasonable prediction of the breakthrough behavior in the batch HTHP reactor using a rate constant based on thermogravimetric analyzer (TGA) measurements. 
To demonstrate the commercial potential of the granulation technique, two $80 \mathrm{lb}$ batches of sorbent with zinc to titanium mol ratios of 0.8 and 1.5 were prepared. These large batches will be tested in DOE/METC's pilot-scale unit.

Based on the results of this study, the following major recommendations are made for future work:

- A 100 cycle test should be conducted with the $Z T-4$ sorbent at its expected operating limit of $750^{\circ} \mathrm{C}$ to evaluate long-term durability.

- Transfer of the zinc titanate sorbent production technology to the private sector should be conducted. This could involve detailed discussions with major catalyst manufacturers and presentation of results at national meetings.

- To assist in the technology transfer, a large $500 \mathrm{~kg}$ batch of the sorbent should be prepared, thereby demonstrating the technology at a semi-commercial scale. Also, the sorbent cost for a commercial operation (i.e., in tonnage quantity) should be investigated by designing and costing a sorbent production plant. Some realistic projections of annualized cost and future sorbent demand should be carried out.

- An optimum particle size needed for the cornmercial fluid-bed reactors should be determined. The suitability of the 100 to $300 \mu \mathrm{m}$ particle size that is currently being used should be reassessed in commercial systems taking into consideration the mode of fluidization, circulation between sulfider and regenerator, etc.

- $\quad$ ZT-4 should be tested with actual coal-derived gases in the field. Potentia! sites include Dow Chemical's LGTI plant and Allison Gas Turbine's bench-scale two-stage direct coalfired turbine system.

- Mathematical models should be developed for continuous hot-gas desulfurization systems using various configurations of fluidized beds (e.g., bubbling, circulating, and transport). Using these models, a semi-pilot scale continuous sulfider-regenerator system with continuous sorbent circulation should be designed, built, and tested to serve as a prototype of a commercial system. 


\section{CHAPTER 1}

\section{INTRDDUCTION}

\subsection{CONTRACT OBJECTIVES}

The objective of this work was to identify and demonstrate methods that can be used for manufacturing zinc titanate sorbents suitable for use in a fluidized-bed reactor for the removal of sulfur-bearing species from hot coal-derived gases. Zinc ferrite sorbents were studied under the base program of this contract. Major findings of that study were described in a previous topical report that was published by DOE/METC (Gupta and Gangwal, 1991).

The scope of work in this part of the contract included the following:

- Investigation of various manufacturing methods to produce zinc titanate sorbents in a particle size range of 50 to $300 \mu \mathrm{m}$;

- Characterization and screening of the formulations for chemical reactivity, attrition resistance, and structural properties;

- Testing of selected formulations in an HTHP bench-scale fluidized-bed reactor to obtain an unbiased ranking of the promising sorbents;

- Investigation of the effect of various process variables, such as temperature, nature of coal gas, gas velocity: on the sorbent performance; and

- Generation of a database on sorbent properties and performance (e.g., rates of reaction, attrition rate) to be used in the design and scaleup of future commercial hotgas desulfurization systems.

\subsection{BACKGROUND}

Coal represents our largest fossil energy resource. The efficiency of converting this stored chemical energy to commonly used electrical energy can be improved significantly if the coal is first gasified and the resulting hot fuel gas is combusted in either a turbine [IGCC systems] or fuel cell (molten carbonate fuel cell [MCFC]). The projected thermal efficiency for such a system can be higher than 45 percent compared to 30 to 35 percent for conventional coal combustion systems.

IGCC and MCFC power systems (shown schematically in Figure 1-1) have been the subject of considerable research over the past decade in the United States and other parts of the world. However, for commercial acceptance, these advanced power generation systems must meet several criteria: 
(a) Simplified IGCC System

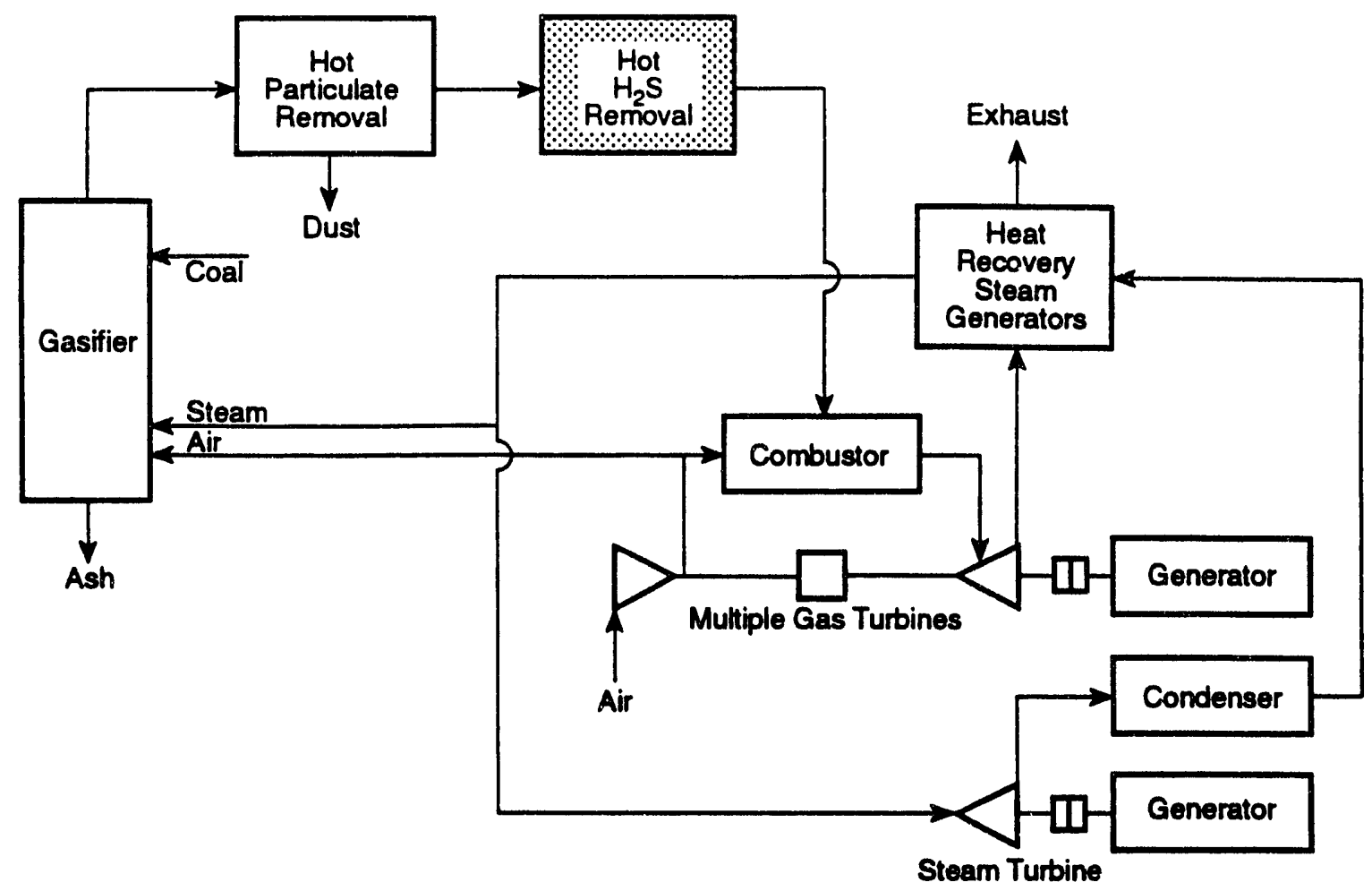

(b) Gasifier/MCFC System

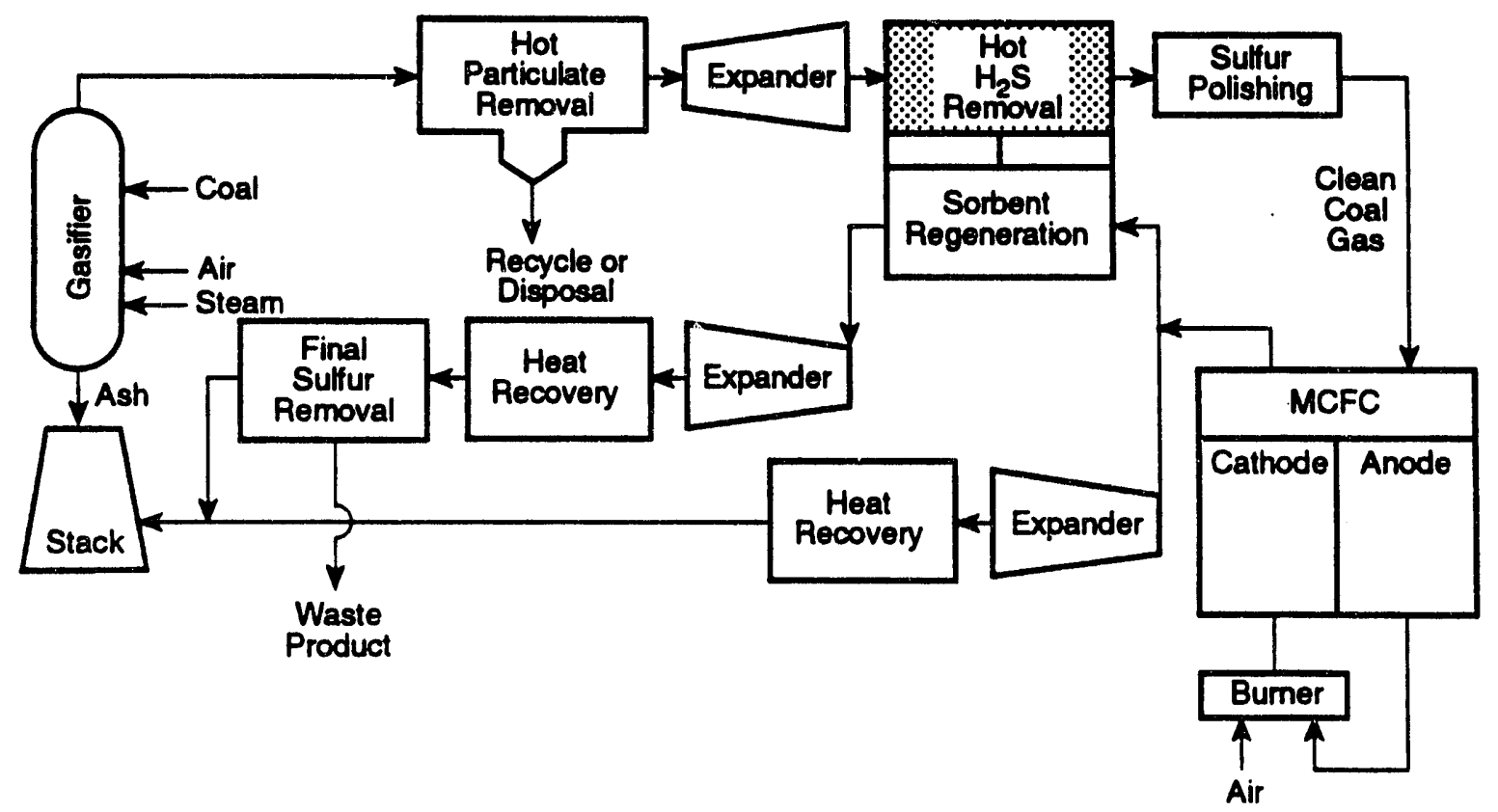

Figure 1-1. IGCC and MCFC power systems. 
- Environmental superiority,

- Low capital and operating costs,

- High thermal efficiency, and

- Low technical risk.

A simplified IGCC system incorporating air- or oxygen-blown gasification, hot gas cleanup, and design standardization meets these criteria. A hot-gas cleanup system consisting of hot particulate removal and hot-gas desulfurization steps is a key component in determining the performance of an IGCC system (Bajura and Bedick, 1991).

\subsubsection{Hot-Gas Desulfurization}

During gasification, sulfur present in coal is converted primarily to $\mathrm{H}_{2} \mathrm{~S}$ and to some extent to $\mathrm{COS}$ and $\mathrm{CS}_{2}$. During combustion of the fuel gas in a turbine, $\mathrm{H}_{2} \mathrm{~S}$ oxidizes to $\mathrm{SO}_{2}$, which is a precursor to "acid rain." In addition to its toxicity to the environment, higher $\mathrm{H}_{2} \mathrm{~S}$ concentrations (several thousand ppm) are also detrimental. The gas is corrosive to turbine blades, other equipment, and process instruments and adversely affects the performance of MCFCs due to sulfur poisoning of electrodes, thus necessitating its removal from the fuel gas to the order of a few ppm or less.

Well-known processes for removing $\mathrm{H}_{2} \mathrm{~S}$ from fuel gas are wet processes operated within a liquid phase, for example, an amine solution. These processes, which operate at relatively low temperatures, require cooling of the fuel gas and therefore impose a severe thermal penalty and additional capital cost for heat exchangers. Furthermore, the costs associated with these wet techniques for treatment of process-generated wastewater are relatively high. Therefore, it would be desirable to have an easily regenerable sorbent for reduced sulfur species at high temperature. Good regenerability would decrease not only the cost of the sorbent but also the costs associated with frequent loading and unloading of the reactors and the costs associated with disposal of spent sorbent.

Recent developments in hot gas desulfurization technologies have focused on solid mixed metal oxide sorbents which remove reduced sulfur species $\left(\mathrm{H}_{2} \mathrm{~S}, \mathrm{COS}\right.$, and $\left.\mathrm{CS}_{2}\right)$ from the coal gas. The sulfided sorbents are reused after regeneration with air. These sulfidation-regeneration steps form cycles, and numerous cycles are carried out until the sorbent deactivates to an unacceptable level of reactivity.

Earlier studies on the desulfurization of hot coal gas were carried out using pure metal oxide sorbents, e.g., zinc oxide and iron oxide. A generic hot-gas desulfurization reaction can be written as

$$
\mathrm{MeO}+\mathrm{H}_{2} \mathrm{~S} \rightarrow \mathrm{MeS}+\mathrm{H}_{2} \mathrm{O}
$$

where Me is any metal. The regeneration of sulfided sorbent using air can be described as 


$$
\mathrm{MeS}+\frac{3}{2} \mathrm{O}_{2} \rightarrow \mathrm{MeO}+\mathrm{SO}_{2}
$$

However, the following potentially detrimental and undesirable reactions can also occur during sulfidation and regeneration

$$
\begin{gathered}
\mathrm{MeO}+\mathrm{H}_{2}(\mathrm{CO}) \rightarrow \mathrm{Me}+\mathrm{H}_{2} \mathrm{O}\left(\mathrm{CO}_{2}\right) \quad \text { (metal oxide reduction during sulfidation), } \\
\mathrm{MeS}+2 \mathrm{O}_{2} \rightarrow \mathrm{MeSO}_{4} \quad \text { (sulfate formation during regeneration). }
\end{gathered}
$$

The above reactions, which can result in poor sorbent utilization and sorbent decrepitation (degradation), need to be minimized by optimizing the process operating conditions as will be discussied later.

Westmoreland and Harrison (1976) investigated a number of single metal oxide sorbents to determine thermodynamic limits of desulfurization reactions. They identified four metal oxides as possessing desulfurization potential over at least a portion of the range of operating conditions of interest. These metal oxides included $\mathrm{MnO}, \mathrm{ZnO}, \mathrm{CaO}$, and $\mathrm{V}_{2} \mathrm{O}_{3}$. It was later discovered that the thermodynamic data used for $\mathrm{V}_{2} \mathrm{O}_{3}$ were erroneous and $\mathrm{V}_{2} \mathrm{O}_{3}$ is not capable of lowering $\mathrm{H}_{2} \mathrm{~S}$ to the required degree. Out of the remaining three, $\mathrm{ZnO}$ was found to be most suitable as it could reduce the $\mathrm{H}_{2} \mathrm{~S}$ in coal gas to a level of a few ppm depending on the temperature and steam content of coal gas.

The main requirements of the metal oxide sorbents are listed below:

- It should selectively react with $\mathrm{H}_{2} \mathrm{~S}$ in a reducing coal-gas environment at desired conditions. The free energy change $(\Delta G)$ for the sulfidation reaction should preferably be highly negative to allow sulfide formation and reduction of $\mathrm{H}_{2} \mathrm{~S}$ to low ppm.

- The sulfided sorbent should be easily regenerable -it should easily convert back into oxide.

- Kinetics of sulfidation and regeneration reactions at desired temperatures should be sufficiently fast to allow reasonable reactor sizes.

- The sorbent should be thermally stable in both oxide and sulfide states. The vapor pressures of the oxide, sulfide, and metal should be sufficiently low under the desired temperature range $\left(538\right.$ to $760^{\circ} \mathrm{C} ; 1,000$ to $\left.1,400{ }^{\circ} \mathrm{F}\right)$.

Iron oxide was investigated as a hot-gas desulfurization sorbent in the 1970s. It has a high sulfur capacity and possesses high reactivity, but it can remove only up to 90 percent sulfur at best. In fact, Ishikawajimi-Harima Heavy Industries (IHI) in Japan is developing a hot-gas desulfurization process using raw iron ore from Australia as a sorbent (Sugitani et al., 1987). However, their reported sulfur removals are only up to 90 percent at $450^{\circ} \mathrm{C}$. Iron oxide is also limited to low severity reducing gases only. Higher temperatures $\left(550^{\circ} \mathrm{C}\right.$ ) lead to severe decrepitation of the iron oxide sorbents due to excessive reduction and iron carbide formation particularly under highly reducing conditions (Gangwal et al., 1988; Gupta and Gangwal, 1991). 
Thermodynamics of $\mathrm{H}_{2} \mathrm{~S}$ removal by zinc oxide is much more favorable than by iron oxide. Figure 1-2 shows the $\mathrm{H}_{2} \mathrm{~S}$ ppm of coal gas that are thermodynamically attainable as a function of temperature. The curve in Figure $1-2$ is based on the assumption that the coal gas contains 17.5 percent water vapor which is typically observed in the case of Texaco $\mathrm{O}_{2}$-blown entrainedbed gasifier gas. It can be seen from Figure $1-2$ that at $650^{\circ} \mathrm{C}(923 \mathrm{~K})$, the $\mathrm{H}_{2} \mathrm{~S}$ level of coal gas can be reduced to $10 \mathrm{ppm}$.

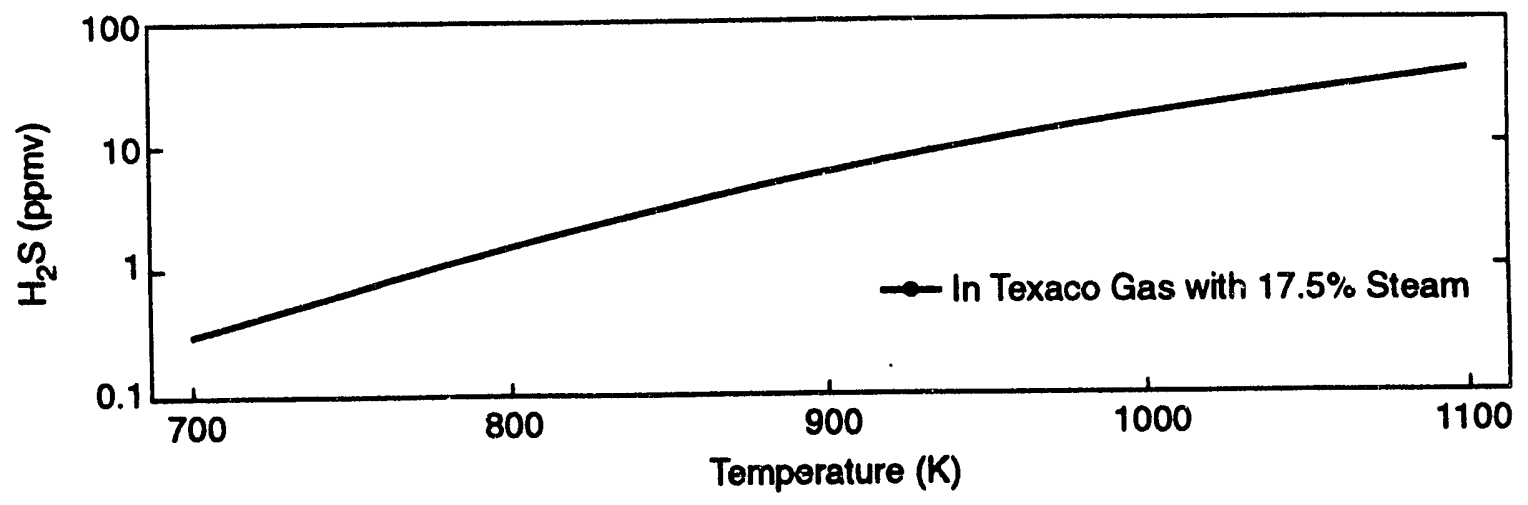

Figure 1-2. Calculation of equillibrium $\mathrm{H}_{2} \mathrm{~S}$ concentrations for $\mathrm{ZnO}$.

Use of zinc oxide has been commercially exploited to remove $\mathrm{H}_{2} \mathrm{~S}$ from a fuel gas. A U.S. patent granted to Institut Francais du Petrole of France (Courty et al., 1978) disclosed a process in which a regenerable zinc oxide sorbent supported on silica and/or alumina was used. The sorbent was prepared by admixing zinc oxide and alumina and was in the form of extrudates suitable for a fixed-bed operation. This sorbent was tested with a gas containing 16.6 percent CO, 16.6 percent $\mathrm{H}_{2}, 33.3$ percent $\mathrm{N}_{2}$, and 33.3 percent $\mathrm{H}_{2} \mathrm{O}$ in a temperature range of 450 to $600^{\circ} \mathrm{C}$. Despite the mild reducing nature of the coal gas tested, a significant decrease in crush strength and bulk density of pellets has been reported, indicating a deterioration in sorbent structure most likely stemming from reduction of zinc oxide to zinc followed by vaporization of zinc. Therefore, pure ZnO sorbents (supported on an inert support) may not be suitable for hotgas desulfurization at temperatures above about $500^{\circ} \mathrm{C}$.

\subsubsection{Zinc Ferrite}

Zinc ferrite, $\mathrm{ZnFe}_{2} \mathrm{O}_{4}$, originally developed at DOE/METC by Grindley and Steinfeld (1981), contains an equimolar mixture of zinc oxide and iron oxide calcined at 800 to $850{ }^{\circ} \mathrm{C}$ with a suitable binder. It can be easily regenerated using air/diluent mixtures and has consistently demonstrated $\mathrm{H}_{2} \mathrm{~S}$ removals to less than 20 parts per million by volume (ppmv) over multiple cycles (Grindley and Goldsmith, 1987; Gangwal et al., 1988). The chemistry of $\mathrm{H}_{2} \mathrm{~S}$ removal by zinc ferrite and subsequent regeneration of sulfided sorbent is discussed elsewhere (Grindley and Steinfeld, 1981; Gangwal et al., 1988; Woods et al., 1989). 
The theoretical maximum sulfur absorption capacity of zinc ferrite is close to $40 \mathrm{~g}$ of sulfur per $100 \mathrm{~g}$ of fresh sorbent based on the stoichiometry of the sulfidation reaction. Typically, about 30 to $\mathbf{5 0}$ ptrcent of the theoretical capacity is achieved in a single fixed bed because sulfur loading varies across the bed when the concentration of $\mathrm{H}_{2} \mathrm{~S}$ in the effluent rises to an unacceptable level, e.g., 100 ppmv. At this point the bed must be regenerated.

Early testing of zinc ferrite was conducted in a fixed-bed reactor system using the sorbent in the form of cylindrical extrudates (Grindley and Goldsmith, 1987; Gangwal et al., 1988, 1989; Haldipur et al., 1987; Wu et al., 1989). However, the fixed-bed reactor system has the following drawbacks:

- Need for valves operating at HTHP conditions;

- Need for exposing the reactors to temperature swings;

- Greater difficulty of the fixed-bed reactor to handle the heat releasied by the highly exothermic regeneration reaction; and

- Nonuniform composition of regeneration off-gas.

To overcome some of the drawbacks of a fixed-bed system, moving- and fluidized-bed reactor systems are currently being developed under the sponsorship of DOE/METC. The GE moving-bed system is currently being demonstrated in a pilot plant (Gal et al., 1987; Cook et al., 1989). Fluidized-bed reactor systems using zinc ferrite sorbents were developed at RTI and at DOE/METC (Gupta and Gangwal, 1991; Gupta et al., 1992; Grindley, 1991). A major obstacle to commercialization of fluidized-bed hot-gas cleanup systems is excessive sorbent loss from the reactor in the form of fines due to attrition. Sorbents for fluidized-bed reactors, therefore, must withstand stresses induced by rapid temperature swings, chemical transformations, and fluidization and transport.

Recently, RTI has completed a study of the development and testing of fluidizable zinc ferrite materials. In this study, a number of sorbent manufacturing techniques were investigated to produce fluidizable zinc ferrite sorbents ranging from 100 to $300 \mu \mathrm{m}$ in size with the desired chemical reactivity and attrition resistance. These techniques included spray drying, impregnation, crushing and screening of durable pellets, and granulation. The spray-drying technique proved to be unsuccessful in producing fluidizable zinc ferrite particles in the 100 to 300 $\mu \mathrm{m}$ range. Sorbent formulations prepared by impregnating up to 20 wt percent zinc ferrite on alumina had very low sulfur capacity and did not appear to be commercially viable. Although a fluidizable zinc ferrite sorbent prepared by crushing and screening of durable sorbent pellets, prepared by $\mathrm{UCI}$ for GE's moving-bed reactor, had acceptable levels of chemical reactivity, it underwent excessive attrition during bench-scale testing, resulting in 42 percent sorbent loss from the reactor over 100 cycles.

Of the techniques investigated, granulation proved to be most successful and a number of zinc ferrite sorbent formulations were prepared using this technique. Testing of these sorbents in a bench reactor demonstrated that these sorbents possess significantly beiter attrition resistance than sorbents prepared by crushing and screening. Also, sulfur capacity of the sorbents prepared by the granulation technique was similar to those prepared by crushing and screening. Results of bench-scale testing of selected zinc ferrite sorbent formulations can be found in a previous topical report (Gupta and Gangwal, 1991). 
Following the successful preparation and encouraging performance of the zinc ferrite sorbents, a $100 \mathrm{lb}$ batch was manufactured to demonstrate the commercial viability of the proposed manufacturing method.

Unfortunately, with zinc ferrite sorbents, excessive sorbent loss was observed at a $625^{\circ} \mathrm{C}$ sulfidation temperature. It is thought that the attrition of the sorbent in the reactor is due primarily to chemical transformations rather than mechanical forces. Possible chemical transformations responsible for attrition are excessive reduction of $\mathrm{ZnFe}_{2} \mathrm{O}_{4}$ and iron carbide formation (Gupta and Gangwal, 1991; Gupta et al., 1992). The applicability of zinc ferrite as a hot-gas desulfurization sorbent, therefore, should be conservatively limited to below $550^{\circ} \mathrm{C}$ and to moderately reducing coal gases, such as a low Btu gas containing at least 15 percent water vapor. Higher temperatures, as shown in the study, would lead to excessive sorbent weakening.

\subsubsection{Copper-based Sorbents}

Copper-based sorbents were investigated extensively at RTI for removal of $\mathrm{H}_{2} \mathrm{~S}$ and COS. These sorbents have a potential to reduce the sulfur levels of coal gas to less than $1 \mathrm{ppm}$ (Gangwal et al., 1988; Jalan, 1990). However, these sorbents were found to be very unsuitable because of the highly exothermic reduction of copper oxide by pressurized coal gas. This led to temperature runaway problems in sulfidation reactors and consequently imposed a severe economic penalty due to loss of valuable coal gas. Also, pressurized regeneration of these sorbents led to severe sulfate formation requiring decomposition temperatures which led to sorbent sintering and loss of reactivity. For these reasons, the performance of the copper-based sorbents deteriorated significantly during subsequent cycles of sulfidation and regeneration. Hence, copper-based sorbents are not the judicious choice for bulk $\mathrm{H}_{2} \mathrm{~S}$ removal. However, they may be used as a throwaway guard bed, especially for MCFC applications (Gangwal et al., 1988).

\subsubsection{Zinc Titanate Sorbents}

To find alternatives to the zinc ferrite sorbents, extensive kinetic and bench-scale studies undertaken at RTI culminated in the development of a zinc titanate sorbent which can be used up to $760^{\circ} \mathrm{C}\left(1,400^{\circ} \mathrm{F}\right)$ and in the presence of severely reducing gases (Gangwal et al., 1988). The zinc titanate sorbent contains $\mathrm{ZnO}$ and $\mathrm{TiO}_{2}$ in a suitable molar ratio typically ranging between 0.5 and 2.0. Only $\mathrm{ZnO}$ is the reactive cumponent of the sorbent, while $\mathrm{TiO}_{2}$ provides stability to the sorbent by preventing zinc vaporization, as will be discussed in detail in Chapter 7 .

A detailed literature review of chemical and ceramic aspects of zinc titanate sorbents is presented in Chapter 2. Chapter 3 is devoted to the description of RTI's bench-scale reactor system that was used extensively in this study. Chapter 4 describes the details of physical and chemical characterizations whereas Chapter 5 deals with the description of sorbent preparation and screening. The details of the $10 \mathrm{HTHP}$ bench runs are described in Chapter 6 . A detailed data analysis including addressing various reactor design issues is presented in Chapter 7. A simple mathematical model that was developed in this study is described in Chapter 8 . Chapter 9 discusses the conclusions and recommendations. References cited in this report are listed in Chapter 10. The $\mathrm{H}_{2} \mathrm{~S}$ and $\mathrm{COS}$ breakthrough data taken during $10 \mathrm{HTHP}$ runs along with particle size distributions of fresh and used sorbents are presented in various appendixes. 


\section{CHAPTER 2}

\section{ZINC TITANATE: A REVIEW OF CHEMICAL AND CERAMIC ASPECTS}

\section{$2.1 \quad$ INTRODUCTION}

Studies on different phases of the $\mathrm{ZnO}-\mathrm{TiO}_{2}$ system are of considerable interest because of their importance in the pigment industry, fusion cast thermistors, and lately in catalysis and desulfurization of hot fuel gas. There has been a lot of interest in the study of crystal structure, dielectric properties and luminescence, etc., of these phases. The unusual optical and electric properties of zinc oxide and titania have attracted the pigment industry for the last several decades. A number of references are available on the formation of different titanates of zinc (Cole and Nelson, 1938; Dulin and Rase, 1960; Bartram and Slepetys, 1961; Reddy et al., 1984; Yamaguchi et al., 1987; Watanabe et al., 1989; Gangwal et al., 1988; and Lew, 1990).

The above references reveal controversies regarding the nature and number of different titanate phases formed in the system. Cole and Nelson (1938) reported the formation of zinc ortho-titanate $\left(\mathrm{Zn}_{2} \mathrm{TiO}_{4}\right)$ by a solid-state reaction between zinc oxide and titanium dioxide in a 2:1 molar ratio. When excess titania was present, a series of solid solutions of $\mathrm{TiC}_{2}$ and $\mathrm{Zn}_{2} \mathrm{TiO}_{4}$ were observed below $900^{\circ} \mathrm{C}$ and these decomposed above $900^{\circ} \mathrm{C}$ to give the ortho-titanate and rutile $\mathrm{TiO}_{2}$ phases. Vosen (1958) reported the synthesis of zinc meta-titanate $\left.(\mathrm{ZnTiO})_{3}\right)$ by calcining an equimolar mixture of zinc oxide and titanium dioxide between 700 and $825^{\circ} \mathrm{C}$.

Later Dulin and Rase (1960) reported the formation of $\mathrm{ZnTiO}_{3}$ in equilibrium with $\mathrm{Zn}_{2} \mathrm{TiO}_{4}$ and rutile depending upon the composition of the reaction mixture and reaction temperature. Figure 2-1, which has been taken from Dulin and Rase's paper, shows this. According to this phase diagram, the only stable zinc titanate phases are $\mathrm{Zn}_{2} \mathrm{TiO}_{4}$ and $\mathrm{ZnTiO}{ }_{3}$ above $750{ }^{\circ} \mathrm{C}$. Bartram and Slepety's (1961) studies indicated formation of zinc sesquit-titanate $\left(\mathrm{Zn}_{2} \mathrm{Ti}_{3} \mathrm{O}_{8}\right)$ by heating $\mathrm{ZnO}$ and $\mathrm{TiO}_{2}$ in a $1: 1 \mathrm{~mol}$ ratio between 600 and $900^{\circ} \mathrm{C}$. These authors further report that beyond $900^{\circ} \mathrm{C}, \mathrm{Zn}_{2} \mathrm{Ti}_{3} \mathrm{O}_{8}$ decomposes to ortho-titanate and rutile. Reddy et al. (1984) also report the formation of $\mathrm{Zn}_{2} \mathrm{Ti}_{3} \mathrm{O}_{8}$ at $700^{\circ} \mathrm{C}$. Gangwal et al. (1988) studied the formation of zinc titanate by heating the mixtures of $\mathrm{ZnO}$ and $\mathrm{TiO}_{2}$ powders in molar ratios of $0.8,1.0,1.5$, and 2.0 at $871^{\circ} \mathrm{C}$. XRD analyses indicated the presence of $\mathrm{Zn}_{2} \mathrm{Ti}_{3} \mathrm{O}_{8}$ and $\mathrm{Zn}_{2} \mathrm{TiO}_{4}$ phases, along with small amounts of $\mathrm{ZnTiO}_{3}$ and both rutile and anatase phases of $\mathrm{TiO}_{2}$.

It has also been reported that the starting titania plays a vital role in formation of the type of zinc titanate phase. For example, the reaction of $\mathrm{ZnO}$ with the anatase form of $\mathrm{TiO}_{2}$ results in $\mathrm{Zn}_{2} \mathrm{Ti}_{3} \mathrm{O}_{8}$ in addition to $\mathrm{Zn}_{2} \mathrm{TiO}_{4}$, while the rutile form of $\mathrm{TiO}_{2}$ leads to the formation of predominantly $\mathrm{ZnTiO}_{3}$ and $\mathrm{Zn}_{2} \mathrm{TiO}_{4}$ (Sheinkman et al., 1977).

\subsection{USE OF ZINC TITANATE COMPOUNDS}

Although a detailed identification and characterization of various zinc titanate phases, as discussed above, is not the focus of this report, and hence a further discussion is not warranted, it may be worthwhile to understand the role of various zinc titanate phases in $\mathrm{H}_{2} \mathrm{~S}$ removal from hot coal gases. Earlier applications of zinc titanate as a sour gas desulfurization sorbent as well as a catalyst for various hydrogenation reactions were discovered at the Phillips Petroleum Company. In a series of patents granted to Phillips as shown in Table 2-1, a process was 
disclosed for removal of $\mathrm{H}_{2} \mathrm{~S}$ irom gas streams for low temperatures (205 to $538{ }^{\circ} \mathrm{C}$ ). As evidenced from Table 2-1, also disclosed in these patents was the role of zinc titanate as a catalyst for a number of applications, including hydrodesulfurization for conversion of organic sulfur compounds into $\mathrm{H}_{2} \mathrm{~S}$ and its subsequent absorption by the catalyst, hydrotreating, catalytic reforming, catalytic hydrodesulfurization and denitrogenation, hydrocracking, oxidative dehydrogenation, and selective hydrogenation.

Almost all the inventions listed in Table 2-1 dealt mainly with process studies in fixed-bed reactors where the use of zinc titanate was demonstrated as a catalyst material of a size of 20 to 40 mesh. As discussed in Chapter 1, fixed-bed reactors may not be an ideal choice for carrying out hot-gas desulfurization due to the highly exothermic regeneration involved. A fluidized bed is perhaps a more preferable choice over a fixed bed. Particles of 20 to 40 mesh used by Phillips inventors may not be a good choice for use in a fluidized bed.

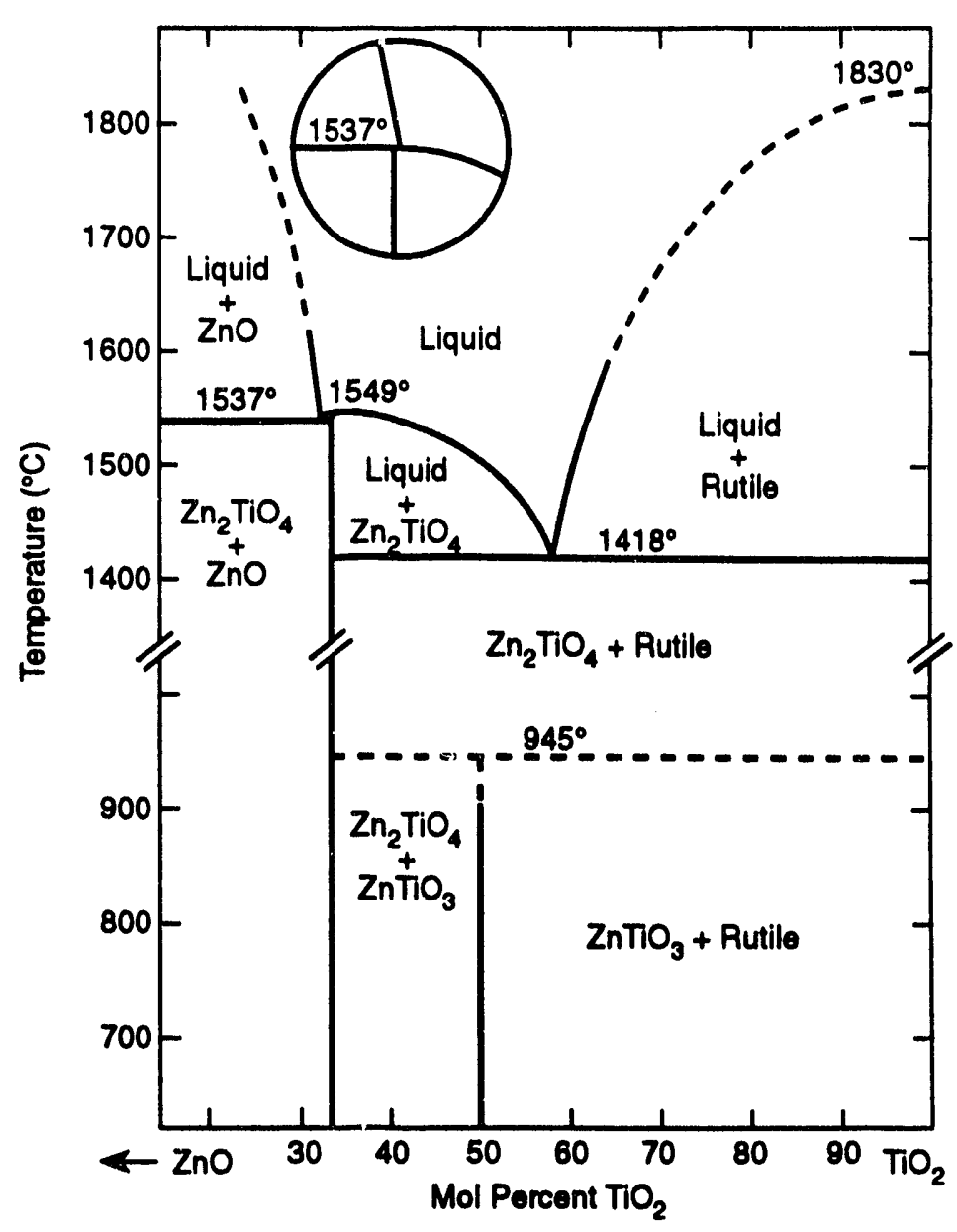

Source: Dulin and Rase 1960.

Note: The inset illustrates the possible incongruent metting of the compound $\mathrm{Zn}_{2} \mathrm{TIO}_{4}$.

Figure 2-1. A phase dlagram of $\mathrm{ZnO}^{-\mathrm{TIO}_{2}}$ system.

As discussed in Chapter 1, pure zinc oxide is not very suitable as a hot-gas desulfurization sorbent because of its high reduction potential to elemental zinc. However, addition of $\mathrm{TiO}_{2}$ in zinc oxide considerably overcomes the problem of $\mathrm{ZnO}$ reduction as reported by Lercher et al. (1984) and Lew et al. (1992). It has been reported that the amount of $\mathrm{Zn}^{2+}$ cations on the surface of $\mathrm{ZnO}-\mathrm{TiO}_{2}$ mixtures decreases as the $\mathrm{TiO}_{2}$ content of the sorbent increases, thus raising the possibility of stabilizing $\mathrm{ZnO}$ against reduction by addition of $\mathrm{TiO}_{2}$.

Use of zinc titanate as an $\mathrm{H}_{2} \mathrm{~S}$ removal sorbent has been demonstrated in both laboratory scale and semi-commercial reactors at temperatures as high as $768{ }^{\circ} \mathrm{C}$. Pioneering HTHP studies at RTI (Gangwal et al., 1988) have clearly indicated the ability of zinc titanate materials to reduce the $\mathrm{H}_{2} \mathrm{~S}$ levels of a fuel gas down to a few ppm under realistic operating conditions of a commercial IGCC plant. GE has been developing a commercial process employing zinc titanate pellets in a moving-bed reactor for desulfurization of hot coal gas (Cook et al., 1989). 
Table 2-1. U.S. Patents Issued to Phillips Petroleum on ZInc TItanate Catalyst

\begin{tabular}{|c|c|c|c|}
\hline $\begin{array}{l}\text { Patent } \\
\text { No. }\end{array}$ & Authors & Date & Titles \\
\hline $5,045,522$ & Kidd & $9 / 3 / 91$ & $\begin{array}{l}\text { Absorption Composition Comprising Zinc } \\
\text { Titanate for Removal of } \mathrm{H}_{2} \mathrm{~S} \text { from Fluid } \\
\text { Streams }\end{array}$ \\
\hline $4,725,415$ & Kidd & $2 / 16 / 88$ & $\begin{array}{l}\text { Selective Removal of } \mathrm{H}_{2} \mathrm{~S} \text { over Zinc } \\
\text { Titanate and Alumina }\end{array}$ \\
\hline $4,707,246$ & $\begin{array}{l}\text { Gardner and } \\
\text { Parrott }\end{array}$ & $11 / 17 / 87$ & Hydrotreating Catalyst and Process \\
\hline $4,693,991$ & Bjornson et al. & $9 / 15 / 87$ & Hydrotreating Catalyst Composition \\
\hline $4,655,906$ & Bjornson ot al. & $4 / 7 / 87$ & $\begin{array}{l}\text { Hydrotreating Process Employing a Novel } \\
\text { Catalytic Composition }\end{array}$ \\
\hline $4,636,371$ & Farha & $1 / 13 / 87$ & $\begin{array}{l}\text { Removal of Sulfur Oxides from Fluid } \\
\text { Streams }\end{array}$ \\
\hline $4,566,967$ & Aldag & $1 / 28 / 86$ & Catalytic Reforming \\
\hline $4,522,709$ & Aldag and Garner & $6 / 11 / 85$ & $\begin{array}{l}\text { Catalytic Hydrodesulfurization or } \\
\text { Hydronitrogenation }\end{array}$ \\
\hline $4,446,013$ & Aldag & $5 / 1 / 84$ & Catalytic Skeletal Isomerization \\
\hline $4,394,301$ & Gardner & $7 / 19 / 83$ & $\begin{array}{l}\text { Catalytic Hydrocracking, } \\
\text { Hydrodesulfurization, and/or } \\
\text { Hydrodenitrogenation of Organic } \\
\text { Compounds Employing Promoted Zinc } \\
\text { Titanate and a Zeolite as the Catalytic } \\
\text { Agent }\end{array}$ \\
\hline $4,313,820$ & Farha et al. & $2 / 2 / 82$ & $\begin{array}{l}\text { Hydrodesulfurization of Organic Sulfur } \\
\text { Compounds and Hydrogen Sulfide } \\
\text { Removal with Incompletely Sulfided Zinc } \\
\text { Titanate Materials }\end{array}$ \\
\hline $4,263,133$ & Drehman et al. & $4 / 21 / 81$ & $\begin{array}{l}\text { Catalytic Reforming and Hydrocracking of } \\
\text { Organic Compounds Employing Zinc } \\
\text { Titanate as the catalytic agent }\end{array}$ \\
\hline $4,263,132$ & Drehman et al. & $4 / 21 / 81$ & $\begin{array}{l}\text { Catalytic Reforming and Hydrocracking of } \\
\text { Organic Compounds Employing Promoted } \\
\text { Zinc Titanate as the Catalytic Agent }\end{array}$ \\
\hline $4,228,040$ & Bertus and Walker & $10 / 14 / 80$ & $\begin{array}{l}\text { Li.- or Mg-Promoted Zinc Titanate Catalyst } \\
\text { for Dehydrogenation of Hydrocarbons }\end{array}$ \\
\hline $4,798,863$ & $\begin{array}{l}\text { Leland and } \\
\text { Martinovich }\end{array}$ & $1 / 17 / 89$ & $\begin{array}{l}\text { Zinc Titanate in Poly (Arylene Sulfide) } \\
\text { Compositions }\end{array}$ \\
\hline
\end{tabular}

(continued) 
Table 2-1 (continued)

\begin{tabular}{|c|c|c|c|}
\hline $\begin{array}{l}\text { Patent } \\
\text { No. }\end{array}$ & Authors & Date & Titles \\
\hline $4,636,371$ & Farha & $1 / 13 / 87$ & $\begin{array}{l}\text { Removal of Sulfur Oxides, Especially } \\
\text { Claus Process Tail Gas, with Zinc } \\
\text { Titanate Catalyst }\end{array}$ \\
\hline $4,599,161$ & Scinta ot al. & $7 / 8 / 86$ & $\begin{array}{l}\text { Retorting Process with Contaminant } \\
\text { Removal }\end{array}$ \\
\hline $4,522,709$ & $\begin{array}{l}\text { Aldag and } \\
\text { Gardner }\end{array}$ & $6 / 11 / 85$ & $\begin{array}{l}\text { Catalytic Hydrodesulfurization or } \\
\text { Hydrodenitrogenation }\end{array}$ \\
\hline $4,463,213$ & Aldag & $7 / 31 / 84$ & $\begin{array}{l}\text { Dehydrogenation of Organic Compounds } \\
\text { with a Zinc Titanate Hydrogel }\end{array}$ \\
\hline $4,434,079$ & Aldag and Kolts & 2/28/84 & $\begin{array}{l}\text { Conversion and/or Selectivity of a Zinc } \\
\text { Titanate Catalyst }\end{array}$ \\
\hline $4,368,344$ & Kolts & $1 / 11 / 83$ & $\begin{array}{l}\text { Oxidative Dehydrngenation of Organic } \\
\text { Compounds with a Zinc Titanate Catalyst }\end{array}$ \\
\hline $4,333,855$ & Gardner & 6/8/82 & $\begin{array}{l}\text { Promoted Zine Titanate as a Catalytic } \\
\text { Agent }\end{array}$ \\
\hline $4,327,238$ & Eastman ot al. & 4/27/82 & $\begin{array}{l}\text { Dehydrogenation of Organic Compounds } \\
\text { with a Promoted Zinc Titanate Catalyst }\end{array}$ \\
\hline $4,313,017$ & McGinnis ot al. & $1 / 26 / 82$ & $\begin{array}{l}\text { Selective Hydrogenation of Polynuclear } \\
\text { Aromatic Reactants }\end{array}$ \\
\hline $\begin{array}{l}1,114,803 \\
\text { (Canadian) }\end{array}$ & Walker ot al. & $12 / 22 / 81$ & $\begin{array}{l}\text { Dehydrogenation of Hydrocarbons with } \\
\text { Zinc Titanate Catalyst }\end{array}$ \\
\hline $4,287,050$ & Eastman ot al. & 9/1/81 & $\begin{array}{l}\text { Catalytic Hydrodesulfurization of Organic } \\
\text { Compounds Employing Alumina, } \\
\text { Promoted with Zinc Titanate, Co and Mo } \\
\text { as the Catalyst Agent }\end{array}$ \\
\hline $4,268,399$ & Box et al. & $5 / 19 / 81$ & Purification of Polluted Water \\
\hline $4,176,140$ & Bertus et al. & $11 / 27 / 79$ & $\begin{array}{l}\text { Dehydrogenation of Hydrocarbons with } \\
\text { Zinc Titanate Catalyst }\end{array}$ \\
\hline $4,218,346$ & Walker and Farha & $8 / 19 / 80$ & $\begin{array}{l}\text { Zinc Titanate Catalyst for } \\
\text { Dehydrogenation of Hydrocarbons }\end{array}$ \\
\hline $4,525,144$ & Aldag & $6 / 18 / 85$ & $\begin{array}{l}\text { Alkali Metal-Promoted Zinc Titanate } \\
\text { Hydrogel Catalyst for Dehydrogenation of } \\
\text { Organic Compounds }\end{array}$ \\
\hline $4,394,207$ & Kolts & $7 / 19 / 83$ & Zinc Titanate Catalyst \\
\hline $4,477,592$ & Aldag & $10 / 16 / 84$ & Catalyst for Skeletal Isomerization \\
\hline
\end{tabular}


Texaco is also testing the zinc titanate pellets in their fixed-bed system that is coupled to their oxygen-blown entrained-bed gasifier (Robin et al., 1992).

\subsection{ZINC TITANATE PREPARATION}

A number of techniques have been reported in the literature to produce zinc titanate materials. Most of these techniques involve wet chemistry with zinc and titanium salts as starting raw materials with a suitable precursor. Obviously, applicability of a particular technique will depend directly on the end-use of the product.

Zinc titanate compounds for use as pigments and dielectrics have been prepared by mixing the slurries of fine powders of $\mathrm{ZnO}$ and $\mathrm{TiO}_{2}$ in a desired ratio at a suitable pH and precipitating the powder. The powder was then calcined at 900 to $1200{ }^{\circ} \mathrm{C}$ for 6 to $20 \mathrm{~h}$, depending on the application. Calcined material thereof was crushed to the desired size and treated with suitable reagents to impart the desired physical and chemical properties. The material was finally recalcined. All these studies were carried out in small laboratory batches, thus no references are available for scaleup of these techniques. Of particular note is a technique described in U.S. Patent No. 3,607,338 assigned to the National Aeronautics and Space Administration (NASA) in which a degradation-resistant zinc titanate compound was prepared by mixing a slurry of high-purity zinc oxide (SP500) with an average particle size of about 0.2 to $1.5 \mu \mathrm{m}$ with a slurry of a very finely divided titania with anatase crystalline structure in a molar ratio of $2: 1$. This was followed by a calcination over $900^{\circ} \mathrm{C}$ for at least $6 \mathrm{~h}$. The final step in this process included the treatment of zinc titanate obtained with a zinc oxide extractant solution (such as acetic acid) in order to impart resistance to degradation. This extractant solution removed any unreacted free zinc oxide from the zinc titanate by reaction of acetic acid with $\mathrm{ZnO}$. The zinc titanate does not react with acetic acid. The inventors reported that a molar ratio of 2:1 is essential to the formation of zinc ortho-titanate $\left(\mathrm{Zn}_{2} \mathrm{TiO}_{4}\right)$. Substantial variations from this stoichiometry render the product less reflective and less resistant to degradation. This is primarily because of the presence of unreacted $\mathrm{TiO}_{2}, \mathrm{ZnO}$ or other forms of zinc titanate such as meta $\left(\mathrm{ZnTiO}_{3}\right)$ and sesquit $\left(\mathrm{Zn}_{2} \mathrm{Ti}_{3} \mathrm{O}_{8}\right)$ phases. These inventors report that a slight excess, e.g., up to 5 percent by weight, of zinc oxide can be tolerated, provided the preparation process employs a final zinc oxide extraction phase.

The zinc titanate preparations carried out by the researchers at Phillips Petroleum also involved a process similar to the one described above except for the addition of a number of promoters containing $\mathrm{Co}, \mathrm{Mo}, \mathrm{V}$, etc., that were added to impart a catalytic function. No zinc titanate formulations were produced for the fluidized-bed applications except for a process in which a zinc titanate catalyst was used for the catalytic reforming of a cyclo-pentane-containing organic feedstock in a fluidized bed (Aldag, U.S. Patent No. 4,477,592). A hydrogelling step was added in the manufacturing process to impart additional attrition resistance to the catalyst that was used in a transport reactor type system. This hydrogelling step involved dispersion of a finely powdered $(2$ to $10 \mu \mathrm{m})$ zinc titanate in a suspension of $\alpha$-alumina monohydrate with the addition of nitric acid to form a hydrosol, which was then dried, calcined at $648^{\circ} \mathrm{C}$ for $2 \mathrm{~h}$, and finally crushed and screened to produce a 420 to $1,190 \mu \mathrm{m}$ size catalyst to be used in a transport reactor. The attrition resistance of the catalyst thus prepared was claimed to be an order of magnitude better than the material prepared without hydrogelling.

The enhancement in attrition resistance occurred at the cost of significantly reduced catalyst capacity due to reduced zinc titanate content. The maximum zinc titanate content 
claimed for the hydrogel material was only 50 percent by weight. Furthermore, suitability of hydrogel material was demonstrated only as a reforming catalyst and not as a high-temperature df sulfurization agent. No mention was made of the cost of the material, although one would expect that a significant number of wet processing steps required in hydrogelling the zinc titanate would add to the cost considerably.

Attempts were also made to produce zirc titanate materials in a granular form as aerogels suitable for a catalyst support primarily in polymerization and, to a lesser extent, in hydrogenation and isomerization applications as disclosed in U.S. Patent Nos. 4,619,908 and 4,717,708, assigned to Cheng et al. of Stauffer Chemical Company. The preparation of these aerogels consisted of hydrolyzing zinc- and titanium-containing solvents to produce a gel, then contacting the gel with an extraction fluid at supercritical conditions, and finally drying the gel. No specific mention of a zinc and titanium combination was made in these patents. Also, because the materials were produced primarily for catalyst support, no specific mention of either particle size or attrition resistance was made. The manufacturing process involved a series of complicated steps that were hard to reproduce and control, and therefore unlikely and expensive for commercial-scale manufacturing. The material had a high surface area and very high pore volume and was only suitable as a catalyst. Very high pore volumes are known to lead to materials with low attrition resistance - highly undesirable for use in fluidized-bed reactors.

Lately, Professors Flytzani-Stephanopoulos and Sarofim at the Massachusetts Institute of Technology (MIT) have been preparing zinc titanate sorbents using an aqueous citrate complexation technique (Lew et al., 1989, 1992; Lew, 1990) that was originally developed by Marcilly et al. (1970) and Courty et al. (1973). This method consists of preparing a citrate precursor of the desired metal oxide, calcining it for 4 to $8 \mathrm{~h}$ at 550 to $850{ }^{\circ} \mathrm{C}$, crushing and screening the calcined material to less than $210 \mu \mathrm{m}$ size, adding 2 to 7 percent of clay binder (typically bentonite), making a paste and extrudating it through a die to produce pellets of a desired size and shape, drying the extrudates, and finally recalcining them for 2 to $6 \mathrm{~h}$ at 650 to $850^{\circ} \mathrm{C}$. Thus, this process requires 8 to 10 complex steps.

Although Flytzani-Stephanopolous and Jothimurugesan (1990) claim in their patent (U.S. Patent No. 4,977,123) that materials thus produced can be used in a fluidized bed, the invention describes a method to prepare sorbents for only fixed-bed applications. Also in this study, no data on either the short- or long-term chemical reactivity and mechanical strength of zinc titanate compounds produced by this technique are furnished. Available literature on the MIT work indicates that these zinc titanate materials were never tested even in a simulated fuel gas environment containing all the major components such as $\mathrm{H}_{2}, \mathrm{CO}, \mathrm{H}_{2} \mathrm{O}$, and $\mathrm{CO}_{2 .}$. Also, due to the complex nature of the manufacturing process, it is not certain to what extent the physical and chemical properties of sorbents prepared batch-wise can be reproduced.

Another technique reported in the literature for preparing the zinc titanate sorbents is a hydrolysis-pyrolysis technique (Reddy et al., 1984; Lercher et al., 1984; and Yamaguchi et al., 1987). An intermediate known as zinc titanyl oxalate hydrate was formed by adding equal volumes of equimolar solutions of titanium tetrachloride and zinc chloride to oxalic acid at 60 to $70{ }^{\circ} \mathrm{C}$. Finally, this intermediate was pyrolyzed by heating to $700{ }^{\circ} \mathrm{C}$ to form zinc titanate compounds. Reddy et al. (1984) were able to produce $\mathrm{Zn}_{2} \mathrm{Ti}_{3} \mathrm{O}_{8}$ phase by this technique. Because this technique involves a series of complex wet processing steps which are difficult to reproduce and control, it is very unlikely that it can be scaled up to produce tonnage quantities. 
$\mathrm{UCl}$ has used a relatively simple technique to prepare zinc titanate sorbents. This technique involves mixing fine zinc oxide and titanium dioxide powders in a desired ratio with a suitable clay binder, such as bentonite, making a paste, and pelletizing to form a product of the desired size. The product is calcined at $871^{\circ} \mathrm{C}$ for $2 \mathrm{~h}$ to impart mechanical strength and porosity. This method has been used successfully to produce zinc titanate material in the form of extrudates suitable for fixed-bed and moving-bed applications (Gangwal et al., 1988).

Despite the work discussed above, there is still a need to prepare durable zinc titanate particles for fluidized-bed applications. The durability here refers to the ability of the material to maintain the desired physical and chemical characteristics over the long term in continuous operation in a fluidized-bed system. The most desired physical characteristic is high resistance to attrition, while the most desired chemical characteristics include high desulfurization and regeneration efficiency and high chemical reactivity for $\mathrm{H}_{2} \mathrm{~S}$ and $\mathrm{COS}$. This is the major objective of the work reported in this study. 


\section{CHAPTER 3}

\section{BENCH-SCALE SORBENT TEST FACILITY}

\subsection{DESCRIPTION OF BENCH UNIT}

The cyclic (sulfidation/regeneration) desulfurization tests for sorbent development were carried out in a high-pressure semi-batch bench-scale reactor designed for operation at pressures up to $35 \mathrm{~atm}$ and temperatures up to $788^{\circ} \mathrm{C}$. The fixed-bed sorbent test facility used in a previous DOE/METC contract (No. DE-AC21-86MC23126) was modified for fluid-bed operation (Gangwal et al., 1988). The modifications were made so that the facility could be used in either a fluid-bed or a fixed-bed mode with minimum downtime during inter-conversion. Although a detailed description of the bench unit appeared in eartier reports (Gupta and Gangwal, 1991), it is briefly described again here.

Figure 3-1 shows a schematic diagram of the modified test facility. For ease of transportation, the unit was constructed as a skid-mounted system. Most of the system components were constructed with 316 and 304 stainless steel. All hot $\mathrm{H}_{2} \mathrm{~S}$-wetted parts were Alon-processed (a high-temperature aluminum vapor treatment) to prevent corrosion of stainless steel by sulfur gases in the presence of steam.

The entire bench-scale test facility can be divided into five subsystems:
1. Gas delivery system,
2. Reactor assembly,
3. Data acquisition ar.j process control,
4. Outlet gas analysis system, and
5. Reactor off-gas venting system.

\subsubsection{Gas Dellvery System}

The gas delivery system has excellent versatility in generating simulated coal gasifier gases representative of all types of gasifiers. Bottled gases are used for $\mathrm{CO}, \mathrm{H}_{2}, \mathrm{CO}_{2}, \mathrm{~N}_{2}, \mathrm{H}_{2} \mathrm{~S}$, $\mathrm{O}_{2}$ and air. $\mathrm{H}_{2} \mathrm{~S}$ is obtained as a mixture of 10 percent $\mathrm{H}_{2} \mathrm{~S}$ in either $\mathrm{N}_{2}$ or $\mathrm{H}_{2}$.

A battery of seven mass flow controllers capable of operation at pressures up to $100 \mathrm{~atm}$ is used to control the flow rate and composition of simulated coal gas. Deionized water is fed to a steam generator using a positive displacement pump to generate the steam. The facility is equipped with three water pumps having operating ranges to accurately generate steam at any composition required in simulated coal gas. The gases are mixed in a gas manifold and sent to a preheater and a superheater for heating to the desired temperature. The preheater shown in Figure 3-2, surrounded by a tubular furnace, is also used to generate steam. The superheater consists of 1/4-in. tubing coiled around a 16-in. long Inconel rod-heater. The preheated gases from the superheater are sent to the reactor.

Because the regeneration of sulfided sorbent is carried out with air and nitrogen mixtures and no steam is used, the water line going to the regeneration preheater, shown in previous reports (Gupta and Gangwal, 1991; Gangwal et al., 1988), was disconnected. 


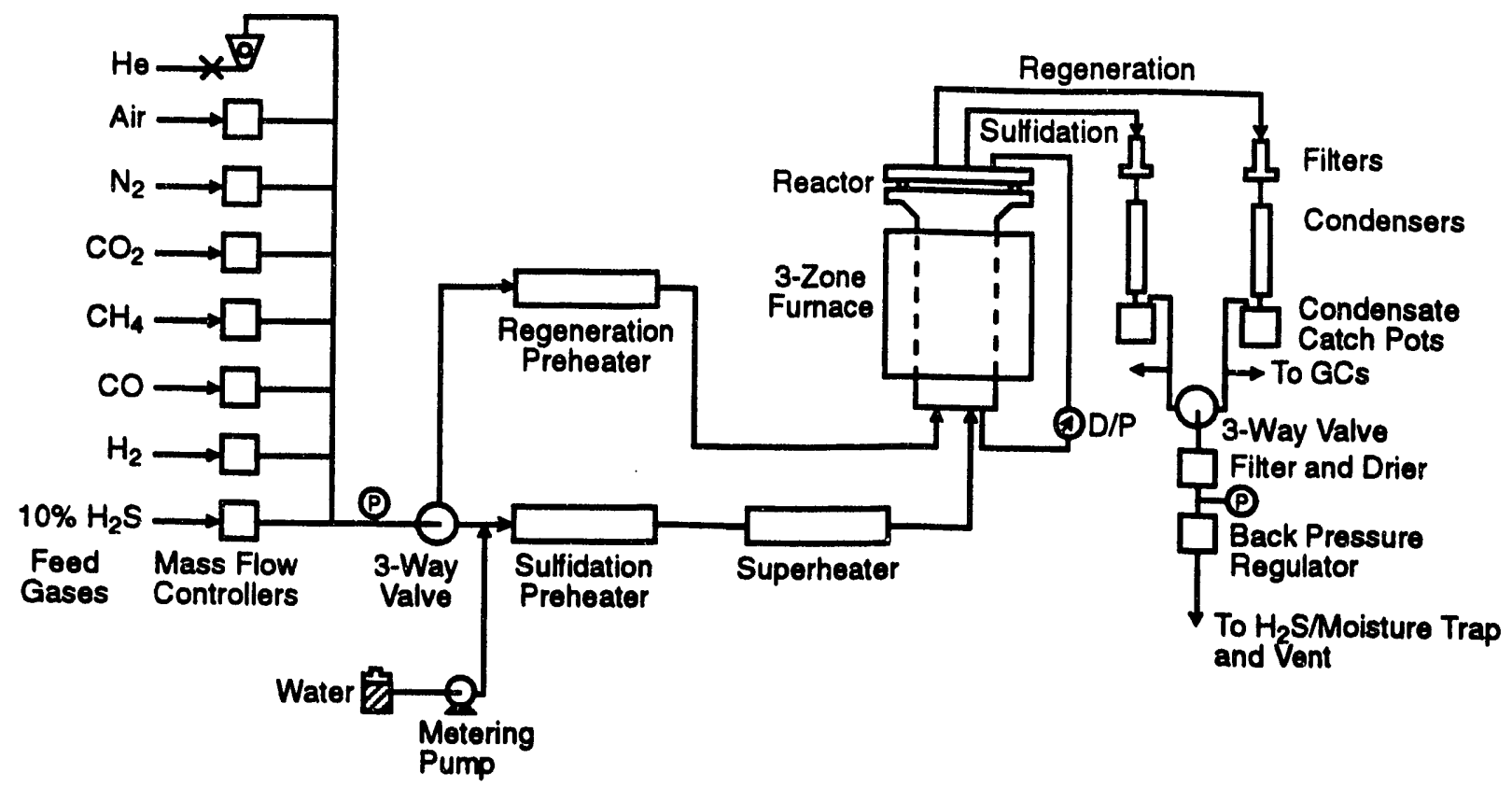

Figure 3-1. Bench-scale fluid-bed sorbent test facility.

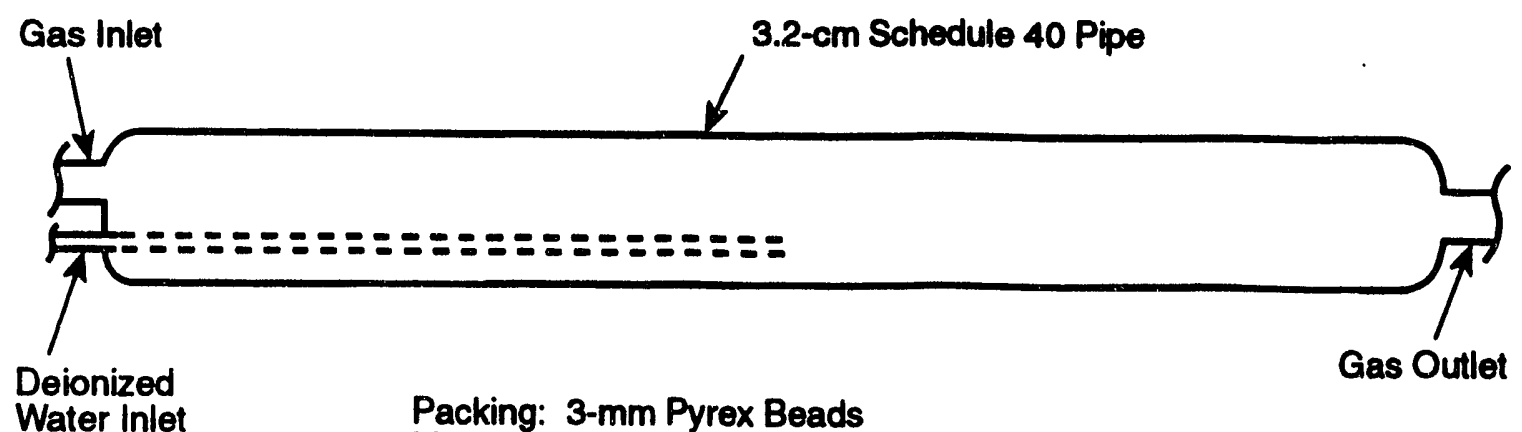

Maximum Temperature: $475^{\circ} \mathrm{C}$

Power: $4 \mathrm{~kW}$

Material of Construction: S.S. 304, Alon Processed

Figure 3-2. Sulfidation gas preheater. 
Separate controllers are used for each of the heaters, i.e., the sulfidation preheater, the regeneration preheater and the superheater. With this arrangement the gas entering the reactor may be heated up to $750^{\circ} \mathrm{C}$.

\subsubsection{Reactor Assembly}

The desulfurization reactor is shown in Figure 3-3. Based on the American Society of Mechanical Engineers (ASME) pressure vessel design code, the reactor system has been designed to withstand up to $35 \mathrm{~atm}$ pressure at $788^{\circ} \mathrm{C}$ and up to $20 \mathrm{~atm}$ pressure at $871^{\circ} \mathrm{C}$.

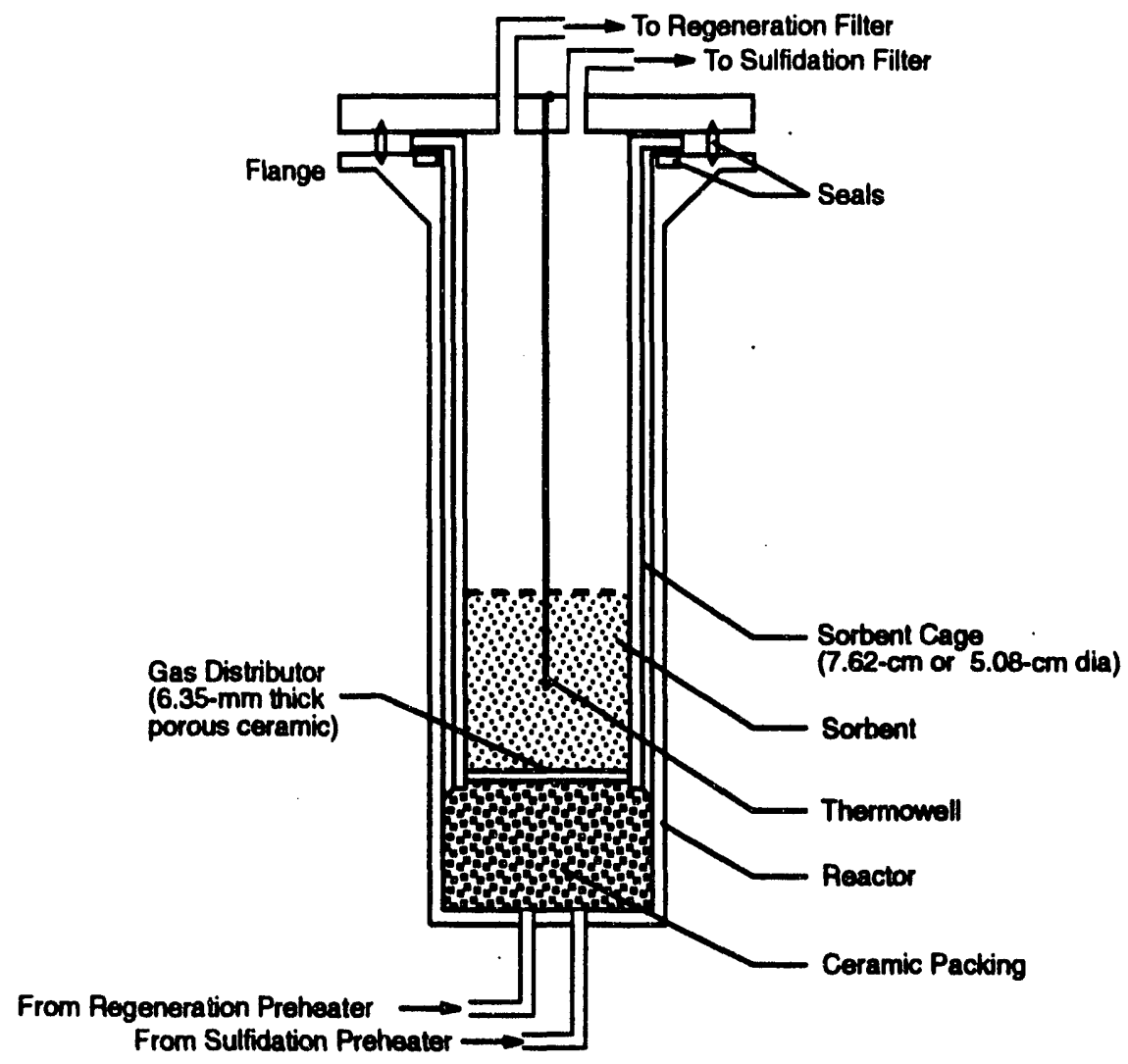

Figure 3-3. Fluld-bed reactor.

The reactor has a removable cage for the sorbent, which gives excellent flexibility of operation by allowing easy removal/oading of the sorbent. A unique feature of this construction, as seen in Figure 3-3, is that the top flange squeezes the main O-ring and at the same time presses down on the cage which in turn squeezes a secondary O-ring. There is essentially no pressure gradient across the secondary O-ring. Its purpose is simply not to allow any gas to bypass the cage.

The reactor is capable of housing both 3 -in. and 2 -in. sorbent cages. An $\alpha$-alumina distributor plate obtained from Zircar and enclosed in a stainless steel ring is welded at the bottom of each cage to introduce hot gas into the reactor. This $1 / 4-$ in. thick distributor is designed for 
appropriate pressure drop to obtain good-quality fluidization in the reactor. This distributor material is heat-treated at $871^{\circ} \mathrm{C}\left(1,600^{\circ} \mathrm{F}\right)$ for $2 \mathrm{~h}$ prior to its use to eliminate any undesired tempering during high temperature reactor operation. The distributor was tested in a cold-flow test facility to ascertain its capability of providing good quality fluidization prior to its use in the bench-scale reactor. A brief description of the cold-flow test facility is given in Section 3.2 later in this chapter.

The reactor is housed inside a three-zone furnace. This three-zone furnace, Model No. 26-29-3ZV, manufactured by Thermcraft, inc., of Winston-Salem, NC, has a total power rating of 8,150 watts. The furnace is equipped with separate electronic controllers for each zone and is capable of heating the reactor up to $871^{\circ} \mathrm{C}$.

To separate elutriated particles from the clean gas, two cyclones were initially used inside the reactor with their diplegs extending to the sorbent bed. Later they were found unnecessary and were removed because of insignificant particle elutriation from the reactor. Ceramic thimble filters downstream of the reactor are used to capture particles from the sulfidation and regeneration exit lines prior to condensers. These filters are found to be very effective in removing particles from the gas.

The reactor exit gas, after passing through the thimble filters, is cooled using a heat exchanger. A separate cooling system is provided for sulfidation and regeneration exit gases. Extensive cooling of regeneration exit gas is not necessary since regeneration is carried out without steam. However, sulfidation exit gas that contains 5 to 25 percent steam (depending on the nature of simulated coal gas used) reiquires efficient cooling to prevent water from entering the downstream gas chromatograph (GC) columns. Hence, a two-stage cooling is carried out. First, the gas is cooled in a double-pipe heat exchanger with tap water flowing in the outer shell and, secondly, in an Inco Alloy C-276 condenser as shown in Figure 3-4. In this condenser, ethylene glycol coolant is circulated at a high velocity to ensure complete condensation of steam. The coolant circulation is maintained using a recirculating cooler manufactured by Lauda MGW Company (Model No. K2RD) equipped with a compressor and a pump capable of cooling the refrigerant to $20^{\circ} \mathrm{F}\left(-7^{\circ} \mathrm{C}\right)$. The water resulting from the condensation of steam is drained periodically from the catchpot into a measuring flask. At the end of each cycle, the volume of the condensate is measured to obtain a water material balance.

\subsubsection{Data Acquisition and Process Control}

An efficient data acquisition and control systern is used to monitor the bench unit closely. The significant process variables that are controlled include the following:

- Temperature,

- Pressure, and

- Flow rate and composition of reactor inlet gas.

The reactor temperature is monitored at the bed inlet below the distributor, halfway in the bed, and at the bed outlet in the freeboard. The temperatures in the preheater, superheater, sulfidation filter, and regeneration filter are also monitored using type-K thermocouples equipped with digital display and connected to a data-logger.

The flow rate of inlet gas to the reactor (in sulfidation and regeneration modes) is measured using seven precalibrated mass flow controllers from Brooks Instruments. The mass 


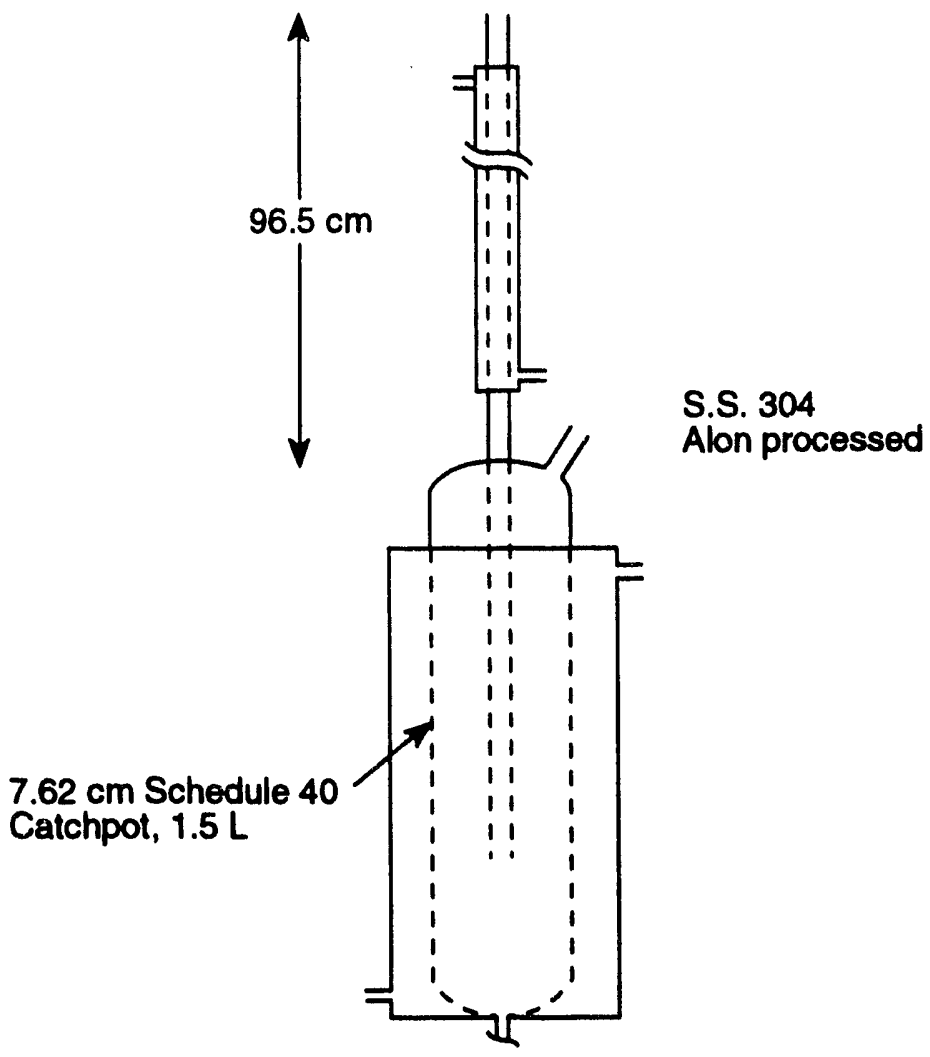

Figure 3-4. Sulfidation gas condenser. flow controllers are connected to a digital display and a data-logger that continuously records the gas flow rates and temperatures.

Precise pressure control is provided by two back-pressure regulators in series. An onset of reactor plugging can be detected by an electronic differential pressure monitor across the reactor (as shown in Figure 3-1). Furthermore, this differential pressure module is also used to ascertain good quality fluidization in the reactor. For proper sorbent fluidization, the measured pressure drop across the bed must be greater than the weight of the sorbent in the reactor. The backpressure regulators are protected from potential particle plugging by passing the gas through a Drierite trap and a Balston filter.

The data-logger is equipped with an alarm system which allows specification of each important process variable's low and high limits. This system, very useful in providing a warning for low gas content in bottles and overheating/underheating of

gases, consists of electronically activated relay coils and allows more than $100 \mathrm{~h}$ of continuous testing, if desired.

Flow rate and composition of reactor outlet gases (sulfidation and regeneration) are measured using a dry gas meter and GCs, respectively. A brief description of the gas analysis procedure is given in Section 3.1.4.

\subsubsection{Outlet Gas Analysis System}

A slipstream of the stearn-free gas from the reactor (after condensers) is diverted to the gas analysis system shown in Figure 3-5. As can be seen, the GC sampling system permits analyzing the inlet as well as outlet gas streams. The outlet gas stream analysis is carried out using two GCs, a Carle Series 400 AGC with a thermal conductivity detector (TCD) and a Varian 3300 with a flame photometric detector (FPD). The GCs are connected to separate Spectra Physics SP4270 integrators which continuously record the gas analysis. Multiple GC sampling valves and dual loops in the Varian FPD provide the capability of measuring $\mathrm{H}_{2} \mathrm{~S}, \mathrm{COS}, \mathrm{SO}_{2}$, and $\mathrm{CS}_{2}$ from 1,500 ppmv to less than $0.1 \mathrm{ppmv}$ every $6 \mathrm{~min}$. A Chromosil-310 column is used to separate the gaseous components at $50^{\circ} \mathrm{C}$. Prior to each run, the Varian $\mathrm{GC}$ is calibrated using a calibration standard gas sample, typically 100 or 500 ppm of $\mathrm{H}_{2} \mathrm{~S}$ in nitrogen.

High concentrations of $\mathrm{H}_{2} \mathrm{~S}, \mathrm{SO}_{2}$, and other bulk gases $\left(\mathrm{H}_{2}, \mathrm{CO}_{2}, \mathrm{~N}_{2}, \mathrm{O}_{2}, \mathrm{CH}_{4}\right.$, and $\left.\mathrm{CO}\right)$ are measured every 25 min with the Carle TCD to evaluate mass balance and the extent of shift reaction $\left(\mathrm{CO}+\mathrm{H}_{2} \mathrm{O} \rightarrow \mathrm{CO}_{2}+\mathrm{H}_{2}\right)$. 


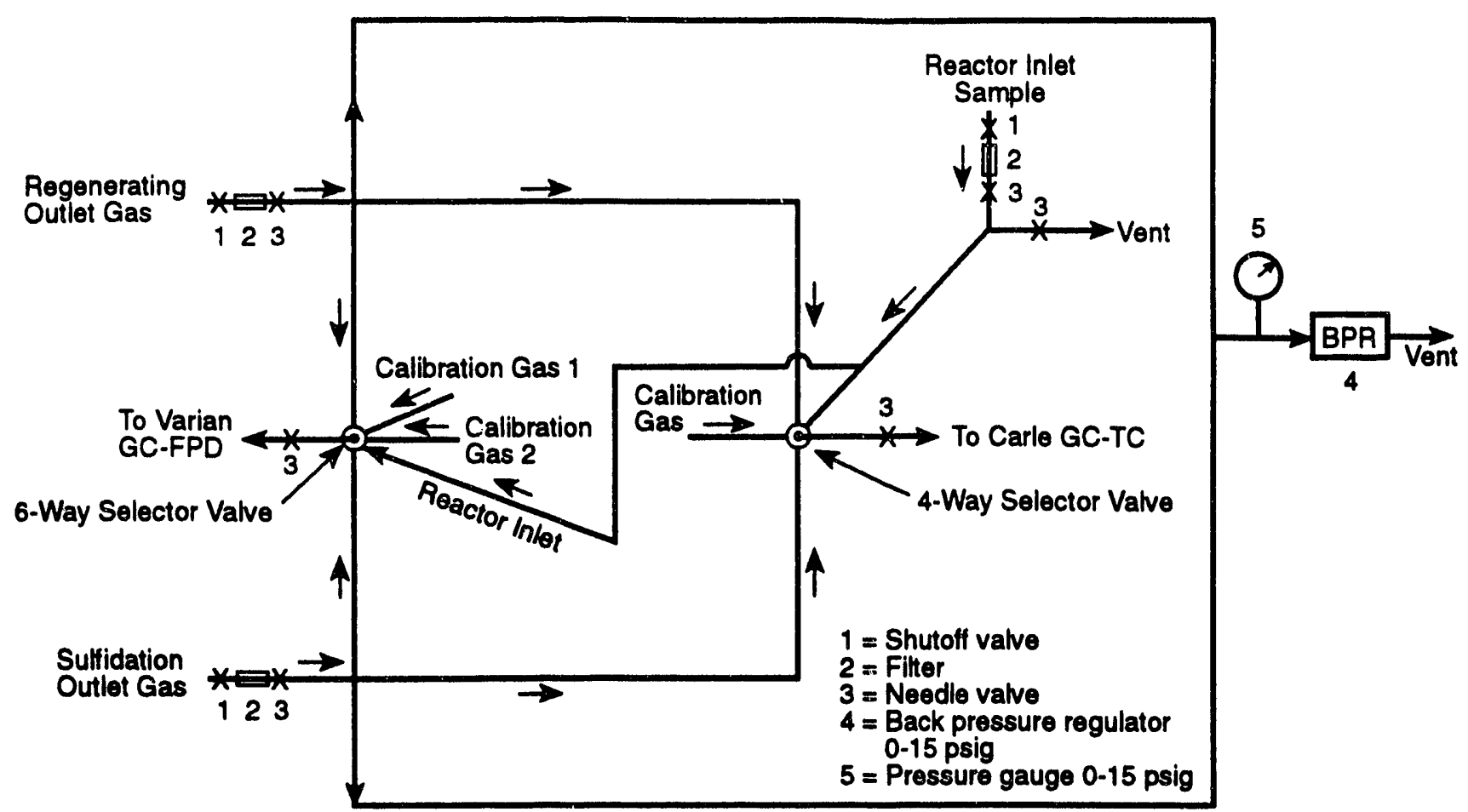

Figure 3-5. Schematic of GC sampling system for bench unit.

\subsubsection{Reactor Off-gas Venting System}

The sulfidation exit gas containing toxic $\mathrm{CO}$ and $\mathrm{H}_{2} \mathrm{~S}$ and regeneration off-gas containing toxic $\mathrm{SO}_{2}$ are properly disposed. A high-powered blower is used to dilute the gases by a factor of 100 before emitting them into the atmosphere. The calculations of total $\mathrm{CO}$ and $\mathrm{S}$ emissions from these tests indicated no environmental problems.

\subsection{COLD FLOW MODEL}

Fluidization research has been carried out primarily at atmospheric pressure and only limited literature on high-pressure fluidization is available. Because the desulfurization reactor in this study required HTHP operation, it was necessary to understand the sorbent fluidization behavior at high pressures prior to actual testing under reacting conditions in the metal reactor.

To this end, two high-pressure see-through cold-flow models were designed and constructed from 2-in. and 3-in. polycarbonate pipes, respectively. A schematic diagram of the 3-in. cold-flow model is shown in Figure 3-6. This 3/8-in. thick pipe is capable of withstanding up to $80 \mathrm{~atm}$ pressure. The same ceramic distributor that was used in the reactor (see Section 3.1.2) was used to introduce the gas.

Specific applications of the see-through high-pressure cold-flow models were to determine minimum fluidization velocity, assess fluidization quality, avoid slugging in the hot reactor, avoid excessive entrainment, confirm distributor pressure drop, and aid in developing a startup and shutdown procedure for the HTHP reactor. 


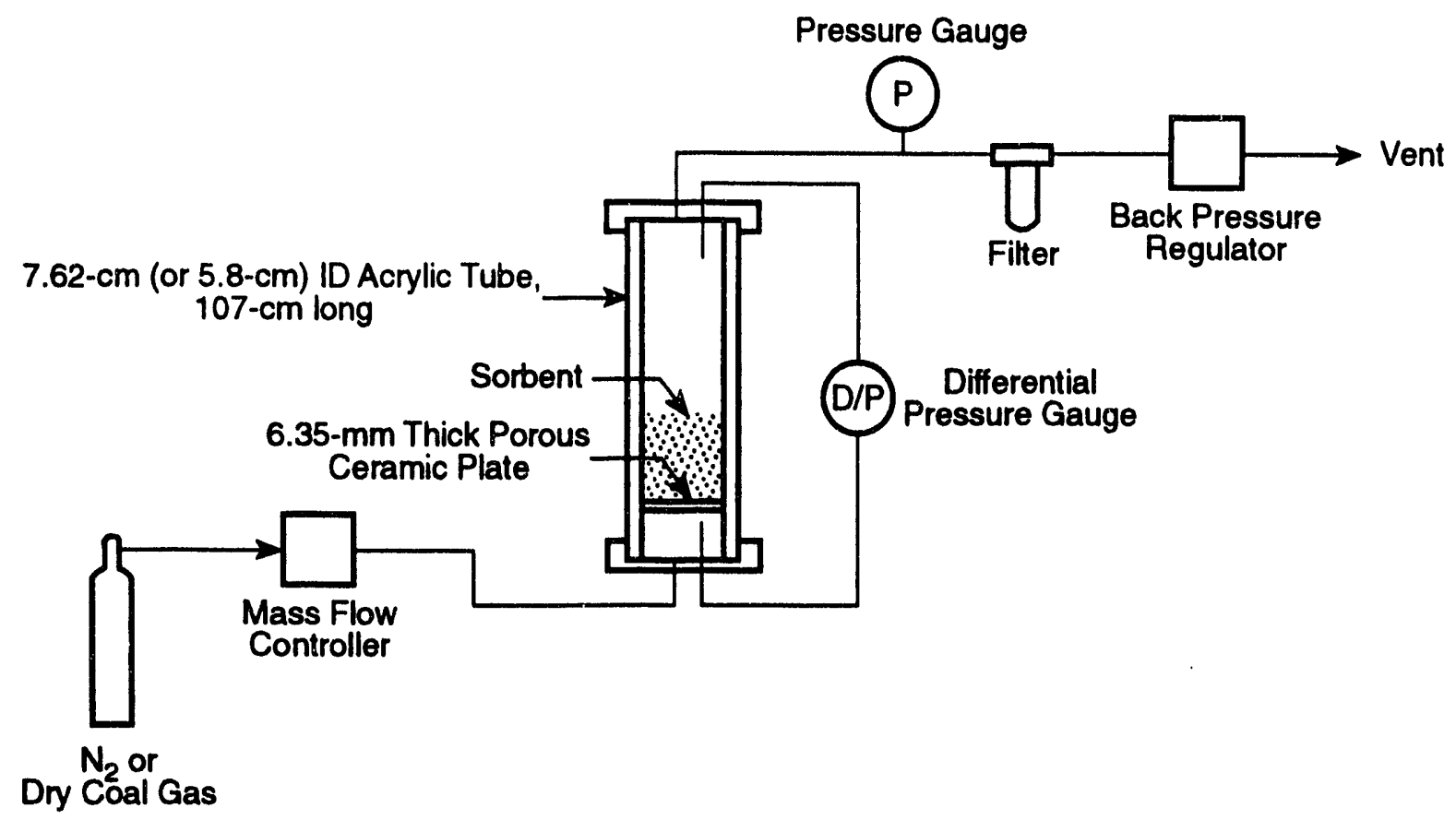

Figure 3-6. High-pressure fluld-bed cold-flow see-through reactor model.

The cold-flow test procedure includes loading a known weight of the sorbent in the bed and then measuring the bed height. This provides an approximate measure of bed-voidage. Nitrogen gas is used for fluidization and a thimble filter (similar to the filter used in the reactor [see Section 3.1.2]) is used for collecting entrained particles. A back-pressure regulator is provided to control system pressure and a differential pressure sensor is used to measure the pressure across the distributor and the sorbent bed.

The cold-flow model was operated at several pressures under conditions based on the design of the actual reactor (i.e., initial sorbent bed height, linear gas velocity). Because of the insignificant effect of temperature on fluidization, the cold flow model, at least qualitativeiy if not quantitatively, was representative of the fluidization behavior of the sorbent in the actual HTHP reactor.

\subsection{TEST PROCEDURE AND CONDITIONS}

Following a number of bench-unit shakedown tests and a study of fluidization behavior in the cold-flow model, a bench-unit test procedure was developed. A typical bench-unit run consists of the following steps:

1. A known weight of the sorbent (typically $350 \mathrm{~g}$ ) in the particle size range of 100 to $300 \mu \mathrm{m}$ is charged to the reactor.

2. The reactor is pressurized to a desired pressure (typically 220 pounds per square inch absolute [psia]) and heated to a desired temperature $\left(550\right.$ to $\left.750{ }^{\circ} \mathrm{C}\right)$ with continuous passage of nitrogen through the reactor. 
3. Sulfidation of the sorbent is carried out by flowing the simulated coal gas and is continued until the $\mathrm{H}_{2} \mathrm{~S}$ concentration in the reactor exit gas reaches 500 ppmv (breakthrough value).

4. Following the sulfidation, the reactor is switched to regeneration mode by stopping the flow of sulfidation gas to the reactor and heating the reactor to the desired regeneration temperature again with continuous passage of nitrogen flowing through the reactor. Generally, the initial regeneration temperatuire is 50 to $150^{\circ} \mathrm{C}$ higher than the sulfidation temperature. Once the desired temperature is attained, the flow of regeneration gas is started. Regeneration is carried out using nitrogen as a diluent with a gas containing 2 to 5 percent $\mathrm{O}_{2}$ and terminated when the outlet $\mathrm{SO}_{2}$ concentration is reduced to less than $250 \mathrm{ppmv}$.

5. Steps (2) to (4) are repeated for subsequent cycles.

At the end of the run, the sorbent is removed from the reactor and weighed to determine any loss of material due to elutriation. Also, the sulfidation and regeneration filters, as shown in Figure 3-1, are examined for any particle buildups. A post-test sorbent characterization is performed to evaluate changes caused by reaction. This characterization includes determination of particle size distribution, attrition resistance, pore volume and pore diameter, BET surface area, TGA reactivity, $\mathrm{Zn}$ and Ti contents, XRD, and SEM analyses. Detailed descriptions of these characterization methods are presented in Chapter 4.

\subsection{1-In.-I.D. QUARTZ REACTOR SYSTEM}

In addition to the bench-scale reactor system, a 1-in.-I.D. quartz reactor system was used to conduct selected tests to study the effect of sulfidation on the sorbent. A schematic of this reactor system is shown in Figure 3-7. The reactor is made of quartz and is housed in a threezone furnace. The reactor has an inside diameter of $26 \mathrm{~mm}, \mathrm{a} 2-\mathrm{mm}$ wall thickness and a total length of $44 \mathrm{in.}(112 \mathrm{~cm})$. The system can handle corrosive gas environments, if needed. Teflon parts are used for components exposed to corrosive gas at lower $\left(<200^{\circ} \mathrm{C}\right)$ temperatures. The reactor operates in a bubbling fluidized-bed mode. A coarse porous quartz frit at the bottom of the reactor bed is used as the distributor for the simulated coal gas. All lines in and out of the reactor are made of quartz.

A syringe pump is used to introduce steam into the reactor through a capillary as shown in Figure 3-7. A special Inconel thermocouple constantly measures the temperature within the sorbent bed.

The partially cooled $\left(200\right.$ to $300^{\circ} \mathrm{C}$ ) gas from the reactor is sent to a glass condenser system in which all the water vapors are condensed and collected. A slipstream of the noncondensable gases is sent to the gas chromatography system described previously for analysis.

The dry gases required for sulfidation and regeneration of the sorbent are obtained premixed in cylinders. A four-way valve is used to pass the appropriate gas through a precalibrated electronic mass flow controller into the bottom of the reactor bed. A purge gas, such as nitrogen, is used during the heating and cooling of the sorbent bed and during the switching between sulfidation and regeneration cycles. 


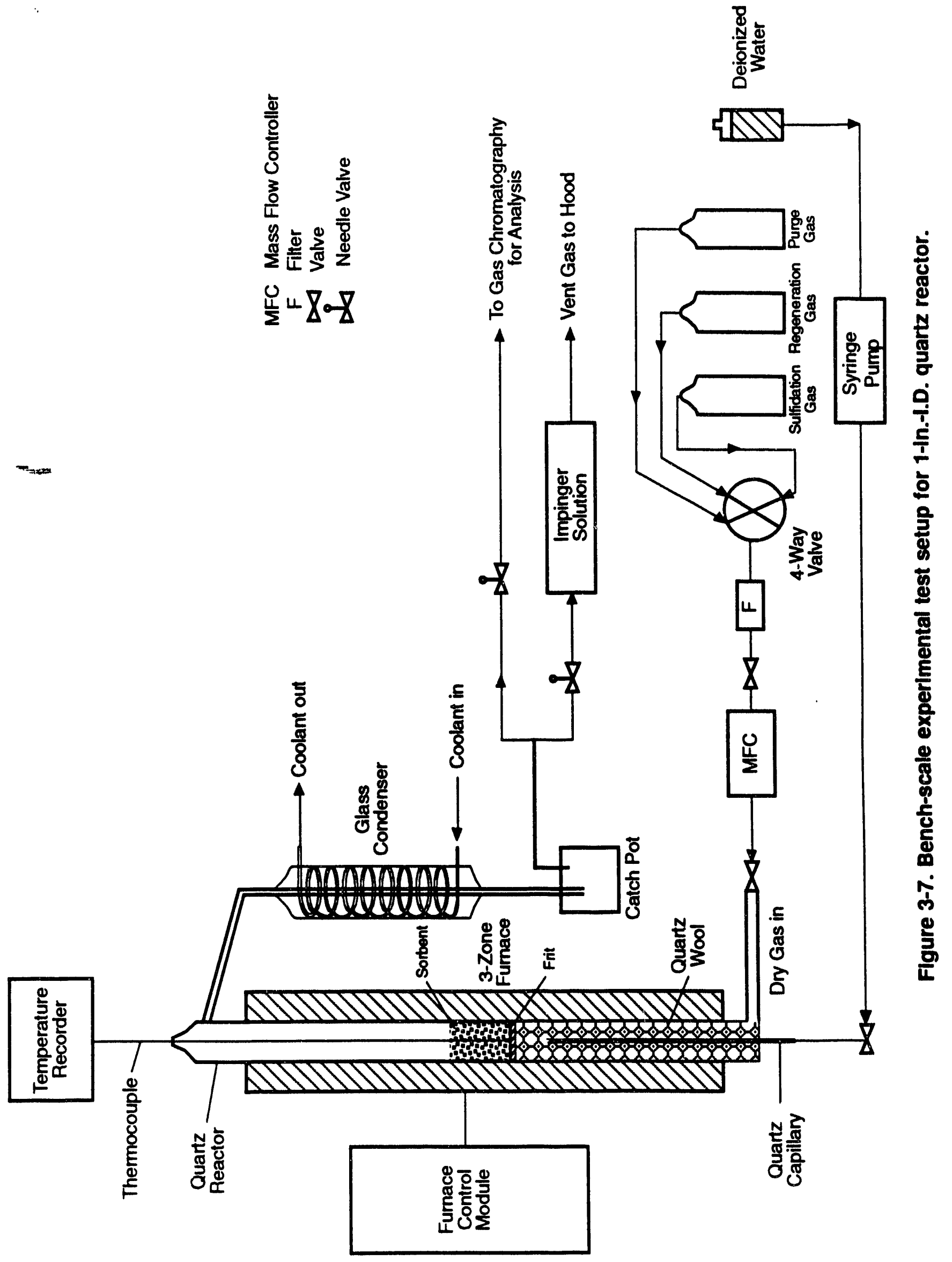




\section{CHAPTER 4}

\section{SORBENT CHARACTERIZATION}

\subsection{PURPOSE}

Since the development of durable zinc titanate sorbents was the major objective of this study, a number of techniques were used to physically and chemically characterize the various sorbent formulations prepared in this study. The physical characterization of sorbent included determination of particle size distribution, BET surface area, pore size distribution, XRD phases, SEM elemental map, and, most importantly, attrition resistance. On the other hand, the chemical characterization included determination of chemical reactivity, sulfur capacity, regenerability, and reduction potential of zinc titanate sorbents in a TGR. All these techniques are described in detail in this chapter.

The above sorbent characterization was carried out for the following:

- Initial screening, and

- Post-test characterization.

Initial screening of various formulations was carried out to obtain promising sorbents that can be tested further in the bench unit. The formulations that exhibited a combination oi good TGR reactivity and attrition resistance along with other properties were primarily selected for bench testing, as discussed in Chapters 5 and 6.

The post-test characterization here refers to the determination of physical and chemical properties (listed above) of a sorbent formulation that had undergone a multicycle (10 cycles typically) test in the bench unit. The intent of this characterization was to determine various changes in the sorbent properties that occurred during testing to provide an idea about its durability. For example, zinc ferrite sorbents had very poor attrition resistance after 10 cycles of sulfidation-regeneration as compared to the attrition resistance in their unreacted state as reported in the previous topical report (Gupta and Gangwal, 1991).

\subsection{PHYSICAL CHARACTERIZATION}

The physical characterization of zinc titanate sorbent formulation included the determination of the following properties:

- Particle size distribution,

- BET surface area,

- Pore size distribution,

- XRD analysis,

- SEM/energy dispersive scan (EDS) analysis, and

- Attrition resistance.

Each of these is described in Sections 4.2.1 through 4.2.6. 


\subsubsection{Particle Size Distribution}

Most sorbent particle size analyses during the project were conducted using a sieve train and a sonic sifter. Standard Tyler sieves were used to produce various particle size cuts. Since a major fraction of the sorbent used was coarser than 200 mesh $(74 \mu \mathrm{m})$, although time consuming, sieving worked very effectively.

Large batches ( $<50 \mathrm{lb}$ ) of sorbents that were supplied to DOE/METC were screened in a SWECO vibro screener. A selected number of zinc titanate sorbent samples were also analyzed for their particle size distribution using a Coulter Counter and a laser-based Microtrac system.

Typically, the particle size distribution was expressed as a plot between the cumulative weight percent and particle diameter (e.g., see Appendix F).

\subsubsection{BET Surface Area}

BET surface area is an important measure for correlating the reactivity of a sorbent/catalyst to its physical properties. It is routinely used in most catalyst/sorbent studies. It was originally developed by Brunauer, Emmet and Teller (1938). A Quantasorb analyzer system is employed at RTI to determine the BET surface areas. The surface area measurement in this system is based on the volume of nitrogen uptake by a known amount of sample at liquid nitrogen temperature $\left(-196^{\circ} \mathrm{C}\right)$. An outgassing station with a heating mantle is provided to degas the sample prior to measurement. Sample cells can be interchanged quickly between outgassing and measuring stations using quick-connect fittings that seal them from the atmosphere. Nitrogen is first adsorbed onto the sample at $-196^{\circ} \mathrm{C}$ by flowing a nitrogen-helium stream of known composition (in the range of 10 to 30 percent nitrogen) over the sample. Two mass flow controllers are used to mix the gases accurately in the required ratio. The sample is then desorbed quickly by placing the sample cell in warm water. The nitrogen desorption peak is measured by a calibrated thermal conductivity detector and integrated to yield the volume (and mass therefrom) of nitrogen adsorbed. This procedure is repeated for at least two other compositions in the 10 to 30 percent $\mathrm{N}_{2}$ range if a three-point surface area is desired. The mass adsorbed at different partial pressures is plotted using the standard BET equation. The details of the BET method and the plotting parameters are covered in several standard surface chemistry and kinetics texts (e.g., Satterfield, 1980).

\subsubsection{Pore Size Distribution}

Measurement of pore volume, pore volume distribution, and median pore diameter using mercury intrusion provides a direct indication of the diffusional resistances associated with reaction of $\mathrm{H}_{2} \mathrm{~S}$ with the sorbent. At RTI this is done with an Auto Pore 9220 II instrument manufactured by Micromeritics Instrument Company. The instrument is rated at $414 \mathrm{MPa}(60,000$ psi) maximum and is capable of characterizing pores as small as $6 \mathrm{~nm}$, well below the desirable pore size of the sorbent, which normally ranges between 150 and $350 \mathrm{~nm}$. Sulfidation in very small micropores can lead to pellet weakening/cracking. When the bigger sulfur atom replaces the smaller oxygen atom, stresses are created on small pore walls. These stresses can eventually lead to cracking and mechanical disintegration of the sorbent. 
Mercury porosimetry is based on equilibrated intrusion of mercury into a porous material as a function of pressure. The sample is evacuated and immersed in mercury, and the mercury pressure on the sample is isostatically increased causing mercury to intrude into the pores. The displaced pore volume is inversely proportional to the applied pressure. This permits a direct measurement of pore size and volume and supplies the basis for providing related information.

The instrument is highly automated (interfaced with an IBM PC) and provides the following information:

- Pore volume,

- Median pore diameter (diameter at 50 percent intrusion),

- Pellet density (skeletal and bulk),

- Macroporosity (>50 nm), and

- Tables and plots for

- cumulative pore volume vs. pressure and/or pore diameter,

- differential pore volume vs. pressure and/or pore diameter.

All these data can be stored on a floppy disk for future retrieval and comparison purposes. A typical pore size distribution report generated by this system appears in Appendix $A$.

\subsubsection{XRD Analysis}

XRD analysis of the zinc titanate samples was performed to determine various crystalline phases present in the sorbent. It is believed, as discussed in Chapter 2, that relative amounts of $\mathrm{Zn}_{2} \mathrm{Ti}_{3} \mathrm{O}_{8}, \mathrm{Zn}_{2} \mathrm{TiO}_{4}$, and $\mathrm{ZnTiO}_{3}$ phases exhibit a weak correlation with the attrition resistance of the sorbent. This is based principally on the fact that the molar volume expansion associated with ZnS formation is significantly different for all these three zinc titanate phases. For example, reaction of $\mathrm{Zn}_{2} \mathrm{TiO}_{4}$ with $\mathrm{H}_{2} \mathrm{~S}$ will lead to a 45 percent increase in the molar volume while a 37 percent expansion in molar volume of the sorbent will take place with the $\mathrm{ZnTiO}$ phase (Datta, 1992). This increase in molar volume is perhaps related to the final mechanical strength of the material. Another important purpose of XRD analysis was to determine the presence of free zinc oxide in the sorbent.

The XRD analysis was performed at West Virginia University using a Philips PW1800 automatic XRD unit employing single-crystal monochromated copper $\mathrm{K} \alpha$ radiation. This unit is equipped with an automatic divergent slit to maintain constant area of illumination, a sample spinner to minimize sample heterogeneity, and a 24-place automatic sample changer. The unit is controlled and data are analyzed with a VAX 3100 workstation. This workstation provides total operational control of the instrument as well as a variety of data analysis capabilities including both absolute and integrated peak area measurement, crystallite size determination, various kinds of graphic presentations and comparisons, and mineral quantification. The unit is also equipped with the JCPDS powder data file and automatic search/match software for the identification of 60,000 components for unknown samples. All data generated by the unit are stored on a hard drive for future retrieval.

Samples are prepared by first reducing the material to below $74 \mu \mathrm{m}$ ( 200 mesh) by crushing and screening. The powder is then pressed onto the surface of a $40-\mathrm{mm}$ plastic pellet under a 15-ton total load. All samples are stored under vacuum until analyzed. The PW1800 has an automatic sample changer which allows the unattended analysis of up to 20 samples. 
Two different scan modes are used for the zinc titanate samples. If the composition of the sample is either unknown or is in question, the sample is step-scanned from $10^{\circ} 2 \theta$ to $90^{\circ}$ $2 \theta$ to allow the use of the search-match program. If the various crystalline phases are known with some degree of certainty, the sample is only scanned from $25^{\circ} 2 \theta$ to $40^{\circ} 2 \theta$ in order to record the strongest diffraction lines for each of the various crystalline phases. All scans are made at a speed of $0.01^{\circ} 2 \theta$ per second.

Semiquantification of the various crystalline phases is accomplished by using the lineprofile program in the Philips software package and the integrated intensities of selected analytical lines generated by the short scan mode. Semiquantification is accomplished by ratioing the intensities of the analytical lines determined by the short scan, taking into consideration the relative intensity for the line as reported in the standard diffraction dataset. Standard diffraction data for the individual crystalline phases are obtained from both the JCPDS file and published data.

The crystalite size of the zinc titanate phase is determined by a Philips software procedure that compares the line profile of the strongest zinc titanate line to that of the $26.662 \theta$ line of a quartz standard. Figure 4-1 shows the Bragg reflection positions for various zinc titanate phases on a diffractogram. It is important to note that the reported crystallite size is not an absolute measurement but, rather, can be used only for a relative comparison. A typical XRD report generated by the machine is enclosed in Appendix B.

\subsubsection{SEM/EDS Analysis}

SEM/EDS analyses of various zinc titanate formulations were performed to examine the surface morphologies and crystal orientations. The EDS can examine the homogeneity of zinc and titanium, and sulfur in the case uf sulfided samples, in the sorbent matrix. Segregation of zinc in the matrix is believed to lead to excessive zinc vaporization at high temperatures during sulfidation reaction.

These analyses were performed using a Philips Model 525 scanning electron microscope equipped with an energy dispersive analyzer X-ray (EDAX) spectrometer for elemental analysis and the Philips FAXSCAN image analysis system. The combination of the EDS and the FAXSCAN units allows size, shape, and elemental mapping of individual particles. The unit is equipped with a multisample sample holder and an automatic stage which allows sequential, programmed, automatic analysis of multiple samples. Samples are mounted on aluminum or carbon stubs and coated with gold. Typical scanning electron micrographs for one of zinc titanate formulations are shown in Appendix B.

\subsubsection{Attrition Resistance}

Relatively little is known about the attrition of the sorbent in fluidized-bed reactors. Loss of sorbent due to attrition in the form of fines from a commercial hot-gas desulfurization reactor operating in a fluidized-bed mode is perhaps the most important concern that is impeding the commercialization of this technology. Therefore, accurate measurement of the attrition tendency of various sorbents is very important.

Bemrose and Bridgwater (1987) provide a comprehensive review of attrition test methods. The attrition rate for sorbents used in fixed-bed and moving-bed reactors is normally measured 


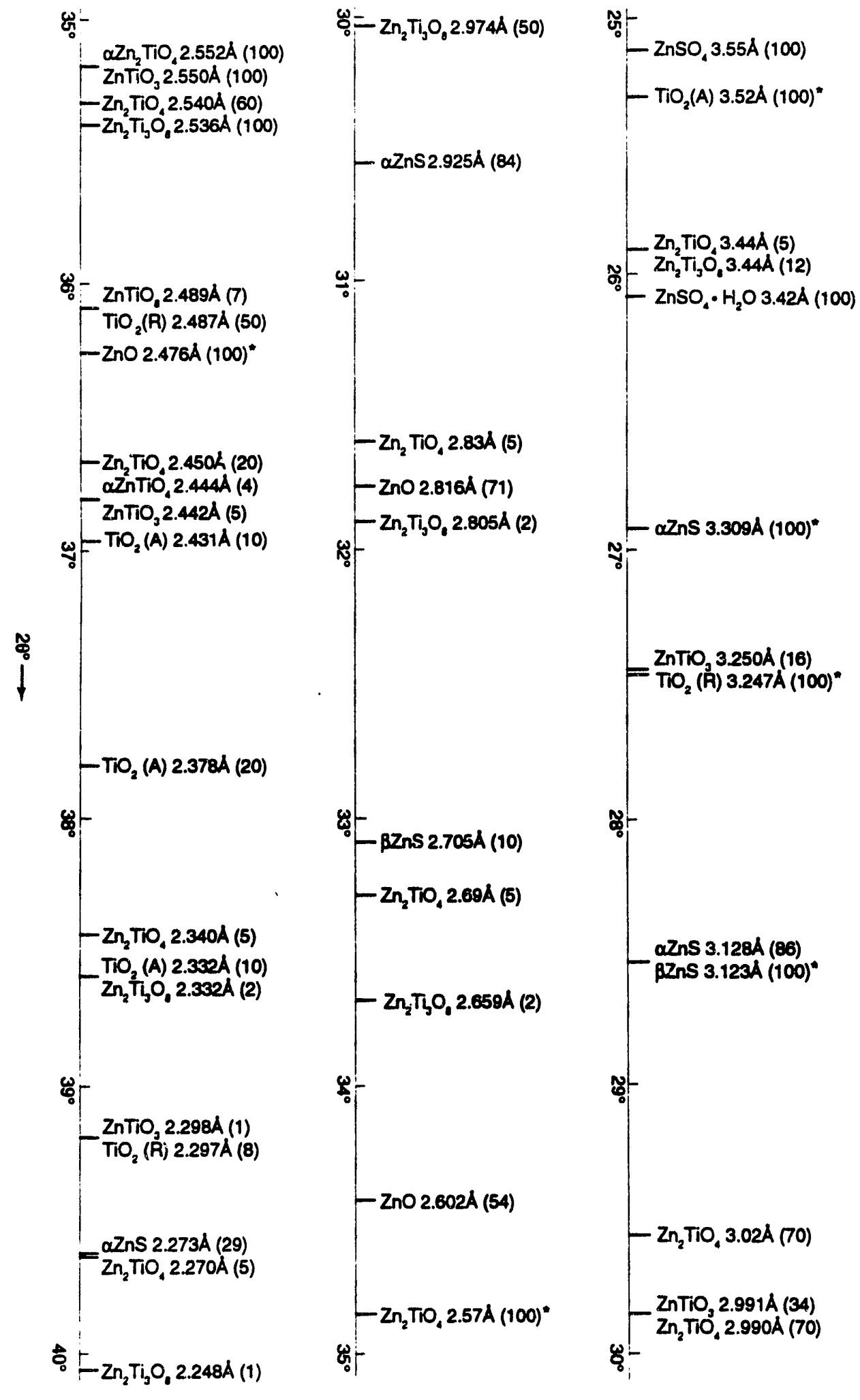

Figure 4-1. Bragg reflection positions for zinc titanate samples. 
using ASTM procedure D-4058 (ASTM, 1981). However, for sorbents and catalysts used in a fluidized-bed system, there are no standard tests available. The two types of attrition tests used in this study are described below.

\subsubsection{C'ngle-Hole Attrition Tester}

Initially, a single-hole attrition tester was used following the design of a high-velocity air jet apparatus by Forsythe and Hertwig (1949), also described by Anderson and Pratt (1985). Figure 4\%2 shows a schematic of this attrition tester. This device consisted of a 2.54-cm I.D. quartz tube with a single $0.4-\mathrm{mm}$ hole gas inlet and had the capability of cold and hot attrition tests as well as in-situ sulfidation and regeneration. During a typical attrition test of $1 \mathrm{~h}$ with a 50-cc sorbent bed, the nitrogen gas flow was adjusted to 7 standard liters per minute (s/pm) to generate sonic velocity through the hole, which in turn provided high shearing and turbulence to the sorbent. The high shearing presumably produced measurable attrition and simulated attrition in commercial fluid-bed reactors over a much longer period. The test was not intended to develop attrition rate data on an absolute basis, but instead was used to develop a measure of relative resistance to attrition to compare different sorbents.

The particle size distribution of the sample was measured before and after the test to determine the amount of fines produced below a predesignated cut point. For the particle size range of sorbent used in the benchscale testing, i.e., 100 to $300 \mu \mathrm{m}$, $100 \mu \mathrm{m}$ was designated as the cut point. The attrition resistance $\left(A_{R}\right)$ was arbitrarily defined as

$$
A_{R}=100\left[1-\frac{B}{A}\right]
$$

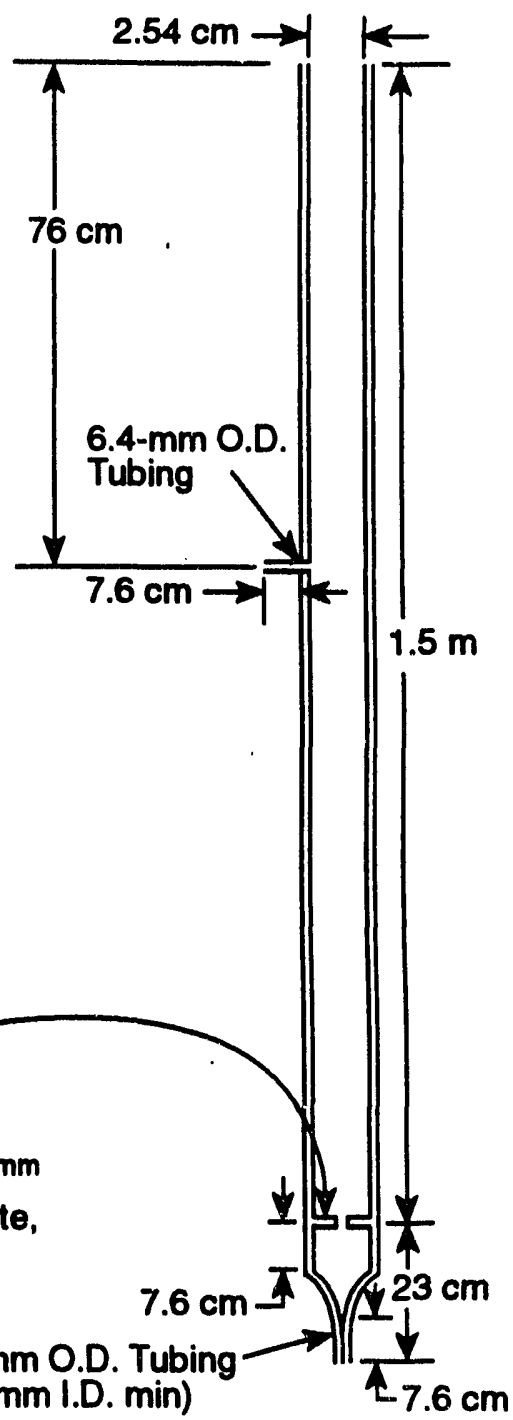

3-mm thick $\times 25.4-\mathrm{mm}$ dia Plate, Hole in Center of Plate

Not to Scale

6.4-mm O.D. Tubing
(3.2-mm I.D. $\mathrm{min})$

Plate Details

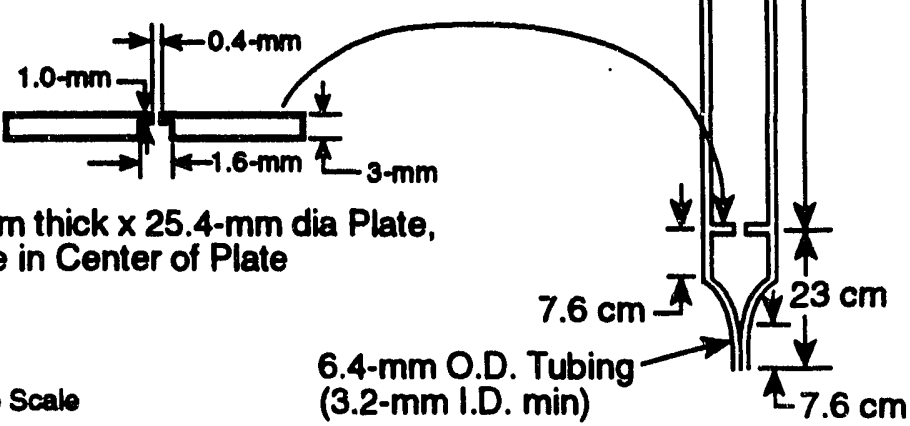

Figure 4-2. Schematic of single-hole attrition tester.

where

$A=$ Original sorbent amount tested less initial amount of fines (below cut point),

$B=$ Increase in amount of fines (below cut point) after test. 
If $F$ is the weight of the sorbent initially charged in the attrition tube and $P$ is weight recovered, and $x$ and $y$ are the fractions of fines (below cut point) in feed and recovered sorbent, respectively, then $A_{R}$ can be written as:

$$
A_{R}=100\left[1-\left(\frac{F-P}{F}+(y-x)\right)\right] \text {. }
$$

Rearranging the above expression yields

$$
A_{R}=100\left[\frac{P}{F}-(y-x)\right]
$$

or

$$
A_{R}=100\left[\frac{\text { Sorbent after test }}{\text { Sorbent before test }}-\text { Increase in fraction of fines }\right] \text {. }
$$

A commercially available fluid catalytic cracking (FCC) catalyst was initially subjected to an attrition test in this device. The attrition resistance of the FCC catalyst was determined to be close to 100 percent. This attrition tester was also used for high-temperature attrition testing, e.g., at $650^{\circ} \mathrm{C}$. The gas flow was adjusted to yield the same velocity through the tube as the roomtemperature test. The results showed that high-temperature attrition resistance for sorbents was higher than room temperature attrition resistance. Thus the high-temperature attrition resistance measurements were not critical and therefore were not continued.

During the initial phase of this study, the single-hole attrition tester described above was used. Later attrition rate measurements were performed using the three-hole tester described in Section 4.2.6.2.

\subsubsection{Three-Hole Attrition Tester}

One of the main reasons behind using a single-hole tester rather than a three-hole tester was to determine the attrition resistance at high temperatures. Since high-temperature attrition measurements were not found to be critical (as discussed above), this tester was replaced with a three-hole tester thai is more commonly used in the catalyst community. The three-hole design is considered superior to the single-hole tester because in the latter fines are not removed from the body of the sorbent during the attrition test and, hence, may result in some reduction in severity of attrition conditions, since the fines impede impact between the larger particles. In a three-hole tester, however, as shown in Figure 4-3, continuous removal of fines takes place and the operation proceeds for a long time.

As shown in Figure 4-3, the upper section of the attrition tester has a diameter of 5-3/4 in. with 1-5/8 in. for the lower section. The large-diameter upper part serves as an elutriator for the separation of fines $(<20 \mu \mathrm{m})$, which are ultimately collected in the flask/filter (thimble) assembly. This design was originally developed in 1969 by J.E. Gwyn of Shell Oil Company. The perforated plate at the bottom of the tester contains three 0.4-mm dia equi-spaced holes as compared to $0.4-\mathrm{mm}$ dia single hole in the previous version. 


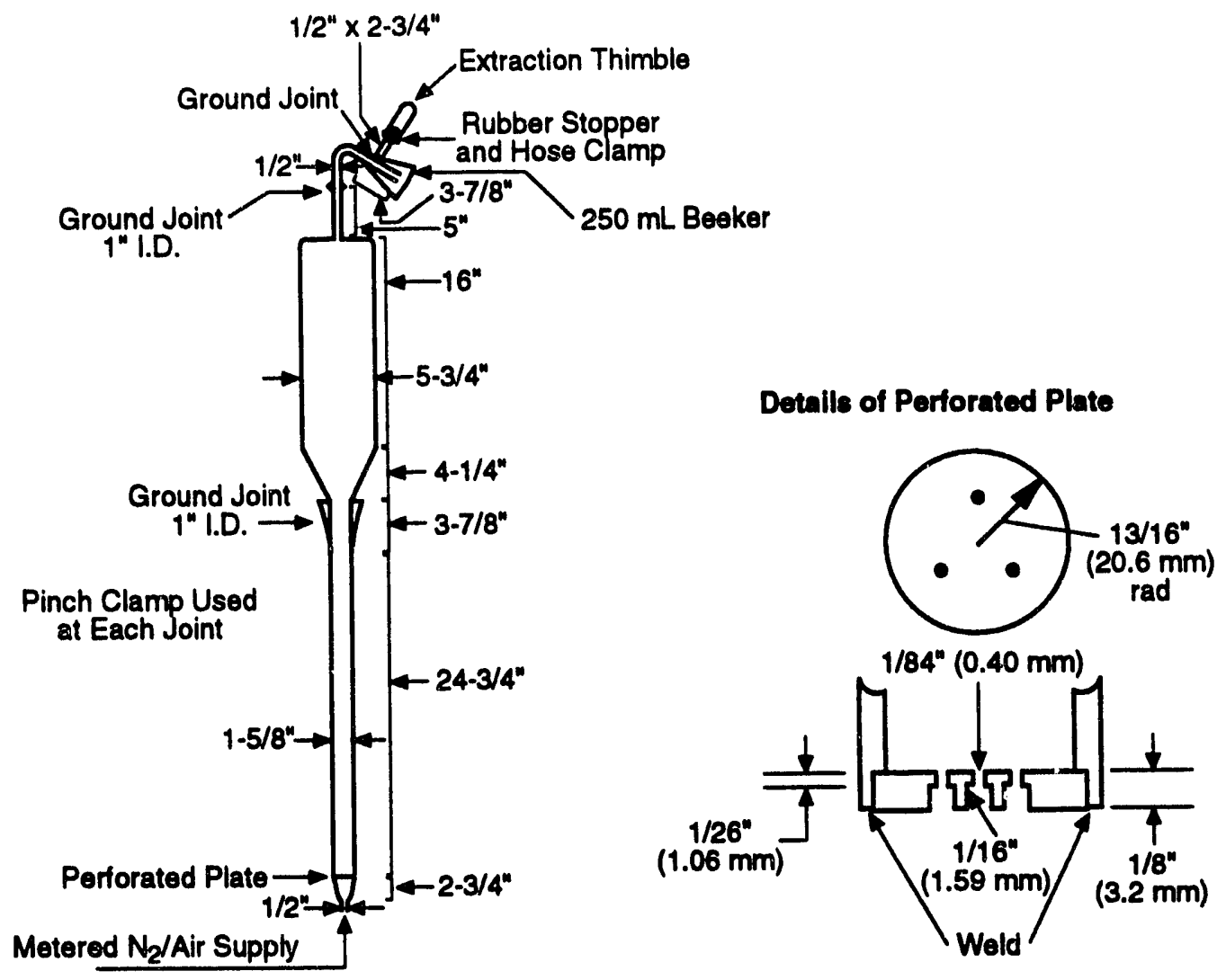

Figure 4-3. Schematic of a three-hole attrition tester.

The attrition resistance measurement procedure in this tester involved the following steps:

- Loading $50 \mathrm{~g}$ of the sample of a known particle size distribution;

- Passing a nitrogen/air supply at a flow rate of 7 to 21 slpm;

- Intermittently stopping the gas flow after every hour and weighing the filter/flask assembly to determine the amount of fines collected;

- Continuing the test up to $20 \mathrm{~h}$ (hourly readings were taken only for initial $5 \mathrm{~h}$ ); and

- Collecting the remaining sample from the tube and measuring its weight and particle size distribution at the end of the test.

Initially, since the tester was constructed of glass, severe sticking of fine particles to the walls of the tube was observed, perhaps because of electrostatic charge buildup. Attempts were 
made to rectify this problem by adding 1 percent of an anti-static agent, called Larostat 519 (a quarternary ammonium compound), to the sample and thoroughly mixing it. Although addition of Larostat 519 to the sample initially showed some improvement in the extent of sticking, it did not completely eliminate the sticking. It was thought that replacing the glass tube with a metal tube might resolve the sticking problem; therefore, another tester was built of brass with the perforated plate made of hardened steel. Initial tests in this tester did not exhibit that serious a sticking problem; however, the problem was not completely eliminated.

To eliminate this problem, the dry nitrogen used in the test was replaced with house air coming from an in-house compressor. A series of absolute filters were used to eliminate any mist in the air but no provisions were made to dehumidify the air. Attrition tests made with this arrangement (with the use of house air) exhibited remarkable reproducibility and the sticking problem was nearly completely resolved.

\subsection{CHEMICAL CHARACTERIZATION}

The chemical characterization of zinc titanate sorbent formulations includes the following:

- Chemical reactivity in a TGR, and

- $\quad \mathrm{Zn}, \mathrm{Ti}$, and $\mathrm{S}$ (for sulfided samples) analyses.

Procedures for these characterizations are described below.

\subsubsection{Thermogravimetric Analysis (TGA)}

The progress of a gas-solid noncatalytic reaction can be monitored easily by determining the change in mass of the solid. For example, the sulfidation of zinc titanate will result in an increase in the mass $\left(\mathrm{ZnO}+\mathrm{H}_{2} \mathrm{~S} \rightarrow \mathrm{ZnS}+\mathrm{H}_{2} \mathrm{O}\right)$, as zinc sulfide has higher molecular weight than zinc oxide. On the other hand, the reduction and regeneration reactions will lead to a decrease in the mass (Reduction : $\mathrm{ZnO}+\mathrm{CO} \rightarrow \mathrm{Zn}+\mathrm{CO}_{2}$; Regeneration : $\mathrm{ZnS}+1.5 \mathrm{O}_{2} \rightarrow \mathrm{ZnO}+$ $\mathrm{SO}_{2}$ ). Once the exact stoichiometry of the reaction is known, the change in sample mass can be directly related to the extent of conversion. A thermogravimetric analyzer is ideally suited to carry out these studies.

At RTI, a DuPont 1090 Thermal Analysis System interfaced with an IBM PC and a Hewlett Packard Plotter is used. Figure 4-4 shows a schematic of the TGA system. This system is primarily operated to measure the weight and rate of weight change of a sample continuously, either as a function of increasing temperature or at a preselected temperature over a period of time. This module can be interfaced easily with other analytical equipments, such as the gas chromatograph/mass spectrometer (GC/MS), for multiple measurements. Its low thermal mass furnace, small sample size, and fast heating rate allow a rapid turnaround time for analysis. Atmosphere, a critical parameter in TGA, is easily monitored and controlled. The equipment has the capability to operate up to a temperature of $1,200^{\circ} \mathrm{C}$.

As shown in Figure 4-4, RTI's DuPont 951 TGA is connected to the DuPont Thermal Analysis (TA) 2000 system via a module. The TA 2000 system has excellent thermal programming capabilities, versatile and accurate analysis modules, and a wide range of analysis software. This system provides a series of thermal programming features including 


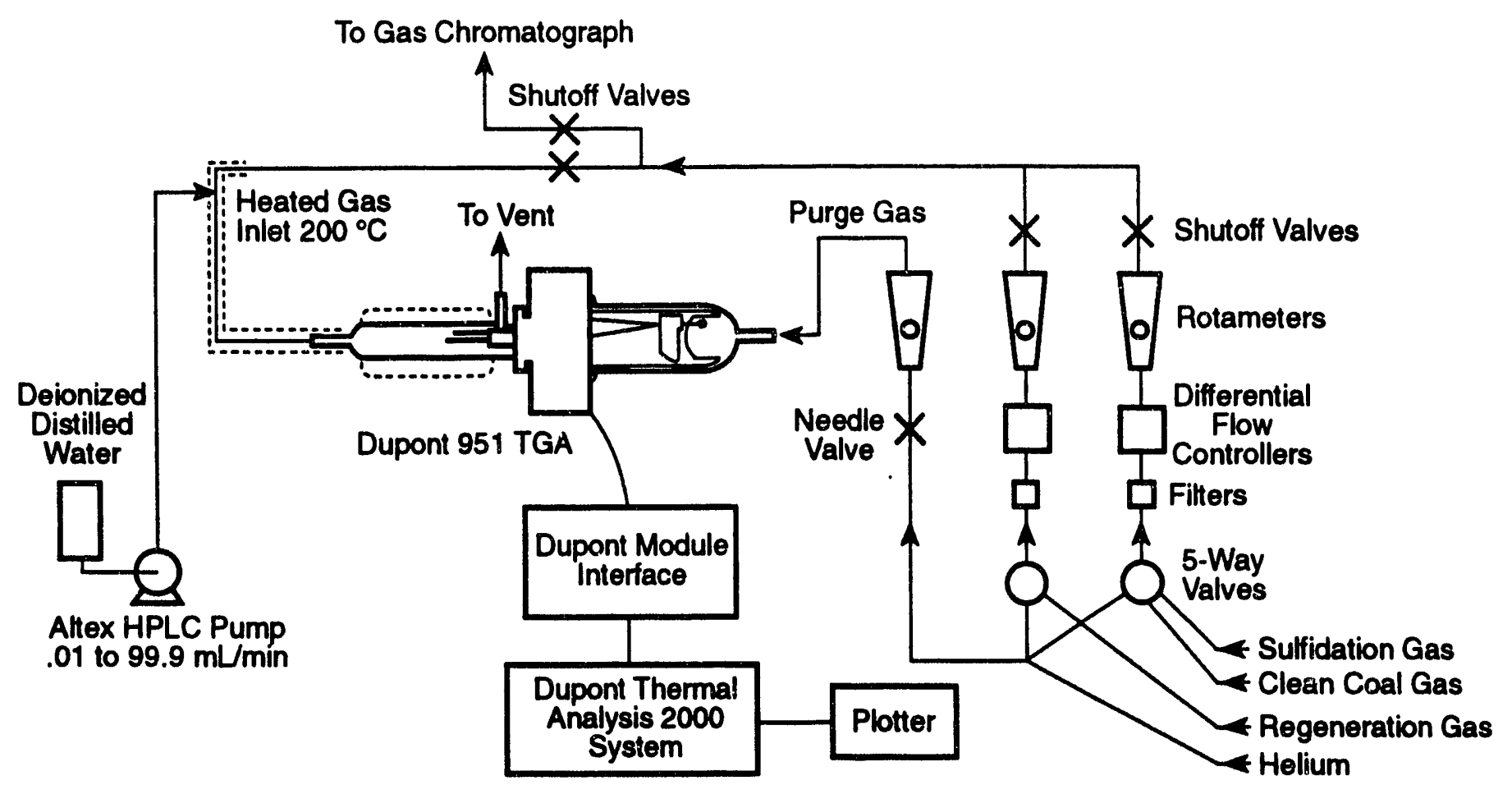

Figure 4-4. RTI atmospheric pressure TGR system.

- 18 available functions for construction of thermal programs and methods,

- Memory storage for 1 to 15 methods containing up to 60 program segments,

- Heating and cooling rates in operator-selectable increments of $0.01^{\circ} \mathrm{C} / \mathrm{min}$,

- Isothermal and Iso-trac programming, and

- Automatic control of purge gas and event accessories.

As shown in Figure 4-4, a battery of rotameters connected to various gas cylinders provides a wide range of gas compositions. A Harvard apparatus syringe pump capable of operating in the 0.005 to $5.00 \mathrm{~mL} / \mathrm{min}$ range is used to generate steam at any desired flow rate.

Since the entire system is operated and controlled through a personal computer, the TA software permits preprogramming of the desired method. A standard TGA screening test consists of the following steps:

- Loading the sorbent sample ( $50 \mathrm{mg}$ ) in the platinum sample pan,

- Heating the sample up to the desired temperature with the purge, 
- 30-min reduction at $550^{\circ} \mathrm{C}$ in an $\mathrm{H}_{2} \mathrm{~S}$-free clean coal gas,

- $\quad 30$-min sulfidation at $550^{\circ} \mathrm{C}$ in a simulated coal gas,

- $\quad 30$-min regeneration at $650^{\circ} \mathrm{C}$ using a gas containing $\sim 2$ percent $\mathrm{O}_{2}$ in a diluent,

- $\quad 30$-min second reduction at $550^{\circ} \mathrm{C}$ in an $\mathrm{H}_{2} \mathrm{~S}$-free clean coal gas, and

- $\quad 150$-min extended sulfidation at $550^{\circ} \mathrm{C}$ in a simulated coal gas.

The above steps can be preprogrammed and stored as a method for future use. As discussed above, this allows the excellent reproducibility of data and results in an efficient operation. Similarly, the run data stored can be analyzed using a series of built-in programs in the TA 2000 software to obtain information about the first and second derivative of the weighttime profile, to compare up to four data sets, etc. The data files can be converted easily into a spreadsheet program such as Lotus 1-2-3.

The 1.5-cycle TGA test, described above, was designed to qualitatively and, to some extent, quantitatively determine the following:

- Zinc loss during reduction,

- Kinetics of sulfidation and regeneration reactions,

- Sorbent sulfur capacity, and

- Extent of sulfate formation during regeneration.

Both the temperature and gas composition could be easily varied to determine their effect on the above four subprocesses. In fact, due to the relatively inexpensive and less timeconsuming nature, the TGA testing can provide much invaluable information as will be discussed in Chapter 7.

Most of the sorbent samples were screened using a simulated Texaco-type medium-Btu coal gas. A typical composition of gases used during reduction, sulfidation, and regeneration steps is shown in Table 4-1.

Table 4-1. Composition of TGA Test Gases

\begin{tabular}{cccc}
\hline \hline $\begin{array}{c}\text { Composition } \\
\text { (vol \%) }\end{array}$ & Reduction & Sulfidation & Regeneration \\
\hline $\mathrm{CO}_{2}$ & 11.90 & 11.21 & 0.00 \\
$\mathrm{CO}^{*}$ & 37.45 & 37.88 & 0.00 \\
$\mathrm{H}_{2}$ & 30.75 & 29.80 & 0.00 \\
$\mathrm{~N}_{2}$ & 0.00 & 0.00 & 78.51 \\
$\mathrm{H}_{2} \mathrm{O}$ & 19.90 & 19.90 & 19.87 \\
$\mathrm{O}_{2}$ & 0.00 & 0.00 & 1.62 \\
$\mathrm{H}_{2} \mathrm{~S}$ & 0.00 & 1.21 & 0.00 \\
\hline Total & 100.00 & 100.00 & 100.00 \\
\hline \hline
\end{tabular}

asimulated Texaco-type medium-Btu gas. 
As discussed earlier, the TGA testing of sorbent samples was carried out for initial screening (described in Chapter 5) as well as for determining the sorbent capacity and reactivity after multicycle testing in the bench unit (described in Chapter 6).

\subsubsection{Determination of ZInc and Titanium Contents}

Zinc and titanium contents of fresh and reacted sorbent samples were measured to determine the exact $\mathrm{Zn}$ and $\mathrm{Ti}$ atomic ratio and any zinc loss that occurred during multicycle testing. Samples were analyzed by an ICP technique using a Leeman Plasma-Spec Sequential Spectrometer. Prior to the testing of actual samples, the spectrometer was calibrated using a 200 ppm solution of $\mathrm{Zn}$, a $100 \mathrm{ppm}$ solution of $\mathrm{Ti}$, and a $0 \mathrm{ppm}$ standard. $\mathrm{Zn}$ and Ti wavelengths (with a 3-s integration time for both) are 213.86 and $334.94 \mathrm{~nm}$, respectively. The calibration was checked with a National Institute for Standards and Technology (NIST) quality assurance (QA) solution containing $\mathrm{Zn}$ and $\mathrm{Ti}$.

A $0.005-\mathrm{g}$ sorbent sample was weighed into a $120-\mathrm{mL}$ microwave digestion vessel. The sample was dissolved in an acid mixture containing $3 \mathrm{~mL} \mathrm{HNO}, 2 \mathrm{~mL} \mathrm{HF}$, and $1 \mathrm{~mL} \mathrm{HCl}$ and digested in a CEM-MDS-810 microwave oven using the following program:

- $3 \mathrm{~min}$ at 20 percent power,

- $3 \mathrm{~min}$ at 50 percent power, and

- $15 \mathrm{~min}$ at 75 percent power.

The vessel was cooled and contents of the vessel were transferred to a $100-\mathrm{mL}$ volumetric flask. The sample prepared was analyzed using ICP as described above. Duplicate samples were run to get an average value. 


\section{CHAPTER 5}

\section{SORBENT PREPARATION AND SCREENING}

\subsection{OBJECTIVES}

In view of limited applicability of zinc ferrite sorbents to relatively low temperatures $\left(<600^{\circ} \mathrm{C}\right)$ and moderately low severity coal gas, e.g., a low-Btu coal gas containing at least 15 percent water vapor (discussed in Chapter 1), the sorbent selected for this study was zinc titanate. A series of studies on zinc titanate pellets suitable for use in fixed-bed and moving-bed hot-gas desulfurization reactors have been reported in the literature (discussed in Chapter 2). However, no studies have been carried out with zinc titanate sorbents in a fluidized-bed reactor.

Although a fluidized-bed reactor is ideally suited for carrying out the hot-gas desulfurization, particularly to handle the heat generated by the highly exothermic regeneration reaction, and it integrates nicely between the gasifier and the turbine in an IGCC plant, as will be discussed further in Chapter 7, excessive sorbent loss from the reactor in the form of fines due to atirition remains a major concem. Therefore, one of the major requirements is that the sorbent used in the reactor must be highly attrition resistant in addition to having a desired chemical reactivity, sulfur capacity, good regenerability, and pore size distribution.

Just to give an idea of the impact of sorbent attrition on the cost of electricity, Figure 5-1 shows a plot between the marginal electricity cost as a function of sorbent loss rate for a $360 \mathrm{MW}$ IGCC plant. This figure is taken directly from a report published by IHI, Japan (Sugitani, 1990), except Japanese yens have been converted into U.S. dollars at a rate of 120 yens to one U.S. dollar. This figure also shows an impact of unit price of sorbent. For example, a typical unit price of crushed iron ore used by $\mathrm{IHI}$ is about $\$ 1.14 / \mathrm{b}$, while the price of zinc titanate sorbent is anticipated to be less than $\$ 3.80 / \mathrm{b}$. For comparison purposes, a hypothetical sorbent costing about $\$ 11.35 / \mathrm{b}$ is also included in this figure.

It may be noted from Figure 5-1 that a higher priced $(\$ 3.80 / \mathrm{lb})$ sorbent will have less impact on electricity cost provided the sorbent loss rate can be minimized. Two possible scenarios are delineated in this figure, one for crushed iron ore and another for zinc titanate sorbent. The overall impact on the electricity cost in both cases is approximately $0.5 \mathrm{mills} / \mathrm{kWh}$ despite a unit price of $\mathbf{3 . 3}$ times for zinc titanate as compared to iron ore. Thus zinc titanate, which removes $>99$ percent of the sulfur compared to iron oxide which can remove 90 percent at best, will have a similar order of impact on electricity cost. This impact on the electricity cost accounts for about 1 percent of the total electricity price. Clearly the zinc titanate, in this scenario, will be a much better sorbent because not only will it remove more sulfur at relatively higher temperatures than iron oxide, it will also have lower handling cost associated with downstream attrited material.

\subsection{SORBENT PREPARATION TECHNIQUES INVESTIGATED}

A number of sorbent preparation techniques were investigated in this study. Since a crushing and screening technique that was used to produce fluidizable zinc ferrite particles as described in the previous topical report (Gupta and Gangwal, 1991) led to a sorbent that had a reasonable chemical reactivity, but very poor attrition resistance, this technique was not used to 


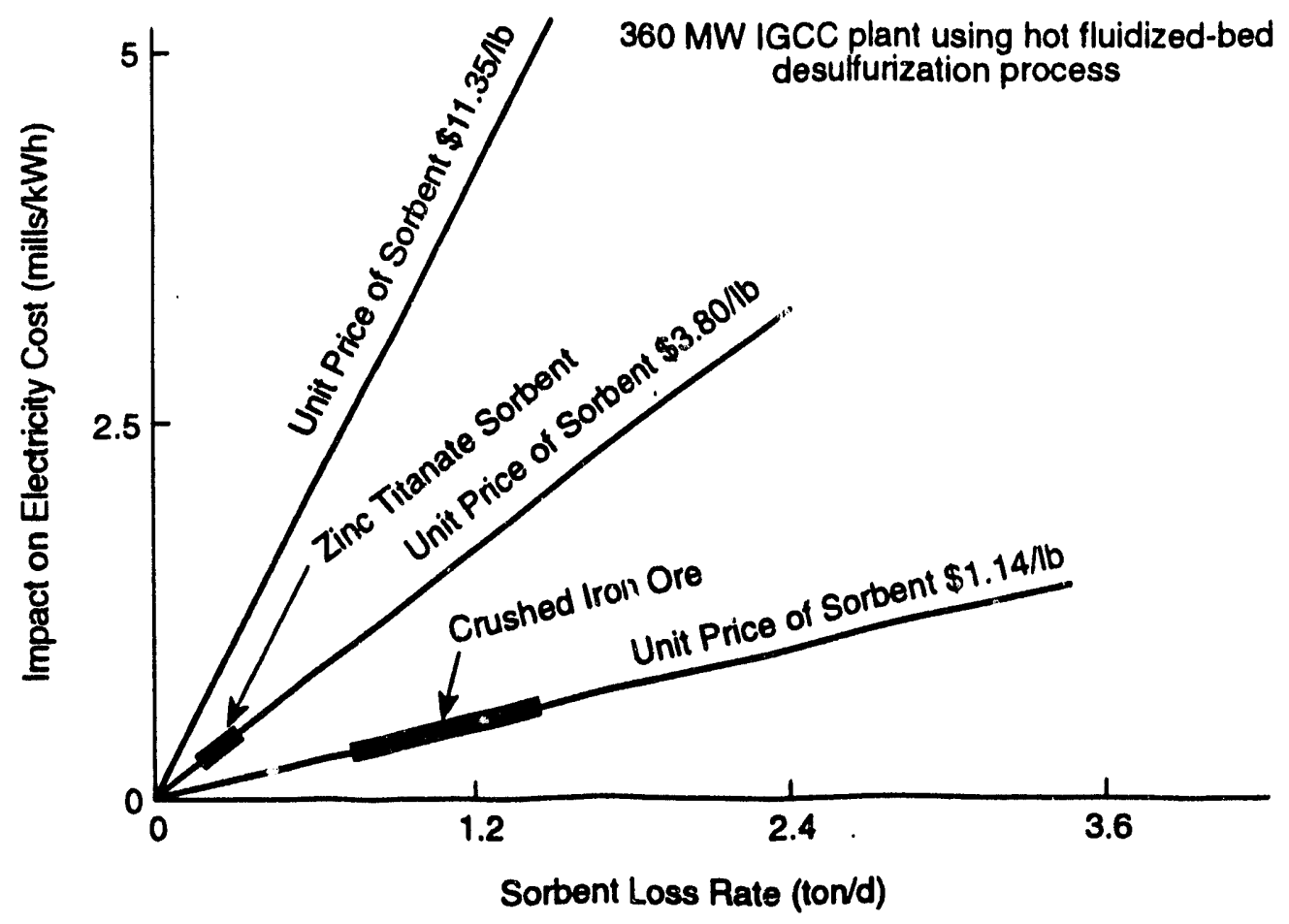

Source: Sugitani et al., 1990.

Figure 5-1. Effect of sorbent loss on electricity cost.

produce fluidizable zinc titanate particles. The techniques investigated here include the following:

- UCl's technique,

- Spray drying, and

- Granulation.

The majority of the sorbent formulations in this study were produced using the granulation technique.

\subsubsection{UCl's Technique}

$\mathrm{UCl}$ prepared two zinc titanate formulations designated as L-3758 and L-3757 with a ZnO to $\mathrm{TiO}_{2}$ molar ratio of 1.5 and 0.8 , respectively. These sorbent formulations served as baseline sorbents in this study. These formulations were prepared by mixing dry powders of $\mathrm{ZnO}$ and $\mathrm{TiO}_{2}$ in a molar ratio of 1.5 (for L-3758) and 0.8 (for L-3757) with 3 wt percent bentonite binder. The thoroughly homogenized powder was slurried and the slurry was processed to yield a fluidizable material in a manner that prevented excessive flaking and powdering. The sorbent was calcined at $1600{ }^{\circ} \mathrm{F}\left(871^{\circ} \mathrm{C}\right)$ for $2 \mathrm{~h}$. A 100 to $300 \mu \mathrm{m}$ particle size cut of the sorbent was prepared by screening.

While the details regarding the actual description of the technique are proprietary, $\mathrm{UCI}$ nevertheless disclosed that the sorbent was not prepared using a commercially viable technique, as the technique used, if applied at a commercial scale, would result in high volumes of waste 
and create a severe waste management problem (Chemrys, 1992). $\mathrm{UCl}$ is presently developing more promising commercially viable approaches to improve upon L-3758.

Between L-3758 and L-3757, formulation L-3758 was the one primarily used to compare the performance of the zinc titanate sorbents produced using the granulation technique. L-3758 served as an unoptimized baseline formulation. This formulation performed well as discussed in Section 6.2 of Chapter 6.

\subsubsection{Spray Drying}

Spray drying is a proven commercial method for preparation of silica-alumina-based catalysts for FCC and other catalytic processes that operate in a fluidized-bed reactor. The typical particle size range of the catalysts produced using spray drying is between 40 and $150 \mu \mathrm{m}$ with a mean size of about $80 \mu \mathrm{m}$.

As described in the previous topical report (Gupta and Gangwal, 1991), spray drying did not work for zinc ferrite particles. Therefore, much emphasis was not given on researching this technique. Nevertheless, a series of zinc titanate formulations were prepared using this technique. Applicability of a spray drying technique was investigated by $\mathrm{UCl}$ and DuPont; a brief description of the procedures used and the properties of the sorbents prepared follows.

\subsubsection{UCl's Effort}

$\mathrm{UCl}$ prepared four preliminary zinc titanate formulations. The chemical composition of these formulations along with their structural properties is shown in Table 5-1. Approximately $1 \mathrm{~kg}$ batch of each formulation was received from UCl. Formulations 1186-107 and 1186-108 had a light yellow color, perhaps due to a chemical transformation of silica during calcination at $800^{\circ} \mathrm{C}$.

Table 5-1. Chemical Composition and Structural Propertles of Various Spray-drled Sorbent Formulations"

\begin{tabular}{|c|c|c|c|c|c|c|}
\hline Formulation & $\underset{\substack{\text { molar } \\
\text { ratio }}}{\mathrm{ZnO} / \mathrm{TiO}_{2}}$ & Binder & $\begin{array}{l}d_{s 0} \\
(\mu m)\end{array}$ & $\begin{array}{l}\text { BET surface } \\
\text { area }\left(\mathrm{m}^{2} / \mathrm{g}\right)\end{array}$ & $\begin{array}{l}M P V^{b} \\
(c c / g)\end{array}$ & $\begin{array}{l}\text { MPD }^{\circ} \\
\text { (A) }\end{array}$ \\
\hline $1186-105$ & 0.8 & $\begin{array}{l}2 \% \text { Bentonite } \\
0.1 \% \text { Methocel }\end{array}$ & 112.8 & 1.12 & 0.2873 & 19,620 \\
\hline $1186-106$ & 1.5 & $\begin{array}{l}2 \% \text { Bentonite } \\
0.1 \% \text { Methocel }\end{array}$ & 115.8 & 0.38 & 0.2267 & 32,633 \\
\hline $\begin{array}{l}1186-107 \\
1186-108\end{array}$ & $\begin{array}{l}0.8 \\
1.5\end{array}$ & $\begin{array}{l}20 \% \text { Silicad }^{d} \\
20 \text { Silica }^{d}\end{array}$ & $\begin{array}{l}81.5 \\
76.5\end{array}$ & $\begin{array}{l}2.49 \\
2.01\end{array}$ & $\begin{array}{l}0.5392 \\
0.5170\end{array}$ & $\begin{array}{r}6,959 \\
10,360\end{array}$ \\
\hline
\end{tabular}

${ }^{a}$ Calcination conditions were $2 \mathrm{~h}$ and $800^{\circ} \mathrm{C}$.

${ }^{b} M P V=$ mercury pore volume

${ }^{C} M P D=$ median pore diameter

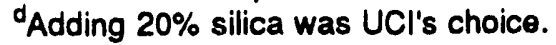

Figure 5-2 shows a particle size distribution for these formulations as supplied by $\mathrm{UCl}$. As can be seen, the particle size appears to fall into a very narrow range unlike a wide 


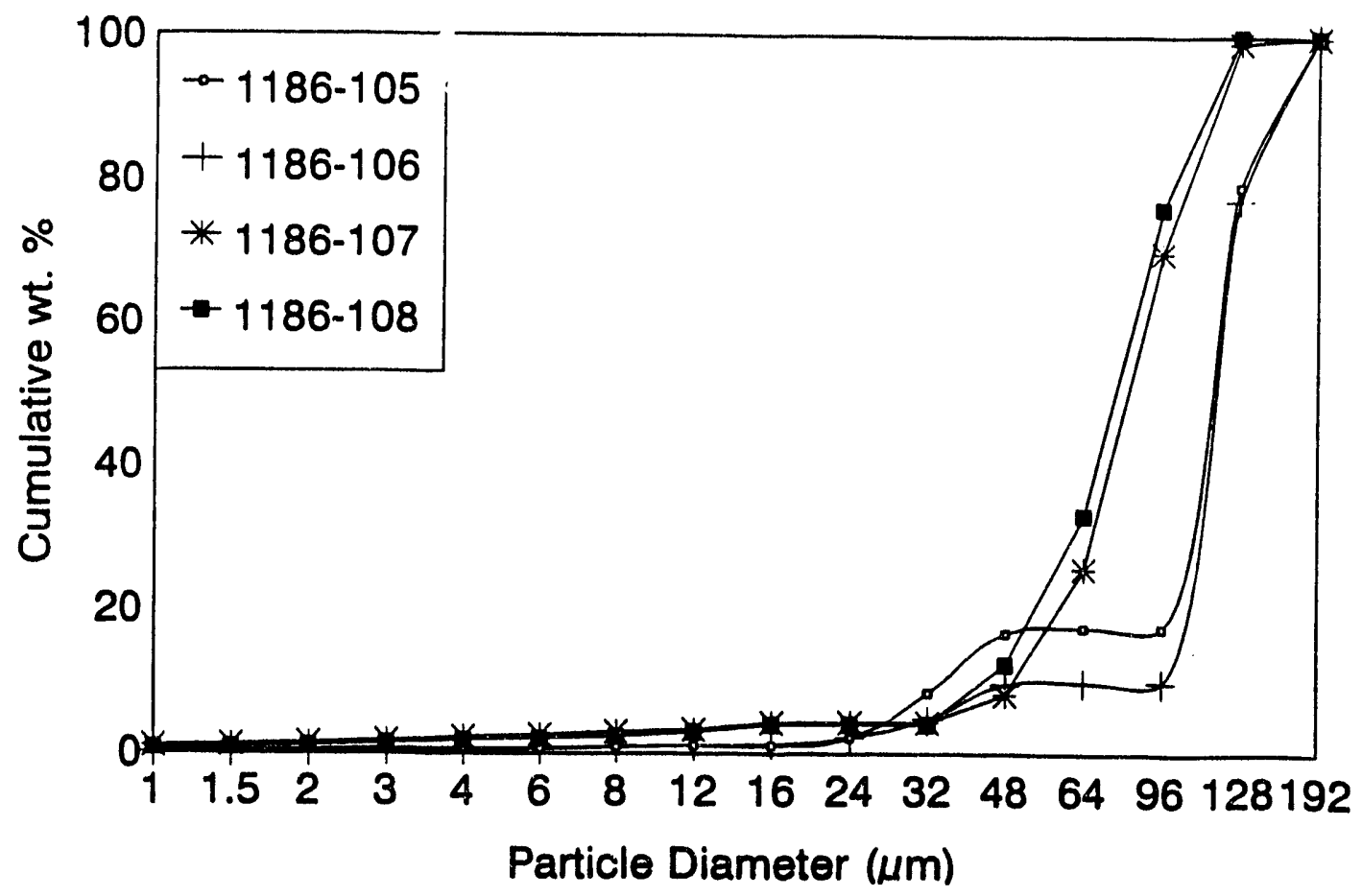

Figure 5-2. Particle size distribution of spray-dried formulations supplied by UCI.

distribution obtained for the forinulations prepared by the granulation technique. Also, as can be seen from Table 5-1, the mean particle size $\left(d_{50}\right)$ for the silica-containing formulations is significantly lower than those that do not contain silica. This indicates that addition of silica significantly affects the viscosity of the slurry and other process characteristics.

The BET surface area is very low for Formulations 1186-105 and 1186-106. The median pore diameters for all the formulations is larger than expected. All formulations except 1186-107 contain unusually large pores, in particular, Formulation 1186-106.

\section{TGA Reactivity}

To determine the chemical reactivity, these formulations were subjected to a 1.5-cycle TGA reactivity test in the Texaco gas using the procedure described in Section 4.3.1. Figure 5-3 shows the results. Also included in this figure is the TGA reactivity curve for $Z T-4$, which proved to be one of the best sorbent formulations (as will be discussed later), for comparison purposes. The sorbent formulations containing 20 percent silica did not have any chemical reactivity. On the other hand, Formulations 1186-105 and 1186-106 had reasonable chemical reactivities, although significantly lower than ZT-4.

As was indicated in Table 5-1, Formulation $1186-106$ has a $\mathrm{ZnO}$ to $\mathrm{TiO}_{2}$ molar ratio of 1.5 as compared to 0.8 in Formulation 1186-105; therefore, a higher sulfur capacity for Formulation 1186-106 than Formulation 1186-105 would be expected. But, this is not the case here. 


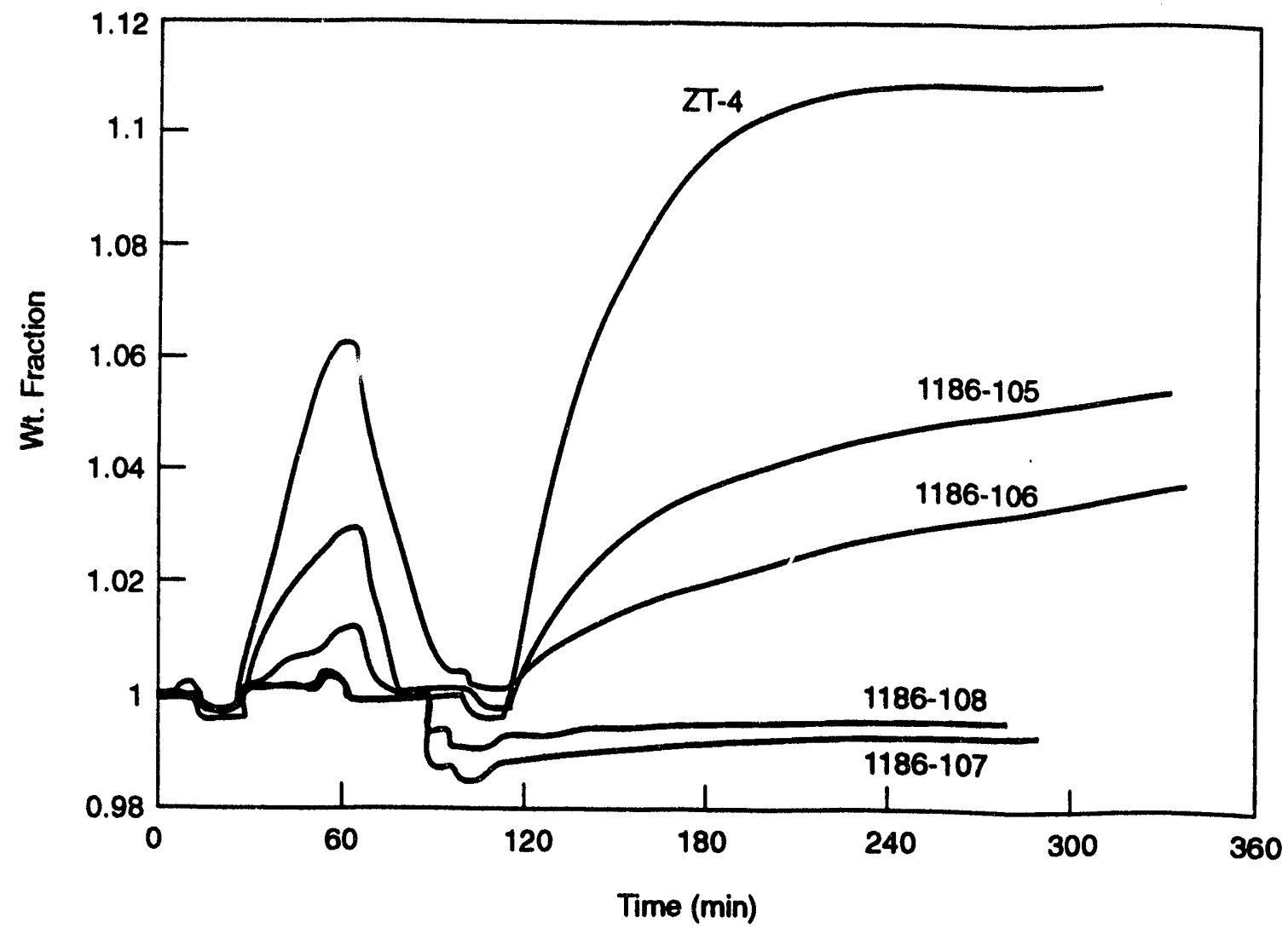

Figure 5-3. TGA reactivity of spray-dried ZT sorbents.

\section{Attrition Resistance}

Finally, all four formulations were characterized for their attrition resistance in the threehole attrition tester, described in Section 4.2.6.2. The diameter of each hole in the tester was $0.4 \mathrm{~mm}$ and an air flow rate of 7 slpm was used in the test. The tester was loaded initially with $50 \mathrm{~g}$ of sample. The fines collected due to attrition and carryover after $5 \mathrm{~h}$ and $20 \mathrm{~h}$ were measured; these results are shown in Figure 5-4.

From Figure 5-4, it can be seen that Formulations 1186-105 and 1186-106 had excessively high attrition rates. In both cases, more than 50 percent of the sample was lost in the first $5 \mathrm{~h}$ and a total of more than two-thirds was lost in $20 \mathrm{~h}$. Although the attrition loss for the formulations containing 20 percent silica (No. 1186-107 and No. 1186-108) was significantly lower, as shown in Figure 5-4, these formulations did not have any chemical reactivity for $\mathrm{H}_{2} \mathrm{~S}$ absorption as shown in Figure 5-3.

\section{Conclusions}

Based on these results, it was concluded that the recipe used for spray-drying the zinc titanate sorbents needs further research. Also, addition of silica, believed to be in the colloidal form, during spray-drying led to a virtually nonreactive sorbent. Therefore, that particular form of silica should not be used in future preparations. Furthermore, these formulations have a very narrow particle size distribution, a low BET surface area, and a large pore diameter. None of these factors is considered desirable in a good sorbent. 


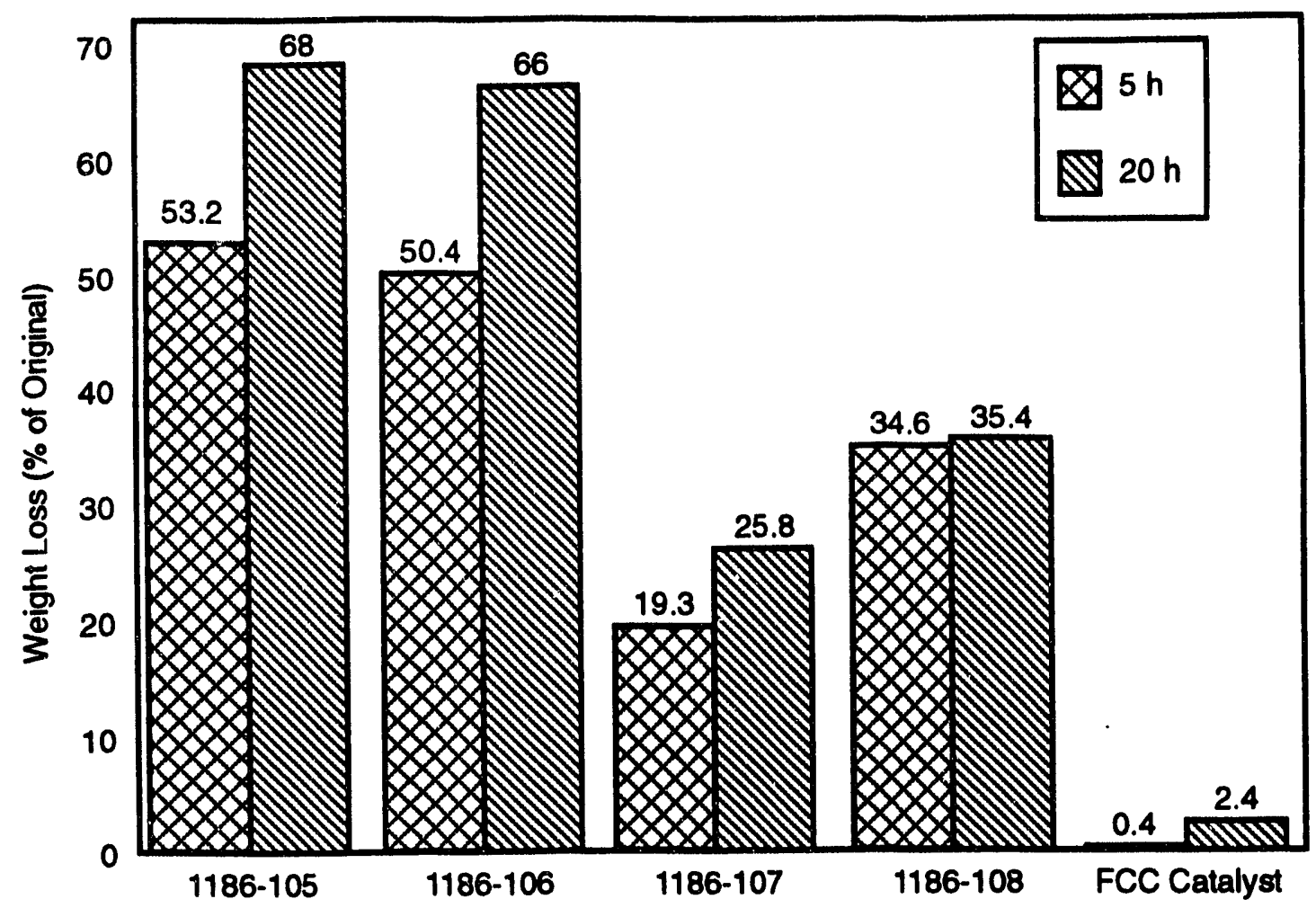

Figure 5-4. Attrition behavior of spray-dried sorbents.

\subsubsection{Spray-dried Formulations Produced by DuPont}

Researchers at DuPont made a major breakthrough by developing a process to produce an attrition-resistant vanadium pentoxide catalyst (suitable for a transport reactor) that is used for the oxidation of $n$-butane to maleic anhydride (Contractor et al. 1987; Contractor and Sleight, 1987). Applicability of this process was investigated for the preparation of attrition-resistant zinc titanate sorbents. It involved slurrying the fine powders of zinc oxide and titanium oxide in a freshly prepared solution of polysilicic acid, bringing the solution $\mathrm{pH}$ to a desired level and spray drying in a pilot-scale unit. Control of pH in a narrow window was necessary in this process to prevent the gelling of polysilicic acid.

After a series of trials, DuPont was finally able to produce a series of zinc titanate formulations using the above technique. Control of pH between 3 and 4 was necessary but was found to be extremely difficult because addition of zinc oxide powder to polysilicic acid solution resulted in a $\mathrm{pH}$ of about 7 . This $\mathrm{pH}$ value was brought down by addition of phosphoric acid.

DuPont prepared four samples for evaluation. Preliminary characterization of these formulations by DuPont led to the selection of the best formulation among the four samples. This formulation was characterized for its chemical reactivity, BET surface area, attrition resistance, and particle size distribution. First, the sample was calcined in a muffle furnace at $800^{\circ} \mathrm{C}$ for 2 $\mathrm{h}$. On calcination, sample color changed from white to yellow, perhaps owing to the chemical transformation of silica at $800^{\circ} \mathrm{C}$. Table 5-2 shows the physical properties of this formulation. Figure 5-5 shows the TGA reactivity in Texaco gas at $550^{\circ} \mathrm{C}$. As can be seen, the weight gain during sulfidation is almost negligible as compared to the sorbent formulations prepared using the granulation technique. 
Table 5-2. Physical Properties of DuPont Prepared ZT Formulation

\begin{tabular}{|c|c|}
\hline $\begin{array}{l}\text { Particle size distribu- } \\
\text { tion }\end{array}$ & $\begin{array}{l}d_{16}=42 \mu \mathrm{m} \\
d_{50}=82 \mu \mathrm{m} \\
d_{84}=161 \mu \mathrm{m} \\
d_{100}=391 \mu \mathrm{m}\end{array}$ \\
\hline BET surface area & $1.41 \mathrm{~m}^{2} / \mathrm{g}$ \\
\hline Mercury pore volume & $0.3371 \mathrm{cc} / \mathrm{g}$ \\
\hline Median pore diameter & $10,184 \AA$ \\
\hline $\begin{array}{r}\text { Attrition resistance } \\
\text { Loss in } 1 \mathrm{~h} \\
\text { Loss in } 5 \mathrm{~h}\end{array}$ & $\begin{array}{l}32 \% \\
56 \%\end{array}$ \\
\hline
\end{tabular}

As indicated in Table 5-2, this formulation had very poor attrition resistance. Therefore, further efforts to produce zinc titanate formulations by this technique were not pursued.

Addition of silica during spray drying both in colloidal form (believed to be used by $\mathrm{UCI}$ ) and in the form of polysilicic acid (used by DuPont) proved to be detrimental to the sorbent's chemical reactivity. In both cases, sorbents did not possess any chemical reactivity. It is believed that silica acts as a barrier between zinc oxide and titanium oxide and hence may not be suitable for use in zinc titanate preparation, at least in the form it was used in these preparations.

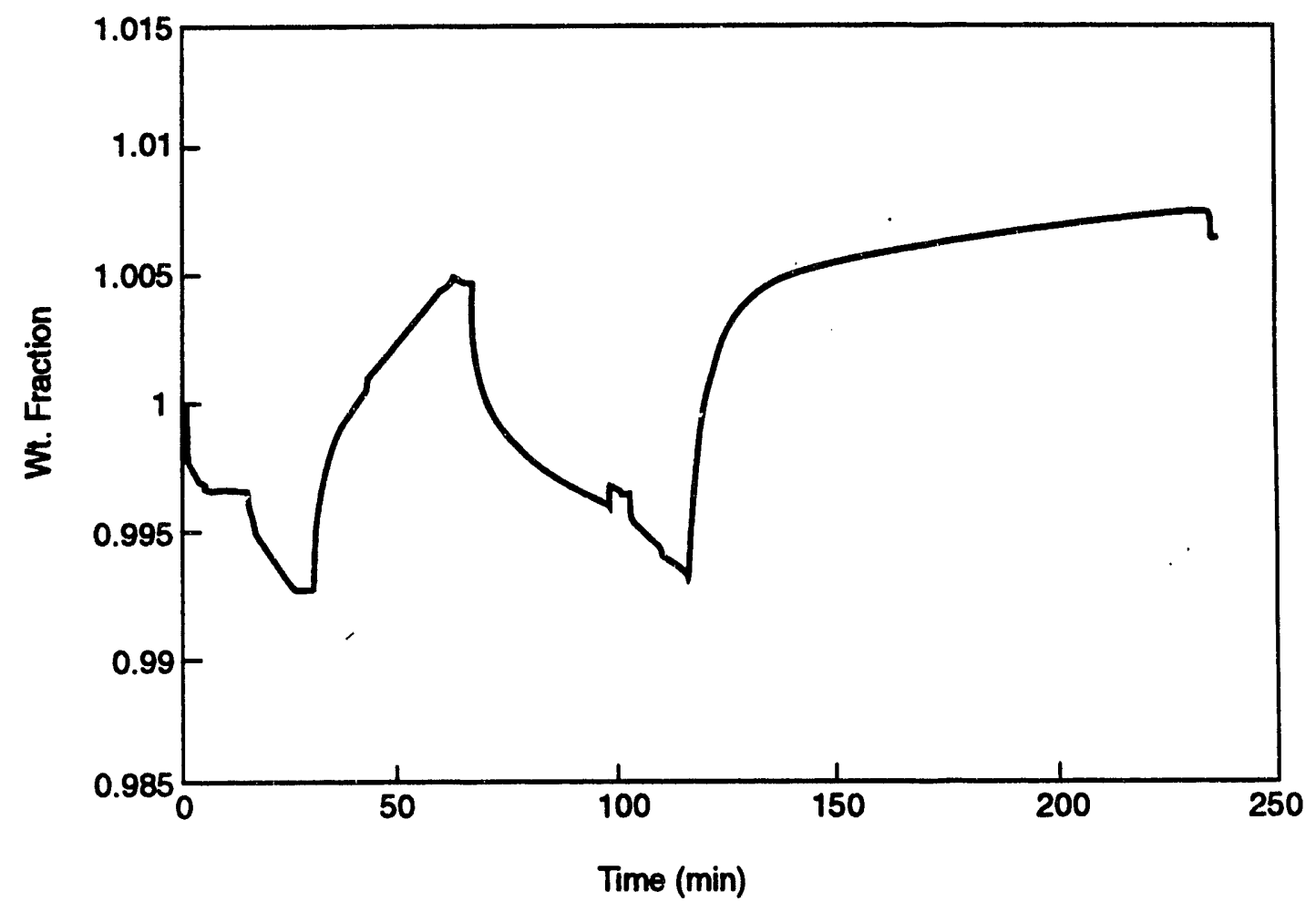

Figure 5-5. TGA reactivity profile of DuPont $\mathrm{ZT}$ formulation In Texaco gas. 


\subsubsection{Granulation}

Following the success of the granulation technique in producing attrition-resistant zinc ferrite sorbents (Gupta and Gangwal, 1991), this technique was used extensively to prepare a number of zinc titanate formulations. The details of the granulation technique are proprietary and a patent is pending. The various formulations prepared by granulation were calcined for 1 to 4 $h$ at a temperature ranging from 800 to $900^{\circ} \mathrm{C}$.

\subsection{SORBENT SCREENING}

A series of sorbent formulations were prepared using the granulation technique by varying the following variables:

- ZnO to $\mathrm{TiO}_{2}$ molar ratio,

- Various binders,

- Various binder levels,

- Calcination conditions,

- Various structural additives, and

- Various catalytic components.

Table 5-3 describes the entire series of zinc titanate sorbent formulations prepared using the granulation technique. Since characterization of all 23 formulations was a cumbersome task, this series was divided into two groups $-Z T-1$ to $Z T-10$ and $Z T-11$ to $Z T-25$. Formulations $Z T-1$ to $Z T-10$ were prepared first and evaluated, and later on the formulations in series $Z T-11$ to $Z T-25$ were prepared and evaluated.

\subsubsection{Screening of First Serles of Sorbents}

Characterization and screening of the first series of sorbents, as discussed above, included the measurement of particle size distribution, pore size distribution, BET surface area, $\mathrm{Zn}$ and Ti contents, TGA chemical reactivity and attrition resistance. Figure 5-6 shows the 1.5cycle TGA reactivity curves for all the bentonite-containing sorbents. Also included in this figure for comparison purposes is the TGA reactivity of ZF-3 which is a zinc ferrite sorbent. Formulation ZO-1 is a nearly pure zinc oxide containing sample which was prepared to study the effect of the addition of $\mathrm{TiO}_{2}$ on the sorbent. As can be seen, the TGA reactivities curves form four natural groups, first for ZF-3 which has the highest capacity because of its stoichiometry, second for ZO1-a pure $\mathrm{ZnO}$ sorbent, third for the $\mathrm{ZnO} / \mathrm{TiO}=1.5$ and contains $Z \mathrm{ZT}-5, \mathrm{ZT}-4$ and $Z \mathrm{~T}-8$, and fourth for the $\mathrm{ZnO} / \mathrm{TiO}_{2}=0.8$ and contains $\mathrm{ZT}-1, \mathrm{ZT}-2$, and $\mathrm{ZT}-7$. This distinction can be clearly seen in Figure 5-7 which shows only the extended sulfidation portion of the TGA cycle.

The weight fraction data shown in Figures 5-6 and 5-7 can be converted into conversions by using proper stoichiometry and Table 5-4 shows the results. In addition to the TGA sulfur capacities, other structural properties of the sorbents are also included in this table. Theoretical sulfur capacity of each formulation was calculated based on stoichiometry, i.e., experimentally measured $\mathrm{Zn}$ content. It is clear from Table 5-4 that most of the zinc titanate sorbents have close to 100 percent conversion in $2 \mathrm{~h}$ except for the ZT-8 formulation. The BET surface areas and pore size distributions of all the formulations are within the expected range. 


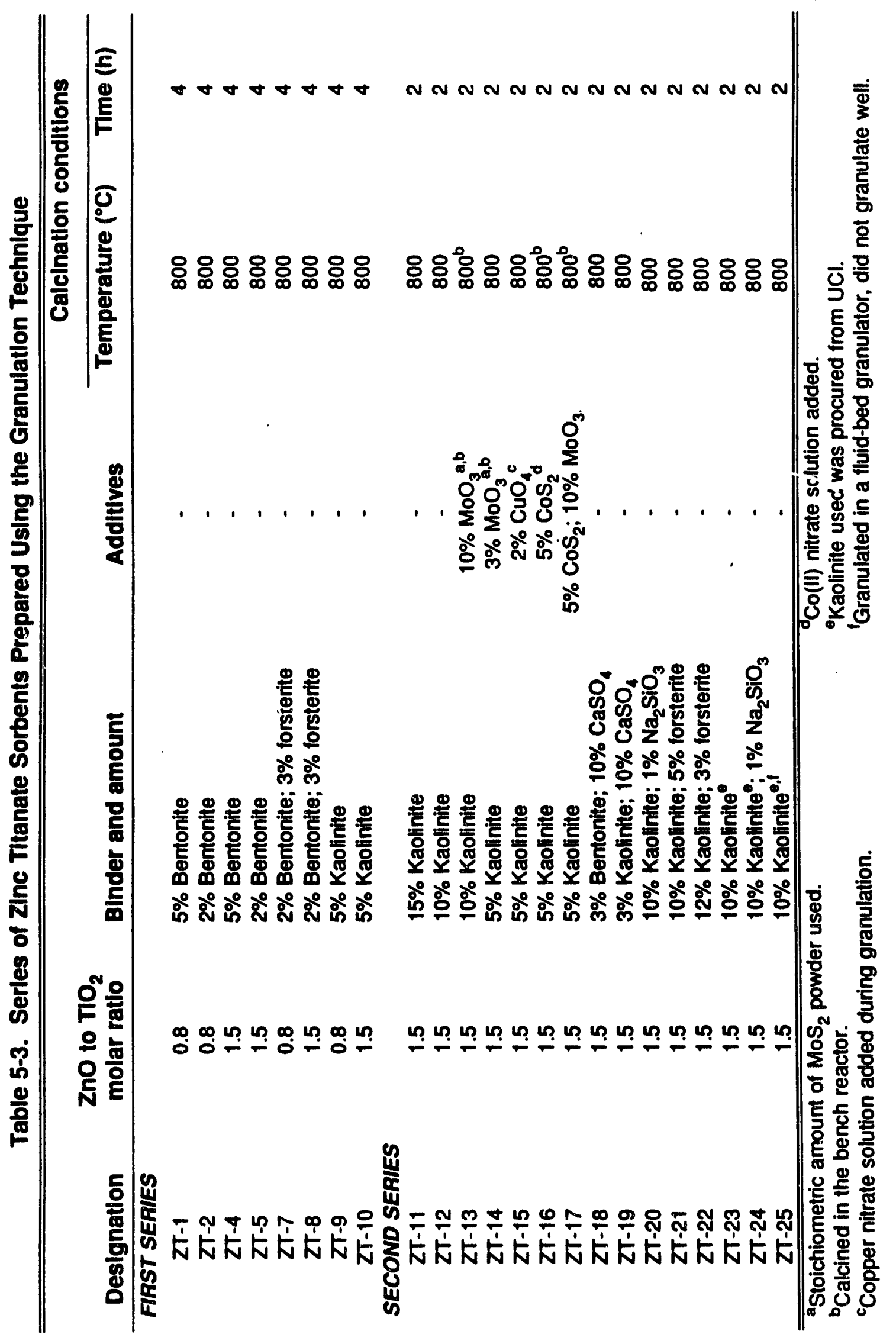




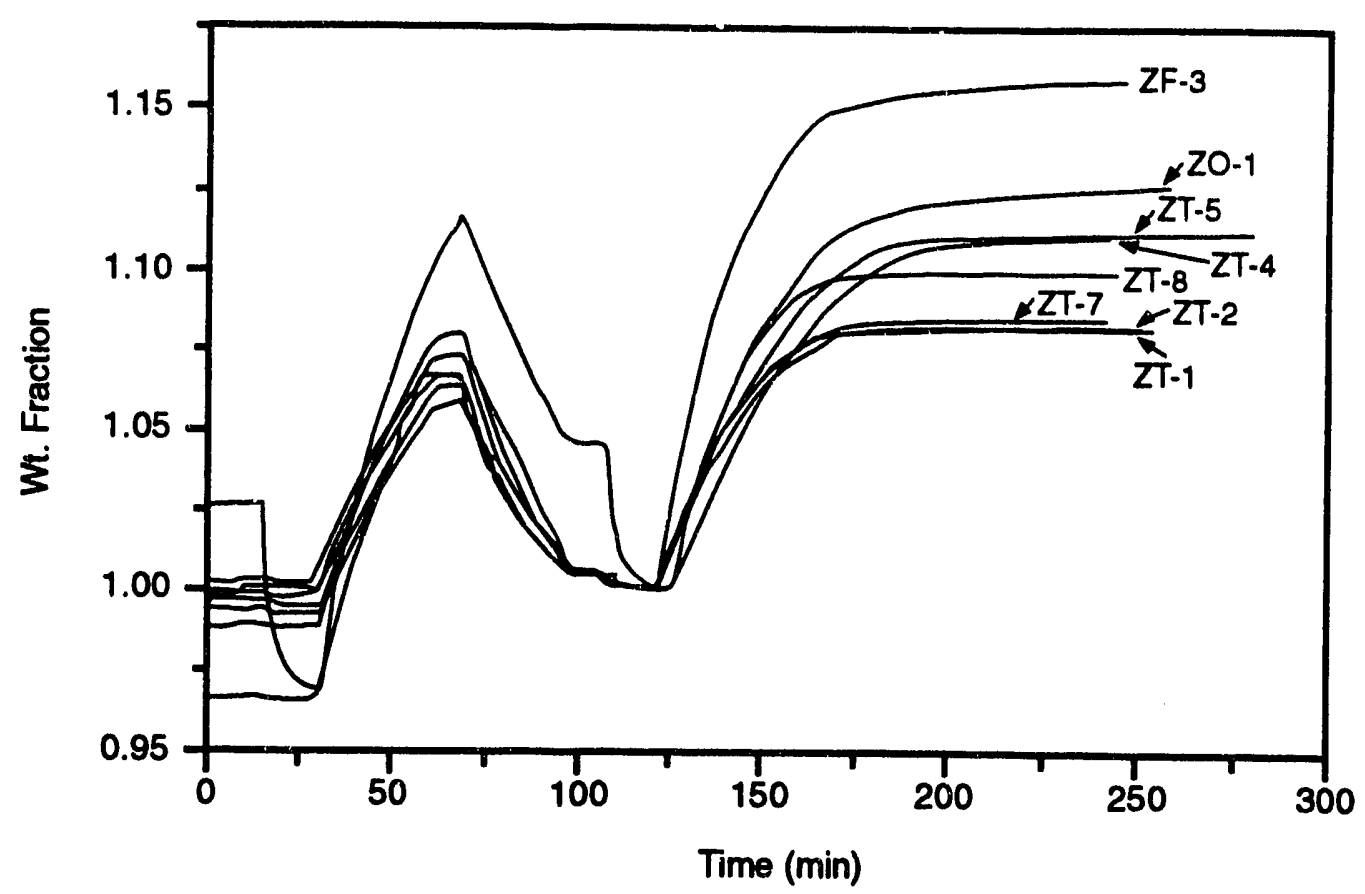

Figure 5-6. TGA reactivitles of varlous zine titanate formulations In a TGR at $550^{\circ} \mathrm{C}$ in the Texaco gas.

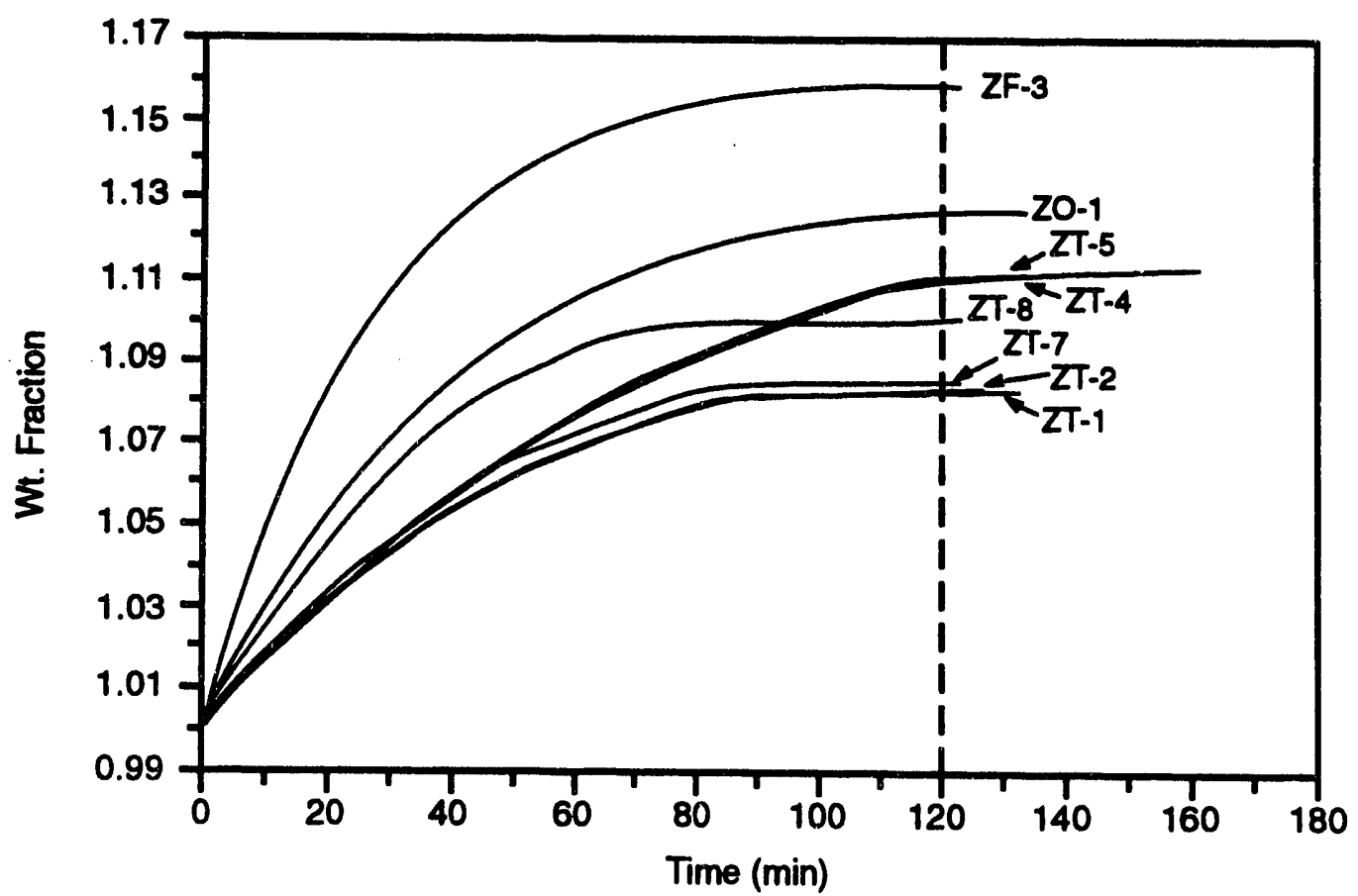

Figure 5-7. Sulfur capacitles of varlous zinc titanate formulations in a TGR at $550^{\circ} \mathrm{C}$ in the Texaco gas. 


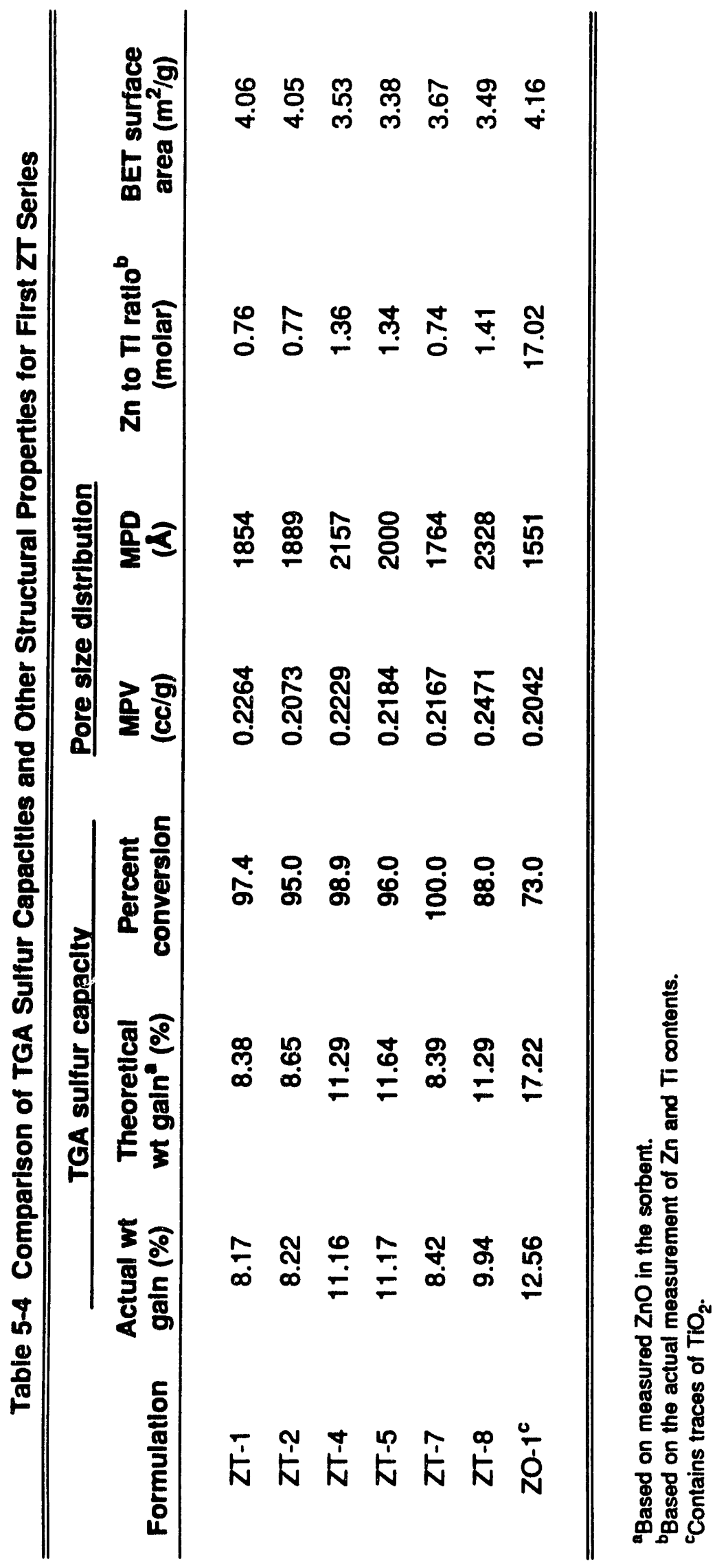


Another important factor in selecting the most promising sorbents was their attrition resistance. Attrition tendency of all the formulations listed in Table 5-4 was measured in the three-hole attrition tester described in Section 4.2.6.2. Figure 5-8 shows a plot of cumulative wt percent attrited as a function of time for six zinc titanate formulations. It should be noted here that this test provides a relative ranking of various sorbents rather than being an absolute test. The attrition numbers shown on the ordinate in Figure 5-8 have no correlation with the attrition rate in an actual reactor.

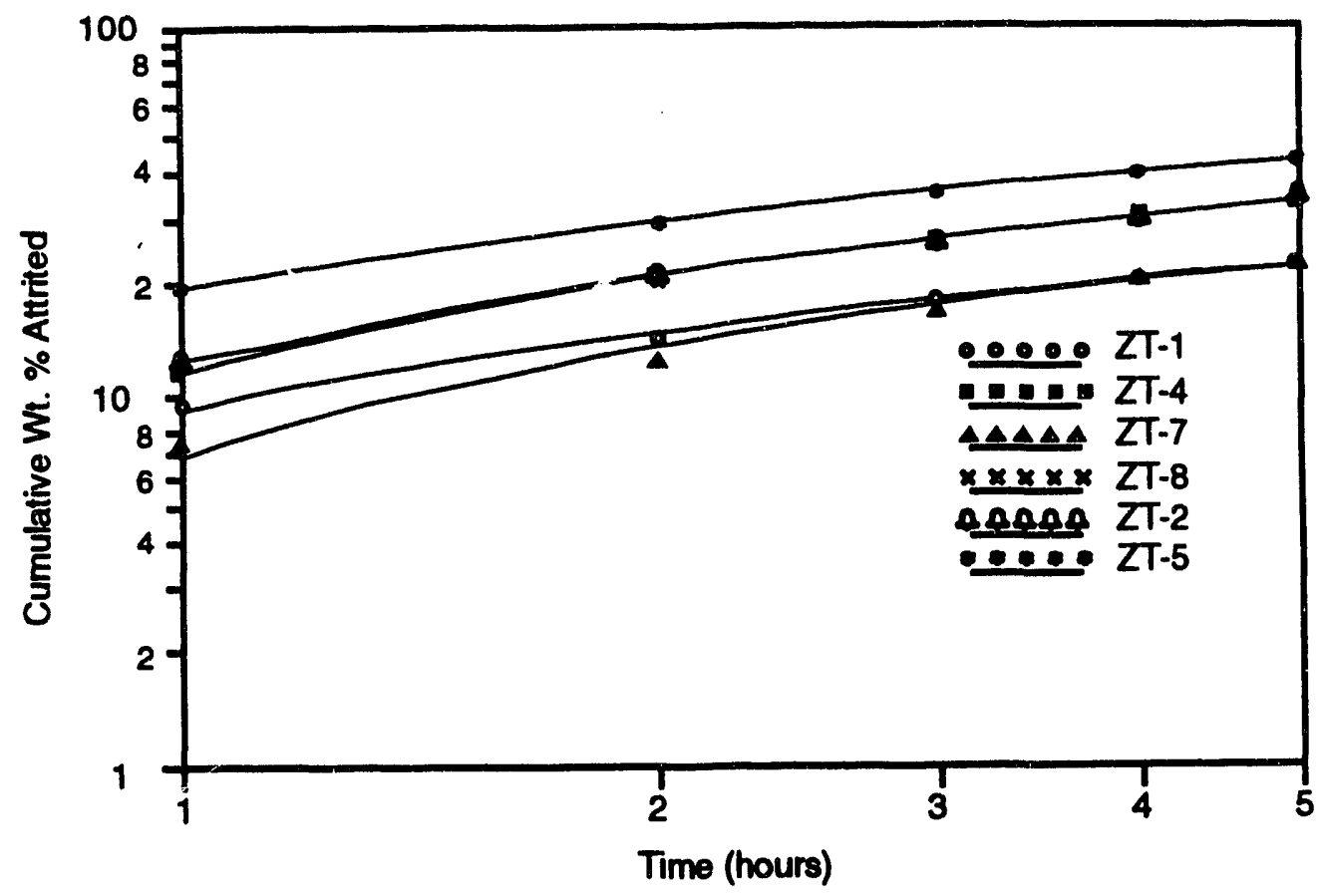

Figure 5-8. Attrition tendency of varlous zine titanate formulations measured In the three-hole attrition tester.

It has been proposed in the literature (Gwyn, 1969) that a nearly linear relationship exists between the $\log$ of cumulative wt percent attrited and the $\log$ of time. This can be clearly seen from Figure 5-8. Mathematically, this relationship can be described as

$$
\ln \left(1-\frac{W}{W_{0}}\right)=\ln k_{p}+m \cdot \ln \left(t-t_{0}\right) \text {, }
$$

where $W$ is the weight of the sample remaining in the tube at any time $t, W_{0}$ is the initial weight, $t_{0}$ is initial time during which sorbent loss is purely due to elutriation, and $m$ is an exponent.

The term $\left(1-W W_{0}\right)$ is the cumulative weight fraction attrited at anytime $t$. It is assumed that $t_{0} \rightarrow 0$, although this may not be true because sorbent will definitely undergo some elutriation loss in the attrition tester for the following reasons: 
- During screening, all the fines are not separated. Fines tend to stick to the surface of larger particles due to electrostatic forces. These fines tend to detach themselves during a high velocity impact and hence get elutriated.

- All the particles loaded in the tester may not be spherical. Some of them may have sharp corners, although RTI's granulation technique produces the particles in a nearly spherical shape. These sharp corners will be knocked off during a high velocity impact and fines produced by this mechanism will be elutriated.

Thus, the attrition process consists of two steps: (1) the attrition of large particles resulting in fines and (2) subsequent elutriation of fines. Thus, there should be two rate constants, one for elutriation and the other for attrition. The constant $K_{p}$ in Equation (5-1) accounts for attrition only. A more sophisticated mathematical model can be formulated to adequately describe the particle attrition in the attrition tester.

Nevertheless, as indicated by the straight line relationship between $\log \left(1-W W_{0}\right)$ and $\log$ $t$ in Figure 5-8, two rate parameters, $K_{p}$ and $m$, can be estimated. Let $1-W W_{0}=y_{1}$ and $t_{0} \rightarrow$ 0 , then Equation (5-1) can be expressed as

$$
\ln y=\ln K_{p}+m \cdot \ln t
$$

The slope of the above line will represent the exponent $m$ and the intercept will provide the value for in $K_{p}$. The exponent $m$ in Equation (5-2) is believed to be material dependent and may not depend on particle size and velocity of impact. It perhaps depends on the hardness of the material and one should be able to correlate it with the Hardgrove Grinability Index (HGI) as will be discussed in Chapter 7. However, $K_{p}$ is believed to depend on the initial particle size and the velocity of impact.

Table 5-5 shows the values for $K_{p}, m$ and the correlation coefficient obtained for various sorbents by the above analysis. As can be seen, the accuracy of fit is extremely good for all the sorbents as indicated by $R^{2}$ values of 0.99 or better. The results reported in this table indicate that $Z T-7$ has the lowest value of attrition rate while $Z T-5$ has the highest.

Table 5-5. Attritlon Parameters of Various Zinc Titanate Sorbents

\begin{tabular}{crcc}
\hline \hline Formulation & $\mathbf{K}_{\mathbf{p}}(\% / \mathbf{h})$ & $\mathbf{m}^{*}$ (dimensionless) & $\mathbf{R}^{2 \dagger}$ \\
\hline ZT-1 & 9.7017 & 0.5106 & 0.9982 \\
ZT-2 & 12.8493 & 0.5962 & 0.9928 \\
ZT-4 & 12.1454 & 0.6345 & 0.9829 \\
ZT-5 & 20.0027 & 0.4670 & 0.9946 \\
ZT-7 & 7.6202 & 0.6735 & 0.9974 \\
ZT-8 & 12.9139 & 0.5818 & 0.9950 \\
\hline \hline
\end{tabular}

Theoretically reported values of $m$ vary between 0.5 and 0.666 .

tCorrelation coefficient. 
Based on the above characterization, the following sorbent formulations were selected for bench-scale testing:

- ZT-5-to compare its performance with UCI baseline formulation L-3758,

- ZT-2-to study the effect of $\mathrm{Zn}$ to $\mathrm{Ti}$ atomic ratio,

- ZT-7-had best TGA conversion and attrition resistance as discussed above, and

- ZT-4-to study the effect of bentonite content.

\subsubsection{Effect of Calcination Time on the Sorbent Performance}

As indicated in Table 5-3, the first series of zinc titanate formulations were calcined at 800 ${ }^{\circ} \mathrm{C}$ for $4 \mathrm{~h}$. Preliminary estimations of the cost of sorbent for commercial operation indicated that the 4-h long calcination step would be the major component of the cost, accounting for almost 50 percent of the sorbent cost. Therefore, in order to determine whether a 4-h calcination time was really necessary, studies were conducted to determine the effect of the calcination time on the physical and chemical properties of the sorbents.

Both ZT-5 and ZT-2 sorbent samples were calcined for $2 \mathrm{~h}$ and $4 \mathrm{~h}$ at $800^{\circ} \mathrm{C}$. These samples were characterized for their TGA reactivity, attrition resistance, and other structural properties and Table 5-6 shows the results.

Table 5-6. Structural Properties of ZT-5 and ZT-2 Formulations Calcined for 2 and $4 \mathrm{~h}$ at $800^{\circ} \mathrm{C}$

\begin{tabular}{cccccc}
\hline \hline Sample & $\begin{array}{c}\text { MPV } \\
(\mathbf{c c} / \mathbf{g})\end{array}$ & $\begin{array}{c}\text { MPD } \\
(\mathbf{A})\end{array}$ & $\begin{array}{c}\text { BET } \\
\left(\mathbf{m}^{2} / \mathbf{g}\right)\end{array}$ & $\mathbf{A}_{\mathrm{R}}{ }^{*}(\%)$ & $\begin{array}{c}\text { APS }^{\mathrm{b}} \\
(\boldsymbol{\mu} \mathrm{m})\end{array}$ \\
\hline ZT-2 - 2-h calcined & 0.2256 & 1767 & 4.06 & 91.0 & 187 \\
ZT-2 - 4-h calcined & 0.2292 & 1717 & 4.00 & 89.4 & 158 \\
ZT-5 - 2-h calcined & 0.2334 & 2148 & 3.33 & 92.9 & 196 \\
ZT-5 - 4-h calcined & 0.2389 & 2095 & 3.49 & 87.6 & 159 \\
\hline \hline
\end{tabular}

$A_{R}$ - Attrition resistance (measured in the single-hole attrition tester)

APS - Average particle size.

As can be seen, the changes in pore volume, pore size, and BET surface area on extending the calcination time are so small that one would conclude that they are basically the same within the experimental error band. However, a significant decrease in average particle size is observed in both cases, most likely due to the shrinkage during extended calcination. The attrition resistance of the 2-h calcined samples was slightly better than the 4-h calcined samples.

Figure 5-9 compares the TGA reactivities for both pairs. In both cases, it appears that the TGA reactivity for the $2-h$ calcined sample is slightly better than for its counterpart that was calcined for $4 \mathrm{~h}$.

Examination of scanning micrographs in both cases indicates that changes in surface morphology cannot be distinguished for ZT-2 - 2-h and ZT-2 - 4-h, and also for ZT-5 - 2-h and 


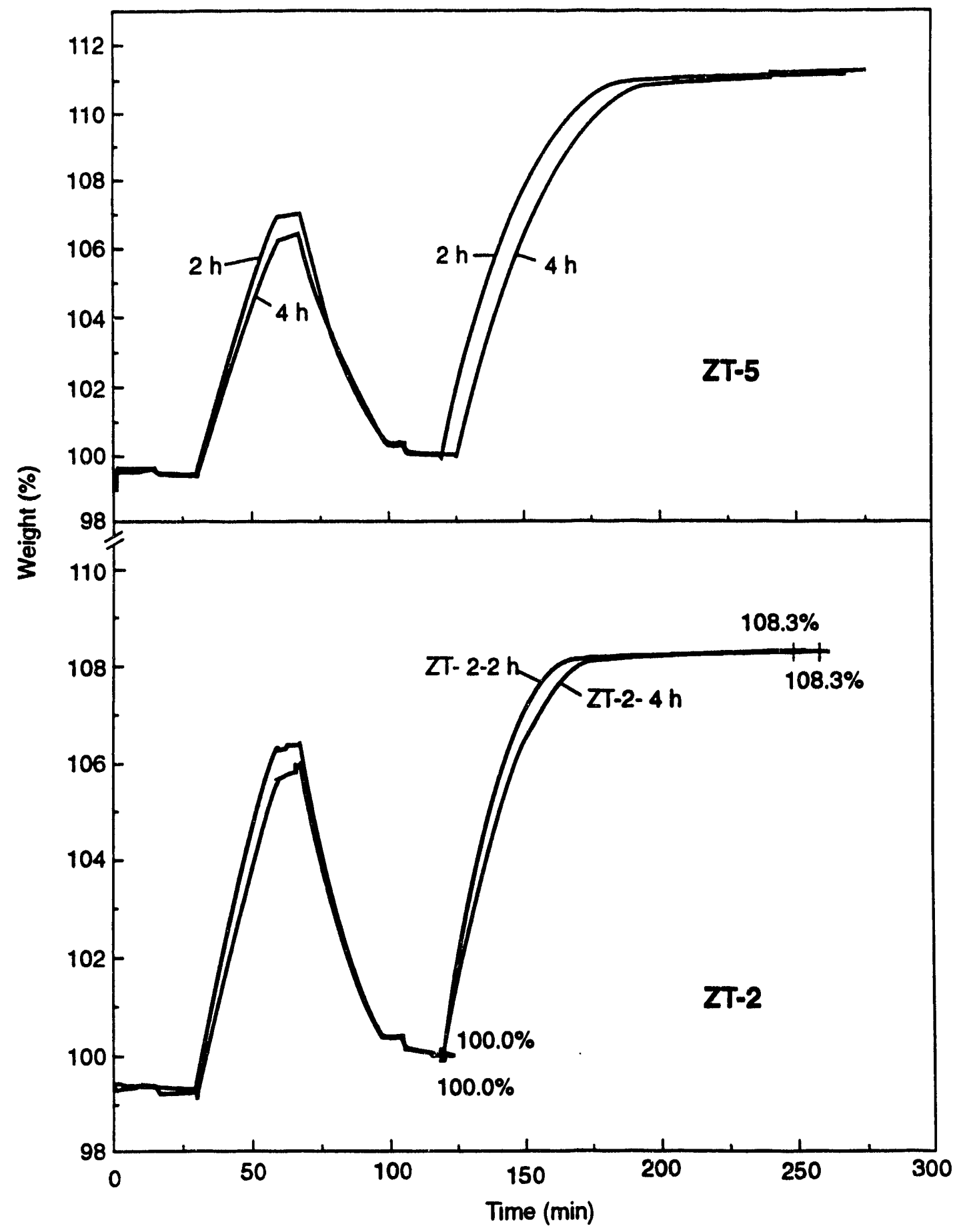

Figure 5-9. TGA reactivities of ZT-5 and ZT-2 formulations as a function of calcination time. 
ZT-5 - 4-h pairs. XRD pattern on both the sample pairs indicated presence of no free zinc oxide in any sample.

Based on the above results, the conclusion was that a 2-h calcination time will be adequate to impart the desired porosity and attrition resistance to the sorbent and also to convert all the ZnO to zinc titanate.

\subsubsection{Screening of Second Series of Sorbents}

As shown in Table 5-3, the second series of zinc titanate sorbents consisted of formulations ZT-11 up to ZT-25. Out of these 15 formulations, 10 were selected for screening. The remaining five that contained either Mo or Co sulfides needed calcination in the bench reactor. Attempts to calcine the Mo or Co sulfide containing formulations in the muffle furnace resulted in a pungent odor due to evolution of $\mathrm{SO}_{2}$.

Table 5-7 shows the physical and structural characteristics of these formulations. Also included in the table are the physical and structural properties of ZT-4 that were used as a baseline formulation prepared by the granulation technique. As can be seen, the pore size distribution and BET surface areas are within the expected range. The attrition resistance data, as shown in Table 5-7, indicate a very disappointing trend. Except for ZT-15, the 5-h loss due to attrition for the remainder of the formulations is between 60 and 80 percent. On the other hand, the 5-h loss for the ZT-4 formulation is only 32.1 percent.

Table 5-7. Physical and Structural Characterization of Second Series of ZT Formulations

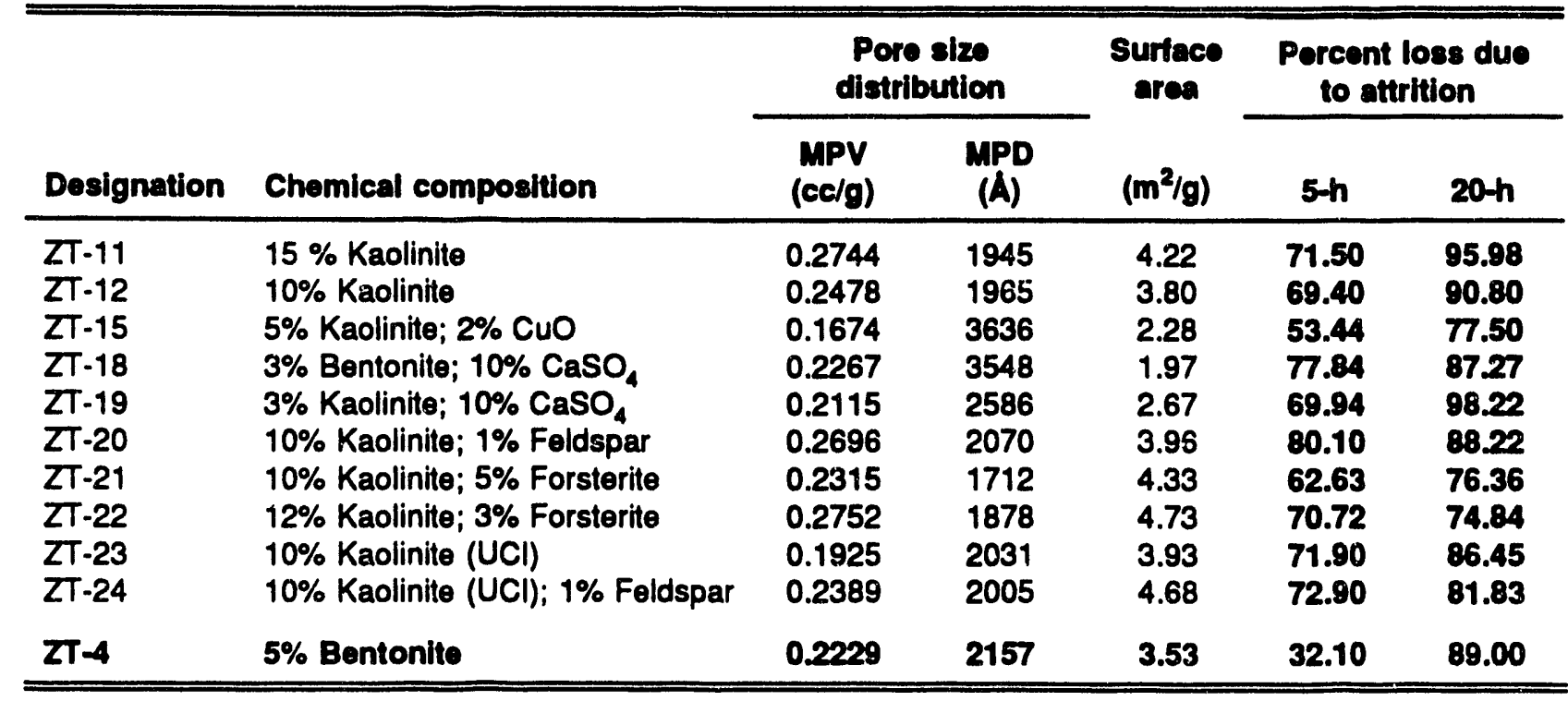


Figure 5-10 shows the TGA reactivities of these formulations which are found to be comparable to the reactivity of ZT-4. As expected, the formulations that contain 15 percent binder have somewhat lower sulfur capacity than those containing 5 percent binder.
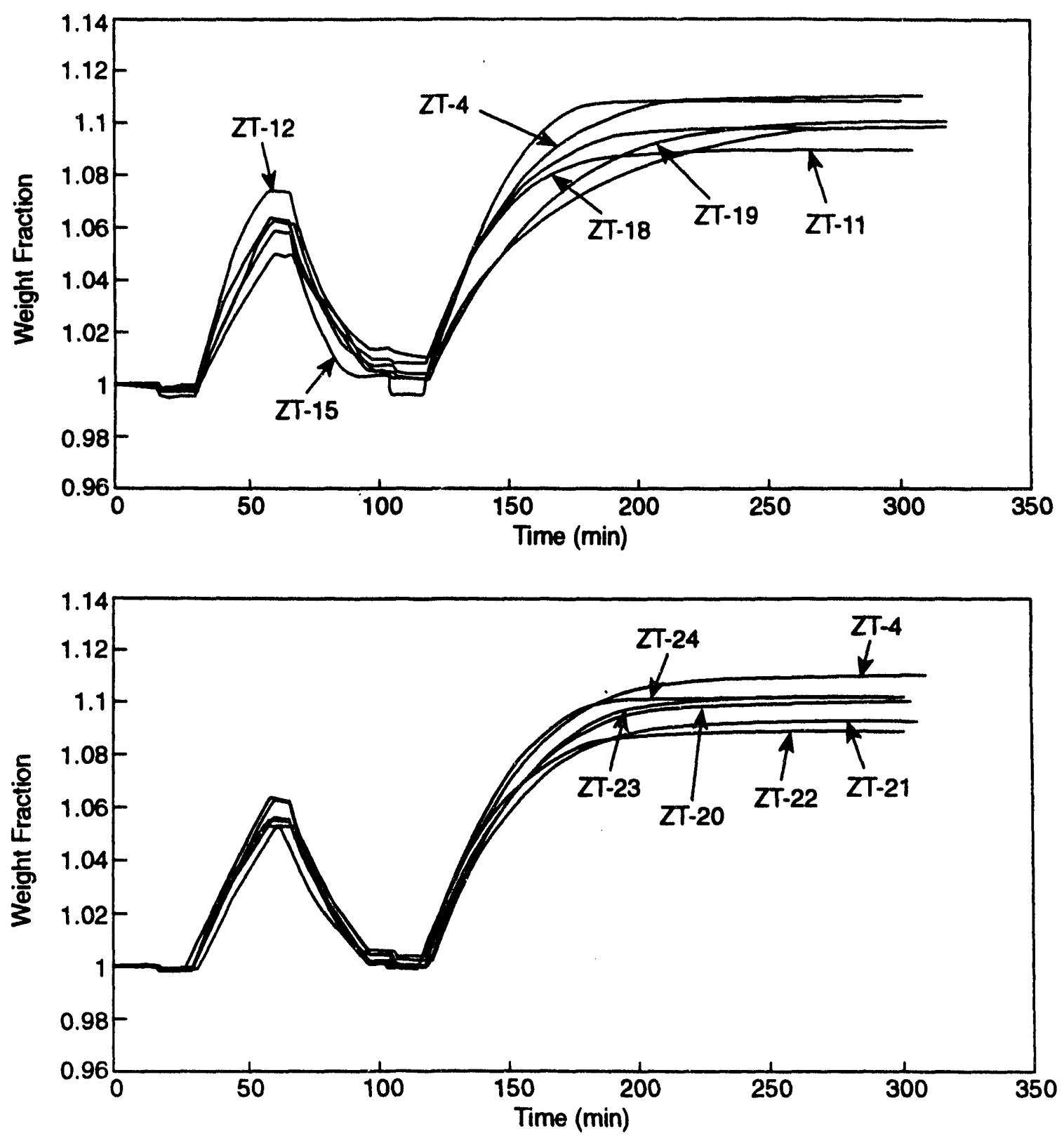

Figure 5-10. TGA reactlvities of second series of ZT-formulations. 
Although the formulations in the second series exhibit reasonably good chemical reactivity, their attrition resistance is quite low as discussed above. This is most likely due to variation in the granulation process conditions. Efforts are under way to minimize these variations in process operating conditions.

\subsection{PREPARATION OF A LARGE BATCH}

According to the contract requirements, a large batch $\left(1 \mathrm{ft}^{3}\right)$ of zinc titanate sorbent was prepared and supplied to DOE/METC. This batch consisted of about $60 \mathrm{lb}$ of ZT-5 and $60 \mathrm{lb}$ of ZT-2.

Both formulations were prepared using the granulation technique. About 25 batches each of ZT-5 and ZT-2 were made in the 2-L machine. These batches were calcined at $800^{\circ} \mathrm{C}$ for 4 $h$, although, as reported in Section 5.3.2, a 2-h calcination time would have been adequate. Future formulations are being calcined only for $2 \mathrm{~h}$. Following the calcination, both batches were screened in a vibro SWECO screener using the 35, 100, and 200 mesh screens.

Table 5-8 shows the physical and chtmical properties of both batches. The XRD analyses reported in Table 5-8 are questionable because of the controversial nature of $\mathrm{Zn}_{2} \mathrm{Ti}_{3} \mathrm{O}_{8}$ phase as discussed earlier. Both formulations had excellent TGA reactivities and good attrition resistance, along with other structural properties. The particle size distribution was in a fairly wide range.

These formulations are due to be tested later this year in METC's pilot unit. 
Table 5-8. Physical and Chemical Propertles of ZT-5 and ZT-2 Zinc Titanate Sorbents Shipped to DOE/METC

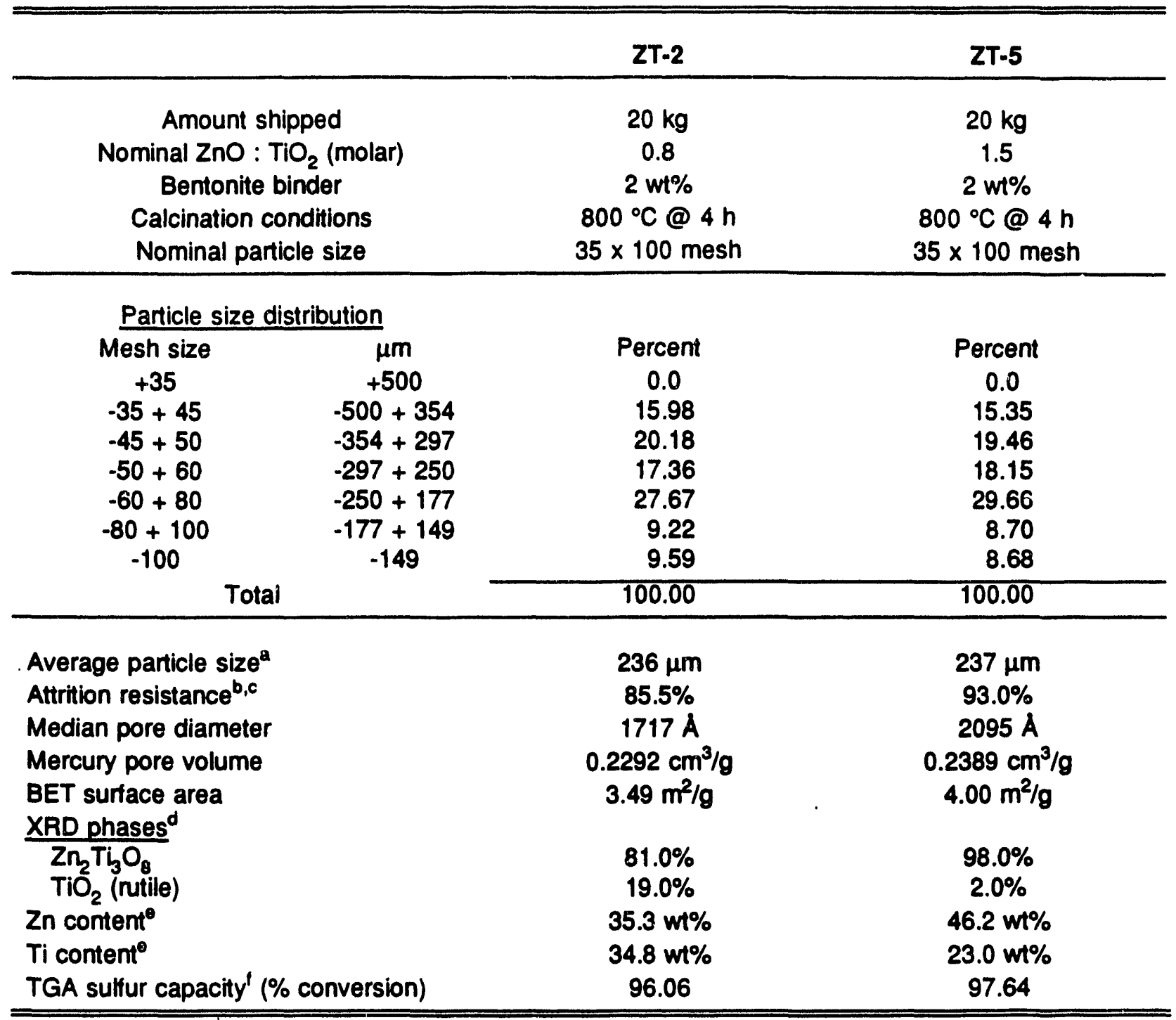

Determined using harmonic mean.

'Particles below $149 \mu \mathrm{m}$ were treated as fines.

"Measured in single-hole attrition tester.

Determined at WVU and expressed as percent. These numbers are only qualitative.

'Determined using inductively coupled plasma.

'Based on stoichiometry. 


\section{CHAPTER 6}

\section{BENCH-SCALE TESTING OF ZINC TITANATE SORBENTS}

\subsection{OBJECTIVE}

The objective of bench-scale testing was to determine the long-term chemical reactivity and attrition resistance of selected zinc titanate formulations. The sorbent selection was carried out by screening as discussed in Chapter 5. Ten 10-cycle runs were made in the bench-scale fluidized-bed reactor system. A complete description of the bench-scale fluidized-bed reactor system, along with the test procedure used, was presented in Chapter 3.

Table 6-1 shows the sorbent formulations arid operating conditions used for various bench runs in the order they were carried out. The first run was conducted with the baseline zinc titanate formulation, L-3758, supplied by $U \mathrm{Cl}$ as discussed in Section 5.2.1. The remaining nine runs were made with the sorbent formulations that were prepared using the granulation technique.

Table 6-1. Summary of Varlous Bench Runs"

\begin{tabular}{cccc}
\hline Run no. & Sorbent formulation & Temperature $\left({ }^{\circ} \mathrm{C}\right)$ & Coal gas $^{b}$ \\
\hline 1 & L-3758 & 650 & KRW gas (20\% steam) \\
2 & ZT-5 & 650 & KRW gas (20\% steam) \\
3 & $Z T-5$ & 650 & KRW gas (5\% steam) \\
4 & $Z T-5$ & 650 & Texaco gas \\
5 & $Z T-2$ & 650 & KRW gas (5\% steam) \\
6 & $Z T-2$ & 650 & Texaco gas \\
7 & $Z T-7$ & 650 & Texaco gas \\
8 & $Z T-4$ & 650 & Texaco gas \\
9 & $Z T-4$ & 750 & Texaco gas \\
10 & $Z T-4$ & $750^{\circ}$ & Texaco gas \\
\hline \hline
\end{tabular}

Operating conditions for sulfidation are given in Table 6-2.

${ }^{b}$ Gas composition for various coal gases is given in Table 6-3.

'This run was carried out at a U/U $\mathrm{m}_{\mathrm{mt}}$ value of 8.34; the sorbent charge was $500 \mathrm{~g}$.

The total gas flow rate, in Juding flow of steam, to the reactor was kept at approximately 35 sipm, except for Run Number 10, where this flow was doubled to study the effect of superficial gas velocity. Table 6-2 shows the typical bench-scale test conditions during sulfidation. The minimum fluidization velocity $\left(U_{m f}\right)$ was calculated using the correlations provided by Kunii and Levenspiel (1990). The typical value of $U_{\mathrm{mf}}$ was estimated to be about $1.87 \mathrm{~cm} / \mathrm{s}$ at $650^{\circ} \mathrm{C}$ and $1.5 \mathrm{MPa}$ for the sorbent in a 100 to $300 \mu \mathrm{m}$ particle size range.

Since one of the objectives of this testing was to study various sulfidation gases, three different gas compositions were studied. Table 6-3 shows the average composition of the three gases used. The KRW (Kellogg-Rust-Westinghouse originally, now Kellogg) gas simulates the gas from the KRW fluidized-bed gasifier. Two KRW gas compositions are shown in Table 6-3, 
Table 6-2. Bench-scale Test Conditions

${ }^{a}$ For Run no. 10, gas flow was 76 slpm.

${ }^{b}$ Ratio of superticial to minimum fluidization velocity.

${ }^{C}$ For Run no. 10, $U_{\mathrm{d}} / U_{\mathrm{mtt}}=8.34$.

${ }^{\circ}$ For Run no. 10, sorbent charge $=500 \mathrm{~g}$.

\begin{tabular}{ll}
\hline \hline Pressure: & $1.5 \mathrm{MPa}(220$ psia) \\
Temperature: & $650-7500^{\circ} \mathrm{C}$ \\
Gas flow: & $\sim 35 \mathrm{slpm}^{\mathrm{a}}$ \\
$U_{\mathrm{o}} U_{\mathrm{mb}}^{\mathrm{b}}:$ & $3-4^{\mathrm{c}}$ \\
Sorbent charge: & $350 \mathrm{~g}^{\mathrm{d}}$ \\
Sorbent particle size: & $100 \mathrm{to} 300 \mu \mathrm{m}$ \\
\hline
\end{tabular}

one with 5 percent steam and another with 20 percent steam. The high steam content of KRW gas here is after the water quench. This gas composition has been used for testing of zinc ferrite sorbents because of its low severity.

In addition to the gas composition, the ratio of $\mathrm{CO}$ plus $\mathrm{H}_{2}$, and $\mathrm{CO}_{2}$ plus $\mathrm{H}_{2} \mathrm{O}$ is also shown in Table 6-3. This ratio provides an indication of the reducing severity of coal gas. For example, the KRW
other two gases. This is why gas with 20 percert steam is significantly less reducing than the other two gases. This is why
this composition has been extensively used in testing zinc ferrite sorbents. The reducing power is sometimes called the 'quality factor' (QF) or 'equivalence ratio.' The QF values can vary between 0.5 and 30 . A value of 30 may be for an extremely reducing fuel gas such as the gas from a dry-feed oxygen-blown Shell or Prenflow gasifier that contains steam plus $\mathrm{CO}_{2}$ in a total of about 3 vol percent.

Table 6-3. Composition of Varlous SImulated Sulfidation Gases (vol \%)

\begin{tabular}{lccc}
\hline \hline & \multicolumn{2}{c}{ KRW gas } & \\
\cline { 2 - 3 } Gas & 20\% steam & $5 \%$ steam & $\begin{array}{c}\text { Texaco } \mathrm{O}_{2}- \\
\text { blown gas }\end{array}$ \\
\hline $\mathrm{H}_{2}$ & 8.85 & 11.65 & 27.70 \\
$\mathrm{CO}$ & 15.01 & 18.97 & 39.44 \\
$\mathrm{CO}_{2}$ & 6.89 & 6.75 & 13.10 \\
$\mathrm{H}_{2} \mathrm{O}$ & 19.17 & 5.12 & 18.64 \\
$\mathrm{H}_{2} \mathrm{~S}$ & 0.44 & 0.55 & 1.12 \\
$\mathrm{~N}_{2}$ & 49.54 & 56.95 & 0.00 \\
Total & 100.00 & 100.00 & 100.00 \\
& & & \\
\hline Reducing Power/Quality Factor & & & \\
$\left(\mathrm{CO}+\mathrm{H}_{2}\right) /\left(\mathrm{CO}_{2}+\mathrm{H}_{2} \mathrm{O}\right)$ & 0.92 & 2.58 & 2.11 \\
\hline \hline
\end{tabular}


During sulfidation, in addition to $\mathrm{H}_{2} \mathrm{~S}$ and COS removal,

$$
\begin{aligned}
& \mathrm{Zn}_{2} \mathrm{TiO}_{4}+2 \mathrm{H}_{2} \mathrm{~S} \rightarrow 2 \mathrm{ZnS}+\mathrm{TiO}_{2}+2 \mathrm{H}_{2} \mathrm{O} \\
& \mathrm{Zn}_{2} \mathrm{TiO}_{4}+2 \mathrm{COS} \rightarrow 2 \mathrm{ZnS}+\mathrm{TiO}_{2}+2 \mathrm{CO}_{2},
\end{aligned}
$$

carbon monoxide present in coal gas undergoes the shift reaction

$$
\mathrm{CO}+\mathrm{H}_{2} \mathrm{O}-\mathrm{CO}_{2}+\mathrm{H}_{2} \text {. }
$$

The shift reaction is catalyzed by zinc titanate. Zinc oxide is not as good a shift catalyst as iron oxide which is found in zinc ferrite. Conversion of $\mathrm{CO}$ by the shift reaction depends on the temperature and partial pressure of reactant and product species. A discussion of the shift reaction equilibrium for zinc titanate sorbents along with experimental data taken in the benchreactor is presented in Section 7.2.7 of Chapter 7.

Regeneration of the sulfided sorbent was carried out with a gas containing 2 to 3 percent oxygen in nitrogen at maximum temperatures up to $760^{\circ} \mathrm{C}$. During Run No. 9, the oxygen concentration in regeneration gas was varied to study its effect on the overall temperature rise and regeneration kinetics. This study is described in detail in Section 7.2.2.1 of Chapter 7. The flow rates used during the regeneration were similar to those used during sulfidation. Previous fixed-bed experience with zinc titanate showed that $760^{\circ} \mathrm{C}$ was required to prevent sulfate formation, particularly at higher pressures as used in this study (Gangwal et al., 1988). Table 6-4 shows the nominal regeneration conditions used in most of the runs, except for Run No. 10 where a regeneration gas flow rate of $76 \mathrm{sipm}$ was used to match the sulfidation gas flow rates. The end of regeneration was indicated when $\mathrm{SO}_{2}$ in the off-gas fell below $250 \mathrm{ppm}$.

The choice of nitrogen as a diluent rather than steam was due to ease of operation. Regeneration was significantly simpler to perform in the fluidized-bed system than in the fixed-bed system studied in the previous contract (DE-AC21-86MC23186). The presence of steam in the regeneration gas may also result in the formation of some sulfur due to steam regeneration of the sorbent to $\mathrm{H}_{2} \mathrm{~S}$ followed by the Claus reaction. This would considerably add to the complexity of operation. Regeneration was typically started at about $700{ }^{\circ} \mathrm{C}$ to provide a maximum bed temperature of $760^{\circ} \mathrm{C}$ and to prevent significant residual sulfate formation. Furthermore, unlike a fixed bed, no reductive regeneration was necessary.

The rest of this chapter is devoted to the pertinent details of each run in chronological order. Since it is not possible to include all the experimental data in this chapter fer each cycle, data are summarized in graphs and are included in:
Table 6-4. Regeneration Conditlons for Zinc Titanate Tests

\begin{tabular}{lll}
\hline \hline Starting temperature & $=690$ to $720^{\circ} \mathrm{C}$ \\
Final temperature & $=760^{\circ} \mathrm{C}$ \\
Pressure & $=1.5 \mathrm{MPa}$ \\
Nitrogen flow rate & $=29.5 \mathrm{sipm}^{\mathrm{a}}$ \\
Total gas flow rate & $=33.1 \mathrm{sipm}^{\mathrm{a}}$ \\
$U_{\mathrm{o}} / U_{\mathrm{mf}}$ & 3 to $3.5^{\mathrm{a}}$ \\
\hline
\end{tabular}

aExcept for Run No. 10 where all the flows were approximately doubled. 
Appendix C: $\mathrm{H}_{2} \mathrm{~S}$ Breakthrough Curves, Appendix D: COS Breakthrough Curves, Appendix E: Sulfur Capacities at Breakthrough, and

Appendix F: Particle Size Distribution of Fresh and Reacted Sorbents.

\subsection{RUN NUMBER 1-10-CYCLE TESTING OF L-3758 SORBENT}

Following the testing of zinc ferrite sorbents, the first 10-cycle test was carried out with a baseline sorbent formulation L-3758 supplied by $\mathrm{UCl}$ as discussed in Section 5.2.1. The operating conditions for this run were kept essentially the same as were used for zinc ferrite testing.

During this test, eight cycles were completed without any problems. During the ninth sulfidation, a sudden pressure rise, up to $400 \mathrm{psig}$, was observed in the reactor approximately after $1 / 2 h$ into the sulfidation. It was found that the outlet line to the sulfidation reactor had a plug formed by vaporization of zinc from the sorbent and its subsequent condensation. During this pressurization, $\mathrm{CO}$ present in the reactor was reduced to $\mathrm{C}$, thus depositing carbon on the inside walls of the reactor. The alumina distributor was found to be completely plugged with carbon black and, hence, was replaced.

Out of $350 \mathrm{~g}$ of sorbent that were initially loaded, $335 \mathrm{~g}$ were recovered. The remaining $15 \mathrm{~g}$ and the weight that increased due to sulfidation were lost from the reactor. This sorbent loss was due to either particle deposition on sulfidation and regeneration filters or zinc evaporation. Therefore, all the results reported are for only eight cycles. $\mathrm{H}_{2} \mathrm{~S}$ and $\mathrm{COS}$ breakthrough curves for this run are shown in Figures $\mathrm{C}-1$ and D-1, respectively. The sulfur capacity as shown in Figure E-1 remained fairly constant over eight cycles. The estimated sorbent capacity utilization was approximately 32 percent. The theoretical sulfur capture capacity of L-3758 is $23.05 \mathrm{~g} \mathrm{~S}$ per $100 \mathrm{~g}$ of fresh sorbent as calculated by stoichiometry.

Table 6-5 shows the structural properties of the fresh and the reacted material. A comparison of particle size distribution of the fresh and the reacted material is shown in Figure F-1. As shown in Table 6-5, the attrition resistance of the sorbent after eight cycles of sulfidation-regeneration did not deteriorate. A significant drop in both pore volume and pore diameter was, however, observed.

The principal cause for zinc vaporization from this formulation is believed to be nonhomogeneity in zinc and titanium distribution in the matrix evidenced by SEM/EDX analyses. Also, the XRD analysis indicated the presence of some free zinc oxide. Presence of free zinc oxide in the sorbent is detrimental because it initiates zinc vaporization via reduction of sorbent by $C O$ and/or $\mathrm{H}_{2}$. Therefore, one of the main requirements in the sorbent manufacture is to ascertain that all the zinc oxide in the sorbent has reacted with titania to form one of the zinc titanate phases. The issue of zinc vaporization is discussed in detail in Section 7.2.3 of Chapter 7.

\subsection{RUN NO. 2-10-CYCLE TESTING OF ZT-5 IN KRW-GAS (20\% STEAM)}

The second 10-cycle test was carried out with ZT-5 formulation at $650^{\circ} \mathrm{C}$. The gas composition used was identical to Run No. 1, i.e., KRW gas containing 20 percent steam. The objective of this test was to study the effect of sorbent preparation technique. Both L-3758 and ZT-5 had identical chemical compositions. 
Table 6-5. Structural Propertles of Fresh and Reacted L-3758 Formulation (Run \#1)

\begin{tabular}{lcc}
\hline & Fresh & 9-cycle sulfided \\
\cline { 2 - 3 } Average particle size $(\mu \mathrm{m})$ & 218 & 206 \\
BET surface area $\left(\mathrm{m}^{2} / \mathrm{g}\right)$ & 2.49 & 1.82 \\
Mercury pore volume $(\mathrm{cc} / \mathrm{g})$ & 0.2757 & 0.1830 \\
Median pore diameter $(\AA)$ & 4144 & 3418 \\
Attrition resistance $^{\mathrm{a}}(\%)$ & 96.8 & 97.4 \\
\hline \hline
\end{tabular}

a Measured in single-hole attrition tester.

Ten cycles of sulfidation-regeneration were performed after $358 \mathrm{~g}$ of sorbent in the 100 to $300 \mu \mathrm{m}$ particle size range were loaded. The run went fairly smoothly without any plugging or other operational problems such as were encountered during Run No. 1. At the end of the run, virtually all the sorbent was recovered from the reactor. There was negligible sorbent loss from the reactor due to elutriation or zinc vaporization. $\mathrm{H}_{2} \mathrm{~S}$ and $\mathrm{COS}$ breakthrough curves for this run are included in Figures C-2 and D-2, respectively, while sulfur capacity as a function of cycle number is shown in Figure E-2. The sulfur capacity of the sorbent is close to $15 \mathrm{~g} \mathrm{~S}$ per $100 \mathrm{~g}$ fresh sorbent during cycles 1 to 4; however, it decreases thereafter and stabilizes at a value of about 12. The theoretical sulfur capacity for this sorbent is $23.29 \mathrm{~g} \mathrm{~S}$ per $100 \mathrm{~g}$ sorbent; therefore, approximately 50 percent capacity utilization was achieved.

A post-test characterization was performed on the 10-cycle regenerated material and a comparison of structural properties of the fresh and the reacted material is shown in Table 6-6. The particle size distribution of fresh and reacted material is shown in Figure F-2. This figure shows essentially no change in particle size distribution due to reaction. The data reported in Table 6-6 indicate that the reacted sorbent possesses excellent attrition resistance unlike zinc ferrite sorbents (Gupta and Gangwal, 1991).

Table 6-6. Structural Propertles of Fresh and Reacted ZT-5 Formulation (Run \#2)

\begin{tabular}{|c|c|c|}
\hline & Fresh & 10-cycle regenerated \\
\hline $\begin{array}{l}\text { Average particle size }(\mu \mathrm{m}) \\
\text { BET surface area }\left(\mathrm{m}^{2} / \mathrm{g}\right) \\
\text { Mercury pore volume }(\mathrm{cc} / \mathrm{g}) \\
\text { Median pore diameter }(\AA) \\
\text { Attrition resistance }{ }^{\mathrm{a}}(\%) \\
\text { Zinc content (wt\%) } \\
\text { TGA reactivity (wt fraction) }\end{array}$ & $\begin{array}{l}197 \\
3.38 \\
0.2184 \\
2099 \\
97.3 \\
44.0 \\
1.098\end{array}$ & $\begin{array}{l}200 \\
2.49 \\
0.1817 \\
1635 \\
97.0 \\
44.2 \\
1.095\end{array}$ \\
\hline
\end{tabular}

a Measured in single-hole attrition tester.

${ }^{\text {b At }} 120 \mathrm{~min}$ during seçond sulfidation in TGR. 
The changes in BET surface area, pore volume, and pore diameter are marginal reflecting that the sorbent's internal pore structure has not undergone a drastic change. A comparison of TGA reactivities of fresh and reacted sorbent, as listed in Table 6-6, does not indicate any drop in sulfur capture capacity. These results show that this formulation exhibits a superior performance over its counterpart L-3758, the baseline material, both in terms of sulfur capacity and zinc loss.

\subsection{RUN NO. 3-10-CYCLE TESTING OF ZT-5 IN KRW-GAS (5\% STEAM)}

The next run, i.e., Run No. 3, was also made with ZT-5 in KRW gas. But the steam content of coal gas was reduced from 20 percent to about 5 percent as shown in Table 6-3. Reduction in steam content made this gas extremely reducing as indicated by the quality factor value of 2.58 in Table 6-3. Zinc ferrite was not able to withstand this gas composition even at $550^{\circ} \mathrm{C}$ (Gangwal et al., 1988).

A 10-cycle run with this gas composition was performed. As a precautionary measure, at the end of fifth cycle, the reactor was cooled and all the exit lines to the reactor were examined for possible plugging by zinc. The sulfidation and regeneration filters were removed and weighed to determine any particle deposition. No particle deposition was observed on the filters and all the gas lines were found to be fairly clean. Hence, the run was continued until 10 cycles. Negligible sorbent was lost from the reactor during the run.

The breakthrough curves for $\mathrm{H}_{2} \mathrm{~S}$ and $\mathrm{COS}$ are shown in Figures $\mathrm{C}-3$ and D-3, respectively, while sulfur capacity is shown in Figure E-3. From Figure C-3, it is observed that the breakthrough time for 500 ppmv of $\mathrm{H}_{2} \mathrm{~S}$ in reactor exit gas progressively decreases with cycling. This is also manifested in the sulfur capacity curve in Figure E-3 where the sulfur capacity decreases monotonically with cycle number. The sulfur capacity value is about 18 in cycle 1 and it decreases to about 11 during cycle 10.

The post-test characterization of 10-cycle regenerated material indicated no detrimental effect of cycling on the sorbent structure as shown in Table 6-7. In fact, the attrition resistance of the sorbent slightly increased after testing. However, the mercury pore volume and median pore diameter of the 10-cycle regenerated material were significantly lower than the fresh material. Negligible zinc loss from the sorbent was observed as evidenced by data in Table 6-7. The reduction in sulfur capacity with cycling is consistent with the reduction in pore volume, pore diameter, and TGA reactivity.

\subsection{RUN NO. 4-10-CYCLE TESTING OF ZT-5 IN TEXACO GAS}

Since one of the critical variables in testing of zinc titanate sorbents is the composition of coal gas, both medium- and low-Btu coal gases were used. The KRW gas used in Runs 1 to 3 as discussed earlier was a low Btu gas $\left(\sim 130 \mathrm{Btu} / \mathrm{ft}^{3}\right)$ produced from an air-blown fluidized-bed gasifier. On the other hand, the gas produced from an entrained-bed slurry-fed, oxygen-blown Texaco gasifier contains no nitrogen and hence is a medium-Btu gas ( $\left.260 \mathrm{Btu} / \mathrm{ft}^{3}\right)$. The Texaco gasification technology has been demonstrated on a commercial scale at Cool Water, CA, and a number of IGCC plants using this gasification technology are currently being built worldwide. Therefore, an alternate gas composition selected for this study was a simulated Texaco type gas. The nominal composition of this gas is shown in Table 6-3. 
Table 6-7. Structural Propertles of Fresh and Reacted ZT-5 Formulation (Run \#3)

\begin{tabular}{lcc}
\hline & Fresh & 10-cycle regenerated \\
\cline { 2 - 3 } Average particle size $(\mu \mathrm{m})$ & 188 & 176 \\
BET surface area $\left(\mathrm{m}^{2} / \mathrm{g}\right)$ & 3.38 & 2.89 \\
Mercury pore volume $(\mathrm{cc} / \mathrm{g})$ & 0.2184 & 0.1100 \\
Median pore diameter $(\AA)$ & 2099 & 1110 \\
Attrition resistance $(\%)$ & 97.3 & 99.5 \\
Zinc content $\left.(w)^{\mathrm{a}}\right)$ & 44.0 & 43.7 \\
TGA reactivity $(w t$ fraction) & 1.102 & 1.048 \\
\hline \hline
\end{tabular}

a Measured in single-hole attrition tester.

'At 120 min during second sulfidation in TGR.

A 10-cycle run with the simulated Texaco gas was performed using ZT-5 sorbent. The reactor used $350 \mathrm{~g}$ of sorbent screened in the 100 to $300 \mu \mathrm{m}$ particle size range. Despite the highly reducing nature of the gas, no zinc vaporization problems were encountered. Negligible sorbent loss from the reactor was observed.

$\mathrm{H}_{2} \mathrm{~S}$ and COS breakthrough curves for this run are shown in Figures $\mathrm{C}-4$ and $\mathrm{D}-4$, respectively, while sulfur capacity as a function of cycle number is shown in Figure E-4. The sulfur capacity of the sorbent essentially remains corsstant, except for an initial small drop, at about $14 \mathrm{~g} \mathrm{~S}$ per $100 \mathrm{~g}$ of fresh sorbent, indicating about 60 percent capacity utilization.

A post-test characterization was performed on the 10-cycle regenerated material and a comparison of the structural properties of the fresh and the reacted material is shown in Table 6-8. A comparison of the particle size distribution of fresh and reacted material is shown in Figure F-4. This figure shows essentially no change in particle size distribution due to reaction.

Table 6-8. Structural Properties of Fresh and Reacted ZT-5 Formulation (Run \#4)

\begin{tabular}{|c|c|c|}
\hline & Fresh & 10-cycle regenerated \\
\hline 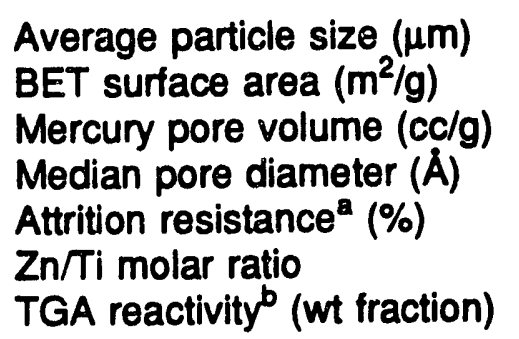 & $\begin{array}{c}188 \\
3.48 \\
0.1885 \\
2023 \\
97.3 \\
1.5166 \\
1.110\end{array}$ & $\begin{array}{c}183 \\
3.89 \\
0.1511 \\
1149 \\
97.9 \\
1.5385 \\
1.085\end{array}$ \\
\hline
\end{tabular}

Measured in single-hole attrition tester.

${ }^{\text {b At }} 120$ min during second sulfidation in TGR. 
The data reported in Table 6-8 indicate that the reacted sorbent possesses excellent resistance, in fact slightly better than that in its fresh state. Also, the changes in BET surface area and mercury pore volume are marginal. The $\mathrm{Zn}$ to $\mathrm{Ti}$ atomic ratio does not change during testing, indicating no zinc loss. A comparison of TGA reactivities of fresh and reacted sorbent, as listed in Table 6-8, indicates a slight drop in sulfur capture capacity.

\subsection{RUN NO. 5-10-CYCLE TESTING OF ZT-2 IN TEXACO GAS}

Following the excellent performance of $Z T-5$ in Texaco gas, the next variable that was investigated was the effect of $\mathrm{Zn}$ to $\mathrm{Ti}$ ratio in the sorbent. To this end, Formulation $\mathrm{ZT}-2 \mathrm{with}$ a $\mathrm{Zn}$ to Ti molar ratio of 0.8 was selected. The binder content of this formulation was 2 percent (bentonite).

A 10-cycle test was performed in the simulated Texaco gas using $350 \mathrm{~g}$ of ZT-2 sorbent in the 100 to $300 \mu \mathrm{m}$ particle size range. Negligible sorbent loss from the reactor was observed. $\mathrm{H}_{2} \mathrm{~S}$ and COS breakthrough curves for this run are shown in Figures C-5 and D-5, respectively, while sulfur capacity as a function of cycle number is shown in Figure E-5. The sulfur capacity of the sorbent essentially remains constant at an average value of about $10.5 \mathrm{~g} \mathrm{~S}$ per $100 \mathrm{~g} \mathrm{of}$ fresh sorbent, indicating about 60 percent capacity utilization. The stoichiometric sulfur capacity of ZT-2 formulation is $17.3 \mathrm{~g} \mathrm{~S}$ per $100 \mathrm{~g}$ of fresh sorbent.

A post-test characterization of the 10-cycle regenerated sorbent was performed and Table 6-9 shows a comparison of the structural properties of fresh and reacted material. A comparison of the particle size distribution of fresh and reacted material is shown in Figure F-5. This figure shows that the particle size distribution has slightly shifted toward the left indicating a drop in the average size. In fact, a 6 percent decrease in mean particle size was observed as shown in Table 6-9. The changes in BET surface area, median pore diameter, and mercury pore volume due to reaction are insignificant. The zinc to titanium ratio values shown indicate a decrease from 0.7693 to 0.7444 , which can very well be within the experimental error band of the measurement. A comparison of the TGA reactivities of fresh and reacted material does not indicate any drop in sulfur capture capacity.

Table 6-9. Structural Properties of Fresh and Reacted ZT-2 Formulation (Run \#5)

\begin{tabular}{|c|c|c|}
\hline & Fresh & 10-cycle regenerated \\
\hline $\begin{array}{l}\text { Average particle size }(\mu \mathrm{m}) \\
\text { BET surface area }\left(\mathrm{m}^{2} / \mathrm{g}\right) \\
\text { Mercury pore volume }(\mathrm{cc} / \mathrm{g}) \\
\text { Median pore diameter }(\AA) \\
\text { Attrition resistance }(\%) \\
\mathrm{Zn} / \mathrm{Ti} \text { molar ratio } \\
\text { TGA reactivity (wt fraction) }\end{array}$ & $\begin{array}{c}176 \\
4.05 \\
0.2073 \\
1889 \\
96.6 \\
0.7693 \\
1.080\end{array}$ & $\begin{array}{c}166 \\
3.84 \\
0.1942 \\
1614 \\
91.4 \\
0.7444 \\
1.078\end{array}$ \\
\hline
\end{tabular}

a Measured in single-hole attrition tester.

${ }^{b}$ At 120 min during second sulfidation in TGR. 


\subsection{RUN NO. 6-10-CYCLE TESTING OF ZT-2 IN KRW GAS (5\% STEAM)}

Following the 10-cycle testing of ZT-2 in Texaco gas, the next 10-cycle test was performed with this formulation in KRW gas containing 5 percent steam. As indicated in Table 6-3, this gas has a reducing power of 2.58 ; this test was designed to investigate the effect of reducing severity of coal gas on the performance of ZT-2 formulation.

A 10-cycle test was performed in the simulated gas using $350 \mathrm{~g}$ of the sorbent in the 100 to $300 \mu \mathrm{m}$ particle size range. Negligible sorbent loss occurred from the reactor during these 10 cycles of sulfidation-regeneration. $\mathrm{H}_{2} \mathrm{~S}$ and $\mathrm{COS}$ breakthrough curves for this run are shown in Figures C-6 and D-6, respectively, while sulfur capacity as a function of cycle number is shown in Figure E-6. As can be seen, the sulfur capacity over 10 cycles remains fairly constant, at an average value of about $14.26 \mathrm{~g}$ of $\mathrm{S}$ per $100 \mathrm{~g}$ of fresh sorbent, indicating an 82.4 percent capacity utilization at $650^{\circ} \mathrm{C}$. This was perhaps the best capacity utilization ever achieved with the zinc titanate formulation and indicates that the reactivity increased at low steam levels.

A post-test characterization of the 10-cycle regenerated sorbent was performed and Table 6-10 shows a comparison of the structural properties of fresh and reacted material. A comparison of the particle size distribution of fresh and reacted material is shown in Figure F-6. As can be seen, the particle size distribution has shifted slightly toward the right, indicating an increase in average particle size. This is further confirmed by the data in Table 6-10 where a 7 percent increase in mean particle size is reported. The attrition resistance of the sorbent measured in the single-hole attrition tester increased from 96.6 percent to 98.7 percent. The changes in BET surface area, median pore diameter, and mercury pore volume due to 10 cycles of sulfidationregeneration are marginal. A comparison of the TGA reactivities of fresh and reacted material does not indicate any drop in sulfur capture capacity of the sorbent due to reaction.

Table 6-10. Structural Propertles of Fresh and Reacted ZT-2 Formulation (Run \#6)

\begin{tabular}{|c|c|c|}
\hline & Fresh & 10-cycle regenerated \\
\hline $\begin{array}{l}\text { Average particle size }(\mu \mathrm{m}) \\
\text { BET surface area }\left(\mathrm{m}^{2} / \mathrm{g}\right) \\
\text { Mercury pore volume }(\mathrm{cc} / \mathrm{g}) \\
\text { Median pore diameter }(\hat{\mathrm{A}}) \\
\text { Attrition resistance }^{\mathrm{a}}(\%) \\
\text { TGA reactivity }^{\mathrm{b}} \text { (wt fraction) }\end{array}$ & $\begin{array}{c}189 \\
4.05 \\
0.2073 \\
1889 \\
96.6 \\
1.08\end{array}$ & $\begin{array}{c}203 \\
3.83 \\
0.1595 \\
1119 \\
98.7 \\
1.075\end{array}$ \\
\hline
\end{tabular}

a Measured in single-hole attrition tester.

'At 120 min during second sulfidation in TGR. 


\subsection{RUN NO. 7-10-CYCLE TESTING OF ZT-7 IN TEXACO GAS}

In view of the excellent attrition resistance and TGA reactivity of $Z T-7$ during primary screening, as reported in Chapter 5, a 10-cycle test was carried out with this formulation in the bench unit. ZT-7 contained 2 percent bentonite and 3 percent forsterite and was prepared with a zinc to titanium molar ratio of 0.8 .

A 10-cycle test was performed in the simulated Texaco gas using $350 \mathrm{~g}$ of sorbent in the 100 to $300 \mu \mathrm{m}$ particle size range. At the end of the tenth regeneration, $326.52 \mathrm{~g}$ of the sorbent were recovered from the reactor and approximately $0.6 \mathrm{~g}$ from sulfidation and regeneration filters. At first it was thought that some of this loss may be due to zinc vaporization, but based on the $\mathrm{Zn}$ and $\mathrm{Ti}$ analyses as reported in Table 6-11, this was not possible. It was later discovered that the alumina distributor ring at the bottom of the reactor was not welded properly to the sorbent cage and sorbent was leaking around the ring. This problem was fixed using a high-temperature alumina cement.

Table 6-11. Structural Propertles of Fresh and Reacted ZT-7 Formulation (Run \#7)

\begin{tabular}{lcc}
\hline & Fresh & 10-cycle regenerated \\
\cline { 2 - 3 } Average particle size $(\mu \mathrm{m})$ & 185 & 199 \\
BET surface area $\left(\mathrm{m}^{2} / \mathrm{g}\right)$ & 3.67 & 3.59 \\
Mercury pore volume $(\mathrm{cc} / \mathrm{g})$ & 0.2167 & 0.1912 \\
Median pore diameter $(\AA)$ & 1764 & 1628 \\
Zinc content $(w+\%)$ & 34.2 & 33.0 \\
Ti content $(w \%)$ & 30.6 & 31.5 \\
\hline \hline
\end{tabular}

$\mathrm{H}_{2} \mathrm{~S}$ and $\mathrm{COS}$ breakthrough curves for this run are shown in Figures C-7 and D-7, respectively, while sulfur capacity as a function of cycle number is shown in Figure E-7. As can be seen, sulfur capacity remains fairly constant over 10 cycles of sulfidation-regeneration. However, the actual value of the $S$ capacity is lower than expected. It is about $7.6 \mathrm{~g} \mathrm{~S}$ per 100 $\mathrm{g}$ of fresh sorbent compared to 10.5 for ZT-2 under identical operating conditions. The stoichiometric sulfur capacity value for ZT-7 formulation is 16.77 . Thus, a capacity utilization of 45 percent is achieved.

The post-test characterization of the 10-cycle regenerated material revealed a 7.5 percent increase in mean particle size and virtually insignificant changes in BET surface area, pore volume, and median pore diameter as shown in Table 6-11. A comparison of the particle size distribution of fresh and reacted material is shown in Figure F-7. As can be seen, the particle size distribution has shifted slightly toward the right, indicating an increase in mean size.

A comparison of the TGA reactivities of fresh and reacted sorbent revealed a significant decline in the sorbent's sulfur capture capacity after 10 cycles of sulfidation-regeneration as shown in Figure 6-1, although the sulfur capacity curve (shown in Figure E-7) does not indicate this behavior. The zinc content of the sorbent also dropped from 34.2 to 33 percent. This drop 


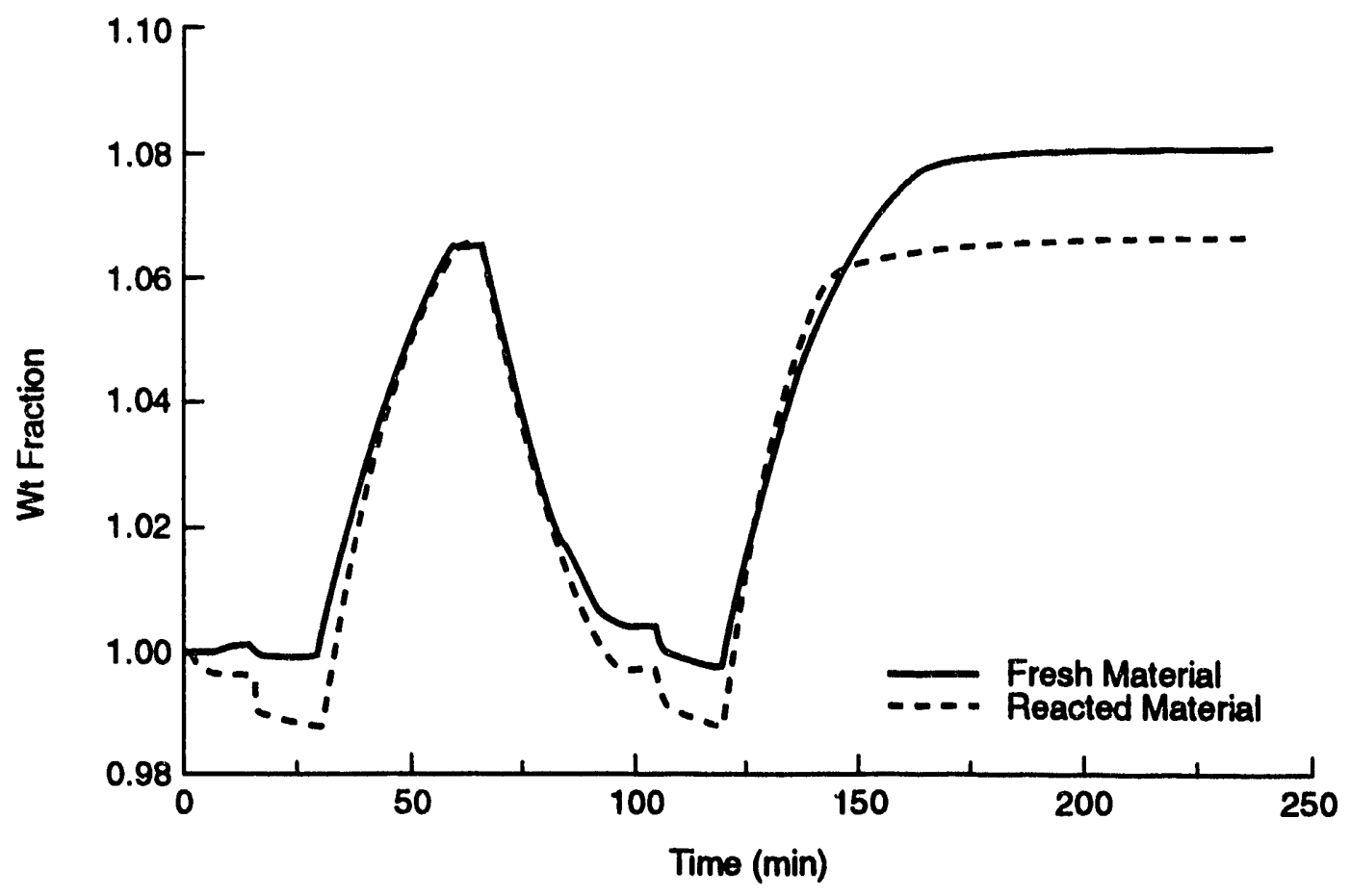

Flgure 6-1. TGA reactivities of fresh and reacted ZT-7 sorbent.

may not necessarily represent zinc loss from the sorbent as these values have significant uncertainty due to the error band of the measurement.

One important point to note, illustrated in Figure 6-1, is that unlike fresh sorbent, the reacted sorbent undergoes a significant weight loss during reduction in the clean coal gas. This, in turn, indicates that the reacted sorbent has become more prone to reduction. This may be due to the degradation of binder or change in the sorbent pore structure. Since pore size distribution, as reported in Table 6-11, does not indicate any such trend, it is believed that degradation of binder is responsible for this behavior. The chemistry of forsterite clay that was used in the preparation of this sorbent along with bentonite is not well understood.

Finally, the attrition resistance of the reacted (10-cycle regenerated) sorbent was significantly better than the fresh material. The attrition test conducted in the 3-hole tester (described in Chapter 4) indicated that 22 percent of fresh material was attrited in $5 \mathrm{~h}$ while only 15 percent of the sample was lost during $5 \mathrm{~h}$ of testing in the case of reacted material.

\subsection{RUN NO. 8-10-CYCLE TESTING OF ZT-4 IN TEXACO GAS AT $650^{\circ} \mathrm{C}$}

Following the slightly disappointing performance of $Z T-7$ in Texaco gas at $650^{\circ} \mathrm{C}$, the next 10-cycle run was carried out with ZT-4. Both ZT-4 and ZT-7 had shown superior performance during the preliminary screening as discussed in Chapter 5 . The ZT-4 formulation contained zinc oxide and titanium oxide in a molar ratio of 1.5 and had a 5 percent bentonite binder. 
A 10-cycle test was performed in simulated Texaco gas using $350 \mathrm{~g}$ of sorbent in the 100 to $300 \mu \mathrm{m}$ particle size range. Negligible sorbent loss occurred from the reactor during 10 cycles of sulfidation-regeneration. $\mathrm{H}_{2} \mathrm{~S}$ and $\mathrm{COS}$ breakthrough curves for this run are shown in Figures C-8 and D-8, respectively, while Figure E-8 shows the sulfur capacity as a function of cycle number. As can be seen, sulfur capacity of the sorbent remains fairly constant over the 10 cycles, at an average value of about 11.70, indicating a 52 percent capacity utilization. The stoichiometric capacity of ZT-4 is $22.58 \mathrm{~g} \mathrm{~S}$ per $100 \mathrm{~g}$ of fresh sorbent.

A post-test characterization of the 10-cycle regenerated material was performed and Table 6-12 shows a comparison of structural properties of fresh and reacted material. A comparison of the particle size distribution of fresh and reacted material is shown in Figure F-8. As can be seen from this figure, the particle size distribution remains essentially unchanged. The changes in BET surface area, mercury pore volume, and median pore diameter are fairly significant. The TGA reactivity data taken on the fresh and reacted sorbent showed a slight decline in the sorbent sulfur capture capacity due to testing. The attrition resistance data taken on fresh and reacted material showed that the reacted material was significantly more attrition-resistant than the fresh material. In the three-hole tester, 32 percent of the material was lost in the first $5 \mathrm{~h}$ in the case of fresh sorbent, while only 14 percent loss was observed when the reacted sample was subjected to the same testing.

Table 6-12. Structural Propertles of Fresh and Reacted ZT-4 Formulation (Run \#8)

\begin{tabular}{lcc}
\hline \hline & Fresh & 10-cycle regenerated \\
\cline { 2 - 3 } Average particle size $(\mu \mathrm{m})$ & 175.8 & 172.6 \\
BET surface area $\left(\mathrm{m}^{2} / \mathrm{g}\right)$ & 3.53 & 2.64 \\
Mercury pore volume $(\mathrm{cc} / \mathrm{g})$ & 0.2229 & 0.1586 \\
Median pore diameter $(\AA)$ & 2157 & 1692 \\
Zinc content $(\omega t \%)$ & 43.5 & 43.1 \\
Ti content $(w t \%)$ & 20.9 & 21.0 \\
\hline \hline
\end{tabular}

\subsection{RUN NO. 9-10-CYCLE TESTING OF ZT-4 IN TEXACO GAS AT $750^{\circ} \mathrm{C}$}

In view of the excellent performance of ZT-4 in Texaco gas at $650^{\circ} \mathrm{C}$, the next 10-cycle run was conducted at $750^{\circ} \mathrm{C}$. The intent of this run was to determine the effect of temperature on the sorbent reactivity and to explore the extent of zinc vaporization at $750^{\circ} \mathrm{C}$.

Ten cycles of sulfidation-regeneration were performed with $350 \mathrm{~g} \mathrm{of} \mathrm{ZT-4} \mathrm{formulation} \mathrm{in}$ the 100 to $300 \mu \mathrm{m}$ particle size range. At the end of the tenth regeneration, sorbent was removed from the reactor. Negligible sorbent loss from the reactor was observed as $350.24 \mathrm{~g}$ of sorbent were recovered from the sorbent cage and sulfidation and regeneration filters. $\mathrm{H}_{2} \mathrm{~S}$ and $\mathrm{COS}$ breakthrough curves for this run are shown in Figures C-9 and D-9, respectively, while Figure E-9 shows the sulfur capacity as a function of cycle number. Both the $\mathrm{H}_{2} \mathrm{~S}$ breakthrough curve (Figure C-9) and the sulfur capacity curve (Figure E-9) indicate no change in breakthrough behavior and the sulfur capacity remains constant at a value of $12.12 \mathrm{~g} \mathrm{~S}$ per $100 \mathrm{~g}$ of fresh 
sorbent, indicating about 54 percent capacity utilization. The pre-breakthrough level of $\mathrm{H}_{2} \mathrm{~S}$ was consistently below 20 ppmv during the entire run despite a sulfidation temperature of $750^{\circ} \mathrm{C}$. The COS evolution behavior as shown in Figure D-9 exhibits no particular trend.

A post-test characterization of the 10-cycle regenerated material was performed to determine the changes in the sorbent structure that could have occurred during testing. Table 6-13 shows a comparison of the structural properties of fresh and reacted material. A comparison of the particle size distribution of fresh and reacted material is shown in Figure F-9. As can be seen, essentially no change in particle size distribution takes place during testing. The mean particle size before testing is $175.8 \mu \mathrm{m}$ becoming $169.6 \mu \mathrm{m}$, after the test.

Table 6-13. Structural Propertles of Fresh and Reacted ZT-4 Formulation (Run \#9)

\begin{tabular}{lcc}
\hline \hline & Fresh & 10-cycle regenerated \\
\cline { 2 - 3 } Average particle size $(\mu \mathrm{m})$ & 175.8 & 169.6 \\
BET surface area $\left(\mathrm{m}^{2} / \mathrm{g}\right)$ & 3.53 & 1.91 \\
Mercury pore volume $(\mathrm{cc} / \mathrm{g})$ & 0.2229 & 0.1897 \\
Median pore diameter $(\AA)$ & 2157 & 2910 \\
Zinc content $(w t \%)$ & 43.5 & 42.2 \\
Ti content $(w t \%)$ & 20.8 & 21.4 \\
\hline \hline
\end{tabular}

As indicated in Table 6-13, a significant drop in BET surface area is observed after the testing. On the other hand, the mercury pore volume decreased slightly while a 35 percent increase was observed in median pore diameter. This increase in median pore diameter was perplexing since the median pore diameter decreased after testing in all previous runs.

The zinc and titanium contents of fresh and reacted samples, as listed in Table 6-13, indicate some zinc vaporization from the sorbent. Again, the chemical analysis has an error margin of \pm 5 percent; therefore, no meaningful estimates of zinc loss can be made with these data. The sulfur capacity and breakthrough data do not indicate any decline in the sorbent reactivity.

Finally, the most important characterization was attrition resistance. The attrition behavior of fresh and reacted ZT-4 was compared to determine the change in the sorbent's mechanical strength and Table 6-14 shows the results. Also included in this table is the attrition behavior of partially sulfided sorbent. The partially sulfided sorbent here refers to a partial sulfidation of 10cycle regenerated sorbent. As can be seen from Table 6-14, the partially sulfided sample exhibits far better attrition resistance than both fresh and reacted sample. Nonetheless, the attrition resistance of the reacted sorbent is significantly better than the fresh sorbent. The effect of sulfidation on the sorbent attrition resistance is discussed in detail in Section 7.2.4 of Chapter 7. 
Table 6-14. Attrition Behavlor of Fresh, Reacted, and Sulfided ZT-4

\begin{tabular}{lcc}
\hline & \multicolumn{2}{c}{ Sample loss due to attrition (\%) } \\
\cline { 2 - 3 } Sample & $5 \mathrm{~h}$ & $20 \mathrm{~h}$ \\
\hline ZT fresh & 39.66 & 89.00 \\
ZT-4 reacted (10-cycle regenerated) & 28.74 & 87.46 \\
ZT-4 sulfided (11th sulfidation) & 2.90 & 14.28 \\
\hline \hline
\end{tabular}

\section{6-11 RUN NO. 10-10-CYCLE TESTING OF ZT-4 UNDER HIGH VELOCITY CONDITIONS}

The last 10-cycle test in this study was made with $\mathrm{ZT}-4$ formulation at $750^{\circ} \mathrm{C}$ and high velocity conditions. Run No. 9 had been carried out at a superficial gas velocity of $7.61 \mathrm{~cm} / \mathrm{s}$. Since most of the commercial bubbling-bed fluidized-bed reactors are operated at a U $U_{\text {mf }}$ ratio of 8 to 10, it was thought that the superficial velocity previously used should be at least doubled, if not more, to get a meaningful comparison. Doubling the velocity required a total gas flow rate of about 76 sipm. To handle these high flows, a number of modifications in the bench-scale test facility (described in Chapter 3) were made including replacement of mass flow controllers with higher flow ratings, installation of a new sulfidation preheater, replacement of the sulfidation condenser by a bigger size condenser, modification of the exhaust gas venting system, etc.

Before performing the actual 10-cycle test on ZT-4, a 1-cycle scoping test with ZT-5 was performed. The test used $500 \mathrm{~g}$ of ZT-5 and it was carried out at a superficial linear velocity of $15.6 \mathrm{~cm} / \mathrm{s}$. The test was successful and demonstrated that the modifications made were adequate to carry out the actual test.

After the successful scoping test, the actual 10-cycle test was performed with ZT-4 sorbent. $500 \mathrm{~g}$ of ZT-4 sorbent in the particle size range of 100 to $300 \mu \mathrm{m}$ were used in the reactor. The highlights of the run are as follows:

- Identical conditions were maintained during each of ten cycles. Figures C-10 and D-10 show the $\mathrm{H}_{2} \mathrm{~S}$ and $\mathrm{COS}$ breakthrough behavior, respectively, during ten cycles. The $\mathrm{H}_{2} \mathrm{~S}$ breakthrough behavior essentially remained unchanged. The COS evolved during the run was in the range of 0 to 10 ppmv.

- The pressure drop across the bed and distributor was 20.5 in. of $\mathrm{H}_{2} \mathrm{O}$ and the bed was vigorously bubbling.

- The sorbent sulfur capacity consistently remained at $13.42 \mathrm{~g} \mathrm{~S}$ per $100 \mathrm{~g}$ of fresh sorbent for each of ten cycles, as shown in Figure E-10, prior to breakthrough at the $500 \mathrm{ppm}$ level. This is higher than 12.12 at low velocity, presumably due to faster kinetics/mass transfer.

- During regeneration, an attempt was made to vary the oxygen concentration from cycle to cycle to examine its effect on regeneration time. However, temperature control was 
found to be more difficult at these high velocity conditions than at the low velocity conditions previously tested and thus conclusive results could not be obtained. The maximum sorbent regeneration temperature was $780^{\circ} \mathrm{C}$. The temperature was maintained at $760^{\circ} \mathrm{C}$ during most of each regeneration.

- The structural properties of fresh and 10-cycle regenerated material are compared in Table 6-15. The particle size distribution remained essentially unchanged (also shown in Figure F-10). A decline in BET surface area and pore volume was observed. The median pore diameter increased similarly to the last run, but not as much.

- At the end of the tenth regeneration, $497.81 \mathrm{~g}$ of the sorbent were recovered from the cage and $1.79 \mathrm{~g}$ from the sulfidation and regeneration filters. Thus, 99.92 percent of the material was accounted for.

- No evidence of zinc loss was seen as indicated by the zinc contents of fresh and reacted sorbents shown in Table 6-15.

- The sorbent attrition resistance improved significantly due to the reaction. The values of attrition loss shown in Table 6-15 indicate that the 5-h loss for the reacted material was only 5 percent as compared to 39.66 percent for the fresh material.

Table 6-15. Structural Propertles of Fresh and Reacted ZT-4 Formulailon (Run \#10)

\begin{tabular}{lcc}
\hline & Fresh & 10-cycle regenerated \\
\cline { 2 - 3 } Average particle size $(\mu \mathrm{m})$ & 172 & 169.5 \\
BET surface area $\left(\mathrm{m}^{2} / \mathrm{g}\right)$ & 3.53 & 2.24 \\
Mercury pore volume $(\mathrm{cc} / \mathrm{g})$ & 0.2229 & 0.1810 \\
Median pore diameter $(\AA)$ & 2175 & 2600 \\
Zinc content $(w t \%)$ & 44.4 & 44.7 \\
Ti content $(w t \%)$ & 22.5 & 22.1 \\
Attrition $(\%)$ & 39.66 & 5.0 \\
$5-h$ loss & 89.00 & 31.4 \\
20-h loss & & \\
\hline \hline
\end{tabular}

Therefore, based on the results of the above multicycle testing (Runs 1 to 10), it is clear that among the various formulations tested, $\mathrm{ZT}-4$ exhibited the best overall performance both in terms of chemical reactivity and attrition resistance. Chapter 7 attempts to analyze the details of the runs as a function of various systems variables and derive a number of inferences that will be invaluable in design of a future hot-gas desulfurization system. 


\section{CHAPTER 7}

\section{DATA ANALYSIS}

Analysis of the experimental data obtained during bench-scale testing was carried out to evaluate the effect of various process variables. The variables studied included

- Method of sorbent preparation,

- Sulfidation temperature,

- Superficial gas velocity,

- Binder content,

- Composition of fuel gas, and

- $\mathrm{Zn}$ to Ti ratio of the sorbent.

The effect of each of these variables is described in detail in Section 7.1 below. The second part of this chapter is devoted to addressing a number of important reactor design issues, including:

- Sulfidation kinetics,

- Regeneration kinetics,

- Sulfate formation,

- Zinc vaporization,

- Effect of sulfidation on sorbent attrition,

- Extent of shift reaction, and

- Conceptual commercial systems.

Again, each of the above issues has been discussed in some detail. The discussion is based principally on the experimental data taken during bench testing and from TGA studies. A relatively simple mathematical model that was developed to describe the breakthrough behavior is presented in Chapter 8.

\subsection{PARAMETRIC STUDIES}

The effect of a number of important process variables was studied on the performance of various zinc titanate sorbents.

\subsubsection{Method of Sorbent Preparation}

As discussed in Chapter 5, the primary method used to prepare fluidizable zinc titanate sorbents was "granulation." However, UCl supplied a baseline material designated as L-3758 for comparison purposes. A discussion on the preparation of this baseline material by $\mathrm{UCl}$ appeared earlier in Section 5.2.1.

Figure 7-1 shows a comparison of the $\mathrm{H}_{2} \mathrm{~S}$ breakthrough curves for L-3758 and ZT-5 sorbents at $650^{\circ} \mathrm{C}, 15 \mathrm{~atm}$ and in KRW gas with 20 percent steam (complete composition was shown in Table 6-3) in the first cycle. Formulation ZT-5 was prepared using the granulation technique and had a zinc to titanium molar ratio of 1.5. Therefore, the principal difference between the ZT-5 and L-3758 sorbents was the preparation method used. Also included in 


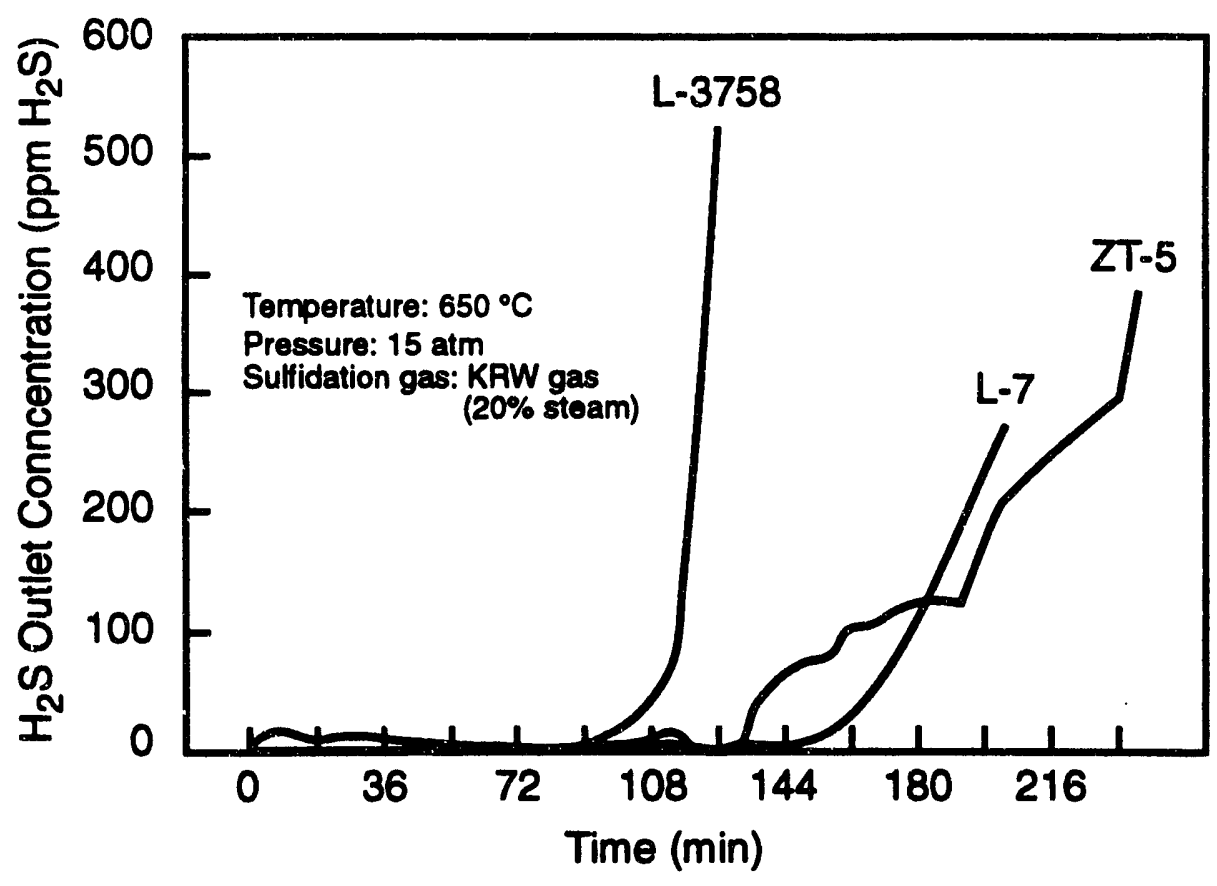

Figure 7-1. A comparison of breakthrough curves during first cycle for L-7 (zInc ferrite), L-3758 (UCI zinc titanate) and ZT-5 (RTI zinc titanate).

Figure 7-1 is the breakthrough curve for L-7, which is a zinc ferrite sorbent prepared using the granulation technique. As seen from this figure, L-3758 has significantly lower capacity and lower chemical reactivity than ZT-5. The theoretical (stoichiometric) capacity of L-7 zinc ferrite is more than 1.5 times that of ZT-5, but experimentally, as shown in Figure 7-2, it exhibits a breakthrough behavior similar to that of $Z T-5$. This is perhaps due to the more rapid decline of zinc ferrite with cycling.

Figure 7-2 shows the sulfur capacity of the same sorbents (L-7, L-3758, and ZT-5) as a function of cycle number. The value of sulfur capacity is expressed in terms of $\mathrm{g} \mathrm{S} / 100 \mathrm{~g}$ of fresh sorbent absorbed at the point of breakthrough arbitrarily defined as 500 ppmv of $\mathrm{H}_{2} \mathrm{~S}$, as discussed in Chapter 6 . As can be seen, the capacity of L-7 continually drops with cycling, a behavior that is typical of zinc ferrite sorbents (Gupta and Gangwal, 1991; Gupta et al., 1992). The sulfur capacity of L-3758 remains fairly constant over 10 cycles at a significantly lower value than that of ZT-5. Plugging of the reactor was also observed with L-3758 during Cycle 9 despite the mild reducing nature of the sulfidation gas employed, as discussed in Chapter 6 . The main cause of the reactor plugging was vaporization of zinc from the sorbent which condensed downstream from the reactor in a low temperature region. Analysis of XRD patterns for L-3758 showed the presence of some free zinc oxide and regions of zinc oxide and titanium oxide siggregation in the matrix.

To further confirm the zinc vaporization problem, a series of tests were made in the TGR, where both $Z T-5$ and $L-3758$ were subjected to a clean coal gas $\left(\mathrm{H}_{2} \mathrm{~S}\right.$-free coal gas) at $650^{\circ} \mathrm{C}$. In both cases, the samples lost weight as shown in Figure 7-3; however, the rate of weight loss for L-3758 was significantly higher than for ZT-5. This further corroborates that zinc oxide in the sorbent is easily accessible to $\mathrm{CC}$ and $\mathrm{H}_{2}$, and hence the sorbent is more prone to the reduction. 


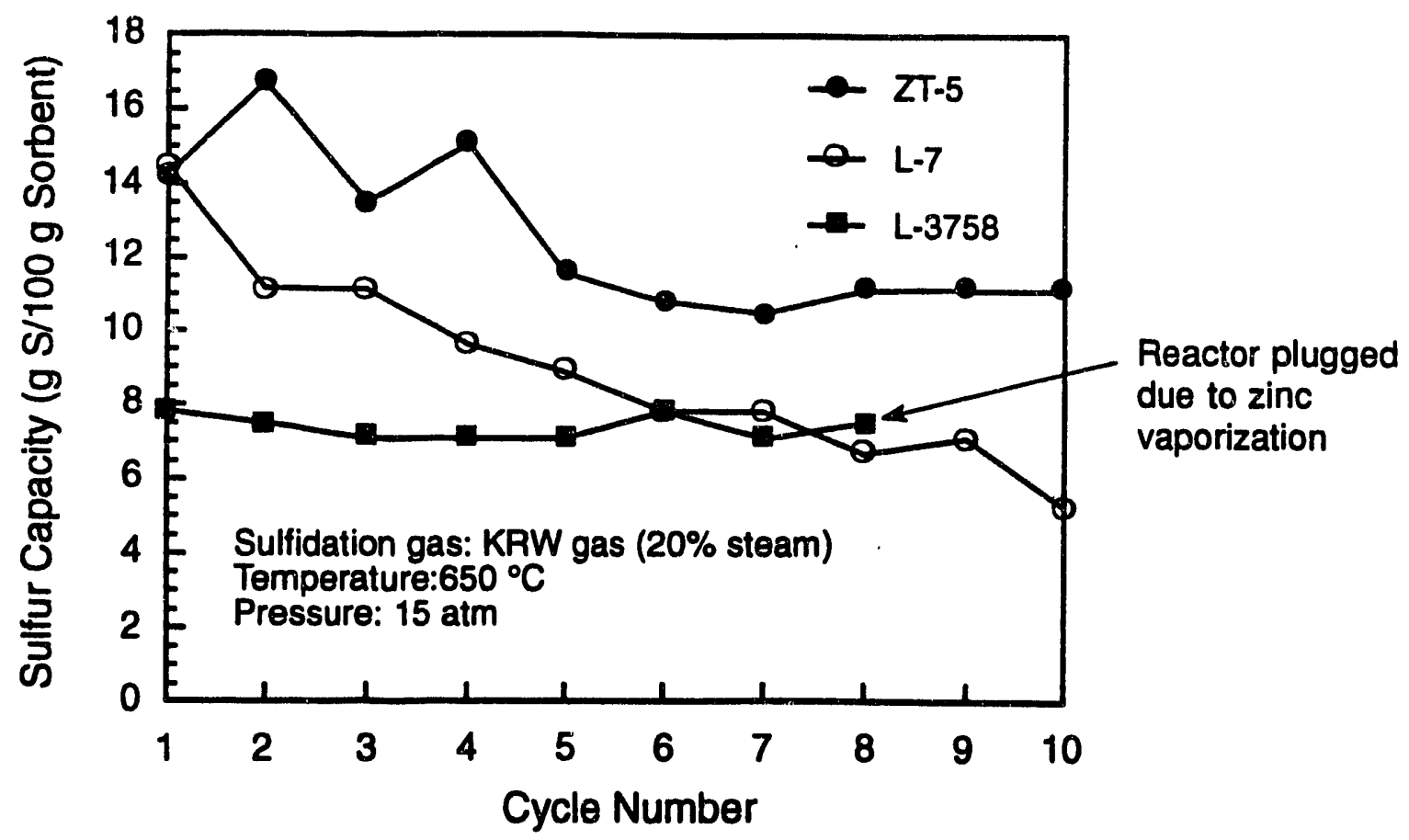

Figure 7-2. Sulfur capacities of various sorbents.

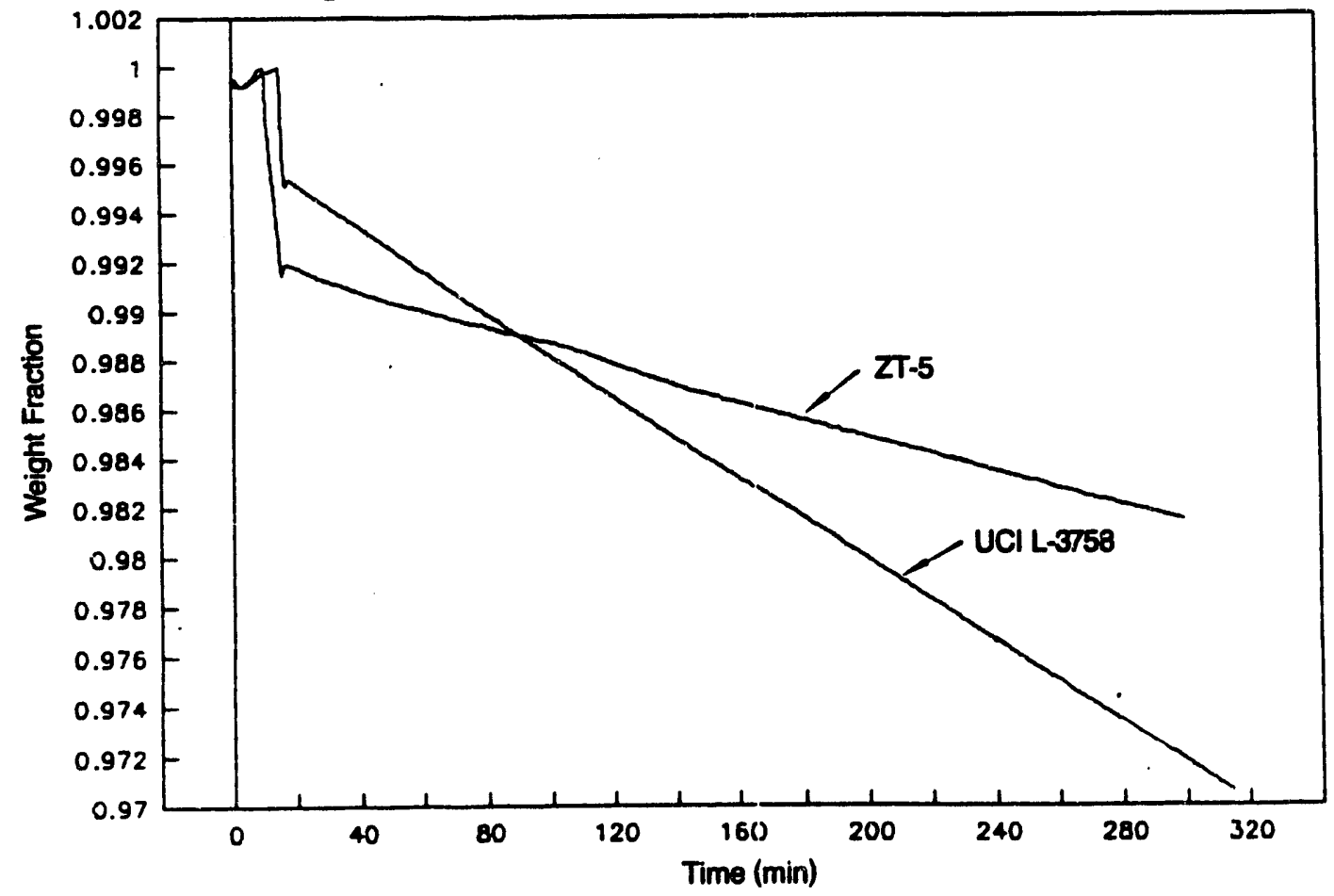

Figure 7-3. Zinc reduction proflles for L-3758 and ZT-5 in KRW reducing gas (20\% steam) at $650^{\circ} \mathrm{C}$. 
In addition to the higher reduction potential of L-3758 as compared to ZT-5, its attrition resistance was also very poor. Figure 7-4 shows attrition rates of various sorbents as a function of time. These data were taken in RTI's three-hole attrition tester (described in Section 4.2.6.2 of Chapter 4) at a gas flow rate of 15 slpm. The attrition rate shown in Figure 7-4 is defined as the amount of sorbent attrited per unit time. This rate is not a global rate but rather an instantaneous rate. For example, the attrition rate at a 2-h time is calculated as the amount of sorbent attrited and collected in the filter flask assembly between Hour 1 and Hour 2 divided by the duration which is $1 \mathrm{~h}$.

In addition to the attrition rates of L-3758 and ZT-5, Figure 7-4 also shows the data for $Z T-4$ and a commercial FCC catalyst. As can be seen, L-3758 has the highest attrition rate while $\mathrm{ZT}-4$ and FCC catalyst have very low rates. The attrition rate for ZT-5 is somewhere in-between. This issue is discussed further in Section 7.2.4.

\subsubsection{Effect of Sulfidation Temperature}

Data taken on zinc titanate sorbents in a fixed bed in RTl's previous contract indicated severe mass transfer limitations at high temperatures. However, in the fluidized bed, since the particle size is fairly small $(0.1$ to $0.3 \mathrm{~mm})$ as compared to the sorbent size used in a fixed bed ( $\sim 5$ to $10 \mathrm{~mm}$ extrudates), the mass transfer resistances are not expected to dominate. This was confirmed in RTI's previous topical report on zinc ferrite sorbents which showed that the sulfur capacity and reaction rates for L-7 zinc ferrite formulation at $625^{\circ} \mathrm{C}$ were more than 50 percent higher than that at $550^{\circ} \mathrm{C}$ (Gupta and Gangwal, 1991).

To verify this finding for zinc titanate sorbents, a series of runs were made using the ZT-5 formulation in the TGA at various temperatures. Figure 7-5 shows the conversion of $\mathrm{ZnO}$ as a function of time for various temperatures from 400 to $650^{\circ} \mathrm{C}$. As can be seen, the extent of conversion of $\mathrm{ZnO}$ to $\mathrm{ZnS}$ increases with an increase in temperature, indicating an increase in reaction rate with temperature. Preliminary calculations of activation energy for the sulfidation reaction indicate a value of about $15 \mathrm{kcal} / \mathrm{mol}$. Similar values of activation energies are also reported by Lew (1990). This issue of sulfidation kinetics is discussed further in Section 7.2.1.

In addition to the TGA data, bench-scale data collected at 650 and $750^{\circ} \mathrm{C}$ on $\mathrm{ZT}-4$ sorbent were also compared to determine the effect of temperature on the breakthrough behavior, and Figure 7-6 shows the results. In this figure, first-cycle breakthrough curves are compared for $\mathrm{ZT}-4$ (Runs no. 8 and 9). As expected, the reactivity of the sorbent at $750^{\circ} \mathrm{C}$, as indicated by the time taken for breakthrough, is significantly higher than at $650^{\circ} \mathrm{C}$. If one were to express this behavior in quantitative terms as will be discussed in Chapter 8 , the curve at $750^{\circ} \mathrm{C}$ will give rise to a rate constant which is about 2.2 times greater than the rate constant at $650^{\circ} \mathrm{C}$. Using the Arrehenius equation for these two temperatures will result in an activation energy value of about $15 \mathrm{kcal} / \mathrm{mol}$. This value is similar to one obtained using the TGA data as discussed earlier.

A comparison of sulfur capture capacities at these two temperatures is shown in Figure 7-7. The sulfur capture capacity at $750^{\circ} \mathrm{C}$ remains constant at around $12 \mathrm{~g} \mathrm{~S} / 100 \mathrm{~g}$ of 


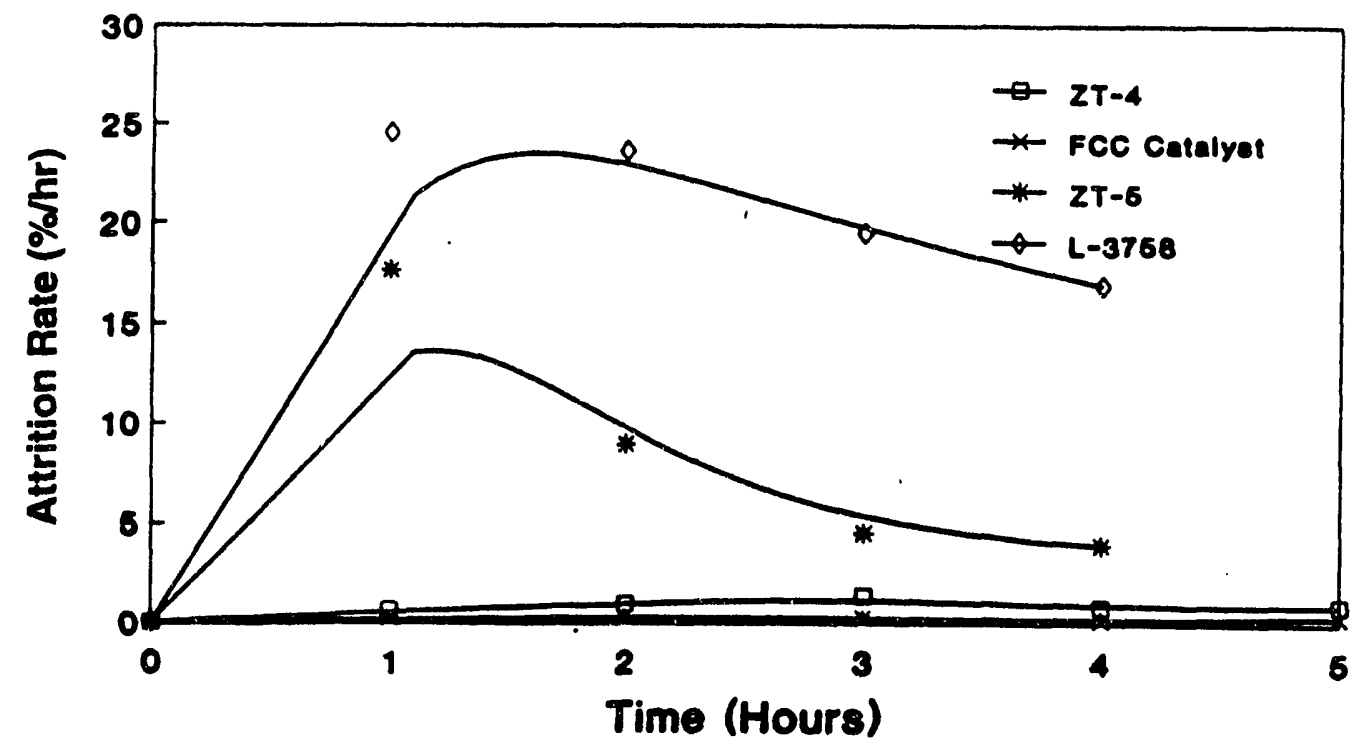

Figure 7-4. Attrition rates of various sorbents measured in three-hole attrition tester (15 sipm).

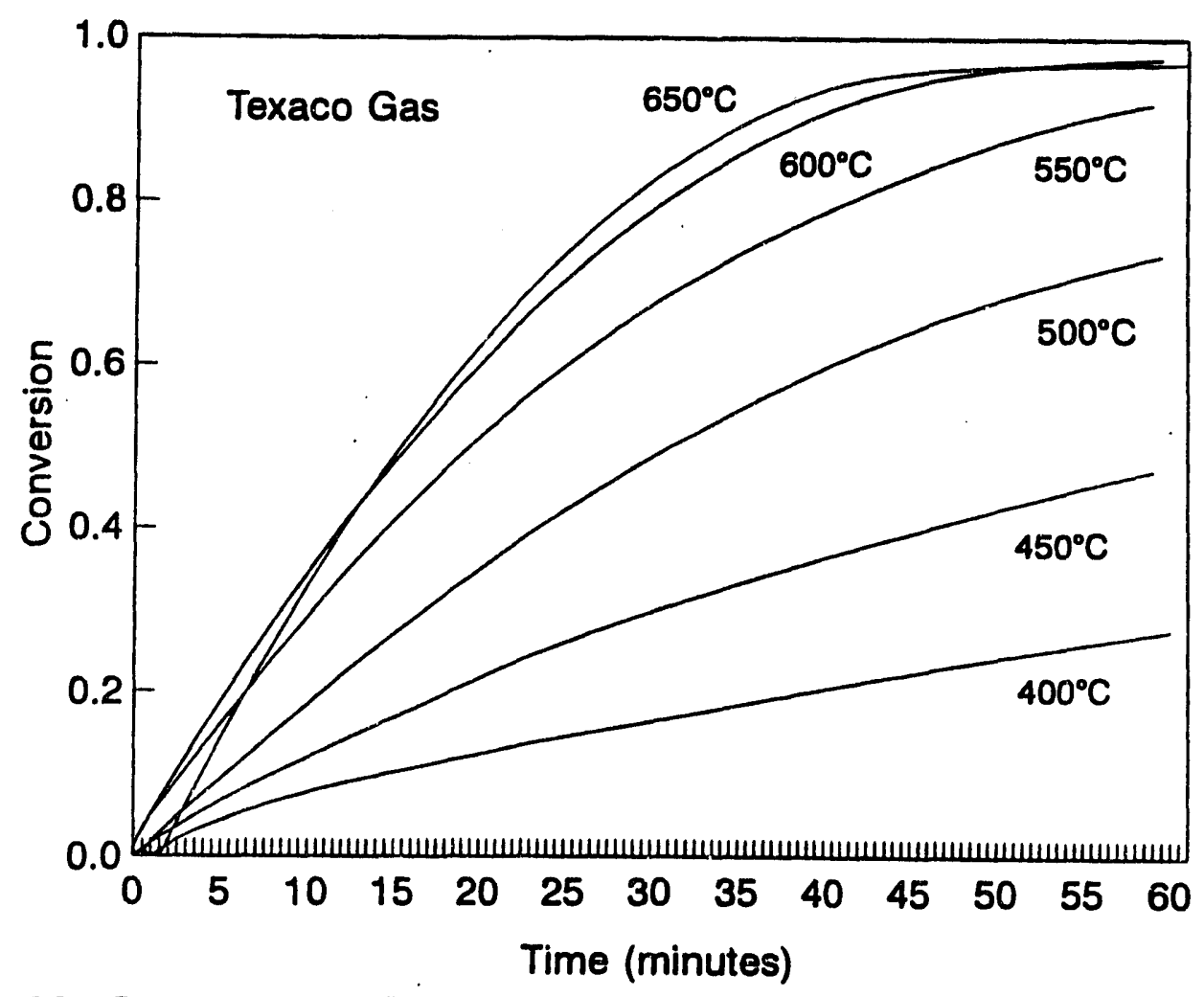

Figure 7-5. Conversion of $2 T-5$ at varlous temperatures in Texaco gas in a TGR. 


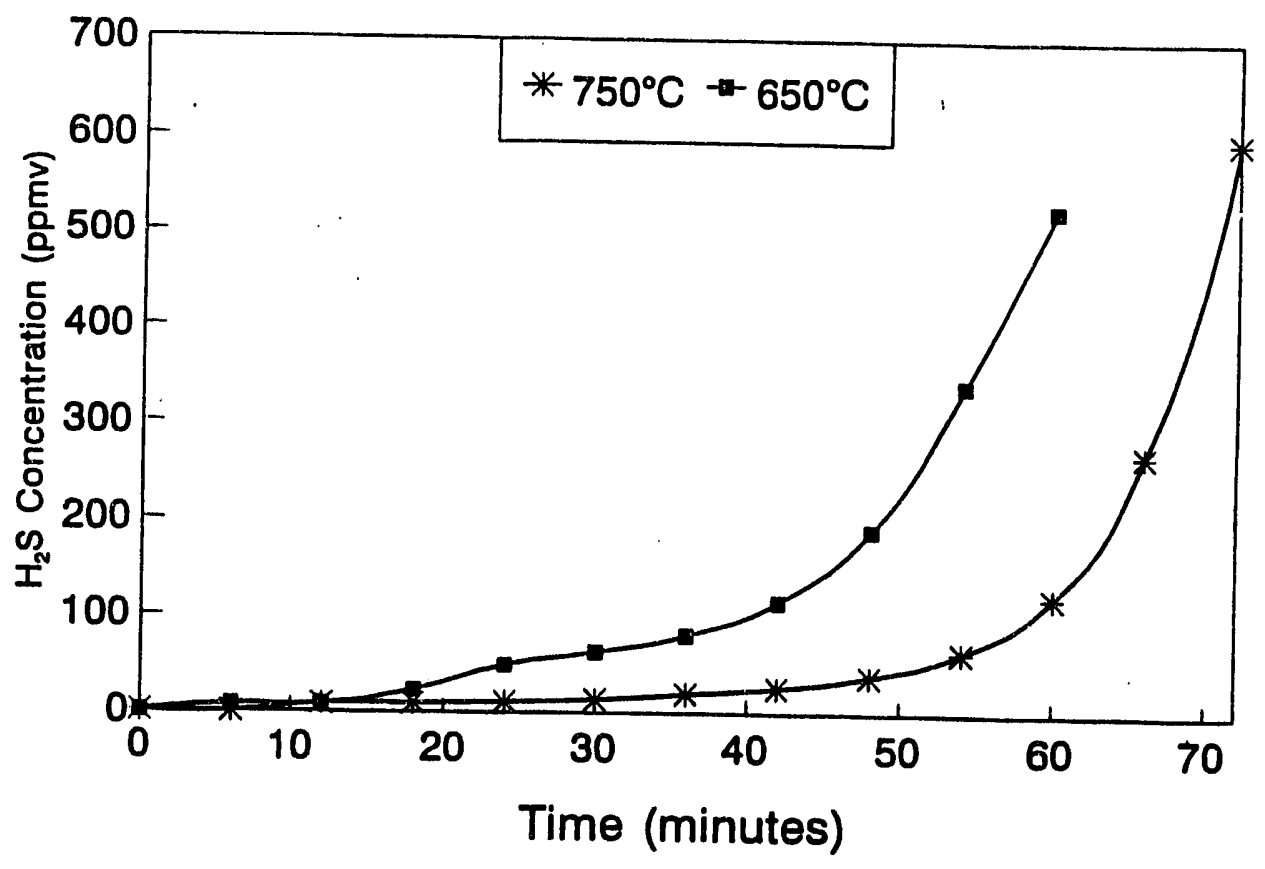

Figure 7-6. $2 T-4$ breakthrough curves at 650 and $7500^{\circ} \mathrm{C}$ in Texaco gas.

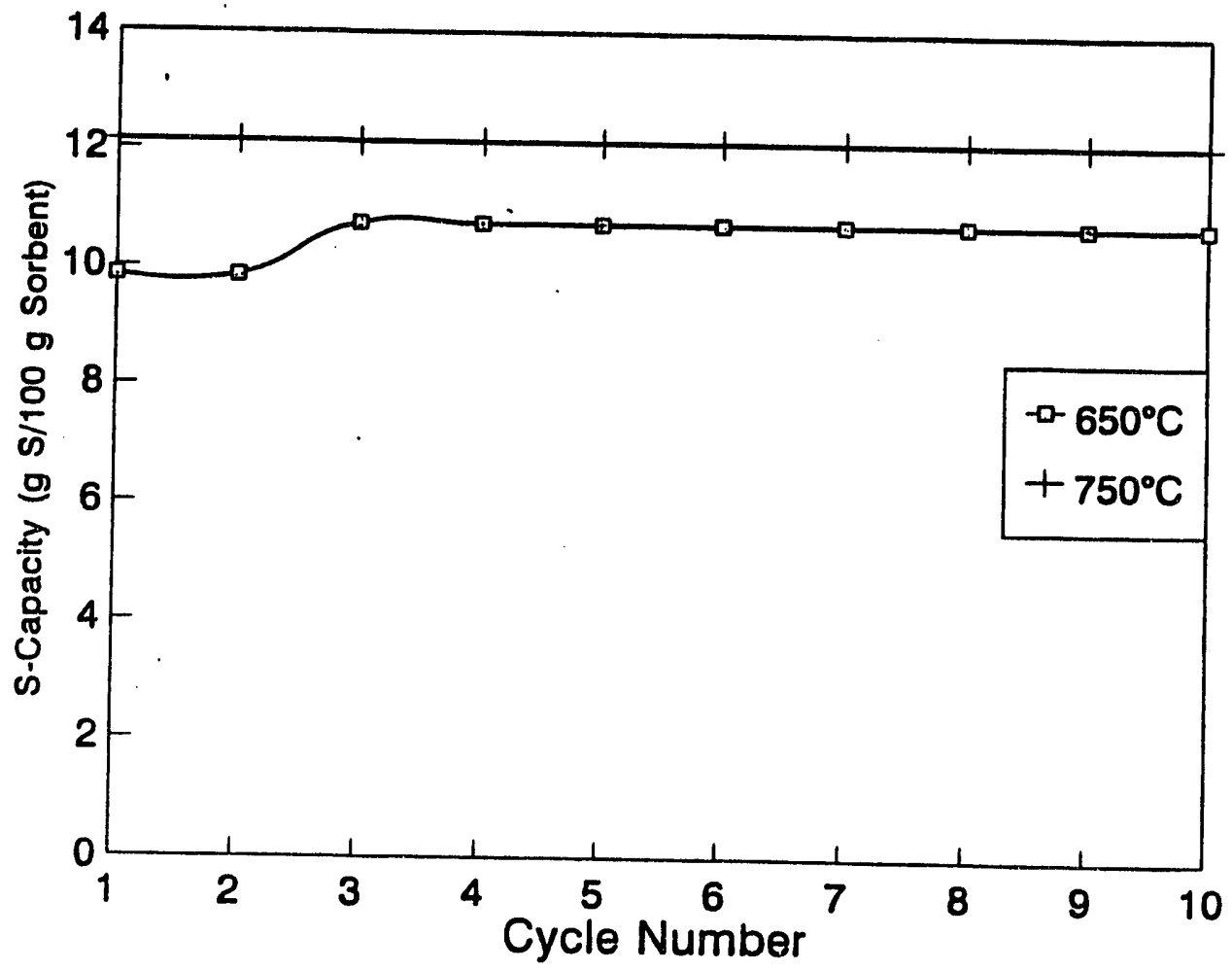

Figure 7-7. Sulfur capacitles of $Z T-4$ at 650 and $7500^{\circ} \mathrm{C}$. 
fresh sorbent through 10 cycles. The capacity at $650^{\circ} \mathrm{C}$ is 10 to 15 percent lower than at $750^{\circ} \mathrm{C}$ because of the slower kinetics.

Perhaps $750^{\circ} \mathrm{C}$ is believed to be an upper limit for zinc titanate sorbents beyond which excessive zinc vaporization may occur from the sorbent, as will be discussed in Section 7.2.3. Nonetheless, operating the desulfurization reactor in the vicinity of $750^{\circ} \mathrm{C}$ will lead to a relatively smaller reactor size due to the faster kinetics as compared to a lower temperature, for instance, $550{ }^{\circ} \mathrm{C}$. Furthermore, the cooling duty of the syngas cooler will be drastically reduced, considering the volume of gas from the gasifier. However, operation of the desulfurization reactor at $750^{\circ} \mathrm{C}$ may create some problems in terms of removal of alkali and other air toxics.

\subsubsection{Effect of Superficlal Gas Velocity}

As discussed in Chapter 6, nine out of ten 10-cycle tests were made at a superficial velocity that was about three to four times that of incipient fluidization velocity $\left(U_{m f}\right)$, also called minimum fluidization velocity. This value translated into a superficial velocity of 6 to $8 \mathrm{~cm} / \mathrm{s}$. Since most of the commercial bubbling-bed fluidized-bed reactors are operated at a velocity ranging between 0.5 to $3 \mathrm{ft} / \mathrm{s}$, it was important to study the effect of superficial gas velocity.

Figure 7-8 shows a comparison of the $\mathrm{H}_{2} \mathrm{~S}$ breakthrough curves for $\mathrm{ZT}-4$ at 0.25 and 0.5 $\mathrm{ft} / \mathrm{s}$ velocities at $750^{\circ} \mathrm{C}, 15 \mathrm{~atm}$ and in Texaco gas in the first cycle. It is to be noted here that doubling the gas flow rate in the high-velocity run reduced the breakthrough time since the $\mathrm{H}_{2} \mathrm{~S}$ content of the feed gas was kept the same in both cases at about $12,000 \mathrm{ppm}$. Therefore, the reduction in breakthrough time shown in Figure 7-8 should not be viewed due to the reduction in sorbent chemical reactivity because of an increase in gas velocity.

Indeed, the sulfur capacity for the sorbent at $0.5 \mathrm{ft} / \mathrm{s}$ increased by 11 percent from a value of 12.12 to $13.42 \mathrm{~g} \mathrm{~S}$ per $100 \mathrm{~g}$ of fresh sorbent. This increase in sulfur capacity due to an increase in gas velocity indicates that better contact between gas and particles may lead to a slight increase in global reaction rate. This issue is discussed further if Chapter 8.

\subsubsection{Effect of Binders}

As discussed in Chapter 5, a series of binders were investigated in this study, including bentonite, kaolinite, forsterite, etc. Based on the bench-scale test data, it may be concluded that perhaps bentonite offers the best binding properties at high temperature, although sorbents prepared using kaolinite were never subjected to bench-scale testing. Initial screening of sorbent formulations prepared using kaolinite had showed encouraging performance, as discussed in Section 5.3.3.

The next issue was the optimum level of bentonite needed for the best periormance. To answer this question, both the TGA and bench-scale data showed that the sorbent formulations containing 5 percent bentonite exhibit better attrition resistance than those containing 2 percent bentonite. The difference in sulfur capacity in the two cases is insignificant. The performance of sorbents containing more than 5 percent bentonite has not been investigated. Increasing the bentonite level to 10 or even 15 percent may result in a product with better attrition resistance than $2 T-4$ (the best formulation thus far). This, however, remains to be explored. 


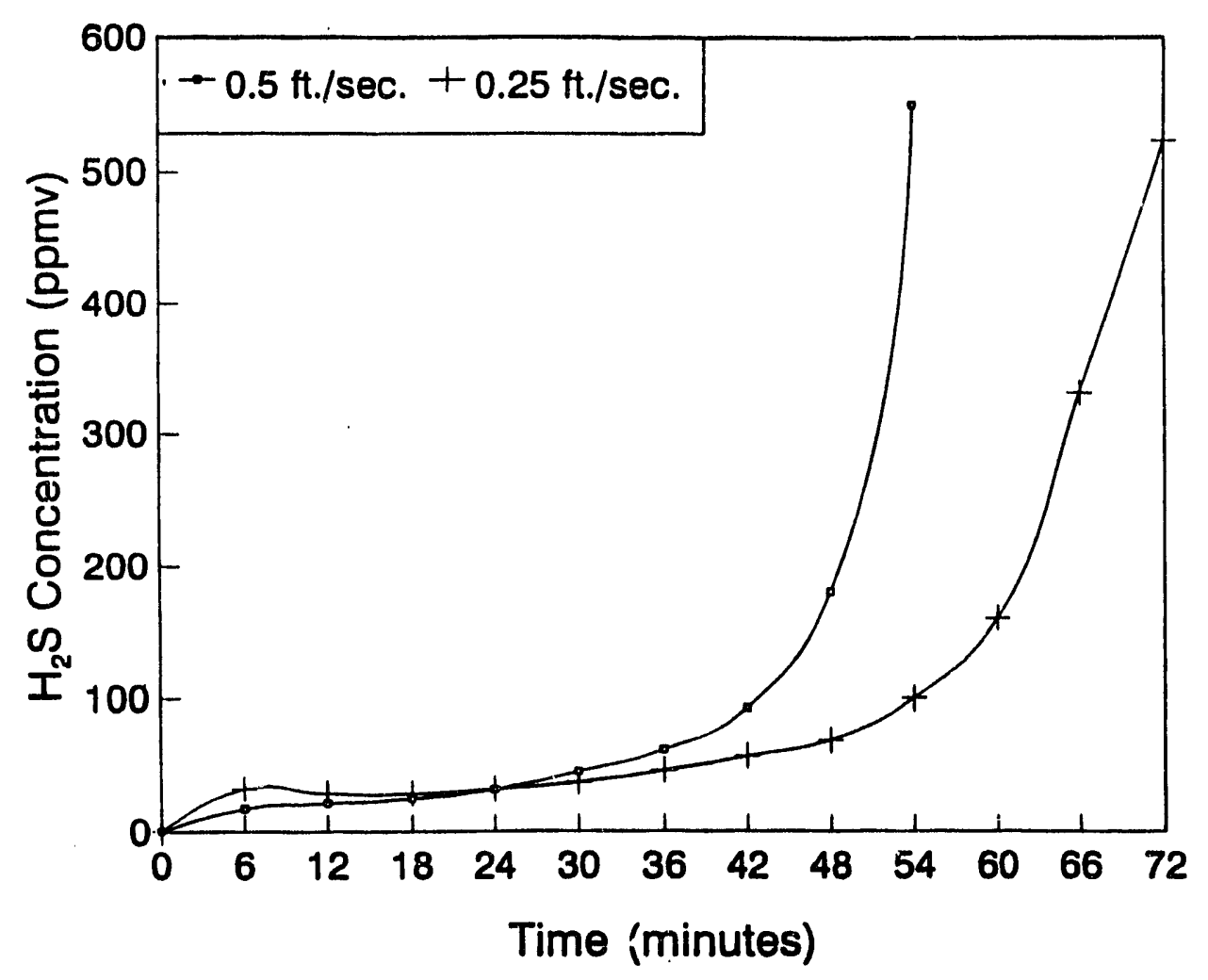

Figure 7-8. Breakthrough behavior of $\mathrm{ZT}-4$ at $750^{\circ} \mathrm{C}$ at low and high superficlal velocltles.

\subsubsection{Effect of Gas Composition}

One of the major objectives of this study was to demonstrate the applicability of zinc titanate sorbents for highly reducing gases for which zinc ferrite would not work. As discussed in Chapter 6, three gas compositions were investigated. Figure 7-9 shows the sulfur capacities of ZT-5 at $650^{\circ} \mathrm{C}$ with three coal gas compositions (given in Table 6-3). As can be seen, in all three cases, the sorbent consistently exhibits 60 to 80 percent of its theoretical capacity without appreciable drop during multicycle testing. The solid line in Figure 7-9 indicates the theoretical capacity based on a $\mathrm{ZnO}$ to $\mathrm{TiO}_{2}$ ratio of 1.5 .

The effect of gas composition was also investigated with a zinc titanate formulation (ZT-2) that contained zinc and titanium in an atomic ratio of 0.8 . Figure 7-10 shows a comparison of the sulfur capacities for Texaco gas and KRW gas with 5 percent steam at $650^{\circ} \mathrm{C}$ and $15 \mathrm{~atm}$. Experimentally measured sulfur capacities of ZT-2, as shown in Figure 7-10, are 70 to 80 percent of the theuretical capacity (shown by the solid line), again with very little, if any, decline during multicycle testing.

No evidence of either loss in attrition resistance or breakdown of pore structure was observed in any of the gas compositions used for both ZT-5 and ZT-2 formulations. Negligible zinc loss was observed even in the case of highly reducing gas such as KRW with 5 percent steam. 


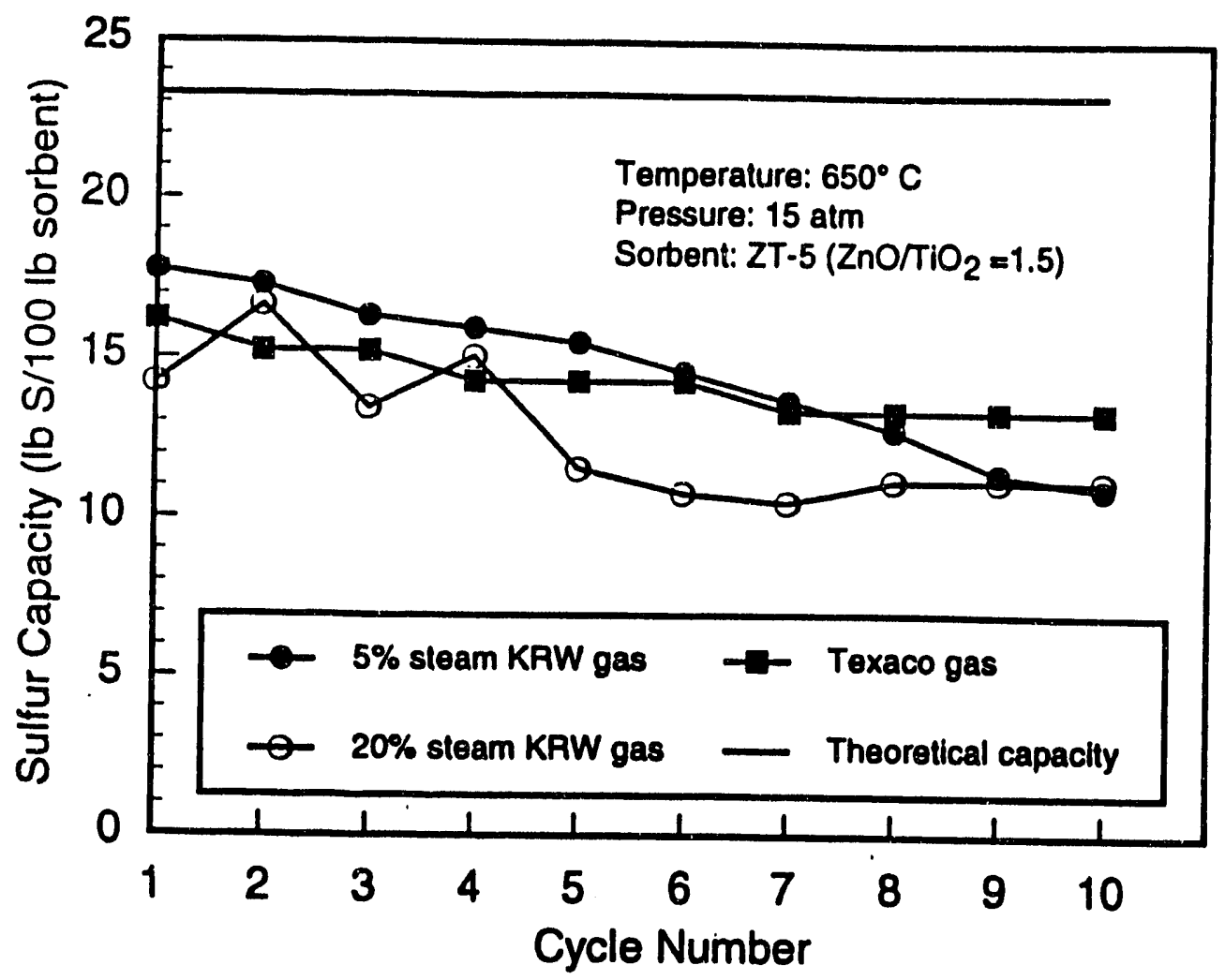

Figure 7-9. Sulfur capacities of ZT-5 sorbent in varlous coal gases.

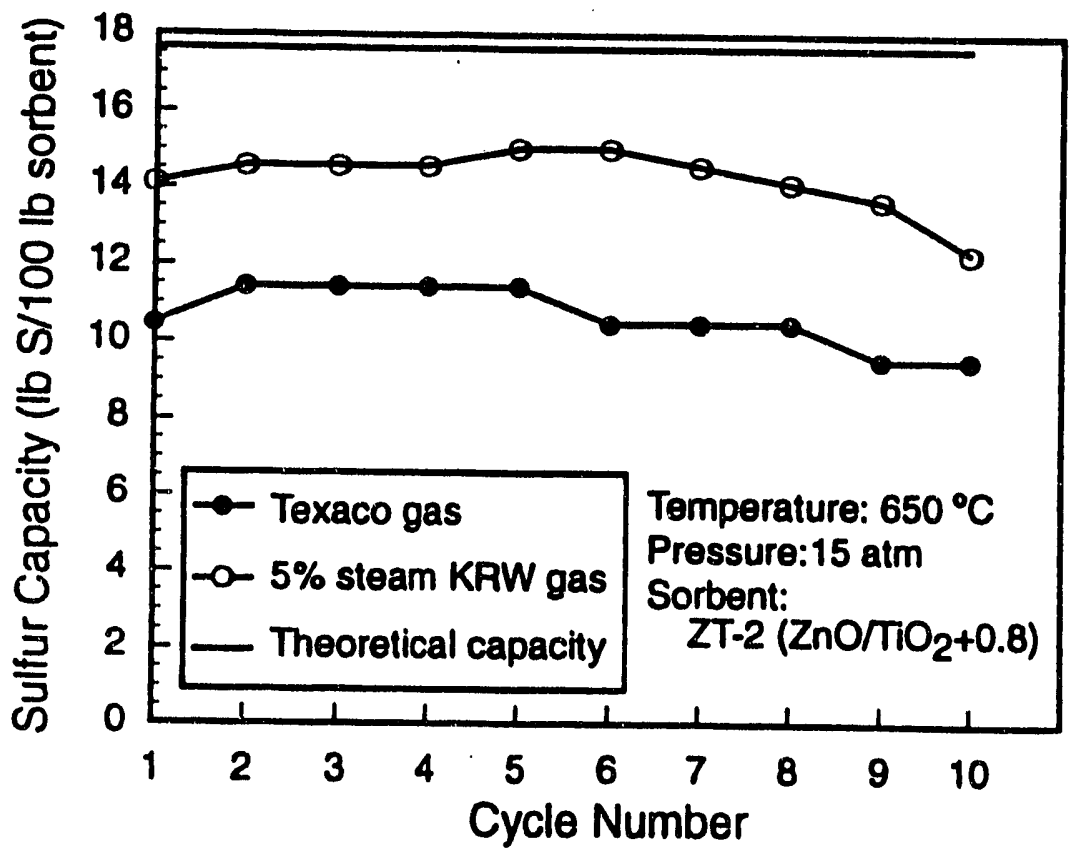

Figure 7-10. Sulfur capacitles of ZT-2 sorbent in various coal gases. 


\subsubsection{Effect of $\mathrm{Zn}$ to TI Ratio}

Previous studies have shown that a zinc titanate sorbent with a $\mathrm{Zn}$ to $\mathrm{Ti}$ atomic ratio of either 0.8 or 1.5 provides the best performance, both in terms of chemical reactivity and resistance to zinc vaporization (Woods et al., 1989; Lew, 1990). Both ratios will lead to a formulation that will contain one or more zinc titanate phases $\left(\mathrm{ZnTiO}{ }_{3}, \mathrm{Zn}_{2} \mathrm{TiO}_{4}\right.$, and $\left.\mathrm{Zn}_{2} \mathrm{Ti}_{3} \mathrm{O}_{8}\right)$, and some free $\mathrm{TiO}_{2}$ that can be present in either rutile or anatase furm. The presence of free $\mathrm{ZnO}$ cannot be tolerated in the sorbent because it will initiate zinc vaporization via the reduction reaction.

As discussed previously, both $\mathrm{ZT}-5(\mathrm{Zn} / \mathrm{Ti}=1.5)$ and $\mathrm{ZT}-2(\mathrm{Zn} / \mathrm{Ti}=0.8)$ exhibited excellent performance in terms of sulfur capacity and attrition resistance, and negligible zinc loss was detected even in the presence of highly reducing gas. It was thought that perhaps a sorbent with the highest possible $\mathrm{Zn}$ to $\mathrm{Ti}$ ratio should be selected to obtain the maximum possible sulfur loading. Therefore, Runs no. 8, 9, and 10 were made with $Z T-4$, which contained $Z n$ to $T i$ in a mol ratio of 1.5 .

Recently, some concerns have been expressed regarding nonstoichoimetric ratios that lead to free $\mathrm{TiO}_{2}$ in the matrix (Darta, 1992). It is being argued that a $\mathrm{Zn} / \mathrm{Ti}$ ratio of 1 and 2 should be used in place of 0.8 and 1.5, respectively, to form nearly pure $Z n T_{10}$ and $Z n_{2} T_{10}$ phases. This is expected to minimize the breakdown of sorbent structure due to the different expansion properties of $\mathrm{TiO}_{2}$ and zinc titanate. While it is difficult to clearly identify whether the present formulations have either a spinel or an illmenite-type structure mainly because of uncertainty in the identification of various XRD phases, it nonetheless can be said that perhaps a solid solution of one of the zinc titanate phases with $\mathrm{TiO}_{2}$ is present. It has also been found previously that zinc titanates with predominantly $\mathrm{Zn}_{2} \mathrm{TiO}_{4}$ phase structure have lower reactivity than those with only $\mathrm{ZnTiO}_{3}$ structure (Gangwal et al., 1988). Also, it is expected that sorbents with a zinc to titanium ratio of 2 will be significantly more prone to zinc vaporization at $750^{\circ} \mathrm{C}$ than one with a ratio of 1 . Therefore, it is recommended that this issue be addressed at a fundamental level to clearly understand the role of $\mathrm{TiO}_{2}$ in preventing zinc vaporization.

\subsection{ADDRESS REACTOR DESIGN ISSUES}

Having described the effect of various process variables on the performance of zinc titanate sorbents, the rest of this chapter is devoted to addressing a number of issues that are critically important in the design and optimization of a commercial hot-gas desulfurization system. Some of these issues are described below.

\subsubsection{Sulfidation KInetlos}

The rate of sulfidation for fixed-and moving-bed pellets of zinc titanate has been reported to be well represented by the shrinking unreacted-core model (Woods et al., 1989), in which the diffusion through the ash layer primarily controls the rate of reaction. This model predicts that the rate of sulfidation increases significantly with $\mathrm{H}_{2} \mathrm{~S}$ scencentration. However, the effect of temperature on the rate is quite small because the rate is controlled by a diffusion process which has a very small activation energy.

The controlling regime, on the other hand, was found to be primarily kinetic for the fluidizable 100 to $300 \mu \mathrm{m}$ zinc titanate particles evaluated in this study. The effect of temperature 
on the prebreakthrough $\mathrm{H}_{2} \mathrm{~S}$ absorption capacity shown in Section 7.1.1 was to significantly increase the capacity, indicating kinetic control of the reaction. This means that operating a reactor at higher temperature would result in a smaller reactor and thus reduced capital cost and sorbent requirement. Thus, it is of significant interest to evaluate the kinetics of the sulfidation reaction. Preliminary kinetic data were obtained using a TGA and are reported in the following sections.

The TGA runs were conducted in Texaco gas at a series of temperatures for sorbents $Z T-5$ and ZT-2. These are shown in Figures 7-5 and 7-11. As seen from these figures, the conversion (defined as fractional sulfidation of available $\mathrm{ZnO}$ in the sorbent) increases more rapidly as temperature is increased in the temperature range from 400 to $550{ }^{\circ} \mathrm{C}$, but mass transfer limitations of the TGA pan are experienced at temperatures above $500^{\circ} \mathrm{C}$. The rate data were fitted to an assumed rate equation of the following form for the reaction: $\mathrm{ZnO}+\mathrm{H}_{2} \mathrm{~S} \rightarrow \mathrm{ZnS}$ $+\mathrm{H}_{2} \mathrm{O}$.

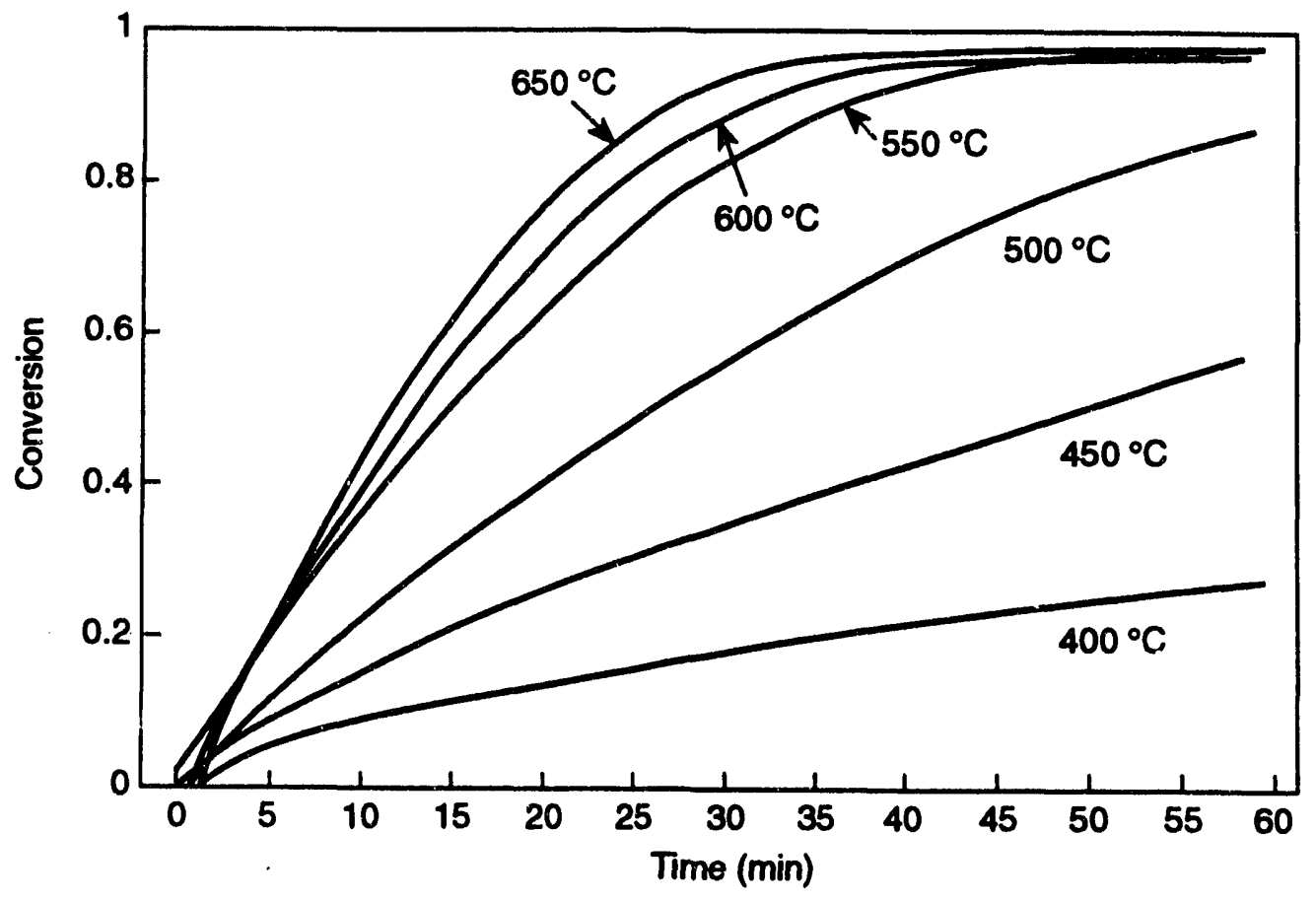

Figure 7-11. TGA reactivitles of $\mathrm{ZT-2}$ sorbent at various temperatures in Texaco gas. 


$$
r_{\mathrm{ZnO}}=-\frac{d C_{\mathrm{ZnO}}}{d t}=k^{\prime} C_{\mathrm{H}_{2} \mathrm{~s}} \cdot C_{\mathrm{ZnO}}
$$

where

$$
\begin{array}{ll}
\mathrm{r}_{\mathrm{ZnO}}=\text { rate of consumption of } \mathrm{ZnO}, & \frac{\mathrm{mol} \mathrm{ZnO}}{\mathrm{cm}^{3} \text { sorbent } \cdot \mathrm{s}} \\
\mathrm{C}_{\mathrm{ZnO}}=\text { concentration of } \mathrm{ZnO}, & \frac{\mathrm{mol} \mathrm{ZnO}}{\mathrm{cm}^{3} \text { sorbent }} \\
\mathrm{C}_{\mathrm{H}_{2} \mathrm{~S}}=\text { concentration of } \mathrm{H}_{2} \mathrm{~S}, & \frac{\mathrm{mol} \mathrm{H}_{2} \mathrm{~S}}{\mathrm{~cm}^{3} \mathrm{gas}} \\
\mathrm{K}^{\prime}=\text { rate constant, } & \frac{\mathrm{cm}^{3} \text { gas }}{\mathrm{mol} \mathrm{H}_{2} \mathrm{~S} \cdot \mathrm{s}}
\end{array}
$$
Since in a TGA the concentration of $\mathrm{H}_{2} \mathrm{~S}$ remains constant, the $\mathrm{K}^{\prime} \mathrm{C}_{\mathrm{H}_{2}} \mathrm{~S}$ was lumped into a pseudo
first-order rate constant $k$, leading to

$$
r_{\mathrm{ZnO}}=-\frac{d C_{\mathrm{ZnO}}}{d t}=k C_{\mathrm{ZnO}}
$$

where $k=k^{\prime} C_{\mathrm{H}_{2}} s=$ pseudo first-order rate constant, $s^{-1}$ for TGA batch systems.

The fractional conversion, $x$, is defined as

$$
x=\frac{C_{\mathrm{ZnO}, 0}-C_{\mathrm{ZnO}}}{C_{\mathrm{ZnO}, 0}}
$$

where $C_{Z n O, O}=$ initial $\mathrm{ZnO}$ concentration, $\frac{\text { mol }}{\mathrm{cm}^{3} \text { particle }}$

Substitution of (7-3) in (7-2) leads to

$$
\frac{d x}{d t}=k(1-x)
$$


which, upon integration with initial condition $x=0$ at $t=0$, leads to

$$
-\ln (1-x)=k t \text {. }
$$

Plotting -In (1-x) against $t$ and evaluating the slope of the resulting line would yield $k$, the pseudo first-order rate constant. It was found that at low conversions, Equation (7-5) yielded a reasonable straight line. The initial $k$ was evaluated in this manner at various temperatures and was fit to an Arrhenius equation $k=A \exp \left(-\frac{E}{R T}\right)$

where

$$
\begin{aligned}
& A=\text { frequency factor, } \mathrm{s}^{-1} \\
& E=\text { activation energy, cal } / \mathrm{mol} \\
& R=\text { gas constant, } 1.987 \mathrm{cal} / \mathrm{mol} \\
& T=\text { absolute temperature, } \mathrm{K} .
\end{aligned}
$$

The Arrhenius plots of $Z T-5$ and $Z T-2$ are shown in Figure 7-12. A reasonable straight line correlation is seen in the 400 to $550^{\circ} \mathrm{C}$ temperature range. The Arrhenius equations for the initial $k$ for ZT-5 and ZT-2 in Texaco gas are as follows:

$$
\begin{aligned}
& \text { ZT-5: } \quad k=4.3754 \exp \left(\frac{-14,391}{R T}\right) \\
& \text { ZT-2 : } \quad k=51.77 \exp \left(\frac{-17,634}{R T}\right) .
\end{aligned}
$$

The relative magnitudes of E, i.e., 14 to $17 \mathrm{kcal} / \mathrm{mol}$, strongly suggest that the sulfidation reaction is controlled by intrinsic reaction kinetics rather than external or pore diffusion. In an actual fast fluidized bed, mass transfer limitations would be virtually non-existent even at temperatures up to $750^{\circ} \mathrm{C}$ (as seen by the data in Section 7.1.1). Thus, Equations (7-6) and (7-7) could be extrapolated to higher temperatures without sacrificing much accuracy. In a previous investigation, Woods et al. (1989) obtained activation energy of the order of $14 \mathrm{kcal} / \mathrm{mol}$ for sulfidation of zinc ferrite as well.

As a cautionary note, Equations (7-6) and (7-7) give $k$ values at low sorbent conversion for a single $\mathrm{H}_{2} \mathrm{~S}$ concentration corresponding to Texaco gas. A similar study needs to be conducted for several $\mathrm{H}_{2} \mathrm{~S}$ concentrations and at higher sorbent conversions so that $k^{\prime}$ can be obtained for use in Equation (7-1), which will be necessary for determining the sorbent requirement in a commercial reactor system. A commercial continuous fluid-bed sulfider is expected to operate in a nearly perfectly mixed mode for solid and close to plug-flow for gas, as 


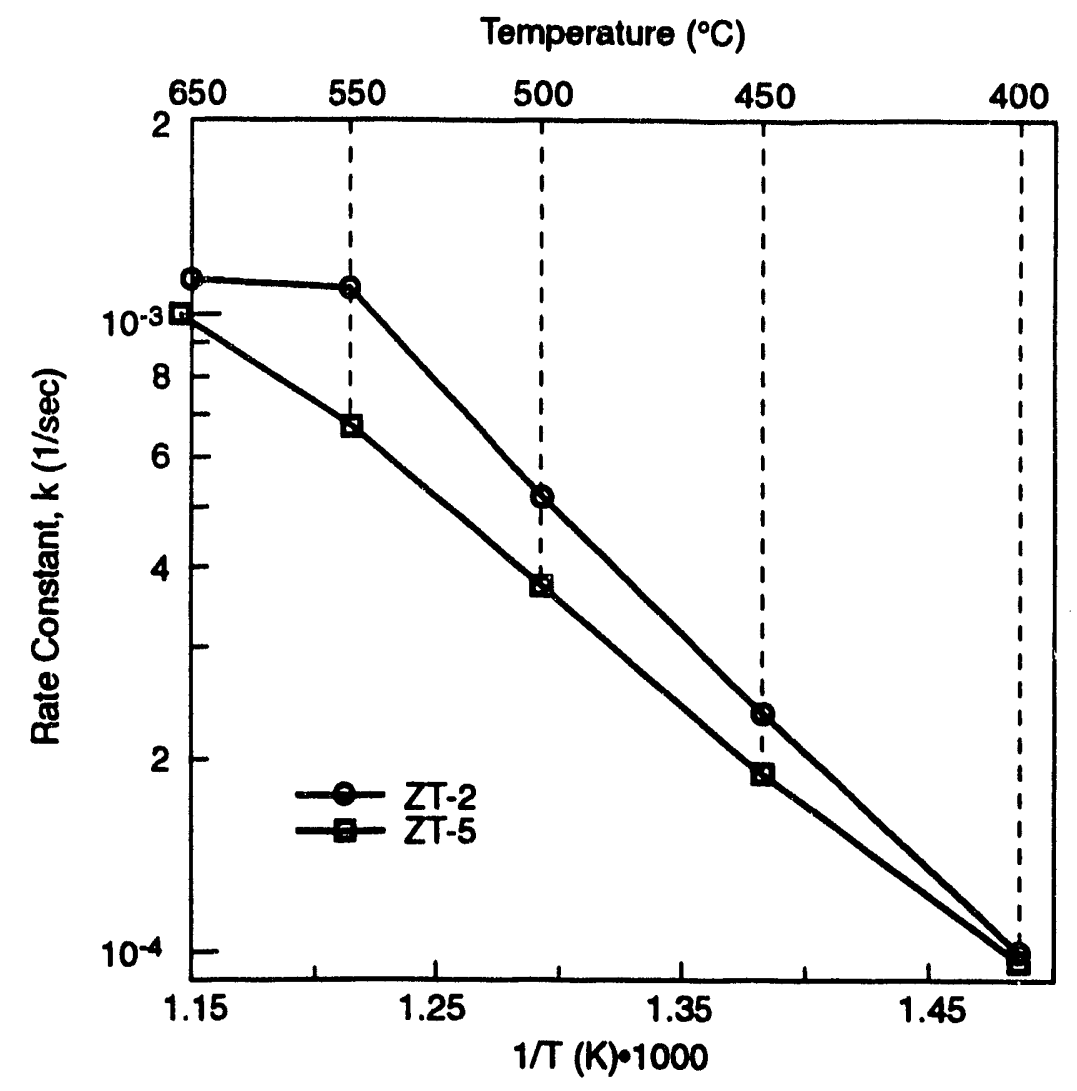

Figure 7-12. Arrehenlus plot for ZT-2 and ZT-5.

described in Chapter 8 . Thus, $C_{z n o}$ in a continuous sulfider may be nearly constant whereas $\mathrm{C}_{\mathrm{H}_{2} \mathrm{~s}}$ will vary in plug flow across the bed from the inlet value to a very low value at the outlet.

Since $\mathrm{C}_{\mathrm{zno}}$ can be assumed to be a constant for the continuous system, it can be lumped into the rate constant to yield a pseudo first-order rate constant $k_{1}$ for the commercial system.

$$
r_{\mathrm{H}_{2} \mathrm{~S}}=k_{1} \mathrm{C}_{\mathrm{H}_{2} \mathrm{~S}}
$$

where

$$
\begin{aligned}
& r_{H_{2} S}=\text { rate of consumption of } H_{2} S \text { in } \frac{\text { mol }}{g \text { sorbent } \cdot \mathrm{s}} \\
& k_{1}=\text { pseudo first-order rate constant for continuous sulfider } \frac{\mathrm{cm}^{3} \text { gas }}{\mathrm{g} \mathrm{sorbent} \cdot \mathrm{s}}
\end{aligned}
$$

Equation (7.3) can be used to calculate the required amount of sorbent in a commercial unit. Plug flow assumption leads to

$$
W=F_{A O} \cdot \int_{0}^{x_{A}} \frac{d x_{A}}{r_{H_{2} S}}
$$


where

$$
\begin{aligned}
& W=\text { mass of sorbent required } \\
& X_{A}=H_{2} S \text { fractional conversion } \\
& F_{A O}=H_{2} S \text { molar flow rate to the reactor mol/s. }
\end{aligned}
$$

The $\mathrm{H}_{2} \mathrm{~S}$ fractional conversion is defined as

$$
x_{A}=\frac{C_{H_{2} S, 0}-C_{H_{2} S}}{C_{H_{2} S, 0}}
$$

where

$$
\mathrm{C}_{\mathrm{H}_{2} \mathrm{~S}, 0}=\text { inlet } \mathrm{H}_{2} \mathrm{~S} \text { concentration, } \frac{\mathrm{mol}}{\mathrm{cm}^{3} \text { gas }} \text {. }
$$

Substituting Equations (7-8) and (7-10) in (7-9) and integration lead to the equation

$$
W=\frac{F_{A O}}{k_{1} C_{A 0,0}} \ln \left(\frac{1}{1-x_{A}}\right)
$$

If the volumetric flow rate $\left(\mathrm{cm}^{3}\right.$ of gas $\left./ \mathrm{s}\right)$ at reactor conditions is defined as $v_{0}$, then

$$
v_{0}=\frac{F_{A O}}{C_{A 0,0}} \text {. }
$$

Substituting Equation (7-12) in (7-11) leads to the design equation

$$
W=\frac{v_{0}}{k_{1}} \ln \left(\frac{1}{1-x_{A}}\right)
$$

which can be used to calculate the sorbent inventory requirement in a commercial system.

Based on experience with the TGA, an approximate $k_{1}$ value for fluidized zinc titanate particles is in the 2 to $8 \mathrm{~cm}^{3} \mathrm{gas} /(\mathrm{g}$ sorbent $\cdot \mathrm{s})$ range; $k_{1}$ is a strong function of temperature. Thus, a typical value at $550{ }^{\circ} \mathrm{C}$ might be close to $2 \mathrm{~cm}^{3}$ gas $/(g$ sorbent $\cdot s)$ whereas at $725^{\circ} \mathrm{C}$ it might be close to $8 \mathrm{~cm}^{3} \mathrm{gas} /(\mathrm{g}$ sorbent $\cdot \mathrm{s})$. 
Using the above approximate $k_{1}$ values, sorbent inventory required in the sulfider was calculated for a $100 \mathrm{MW}$ plant employing the Texaco $\mathrm{O}_{2}$-blown gasifier. A gas flow of $10,000 \mathrm{lb}$ $\mathrm{mol} / \mathrm{h}$ is assumed for the plant. The results are shown in Table 7-1.

Table 7-1. Sulfider Sorbent Requirement for a 100-MW Texaco Plant

\begin{tabular}{ccc}
\hline & \multicolumn{2}{c}{ Sorbent required $(\mathrm{kg})$} \\
\cline { 2 - 3 } Sulfider temperature $\left({ }^{\circ} \mathrm{C}\right)$ & $\begin{array}{c}99 \% \text { removal } \\
\left(x_{A}=0.99\right)\end{array}$ & $\begin{array}{c}99.9 \% \text { removal } \\
\left(x_{A}=0.999\right)\end{array}$ \\
\hline 550 & 9,800 & 14,700 \\
725 & 2,970 & 4,455 \\
\hline \hline
\end{tabular}

Assumptions: Gas flow $=10,000 \mathrm{lb} \mathrm{mol} / \mathrm{h}$; pressure $=20 \mathrm{~atm}$

$k_{1}=2 \mathrm{~cm}^{3} /(g \cdot$ sorbent $\cdot \mathrm{s})$ at $550^{\circ} \mathrm{C}$

$k_{1}=8 \mathrm{~cm}^{3} /(\mathrm{g} \cdot$ sorbent $\cdot \mathrm{s})$ at $725^{\circ} \mathrm{C}$

Thus, a significant advantage in terms of sorbent requirement is seen at higher temperature. This suggests that the sulfider should be operated at the highest possible temperature that is consistent with sorbent integrity. This temperature limit is yet to be established for the zinc titanates developed here for gases of different reducing powers. As reducing power increases, this limit is expected to be lower because of potential for increased zinc vaporization. For the Texaco gas with about 18 percent steam, ZT-4 did not show any signs of degradation at temperatures up to $750^{\circ} \mathrm{C}$.

As a cautionary note, the previous analysis is based on reasonable but assumed rate constants. A rigorous kinetic study is required to evaluate the sorbent inventory more precisely and would be required prior to actual design of the commercial unit.

\subsubsection{Sorbent Regeneration}

Regeneration of sulfided zinc titanate is a highly exothermic reaction. The desirable reaction, $\mathrm{ZnS}+(3 / 2) \mathrm{O}_{2} \rightarrow \mathrm{ZnO}+\mathrm{SO}_{2}$, occurs with ar enormous heat of reaction $(-70.7 \mathrm{kcal} / \mathrm{mol}$ of $\mathrm{O}_{2}$ consumed). To prevent excessive temperature rise, which may lead to sorbent sintering, an air-diluent mixture (typically air-steam or air-nitrogen) is used for the regeneration with an oxygen concentration of about 1 to 5 vol percent. On the other hand, if regeneration is not carried out at a sufficiently high temperature, a competing sulfation reaction, $\mathrm{ZnS}+2 \mathrm{O}_{2} \rightarrow$ $\mathrm{ZnSO}_{4}$, may occur leading to incomplete regeneration. Experience with fixed-bed zinc titanate sorbents (Gangwal et al., 1988) led to a temperature window of 725 to $780{ }^{\circ} \mathrm{C}$ for elevated pressure regeneration. A temperature of $760^{\circ} \mathrm{C}\left(1400^{\circ} \mathrm{F}\right)$ was found to be ideal for preventing both sulfate formation and excessive surface area loss due to sorbent sintering as discussed below.

\subsubsection{Experimental Results}

Regenerations were conducted on fluidizable zinc titanate as a function of oxygen concentration to evaluate temperature rise, regeneration stoichiometry, regeneration rate, and 
residual sulfate formation, if any. All of these experiments were conducted with an inlet regeneration flow rate of 35 slpm.

Four separate regenerations were conducted at inlet $\mathrm{O}_{2}$ concentrations of $2,2.5,3$, and 3.5 vol percent. To approximately reach the target temperature of $760^{\circ} \mathrm{C}$, different initial temperatures were used in each case; these were $735,722,707$, and $695^{\circ} \mathrm{C}$ for $2,2.5,3$, and $3.5 \mathrm{vol}$ percent $\mathrm{O}_{2}$, respectively. Since this is a batch reactor, sorbent temperature would rise until a quasi-steady state would be reached. This behavior is demonstrated in Figure 7-13. At this steady state, the heat generation due to the reaction equals the sum of the net heat carried out by the gas and the heat loss from the sorbent to the reactor wall (sorbent cage). Note that the steady-state periods decrease as $\mathrm{O}_{2}$ concentration increases, indicating faster regoneration.

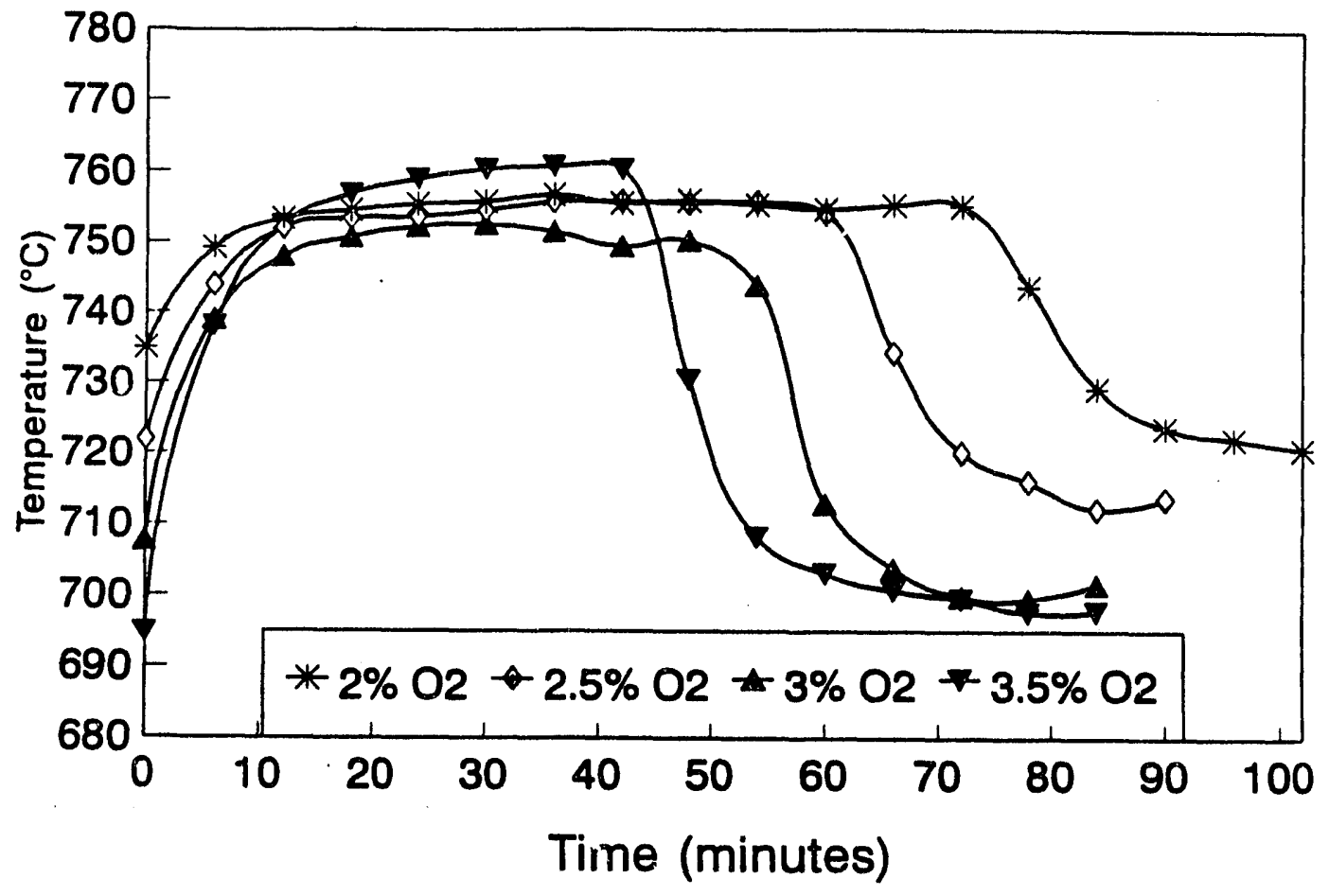

Figure 7-13. Regeneration temperature proflle for ZT-4 In Texaco gas.

The sulfur dioxide $\left(\mathrm{SO}_{2}\right)$ in the effluent gas was measured during this steady-state period. This is shown in Table 7-2, where the experimental value is compared to the stoichiometric value assuming the stoichiometry to be $\mathrm{ZnS}+(3 / 2) \mathrm{O}_{2} \rightarrow \mathrm{ZnO}+\mathrm{SO}_{2}$. The agreement is excellent, indicating that essentially all of the $\mathrm{O}_{2}$ is converted to $\mathrm{SO}_{2}$. This provides indirect evidence of the absence of sulfate formation during the steady-state periods, which were typically at temperatures of 752 to $761^{\circ} \mathrm{C}$ during the four regenerations. Thus, $760^{\circ} \mathrm{C}$ appears to be a reasonable temperature to prevent sulfate formation. This corroborates the earlier fixed-bed results. 


\subsubsection{Analysis of}

Temperature Rise

The temperature rise in a commercial regenerator is an extremely important consideration in the design, as indicated above. A theoretical analysis is presented below assuming an adiabatic regenerator for both a continuous as well as a batch system such as one used in this study.

\section{Continuous System}

In continuous systems

Table 7-2. Comparison of Measured $\mathrm{SO}_{2}$ with Stolchlometric $\mathrm{SO}_{2}$ During Quasl Steady-State Period of Regeneration (vol \%)

\begin{tabular}{ccc}
\hline Inlet $\mathrm{O}_{2}$ & $\mathrm{SO}_{2}$ & $\begin{array}{c}\text { Stoichlometric } \\
\mathrm{SO}_{2}\end{array}$ \\
\hline & & \\
2.0 & 1.42 & 1.33 \\
2.5 & 1.77 & 1.67 \\
3.0 & 2.10 & 2.00 \\
3.5 & 2.43 & 2.33 \\
\hline
\end{tabular}
conceptually described later in Section 7.2.8, the sorbent is continuously circulated between the sulfider and the regenerator. The circulation rate depends on the type of design (e.g., two bubbling beds, circulating sulfider/bubbling regenerator, or riser sulfider and bubbling regenerator). However, heat generated in the adiabatic regenerator is removed not only by the gas but also by the circulating solid.

Because of the well-mixed nature of fluidized beds, both gas and solid leave the regenerator at essenitially the same temperature. The analysis is somewhat simplified by assuming that the inlet temperatures of both gas and solid are also the same without sacrificing the concept it is intended to illustrate. $\left({ }^{\circ} \mathrm{C}\right):$

The adiabatic energy balance leads to the following equation for the temperature rise, $\Delta T$

$$
\Delta T=\frac{\left(-\Delta \mathrm{H}_{\mathrm{f}}\right) \mathrm{Y}_{A O}}{\overline{\mathrm{C}}_{\mathrm{p}}\left[1+\frac{S M}{\overline{\mathrm{C}}_{\mathrm{p}}}\left(\frac{\dot{\mathrm{M}}_{\mathrm{s}}}{\dot{\mathrm{M}}_{g}}\right)\right]}
$$

where

$$
\begin{aligned}
& \Delta \mathrm{H}_{\mathrm{r}}=\text { heat of reaction, } \mathrm{cal} / \mathrm{mol} \mathrm{O}_{2} \text { converted } \\
& Y_{A O}=O_{2} \text { mol fraction in inlet gas } \\
& \overline{\mathrm{C}}_{\mathrm{AO}}=\text { mean gas heat capacity [cal/(mol K)] } \\
& s^{p}=\text { solid phase specific heat [cal/(g K)] } \\
& M \quad=\text { gas molecular weight }(\mathrm{g} / \mathrm{mol}) \\
& \dot{M}_{s}=\text { solid phase mass flow rate } \approx \text { circulation rate }(\mathrm{g} / \mathrm{s}) \\
& \dot{\mathrm{M}}_{\mathrm{g}}=\text { gas mass flow rate }(\mathrm{g} / \mathrm{s})
\end{aligned}
$$


The reasonable assumptions made in deriving Equation (7-14) are as follows:

- Constant gas and solid heat capacities,

- Steady-state operation,

- Constant mass flow of solid (in and out), and

- Constant heat of reaction.

The values of the parameters are listed below:

- $\left(-\Delta \mathrm{H}_{\mathrm{r}}\right)=70,699 \mathrm{cal} / \mathrm{mol} \mathrm{O}_{2}$ converted. Literature data from Knacke et al. (1991) shows that $\left(-\Delta H_{r}\right)$ varies from 70,698 to 70,707 in the 627 to $827{ }^{\circ} \mathrm{C}(900$ to $1,100 \mathrm{~K})$ temperature range.

- $\bar{C}_{p}=7.3 \mathrm{cal} /(\mathrm{mol} \mathrm{K}) . \quad C_{p}$ for regeneration gas varies from 7.27 to $7.34 \mathrm{cal} /(\mathrm{mol} \mathrm{K})$ as $\mathrm{O}_{2}$ content varies from 1 to 5 volume percent.

- $M=29$. The regeneration gas is only slightly heavier than $N_{2}$ because of its dilute nature.

- $S=0.184 \mathrm{cal} /(\mathrm{g} \mathrm{K})$. Literature data (Knacke et al., 1991) show that specific heat values of $\mathrm{ZnO}, \mathrm{ZnS}, \mathrm{TiO}_{2}$, anc $\mathrm{Zn}_{2} \mathrm{TiO}_{4}$ are as listed in Table 7-3 as a function of temperature. Since the 0.184 value is near the middle and also the solid is going to be only partially sulfided to a level of about 15 to 30 percent, 0.184 is a reasonable value to use.

Table 7-3. Specific Heats of Sollds of Interest

\begin{tabular}{cccccc}
\hline & & \multicolumn{4}{c}{ Speciflc heat (cal/g/K) } \\
\cline { 3 - 6 }${ }^{\circ} \mathrm{C}$ & $\mathrm{K}$ & Zno & Zns & $\begin{array}{c}\mathrm{TIO}_{2} \\
\text { (rutlle) }\end{array}$ & Zn $_{\mathbf{2}}$ TIO $_{4}$ \\
\hline 627 & 900 & 0.150 & 0.131 & 0.221 & 0.181 \\
727 & 1000 & 0.153 & 0.133 & 0.223 & 0.184 \\
827 & 1100 & 0.155 & 0.134 & 0.225 & 0.187 \\
\hline \hline
\end{tabular}

Adapted from Knacke et al., 1991.

Using the above values in Equation (7-14) gives the following equation:

$$
\Delta T=\frac{9685 Y_{A O}}{\left(1+0.731 \frac{\dot{m}_{\text {solid }}}{\dot{m}_{\text {gas }}}\right.} \text {. }
$$


Using Equation (7-15), the temperature rise was estimated for various systems over a range of inlet $\mathrm{O}_{2}$ concentrations as shown in Table 7-4.

Table 7-4 shows that the higher the solid circulation rate the closer the regenerator will be to being nearly isothermal. Here, four hypothetical cases are illustrated with solid circulation rate $(2,20,200,2000 \mathrm{~kg} / \mathrm{s})$ as a parameter. As expected, for low solid circulation rates, a case typical to two bubbling bed reactors, the temperature rise will be enormous. On the other hand, for a very high solid circulation rate, for instance in two circulating-bed or riser configurations, the temperature rise would be negligible. The high circulation rates, however, may lead to high sorbent loss due to attrition.

Table 7-4. Estimated Adlabatlc Temperature Rise as a Function of Sorbent CIrculation Rate (100 MW Electric, KRW Gas, 3\% Sulfur Coal)

\begin{tabular}{lccccc}
\hline & & \multicolumn{5}{c}{ Temperature rise $\left({ }^{\circ} \mathrm{C}\right)$} \\
\cline { 3 - 6 } & & \multicolumn{5}{c}{$\left(\mathrm{m}_{\mathrm{s}}(\mathrm{kg} / \mathrm{s})\right.$} \\
\cline { 3 - 6 } $\mathbf{Y}_{\text {AO }}$ & $\begin{array}{c}\mathrm{m}_{\mathrm{gas}} \\
(\mathrm{kg} / \mathrm{s})\end{array}$ & 2 & 20 & 200 & 2000 \\
\hline & & & & 18.7 & 2.26 \\
0.01 & 35 & 93.0 & 68.3 & 20.7 & 2.29 \\
0.02 & 17.5 & 178.8 & 105.3 & 21.5 & 2.30 \\
0.03 & 11.67 & 258.2 & 129.0 & 21.9 & 2.30 \\
0.04 & 8.75 & 332.0 & 145.0 & 22.1 & 2.31 \\
0.05 & 7.0 & 400.5 & 156.8 & & \\
\end{tabular}

Note: The solid circulation rates used above are for illustration purposes only.

\section{Batch System}

The temperature rise in a batch system will vary with time, as was seen for the RTI reactor, until a quasi-steady state is reached in which the heat generated by the reaction is equal to that picked up by the gas and the sorbent and that lost to the reactor walls.

The adiabatic gas temperature rise is given by

$$
\Delta T=\frac{Y_{A O}\left(-\Delta H_{r}\right)}{\bar{C}_{p}} .
$$


This is tabulated in Table 7-5 representing the temperature rise limit of the batch system. In practice, however, the maximum temperature rise will not be realized due to heat losses to the reactor wall and the unsteady-state nature of the process.

Table 7-5. Adlabatic (Maximum) Gas Temperature Rise in a Batch Regenerator

\begin{tabular}{ccc}
\hline $\mathbf{Y}_{\text {AO }}$ & $\begin{array}{c}\overline{\mathbf{C}}_{\mathrm{p}} \\
\text { cal/(mol K) }\end{array}$ & $\begin{array}{c}\text { Adlabatic (maximum) } \\
\left({ }^{\circ} \mathrm{C}\right)\end{array}$ \\
\hline 0.01 & 7.27 & 97 \\
0.02 & 7.29 & 194 \\
0.03 & 7.30 & 291 \\
0.04 & 7.32 & 386 \\
0.05 & 7.34 & 482 \\
\hline \hline
\end{tabular}

Same as $y_{\max }$ in Equation (7-18).

In fact, for a batch system, temperature rise will actually be a function of time. For an adiabatic system (i.e., no heat loss from the sorbent to the wall), the differential equation governing will be:

$$
\frac{d y}{d t}=A-B y
$$

where

$$
\begin{aligned}
y & =\Delta T\left({ }^{\circ} \mathrm{C}\right) & \\
A & =\frac{\left(-\Delta H_{r}\right) F_{A O}}{m S} & (\mathrm{~K} / \mathrm{min}) \\
B & =\frac{F_{T O} \bar{C}_{p}}{m S} & \left(\mathrm{~min}^{-1}\right) \\
F_{A O} & =\text { molar inlet } O_{2} \text { flow } & (\mathrm{mol} / \mathrm{min}) \\
F_{T O} & =\text { total molar inlet gas flow } & (\mathrm{mol} / \mathrm{min}) \\
t & =\text { time variable } & (\mathrm{min})
\end{aligned}
$$

The initial condition for Equation (7-17) is that $\Delta T=0$ at $t=0$. 
The solution of Equation (7-17) leads to the following relation between time and temperature rise in an adiabatic batch regenerator:

$$
y=y_{\max }[1-\exp (-B t)]
$$

where

$y_{\max }=A / B$ which was previously given in Table 7-5.

The experimental temperature rise vs. time data of Figure 7-13 are compared with the calculated data from Equation (7-18) in Table 7-6 for 2 and 3 vol percent $O_{2}$. The experimental values of $F_{\mathrm{AO}}, F_{\mathrm{TO}}$, and $m$ were based on a total regeneration gas flow of $35 \mathrm{sipm}$ and a sorbent inventory of $350 \mathrm{~g}$ in the batch reactor. It is seen from Table 7-6 that the predicted adiabatic temperature rise is much more rapid than the rise in the batch reactor. This is primarily attributed to nonadiabatis nature of the operation of the reactor used in this study, primarily due to the heat losses from sorbent to the reactor walls. A cage heat loss term could be included in Equation $(7-17)$ to simulate experimental data more closely.

Table 7-6. Comparison of Experimental and Adiabatic Temperature Rise $\left({ }^{\circ} \mathrm{C}\right)$ Versus Time Data for Batch Reactor

\begin{tabular}{|c|c|c|c|c|}
\hline \multirow{2}{*}{$\stackrel{t}{t}$} & \multicolumn{2}{|c|}{$2 \% \mathrm{O}_{2}$} & \multicolumn{2}{|c|}{$3 \% \mathrm{O}_{2}$} \\
\hline & Adlabatic & Experimental & Adlabatic & Experimental \\
\hline 0 & 0 & 0 & 0 & 0 \\
\hline 1 & 31.4 & $N A^{a}$ & 47.2 & NA \\
\hline 2 & 57.8 & NA & 86.7 & NA \\
\hline 6 & 126.8 & 15.7 & 190.2 & 40.4 \\
\hline 12 & 170.6 & 18.4 & 255.9 & 43.1 \\
\hline 18 & 185.8 & 19.6 & 278.6 & 44.6 \\
\hline$\infty$ & 193.9 & -- & 290.6 & - \\
\hline
\end{tabular}

${ }^{a} \mathrm{NA}=$ not available.

\subsubsection{Comments on Regeneration KInetics}

In a previous study on fixed-bed sorbents (Woods et al., 1989), it was shown using a TGA that the rate of regeneration increased when the oxygen concentration of the gas was increased. The rate of regeneration for fixed-bed sorbents, however, would be limited by mass transfer and diffusional effects at the high temperatures involved. Thus, the reason why the regeneration rate 
of fixed-bed sorbents increased with $\mathrm{O}_{2}$ concentration was that the concentration gradient (which is directly proportional to mass transfer rate) across the external gas film increased with bulk gas phase $\mathrm{O}_{2}$ concentration.

Because of the small particles used in a fluidized bed, regeneration is expected to be much more rapid. However, no systematic study of the kinetics of fluid-bed sorbent regeneration has, to date, been carried out. The data of Figure 7-13 indicate that as $\mathrm{O}_{2}$ concentration increases, regeneration becomes more rapid. If the assumption is made that the rate of regeneration follows pseudo first-order kinetics for fluidized-bed particles:

$$
r=k_{r} C_{O_{2}}\left[\frac{\text { mol } O_{2}}{g \text { sorbent } \cdot s}\right]
$$

where

$$
k_{r}=\text { regeneration rate constant } \frac{\mathrm{cm}^{3} \text { of gas }}{\mathrm{gsorbent} \cdot \mathrm{s}} .
$$

It is possible to put lower bounds on $k_{r}$ using the regeneration data in this work, but it is not possible to estimate either the actual value or the upper bound.

The lower bound of $k_{r}$ is estimated below on the basis of the high-velocity 10 -cycle run carried out with 76 slpm of regeneration gas containing 2.5 vol percent $\mathrm{O}_{2}$ at $15 \mathrm{~atm}$ and $760^{\circ} \mathrm{C}$.

In this run, essentially all of the $\mathrm{O}_{2}$ was consumed; however, to be consistent with the assumption of first order, it is assumed that 99.9 percent of the input $\mathrm{O}_{2}$ was consumed. Thus, the assumption of first-order reaction and plug-ilow leads to

$$
k_{r}=6.908 \frac{V_{0}}{W} \quad \text { (see Equation 7-13) }
$$

where

$$
\begin{aligned}
& W=\text { mass of sorbent, } g(e . g ., 500 \mathrm{~g}), \\
& v_{0}=\text { gas volumetric flow rate at } 15 \text { atm and } 760^{\circ} \mathrm{C}\left(e . g ., 320 \mathrm{~cm}^{3} / \mathrm{s}\right) .
\end{aligned}
$$

Thus, the lower limit of $k_{r}$ is $4.41 \mathrm{~cm}^{3} /(\mathrm{g} \cdot \mathrm{s})$ at $760^{\circ} \mathrm{C}$. However, a systematic study of regeneration kinetics needs to be carried out in order to find the actual $k_{r}$ value for commercial reactor design. Two approaches could be used. One approach could involve fluid-bed reactor experiments in which the inlet $\mathrm{O}_{2}$ and outlet $\mathrm{O}_{2}$ are measured precisely. The gas flow rate is high enough that all of the $\mathrm{O}_{2}$ is not consumed. Another approach could involve lower temperature TGA experiments with different levels of $\mathrm{O}_{2}$. At low temperatures, the TGA experirnents would yield the true kinetic rate which could then be extrapolated using an Arrhenius-type equation to higher temperatures. 


\subsubsection{Comments on Sulfate Formation}

As indicated in Section 7.2.2.1, no evidence of sulfate formation was seen in the fluid-bed regeneration runs in this study when regeneration was conducted with 1 to 5 percent $\mathrm{O}_{2}$ at about $760^{\circ} \mathrm{C}$. Sulfate formation should be avoided because sulfates that are formed in the regenerator and not decomposed to oxides prior to sorbent being transferred to the sulfider will react with the reducing gas to produce sulfurous gases, which may decrease the effective capacity of the sulfider and consume valuable $\mathrm{H}_{2}$ and $\mathrm{CO}$. Sulfate formation should also be avoided because it may potentially lead to sorbent decrepitation as zinc sulfate is a significantly larger molecule this zinc sulfide or zinc oxide.

The classical work on the subject of thermodynamics of oxidation of zinc sulfide is by Ingraham and Kellogg (1963). Other thermodynamic studies of interest include those by Gray et al. (1973) and Kubaschewski (1972). Thermodynamics indicates that sulfate will be the preferred species in an excess oxygen environment, whereas oxide is the preferred species in an oxygen-starved environment. This suggests that it may be possible to completely avoid sulfate formation by operating the regenerator with partially sulfided zinc titanate at all times and using less than stoichiometric amounts of $\mathrm{O}_{2}$ needed in the feed. Operating in this mode would have added benefits because the attrition resistance of partially sulfided zinc titanate is significantly greater than fresh or completely regenerated zinc titanate, as discussed later in Section 7.2.4.

Sulfate formation could occur directly due to oxidation of $\mathrm{ZnS}$ :

$$
\mathrm{ZnS}+2 \mathrm{O}_{2} \rightarrow \mathrm{ZnSO}_{4}
$$

However, sulfate formation could also occur via $\mathrm{SO}_{2}+(1 / 2) \mathrm{O}_{2} \rightarrow \mathrm{SO}_{3}$ and $\mathrm{ZnO}+\mathrm{SO}_{3} \rightarrow \mathrm{Zn} \mathrm{SO}$. There is also the possibility of basic sulfate $\left(\mathrm{ZnO} \cdot 2 \mathrm{ZnSO}_{4}\right)$ formation, which is believed to. be significantly more stable thermodynamically than $\mathrm{ZnSO}_{4}$. Presently, very little is known about the exact nature of either the mechanism of the sulfate formation or the very nature of various sulfates.

\subsubsection{Extent of Zinc Vaporization}

The leading desulfurization sorbents, zinc ferrit: and zinc titanate, have the potential to undergo zinc loss due to reduction of $\mathrm{ZnO}$ to zinc vapor at elevated temperature $\left(>600^{\circ} \mathrm{C}\right)$. This is a critical issue in the commercialization of IGCC systems. In fact, the development of zinc titanate sorbent was motivated by the need for a sorbent that did not losu zinc at high temperatures. The $\mathrm{TiO}_{2}$ in the zinc titanate matrix provides thermal stability without actually participating in the reaction, as discussed in Chapter 2. A thermodynamic analysis is presented first to determine the extent of maximum possible zinc loss. This is followed by some experimental results.

\subsubsection{Thermodynamic Analysis}

The zinc oxide, subject to reduction by $\mathrm{CO}$ and $\mathrm{H}_{2}$, leads to formation of $\mathrm{Zn}$ vapors which elute from the sorbent. The following reactions are considered to define the thermodynamic equilibrium: 


$$
\begin{gathered}
\mathrm{ZnO}(\mathrm{s})+\mathrm{CO}-\mathrm{Zn}(\mathrm{g})+\mathrm{CO}_{2} \\
\mathrm{ZnO}(\mathrm{s})+\mathrm{H}_{2}-\mathrm{Zn}(\mathrm{g})+\mathrm{H}_{2} \mathrm{O} \\
\mathrm{CO}+\mathrm{H}_{2} \mathrm{O}-\mathrm{CO}_{2}+\mathrm{H}_{2} .
\end{gathered}
$$

Any two of the reactions above could be used to determine the thermodynamic equilibrium, since the third reaction is simply a linear combination of the other two reactions. For example, by adding Reactions (7-22) and (7-23), Reaction (7-21) results. The thermodynamic equilibrium constants for the above reactions are shown in Table $7-7$ at 600 to $750^{\circ} \mathrm{C}$, the temperature range of interest. These data are derived from published thermodynamic data of Knacke et al. (1991).

Table 7-7. Thermodynamic Equilibrlum Constants for Reactions (7-21), (7-22), and (7-23)

\begin{tabular}{cccc}
\hline \hline Temperature ( $\left.{ }^{\circ} \mathrm{C}\right)$ & $K_{1}$ (Reaction (7-21)) & $K_{2}$ (Reaction (7-22)) & $K_{3}$ (Reaction (7-23)) \\
\hline 600 & $1.1185 \times 10^{-5}$ & $5.0912 \times 10^{-6}$ & 2.197 \\
650 & $4.4058 \times 10^{-5}$ & $2.5371 \times 10^{-5}$ & 1.7359 \\
700 & $1.5061 \times 10^{-4}$ & $1.0719 \times 10^{-4}$ & 1.4051 \\
750 & $4.5674 \times 10^{-4}$ & $3.9335 \times 10^{-4}$ & 1.1611 \\
\hline
\end{tabular}

Using the above values, equilibrium zinc vapor concentration in the gas leaving the sulfider can be estimated. This is shown at three total pressures in Table 7-8 for a Texaco coal gas containing 12.25 percent $\mathrm{CO}_{2}, 40.1$ percent $\mathrm{CO}, 30.13$ percent $\mathrm{H}_{2}$, and 17.52 percent $\mathrm{H}_{2} \mathrm{O}$ entering the sulfider.

Table 7-8. Equllibrium Zinc Vapor Concentrution in Texaco Coal Gas Leaving the Sulfider (mol/100 mol gas)

\begin{tabular}{cccc}
\hline & \multicolumn{3}{c}{ Pressure } \\
\cline { 2 - 4 } Temperature $\left({ }^{\circ} \mathrm{C}\right)$ & $1 \mathrm{~atm}$ & $20 \mathrm{~atm}$ & $23.8 \mathrm{~atm}$ \\
\hline 600 & $1.8719 \times 10^{-3}$ & $9.36 \times 10^{-5}$ & $7.8655 \times 10^{-5}$ \\
650 & $8.1156 \times 10^{-3}$ & $4.0578 \times 10^{-4}$ & $3.4099 \times 10^{-4}$ \\
700 & 0.0304 & $1.519 \times 10^{-3}$ & $1.2765 \times 10^{-3}$ \\
750 & 0.1005 & $5.0 \times 10^{-3}$ & $4.2017 \times 10^{-3}$ \\
\hline
\end{tabular}


Fortunately, as pressure increases, the potential for zinc loss decreases. Thus, it would be advisable from a thermodynamic standpoint of zinc evaporation to run the IGCC system at the highest possible pressure. The Texaco gasifier is currently projected to be operated at $23.8 \mathrm{~atm}$ in an IGCC system. Considering a $400-\mathrm{MW}$ Texaco-based IGCC system, the maximum zinc loss potential is shown in Table 7-9. As can be seen, these losses are not trivial, especially at the higher temperatures. The questions that need to be answered from a design standpoint are:
Table 7-9. Equilibrlum (Maximum Potentlal) Zinc Loss from a 400-MW Texaco Coal Gas IGCC Plant (18\% Steam Coal Gas! at 23.8 atm Operating Pressure

\begin{tabular}{cc}
\hline Temperature $\left({ }^{\circ} \mathrm{C}\right)$ & Zlnc loss $(\mathrm{kg} / \mathrm{h})$ \\
\hline 600 & 0.95 \\
650 & 4.1 \\
700 & 15.2 \\
750 & 50.0 \\
\hline
\end{tabular}

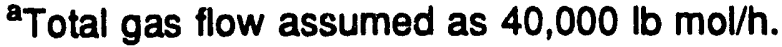

- Can the zinc loss shown in Table 7-9 be tolerated by the downstream valve, turbine, and heat recovery steam generator (HRSG)? Since the gas is cooled in the HRSG, the zinc may cause plugging there.

- Can so much zinc vented into the atmosphere be tolerated?

- Can the zinc loss be tolerated in terms of loss of sorbent requiring replacement and loss of sorbent strength/structure, potentially leading to decrepitation?

\subsubsection{Experimental Results}

Runs of sufficient duration have not yet been conducted to assess zinc loss rates accurately, either in a fixed/moving bed or in a fluid bed. In a previous fixed-bed reactor study (Gangwal et al., 1988), a 15-cycle test with UCI L-3196 fixed-bed sorbent at $15 \mathrm{~atm}, 732^{\circ} \mathrm{C}$, and using a KRW gas with 18 percent steam resulted in a zinc loss rate of about 3 percent per $1000 \mathrm{~h}$ of operation ( $3.4 \times 10^{-4} \mathrm{~mol} \mathrm{Zn} / 100 \mathrm{~mol}$ gas). A 5-cycle test with the same sorbent under the same conditions except a KRW gas with 5 percent steam resulted in a more-than-4-times greater zinc loss rate (14 percent per $1000 \mathrm{~h} ; 95.9 \times 10^{-4} \mathrm{~mol} / 100 \mathrm{~mol}$ gas). Under the same conditions, negligible zinc loss was experienced at $550^{\circ} \mathrm{C}$. These results show that zinc loss rate can be substantially higher in a gas with greater reducing power and at higher temperature.

More recently, 10-cycle atmospheric pressure TGA tests of the L-3196 sorbent with Texaco gas (18 percent steam) has shown the potential for significant zinc loss. At 700 to $725^{\circ} \mathrm{C}$, the zinc loss rate was measured to be $2.34 \times 10^{-2} \mathrm{~mol} \mathrm{Zn} / 100 \mathrm{~mol}$ gas, in good agreement with thermodynamic prediction as shown above. Recent work along the same lines indicates that zinc loss can be minimized substantially by using a sorbent (L-500M) with a more homogeneous zinc and titanium distribution and substantially free of uncombined zinc oxide (Gupta, 1991). 
Bench-scale test results (Chapter 6) on fluidizable zinc titariates presented in this report indicate that negligible zinc loss occurred from the sorberits prepared by granulation at temperatures up to $750^{\circ} \mathrm{C}$ in fluid-bed bench-scale tests with Texaco gas (18 percent steam) at $15 \mathrm{~atm}$. On the other hand, plugging of the reactor downstreain with zinc solids occurred after 8 cycles with the $\mathrm{UCl} L-3758$ sorbent. A comparison of the L-3758 sorbent with granulated sorbents using XRD and SEM techniques indicated the presence of free $\mathrm{ZnO}$ and a less homogeneous distribution of $\mathrm{ZnO}$ and $\mathrm{TiO}_{2}$ in the $\mathrm{L}-3758$ sorbent as opposed to the granulated sorbents. These attributes of L-3758 may have been responsible for its greater zinc loss, as shown experimentally in the bench-scale tests.

Fluidizable zinc ferrites also suffered greater zinc loss than zinc titanate. For example, the T-2465MC sorbent was found to lose about 8 percent ziric in 100 cycles of operation at $625^{\circ} \mathrm{C}$ with KRW gas containing 15 to 20 percent steam at $15 \mathrm{~atm}$ (Gupta and Gangwal, 1991).

To confirm that the zinc loss of L-3758 is greater than that of the granulated sorbents, a number of TGA reduction tests were conducted. These tests consisted of exposing the sorbent to $\mathrm{H}_{2} \mathrm{~S}$-free reducing gas of various reducing powers at $650^{\circ} \mathrm{C}$ for $5 \mathrm{~h}$ and measuring the rate of weight loss. The results are shown in Figures 7-14 and 7-15. In Figure 7-14, the weight losses are measured when using KRW gas containing 20 percent steam. As expected, the rate of weight loss of the granulated sorbents is significantly lower than that of L-3758 sorbent. The rate of weight loss of the granulated sorbents, furthermore, appears to be independent of $\mathrm{Zn}$ to $\mathrm{Ti}$ atomic ratio ( 0.8 to 1.5) and binder content ( 2 to 5 percent). The rate of weight loss of the $\mathrm{UCl}$ sorbents is found to be significantly higher with a $\mathrm{Zn}$ to $\mathrm{Ti}$ atomic ratio of 1.5 (L-3758) versus 0.8 (L-3757). Figure 7-15 (with 5 percent steam KRW gas) also shows a greater zinc loss potential for L-3758 sorbent in contrast to the granulated sorbent ZT-5. Plots of pure ZnO and $\mathrm{TiO}_{2}$ are included for comparison to prove that $\mathrm{TiO}_{2}$ does aid in minimizing zinc loss by forming the zinc titanate phase. Figure 7-3, shown earlier, shows greater zinc loss for L-3758 in contrast to ZT-5. Figures 7-16 and 7-17 show the effect of reducing power on zinc loss. As can be seen, the 5 percent steam air-blown KRW gas causes an even greater zinc loss than Texaco $\mathrm{O}_{2}$-blown gas. The reducing power $\left(R_{0}\right)$, defined earlier in Chapter 6 (the ratio of $\left(\mathrm{CO}+\mathrm{H}_{2}\right)$ to $\left(\mathrm{CO}_{2}+\mathrm{H}_{2} \mathrm{O}\right)$ ) for the three gases, i.e., 26 percent steam KRW gas, Texaco gas, and 5 percent steam KRW gas, are $0.92,2.11$, and 2.58 , respectively, as shown in Table 6-3. $R_{p}$ is plotted against weight loss rate from Figures $7-16$ and $7-17$ in Figure 7-18 which shows that the rate of weight loss (zinc loss) increases with reducing power, as expected. The rate of weight loss and reducing power appear to have a nearly linear relationship for ZT-5 sorbent. include

Zinc loss in granulated sorbents needs to be researched further. Future work could

- A 100-cycle test, which is currently being planned;

- Tests by alternative techniques to TGA to measure the zinc loss of granulated sorbent and $\mathrm{UCl}$ L-3758, for example, mass spectrometer.

\subsubsection{Effect of Sulfidation on Sorbent Attrition}

As reported in Chapter 6, it was consistently found that the attrition resistance of the 10cycle regenerated sorbent was significantly better than the fresh sorbent. Measurement of the attrition resistance of the sulfided sorbent indicated a significant improvement in the attrition 


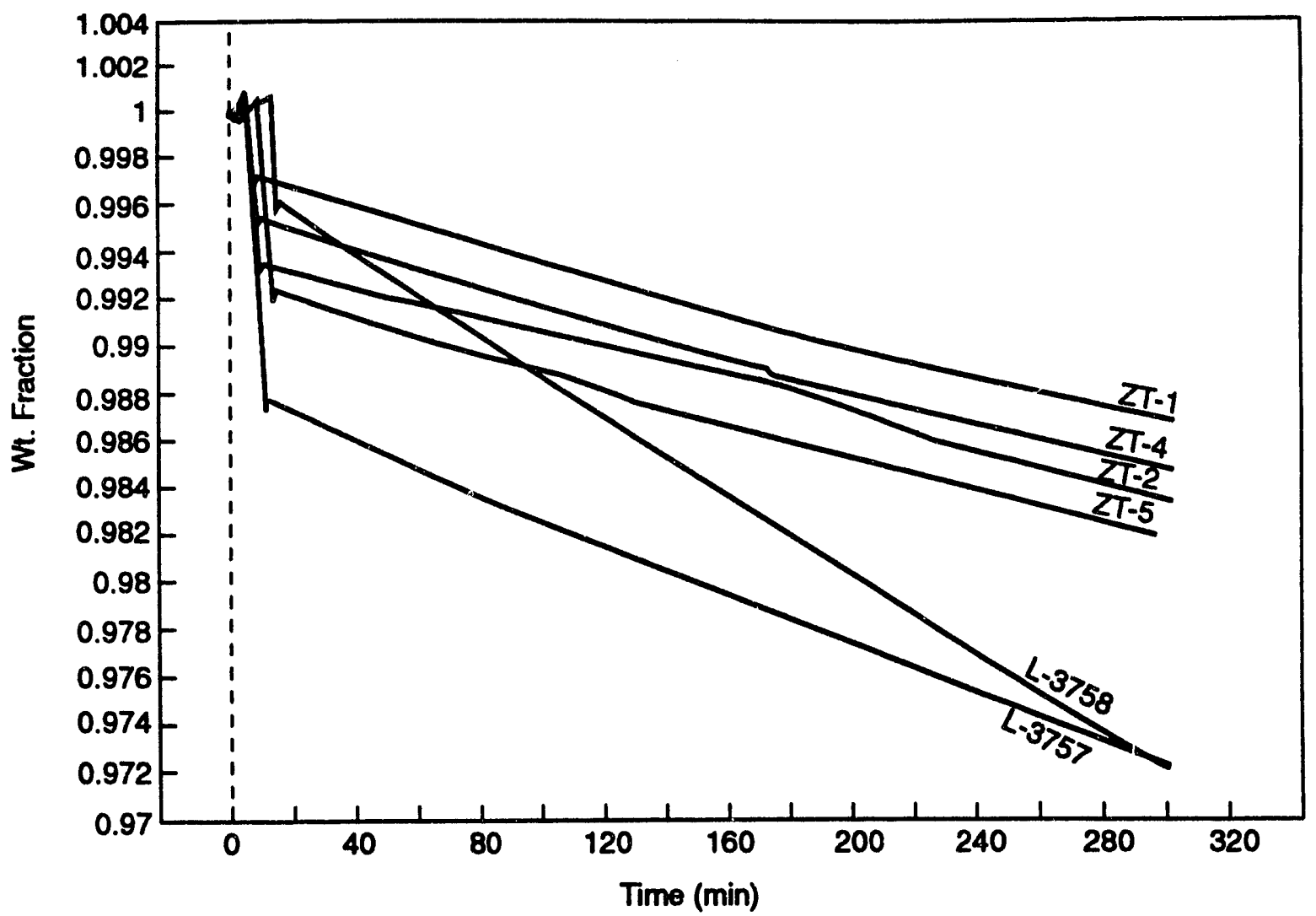

Figure 7-14. Zinc loss as a function of time In KRW reducing gas (20\% steam) at $650^{\circ} \mathrm{C}$.

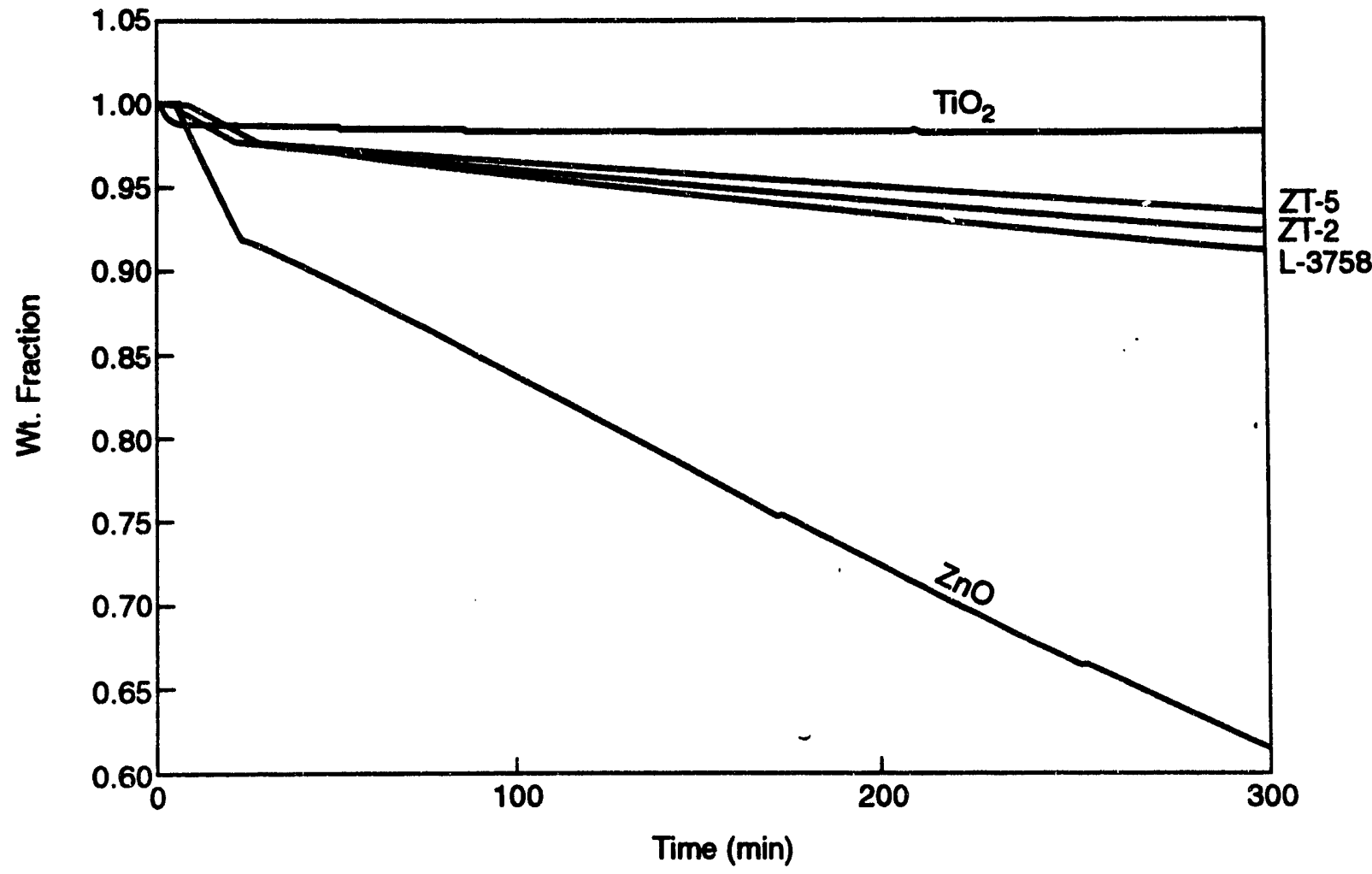

Figure 7-15. Zinc loss as a function of time in KRW reducing gas (5\% steam) at $650^{\circ} \mathrm{C}$. 


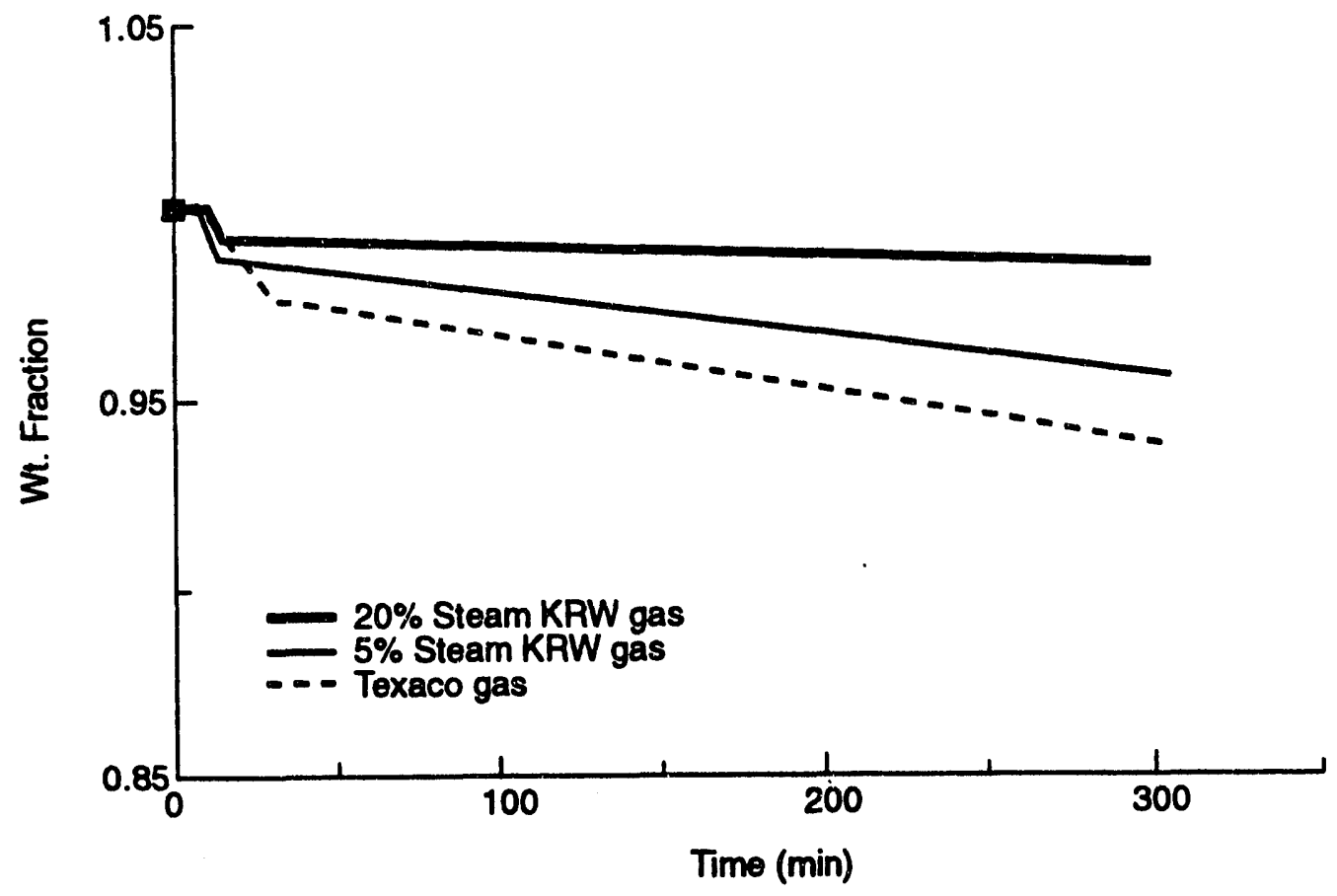

Figure 7-16. Effect of gas composition on reduction of ZT-5.



Figure 7-17. Effect of gas composition on reduction of ZT-2. 


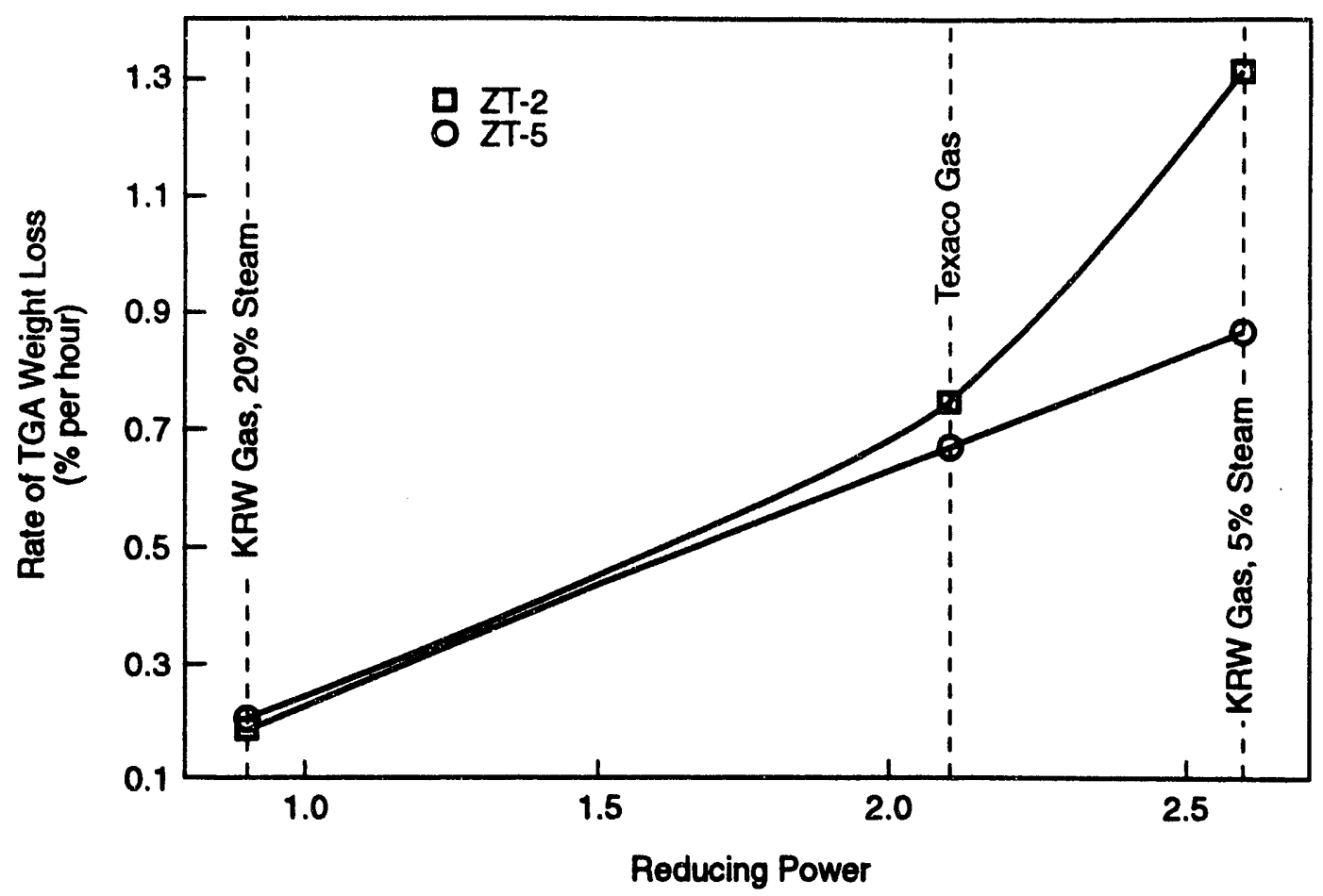

Figure 7-18. Relationshlp betweell reducing power and zinc loss as measured by welght loss rate In a TGA at $1 \mathrm{~atm}, 650^{\circ} \mathrm{C}$ in the presence of various $\mathrm{H}_{2} \mathrm{~S}$-free coal gas compositions.

resistance due to sulfidation. Table 7-10 shows the attrition behavior of fresh, 10-cycle reacted, and partially sulfided sorbent. The sulfidation of the sorbent was carried out in the bench-reactor.

Table 7-10. Attrition Behavior of Fresh, Reacted, and Sulfided Sorbent

\begin{tabular}{ccc}
\hline & \multicolumn{2}{c}{ Attrition loss (\%) } \\
\cline { 2 - 3 } Sample & $5 \mathrm{~h}$ & $20 \mathrm{~h}$ \\
\hline ZT-4 Fresh & 39.66 & 89.0 \\
ZT-4 Reacted & 28.74 & 87.46 \\
ZT-4 Sulfided & 2.90 & 14.28 \\
FCC catalyst & 0.40 & 2.40 \\
\hline
\end{tabular}

After 10 cycles of sulfidation-regeneration at $750^{\circ} \mathrm{C}$ (Run No. 9).

${ }^{b}$ Extent of sulfidation was only 50 percent.

c US260 Equilibrium Catalyst by Englehard, particle size 75 to $150 \mu \mathrm{m}$

The attrition resistance of the 10-cycle regenerated material is slightly better than the fresh material, as indicated by 5-h loss data. However, once the reacted sorbent was sulfided, its attrition resistance improved significantly.

As 50 percent sulfidation of the sorbent improved its attrition resistance significantly, it was thought that a systematic study should be undertaken to determine the attrition resistance as a 
function of extent of sulfidation. To this end, the $Z T-4$ formulation was sulfided to various levels at $650^{\circ} \mathrm{C}$ in Texaco gas in the 1-in.-ID quartz bench-scale reactor described in Section 3.4.

The extent of sulfidation in Table 7-11 is defined as actual sulfur loading of the sorbent as a fraction of its theoretical capacity. For example, the theoretical capacity of ZT-4 is about $22.5 \mathrm{~g} \mathrm{~S} / 100 \mathrm{~g}$ sorbent; therefore, 20 percent sulfidation means that the sulfur absorbed by the sorbent is $22.5 \cdot 20 \%=4.5 \mathrm{~g} \mathrm{~S} / 100 \mathrm{~g}$ of fresh sorbent.

Table 7-11. Attrition Loss as a Function of Extent of Sulfidation

\begin{tabular}{llll}
\hline \hline Sulfidation (\%) & 0 & 20 & 50 \\
Loss in $5 \mathrm{~h}(\%)$ & 32.1 & 7.4 & 2.9 \\
\hline \hline
\end{tabular}

As can be seen from Table 7-11, even a 20 percent sulfidation improved the attrition resistance significantly, a 32.1 percent loss for the fresh catalyst vs. 7.4 percent loss for 20 percent sulfided material. This suggests that a commercial fluidized-bed system should be operated with a sorbent that always remains in a partially sulfided state to minimize the sorbent loss due to attrition. However, the attrition resistance of a partially sulfied sorbent resulting from partial regeneration might differ from that of a partially sulfided material as shown in Table 7-11 but it remains to be verified.

Consequently, the partially sulfided material is expected to result in substantial reduction in sulfate formation during regeneration which is believed to be catalyzed by zinc oxide present in the sorbent as discus ;ed in Section 7.2.2.4. Complete sulfidation of zinc titanate sorbent may not be needed, as partial sulfidation improves the attrition resistance adequately as shown in Table 7-11. A commercial reactor could operate in a window of sulfur loading that could be achieved based on the gas throughput and residence time, for instance, from a level of 15 to 30 percent sulfidation. This level of sulfidation would give adequate attrition resistance.

In a commercial system, partial sulfidation of sorbent could be achieved by treating it with a slipstream of $\mathrm{H}_{2} \mathrm{~S}$ containing reducing gas under gentle fluidizing conditions. Once a desired level of sulfidation is achieved, the material could be used for actual operation. Such an arrangement is expected to lead to a significant decrease in the amount of material lost due to attrition, which would eventually result in large cost savings despite some costs associated with initial partial sulfidation.

In addition to attrition resistance, another measure of mechanical strength of a material is its Hardgrove Grindability Index (HGI), which is usually determined using an ASTM procedure (D-409-71). According to the measure, the higher the value of $\mathrm{HGI}$, the more friable the material is and hence more prone to attrition. Table 7-12 shows the values of HGI for glass beads, FCC catalyst, alumina, ZT-4, and L-3758. As can be seen, the values of HGI for ZT-4 and FCC catalyst are essentially the same, whereas the value of the baseline $\mathrm{UCl}$ zinc titanate $\mathrm{L}-3758$ is 40 percent higher than $Z T-4$. These results are in agreement with the attrition results shown earlier in Figure 7-4. 


\subsubsection{Extent of Shlft Reaction}

The shift reaction, $\mathrm{CO}+\mathrm{H}_{2} \mathrm{O}-\mathrm{CO}_{2}$ $+\mathrm{H}_{2}$, can be catalyzed by the zinc titanate sorbent in the sulfider. Shift is a moderately exothermic reaction $\left(\Delta \mathrm{H}_{298 \mathrm{~K}}=41.2 \mathrm{~kJ} / \mathrm{mol}\right)$. The net result of shift is a small gas temperature increase with a corresponding loss of heating value, since $\mathrm{H}_{2}$ has a slightly lower heating value than $\mathrm{CO}$. Thus, it is important to characterize the extent of the shift reaction from the standpoint of the turbine whose performance is closely dependent on the gas performance is closely dependent on the gas
heating value. Although some heating value is lost, on the plus side is the fact that more $\mathrm{H}_{2}$ is
available in the gas which would lead to better ignitability during startup and system upsets.

Based on the above, the experimental extent of the shift reaction in the fluid-bed reactor was evaluated and compared to the maximum extent limited by thermodynamic equilibrium. Table 7-13 shows the theoretical extent of shift reaction for three types of coal gas at $550^{\circ} \mathrm{C}$ $(823 \mathrm{~K})$ anc $650^{\circ} \mathrm{C}(923 \mathrm{~K})$. As can be seen from Table 7-13, KRW gas with 20 percent steam allows the greatest theoretical $\mathrm{CO}$ conversion. Also, the theoretical maximum decreases with an increase in temperature because of lower $\Delta \mathrm{G}$ at $650^{\circ} \mathrm{C}$ as compared to the $\Delta \mathrm{G}$ at $550^{\circ} \mathrm{C}$. The standard $\Delta G$ for the shift reaction at $650^{\circ} \mathrm{C}$ is $-1.298 \mathrm{kcal} / \mathrm{mol}$ while it is $-2.1 \mathrm{kcal} / \mathrm{mol}$ at $550^{\circ} \mathrm{C}$.

Table 7-13. Theoretical Extent of Shift Reaction

\begin{tabular}{|c|c|c|c|c|c|c|}
\hline \multirow[b]{2}{*}{ Gas } & \multicolumn{4}{|c|}{ Typical composition (mol \%) } & \multicolumn{2}{|c|}{$\begin{array}{l}\text { Equilbrlum CO-fractionsl } \\
\text { conversion }\end{array}$} \\
\hline & $\mathbf{C O}$ & $\mathrm{CO}_{2}$ & $\mathrm{H}_{2}$ & $\mathrm{H}_{2} \mathrm{O}$ & @ 823 K & @ 923 K \\
\hline $\begin{array}{l}\text { KRW-20\% steam } \\
\text { KRW- } 5 \% \text { steam } \\
\text { Texaco-18\% steam }\end{array}$ & $\begin{array}{l}15.01 \\
18.97 \\
38.86\end{array}$ & $\begin{array}{r}6.89 \\
6.75 \\
12.35\end{array}$ & $\begin{array}{r}8.95 \\
11.65 \\
29.77\end{array}$ & $\begin{array}{r}19.17 \\
5.12 \\
17.84\end{array}$ & $\begin{array}{l}0.5536 \\
0.1460 \\
0.2477\end{array}$ & $\begin{array}{l}0.4441 \\
0.0955 \\
0.1782\end{array}$ \\
\hline
\end{tabular}

Based on the inlet and outlet compositions of simulated coal gas for the RTI bubbling-bed reactor, the extent of shift actually achieved with various sorbents at 550 and $650^{\circ} \mathrm{C}$ was calculated. Table 7-14 shows the results. For comparison purposes, the extent of shift achieved using fluidizable zinc ferrites, L-7 and L-16 (Gupta and Gangwal, 1991), and fixed-bed zinc titanate (Gangwal et al., 1988) is also included in this table. The following observations are made:

- Zinc ferrite sorbents have higher shift activity than zinc titanate sorbents, presumably because of the catalytic activity of iron oxide;

- The average CO conversion by fluidizable zinc titanate sorbents is approximately 25 percent of the theoretical maximum; and 


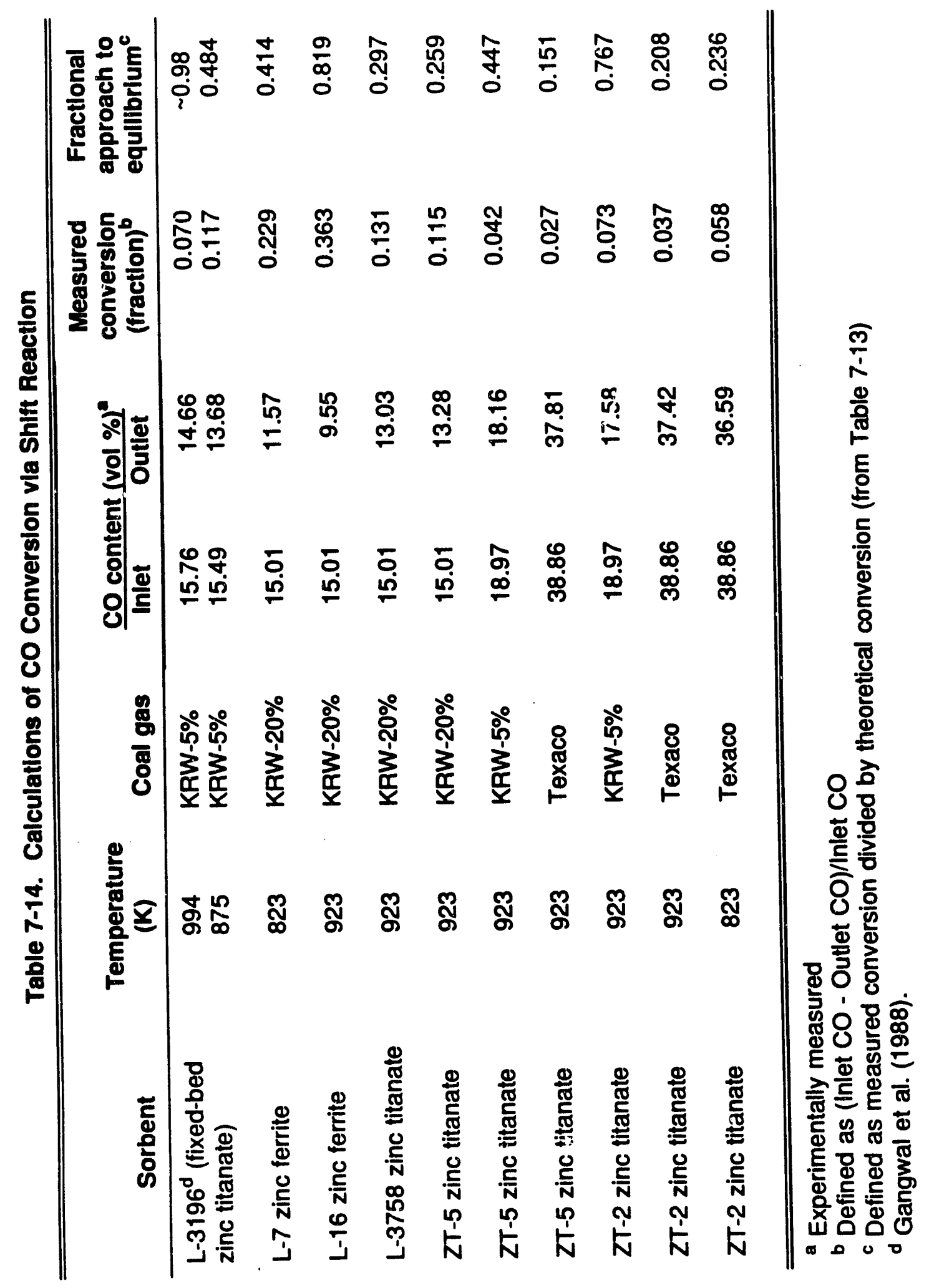


- Equilibrium is essentially reached at the higher operating temperature $\left(721^{\circ} \mathrm{C}(994 \mathrm{~K})\right)$ with fixed-bed zinc titanate.

The average $\mathrm{CO}$ conversion by fluidized-and fixed-bed zinc titanate sorbents in comparison to maximum conversion is presented in Table 7-15. The results are consistent in that the higher residence time in the fixed beds leads to higher shift conversion. Thus, the shift activity of fluidizable zinc titanate and fixed-bed zinc titanates is similar.

Table 7-15. Comparison of Shift Activity In Fixed and Fluid Beds of Zinc Titanate (Ratio of Experimental CO Conversion to Maximum Theoretical Fractional Conversion)

\begin{tabular}{cccc}
\hline \hline & & \multicolumn{2}{c}{ Fractional approach to equilibrium } \\
\cline { 3 - 4 } $\begin{array}{c}\text { Temperature } \\
(K)\end{array}$ & $\begin{array}{c}\text { Superficlal residence } \\
\text { time }(s)\end{array}$ & Flxed bed & $\begin{array}{c}\text { Fluid bed } \\
\text { (average) }\end{array}$ \\
\hline 875 & 7.3 & 0.484 &.- \\
994 & 8.1 & 0.980 & -- \\
823 & 2.1 & -- & $\sim 0.25$ \\
923 & 1.89 & -- & $\sim 0.25$ \\
\hline \hline
\end{tabular}

- A value of 1.0 would mean that experimentally measured CO conversions were the same as those predicted by thermodynamics.

\subsubsection{Conceptual Commercial Systems}

A commercial system would consist of a sulfider and a regenerator with continuous sorbent circulation between the two vessels. The reactors could be circulating fluidized beds, bubbling fluidized beds, or riser type. Proper pressure balancing, L- and J-type valves, and sorbent stripping (to prevent the accidental mixing of oxidizing and reducing gases) would be required. Without showing much detail, three such system configurations are shown in Figures 7-19 to 7-21. Figure 7-19 shows a conceptual diagram with both sulfider and regenerator as bubbling beds. A portion of the regeneration off-gas after downstream processing of $\mathrm{SO}_{2}$ could be recycled to provide the diluent for the regeneration air, as well as the lift gas for the transfer and separator vessels.

Figure 7-20 shows a single pass riser sulfider and a bubbling-bed regenerator, typical of a commercial FCC-type system. A significantly higher (or total) sorbent circulation rate will be required for this configuration as opposed to Figure 7-19. However, much higher sulfider gas velocities can be used for this system, typically 15 to $20 \mathrm{ft} / \mathrm{s}$ as opposed to around $1 \mathrm{ft} / \mathrm{s}$ for the bubbling-bed sulfider, thus resulting in a riser reactor of much smaller diameter than the bubbling bed and higher gas throughputs. 


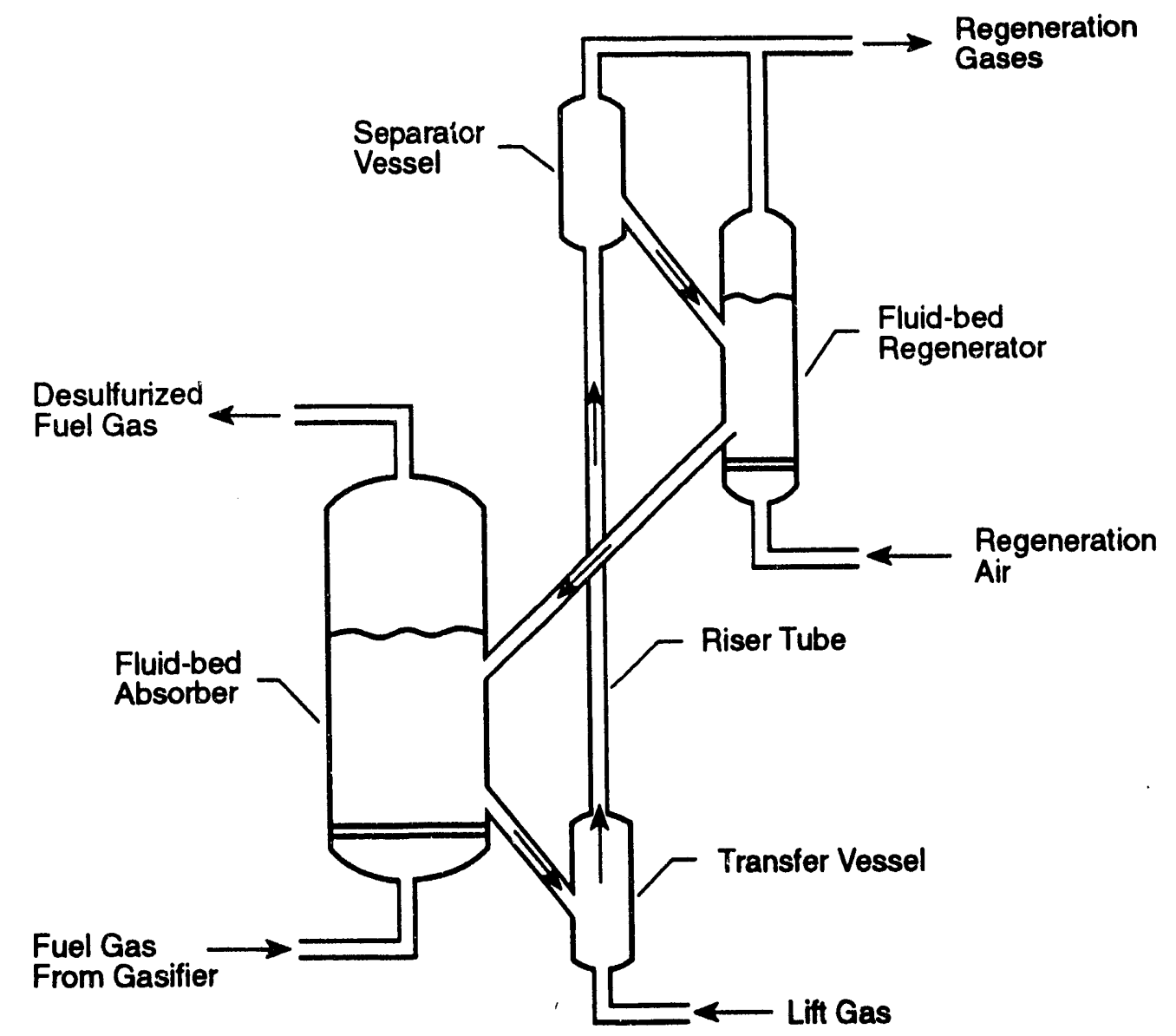

Figure 7-19. Fluld-bed absorber with fluld-bed regenerator both operating in a bubbling fluldized-bed mode.

Figure 7-21 shows a system consisting of a circulating fluid-bed sulfider and a bubblingbed regenerator. This system not only retains the advantage of as high a gas velocity as the riser but also requires a lower circulation rate which would be intermediate between the configurations of Figures 7-19 and 7-20. Figure 7-21 also shows the downstream two-stage Direct Sulfur Recovery Process (DSRP) being developed with DOE/METC sponsorship at RTI (Gangwal and McMichael, 1991). This process is projected to convert up to 99 percent $\mathrm{SO}_{2}$ to elemental sulfur in two catalytic reactors using selective catalysts to reduce $\mathrm{SO}_{2}$ to sulfur using a small slip stream of the reducing gas. A part of the off-gas after sulfur recovery is recycled to provide diluent for the regenerator and used as the sorbent lift gas to transport the sorbent between the two vessels. A portion of the diluent corresponding to the $\mathrm{N}_{2}$ in the incoming air to the regenerator is mixed with the raw coal gas as shown, or alternatively it could be directly discharged to the turbine.

In all cases a bubbling-bed regenerator is used to provide a reasonable amount of counter-flow of the sorbent to the gas. This would help in stripping the sorbent of any residual sulfate that may form by decomposing it at the highest temperature, which is expected to be at the point of air inlet to the regenerator. The systems should be operated with sorbent in partially sulfided mode at all times to minimize overall attrition and sulfate formation in the regenerator. A typical sulfidation conversion window between the regenerator and sulfider might be 15 to 35 percent for the two-bubbling-bed system (Figure 7-19). This is because of the greater solid residence time in this system. The circulating-bed systems will operate within a much smaller window because of the greater circulation rate. The greater circulation rate will also help to moderate significantly the temperature increase in the regenerators shown in Figures 7-19 and 7-20, as demonstrated in Section 7.2.2. 


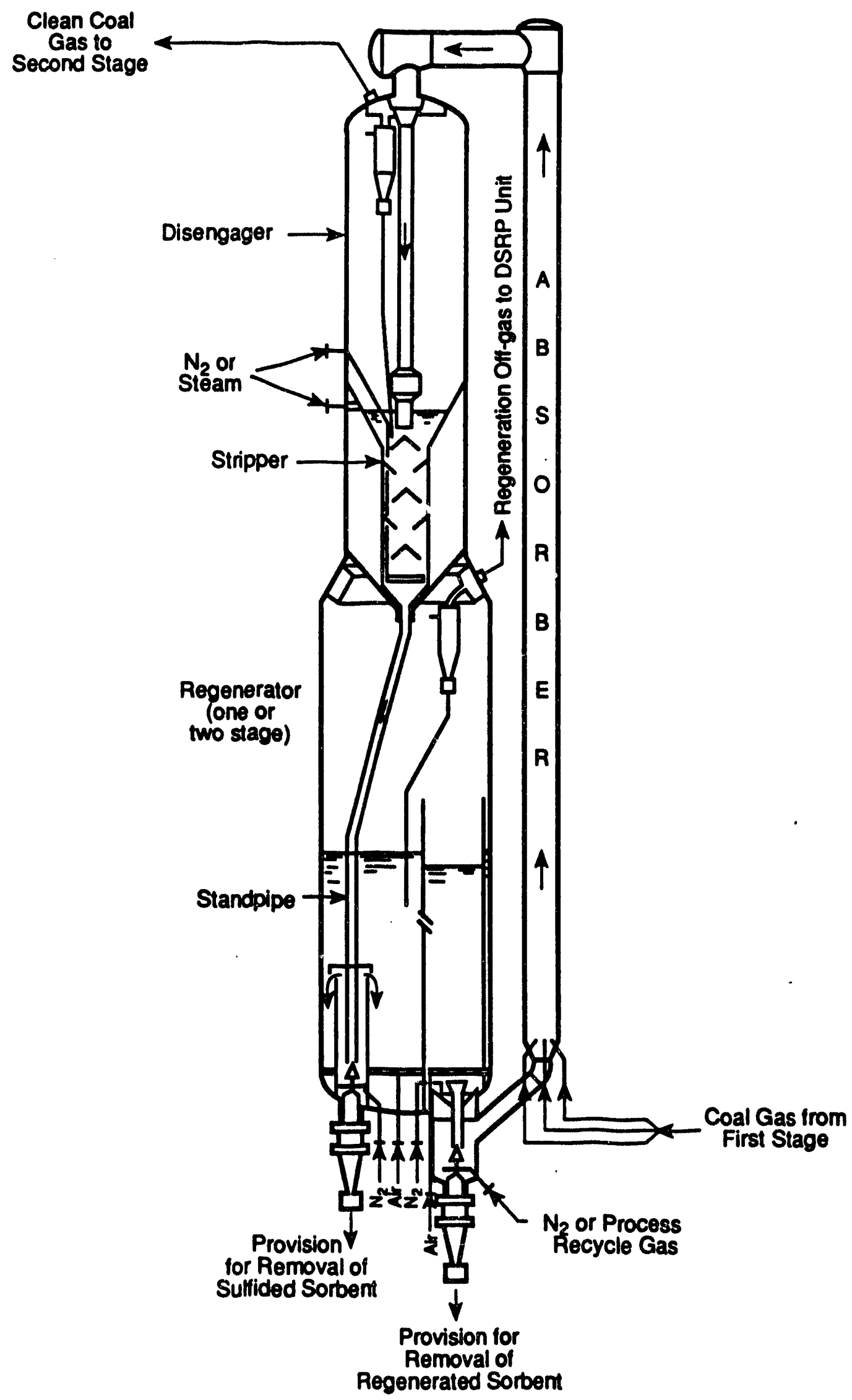

Figure 7-20. Schematic of a conceptual fluld-bed hot-gas desulfurization system employing a riser for sulfider and a bubbling fluid bed for regenerator. 


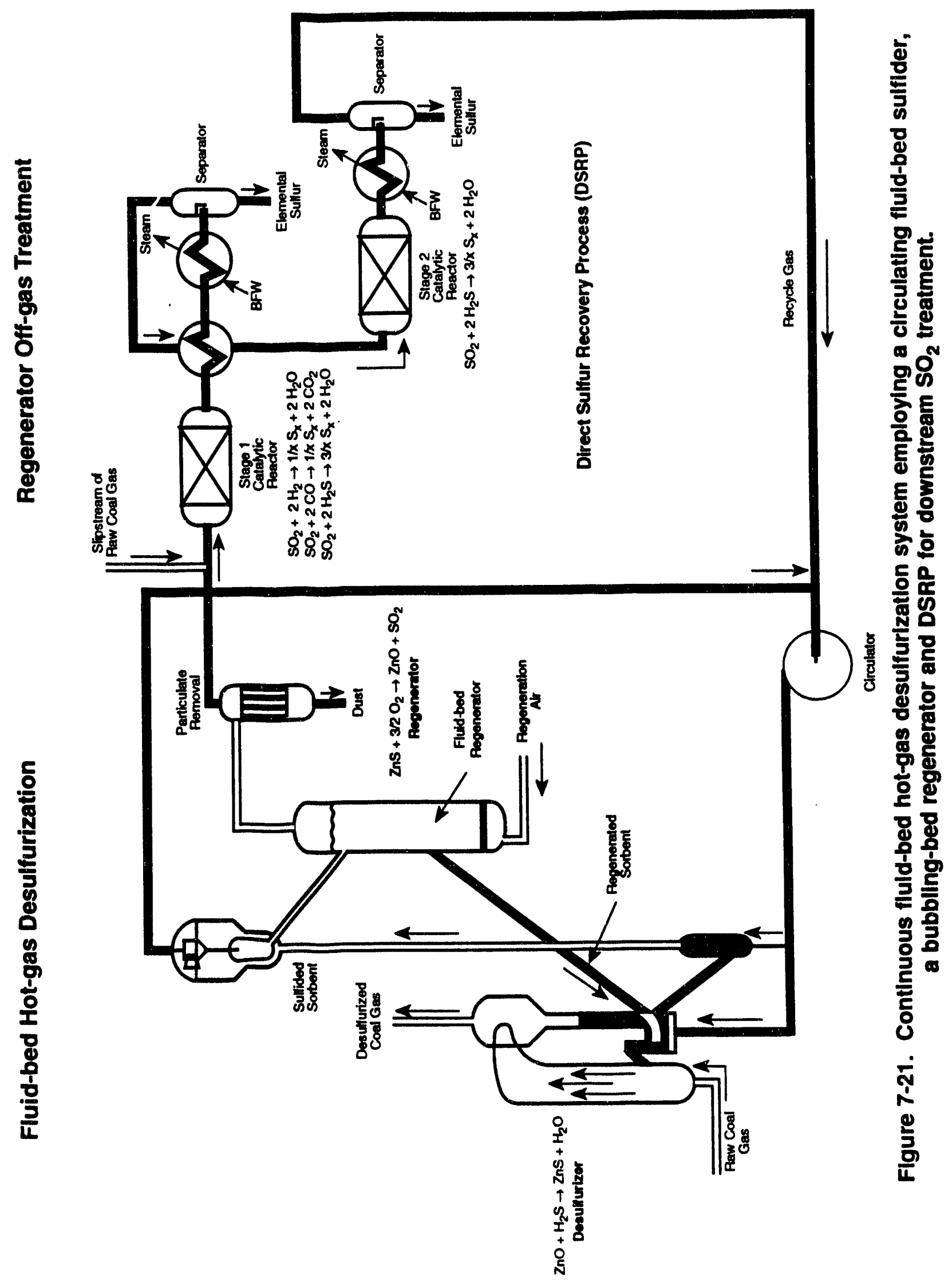




\section{CHAPTER 8}

\section{MATHEMATICAL MODELING}

\subsection{BACKGROUND}

While considerable emphasis has been given in the past to developing highiy reactive and attrition-resistant sorbents for hot-gas desulfurization, very little effort has been expended in understanding the kinetics and hydrodynamics of the desulfurization in a fluidized-bed reactor. Although a number of studies have been reported in the literature on the development of mathematical models describing the behavior of integral reactors, including fluid-bed reactors, used in a high-desulfurization process (Wang et al., 1988; Bagajewicz, 1992; Schrodt, 1981), none of these models adequately predicts the desulfurization of hot coal gas in a semi-batch fluisized-bed reactor used in the present study.

Initial modeling studies of hot-gas desulfurization reactors operating in a fluidized-bed mode by Wang et al. (1988) were aimed at designing and optimizing steady-state continuous recirculation reactors that could be used in a commercial operation. Cockrill et al. (1988) later modified the steady-state material balances in order to describe the nperation of a batch fluidizedbed reactor such as the one used in this study. Although this batch model, which was based on the three-phase fluidization model of Kunii and Levenspiel [K-L] (1969), was fairly successful in describing the limited experimental results of Schrodt (1981), it failed miserably in predicting the experimental results obtained with zinc ferrite sorbents in the bench reactor as discussed in a previous topical report (Gupta and Gangwal, 1991). It is believed that the K-L model is perhaps not applicable at the high pressures (15 atm) that were used in the study. Furthermore, the validity of assuming either the homogeneous reaction model or the shrinking core kinetics is doubtful. Furthermore, there are at least half a dozen unknown parameters in the model. Even if the model were to adequately fit the experimental data by choosing the proper values of these parameters, the model predictions would have very little credibility.

The difficult problem in modeling a fluidized-bed reactor similar to the one that was used in this study is lack of understanding of the hydrodynamics of fluidization and the kinetics of reaction, and, in particular, their interaction. For example, a hot gas desulfurization reaction in a fixed-bed containing cylindrical sorbent pellets is inherently diffusion-controlled while in a fluidized-bed the sorbent with the same chemical composition but in the form of fine particles exhibits kinetics which are frequently predominantly reaction-rate controlled and, to a lesser extent, external or internal diffusion-controlled. This complexity in the reaction mechanism as a function of contacting pattern (fixed bed vs. fluidized bed) does not pose that serious a problem; the real problem, specifically in the case of fluidized-bed reactors, is posed by poor understanding of gas and solid flow patterns and concentrations. In fact, a systematic study conducted a few years ago by DOE showed that the poor understanding of hydrodynamics of fluidized systems in industry was responsible for 87 percent of the operational problems, e.g., poor conversion, low yields, operational problems in transferring solids between process vessels, etc.

The foregoing discussion sheds some light on the importance of understanding the behavior of fluidized-bed reactors, both in terms of hydrodynamics and kinetics, and the two synergistically. Synergy is extremely important because hydrodynamics and kinetic variables in most of the commercial applications cannot be decoupled. For example, increasing the superficial 
velocity in a fluidized-bed reactor might result in higher gas throughputs and higher mass transfer rates between gas and solid, but at the same tim? this increase in velocity may reduce the gas residence time in the reactor so that the desired reaction is never completed. There is a similar argument for the solids inventory or circulation rate in the reactor. Therefore, it is paramount that both hydrodynamics and kinetics be considered simultaneously and their interaction be taken into account. To this end, the following analysis, although simplified, provides some rather intriguing insights into the operation of a semi-batch fluidized-bed reactor.

\subsection{MODEL DEVELOPMENT}

The semi-batch fluidized-bed reactor used in modeling is schematically shown in Figure 8-1. A known quantity of sorbent is initially charged to the reactor. A simulated coal gas containing $\mathrm{H}_{2} \mathrm{~S}$ of known concentration is then fed to the reactor. The following assumptions are made to simplify the mathematics of the problem:

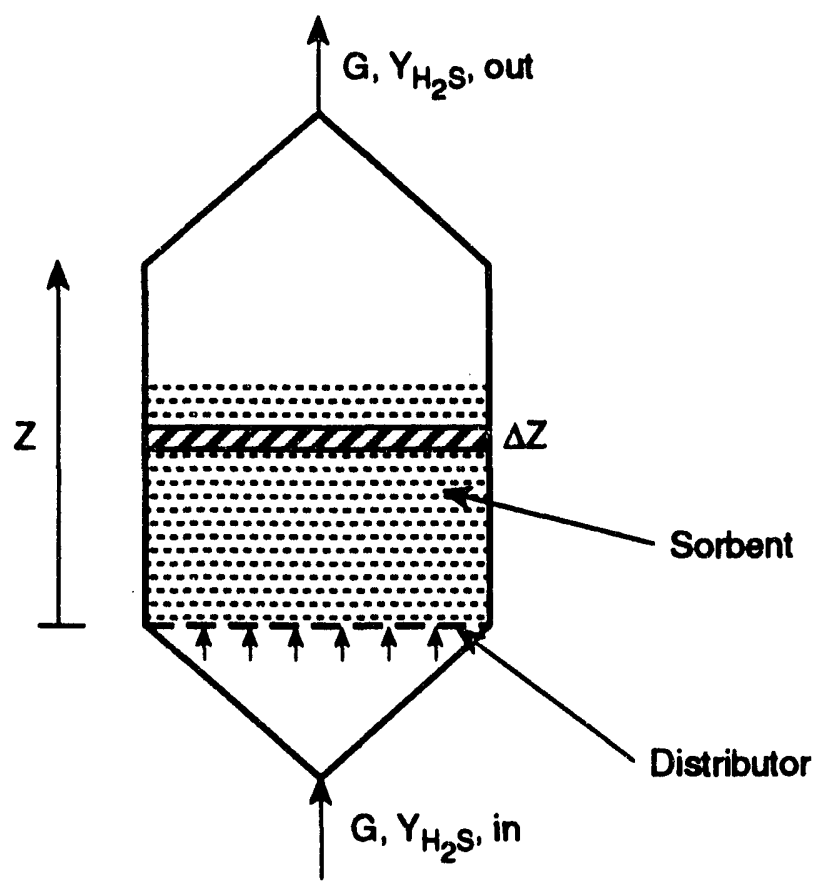

Figure 8-1. Schematic of seml-batch fluidized-bed reactor. 
- Gas in the reactor follows a plug-flow behavior,

$$
\therefore \quad y=y(z, t) \text {. }
$$

- Solids are well-mixed, i.e., behave in a continuc us stirred-tank reactor (CSTR) mode,

$$
\therefore \quad x=x(t) \text {. }
$$

- The external mass transfer between gas and solid is neglected. Therefore, there is no concentration gradient in the gas film surrounding the solid.

- Sulfidation reaction is first order both in $\mathrm{H}_{2} \mathrm{~S}$ and $\mathrm{ZnO}$ concentrations, i.e.,

$$
-r_{\mathrm{H}_{2} \mathrm{~S}}=k C_{\mathrm{ZnO}} P_{\mathrm{H}_{2} \mathrm{~S}}
$$

- The total molar gas flow remains approximately constant because of the very low $\mathrm{H}_{2} \mathrm{~S}$ content of the coal gas,

$$
\frac{\partial G}{\partial t}=0 \quad \text { and } \quad \frac{\partial G}{\partial Z}=0
$$

The nomenclature for the symbols used in this chapier is given in the "List of Symbols" (on page 137).

Taking an $\mathrm{H}_{2} \mathrm{~S}$ balance between levels $\mathrm{Z}$ and $\mathrm{Z}+\Delta Z$, one gits

$$
G Y_{H_{2}} \mathrm{~s}\left|z-G Y_{H_{2}} \mathrm{~s}\right| z+\Delta Z=(\Delta Z) \cdot A \cdot \rho_{B}\left(-r_{H_{2}} \mathrm{~s}\right)
$$

or

$$
G \frac{\partial Y_{H_{2} s}}{\partial Z}=-A \rho_{B}\left(-r_{H_{2} s}\right)
$$

Here $A$ is cross-sectional area $\left(\mathrm{cm}^{2}\right) ; \rho_{B}$ is bed density $\left(\mathrm{g} / \mathrm{cm}^{3}\right), G$ is the total molar rate, $Y_{\mathrm{H}_{2}} \mathrm{~S}$ is the mol fraction of $\mathrm{H}_{2} \mathrm{~S}$. 
Substituting the expressions for $-\mathrm{r}_{\mathrm{H}_{2} \mathrm{~S}}$ from Equation (8-3), one obtains

$$
G \frac{\partial Y_{\mathrm{H}_{2} \mathrm{~S}}}{\partial Z}=-A \rho_{B} k C_{Z n O} P_{\mathrm{H}_{2} \mathrm{~S}}
$$

$k$ here is the global reaction rate constant. The concentration of zinc oxide at any time $t$, i.e., $\mathrm{C}_{\mathrm{ZnO}}$, can be expressed in terms of conversion, $x$

$$
C_{\mathrm{ZnO}}=\left[C_{\mathrm{ZnO}}\right]_{t=0}(1-x)
$$

$\mathrm{C}_{\mathrm{ZnO}}$ at $t=0$ is a constant and depends primarily on the zinc to titanium ratio of the sorbent.

Equation (8-7) can be expressed as

$$
G \frac{\partial Y_{H_{2} S}}{\partial Z}=-\left.A P_{B} k C_{Z n_{0}}\right|_{r_{0}}(1-x) P_{H_{2} S} .
$$

Now $\mathrm{P}_{\mathrm{H}_{2} \mathrm{~S}}$ can be expressed in terms of mol fraction of $\mathrm{H}_{2} \mathrm{~S}$, i.e., $\mathrm{Y}_{\mathrm{H}_{2} \mathrm{~S}}$

$$
\begin{aligned}
& G \frac{\partial Y_{\mathrm{H}_{2} S}}{\partial Z}:-A \rho_{B} k C_{Z n o l_{1=0}}(1-x) P_{T} \cdot Y_{\mathrm{H}_{2} S} \\
& \frac{\sigma Y_{\mathrm{H}_{2} S}}{Y_{\mathrm{H}_{2} \mathrm{~S}}}=-\frac{\left.A \rho_{B} k C_{Z n o}\right|_{1=0} \cdot P_{T}}{G}(1-x) \partial Z .
\end{aligned}
$$

For the sake of simplicity, the variables can be expressed in terms of dimensionless quantities by using the following algebraic transformations:

Let $z^{\circ}=z / H$ where $H$ is the reactor height used, and $y^{*}=y_{H_{2} s} / y_{H_{2} S, i n}$ where $y_{H_{2} s} s_{H_{2} S, i n}$ is the mol fraction of $H_{2} S$ in the coal gas at the inlet of the reactor. Then,

$$
\begin{aligned}
& \frac{\partial y^{*}}{y^{*}}=-\frac{\left.A \rho_{B} H \cdot k C_{Z n o}\right|_{1=0}}{G} \cdot(1-x) \partial z^{*} . \\
& \text { Let } \quad \frac{\left.A \rho_{B} H \cdot k C_{Z n o}\right|_{t=0} P_{T}}{G}=\alpha .
\end{aligned}
$$

Now $A p_{B} H$ represents the total sorbent inventory in the reactor $W_{0}$; therefore, 


$$
\alpha=\frac{\left.W_{0} k C_{\mathrm{ZnO}}\right|_{t=0} P_{T}}{G}
$$

The dimensionless number, $\alpha$, is similar to a Peclet number. It is essentially a ratio of the kinetic flux to the momentum flux. As will be seen, this dimensionless group will be a major design parameter.

Now, Equation (8-12) can be written simply as

$$
\frac{\partial y^{*}}{y^{*}}=-\alpha(1-x) \partial z^{*} \text {. }
$$

Since $x \neq x\left(z^{*}\right)$, Equation $(8-15)$ can be integrated with a boundary condition that at $z=0\left(\therefore z^{*}\right.$ $=0), y_{H_{2} s}=y_{H_{2}} s$,in $\rightarrow y^{*}=1$, giving

$$
y^{*}=\exp \left[-\alpha(1-x) z^{*}\right]
$$

Now a second equation is needed to determine the dependence of conversion on time. This can be done simply by taking an unsteady-state sulfur balance on the sorbent. Between time " $t$ " and " $t+\Delta t$," the sulfur picked up by the sorbent must be equal to the sulfur removed from the gas stream. This can be mathematically expressed as

$$
G\left(Y_{\mathrm{H}_{2} \mathrm{~s}} \text {, inlet }-Y_{\mathrm{H}_{2} \mathrm{~s}}, \mathrm{exit}\right)=A H_{\rho_{B}} \cdot \lambda_{0} \cdot \frac{d x}{d t}
$$

Here, $\lambda_{0}$ represents the mols of $\mathrm{ZnO}$ initially present per $\mathrm{g}$ of total sorbent. For example, for $\mathrm{ZT}$ 4 , which has a $\mathrm{ZnO}$ to $\mathrm{TiO}_{2}$ molar ratio of 1.5 and a 5 percent bentonite content, $\lambda_{0}=0.007056$. $x$ in Equation (8-17) is the conversion of $\mathrm{ZnO}$ into $\mathrm{ZnS}$ via $\mathrm{ZnO}+\mathrm{H}_{2} \mathrm{~S} \rightarrow \mathrm{ZnS}+\mathrm{H}_{2} \mathrm{O}$, as defined by Equation (8-8).

Equation (8-17) can be simplified and expressed as

$$
\frac{d x}{d t}=\frac{G Y_{H_{2} S \text {,indet }}\left(1-y_{\theta}^{*}\right)}{A H P_{B} \lambda_{0}}=\frac{G Y_{H_{2} S \text {,indet }}\left(1-y_{\theta}^{*}\right)}{W_{0} \lambda_{0}} .
$$

Here again, $A H \rho_{B}=W_{0}$ represents sorbent inventory in the reactor and $y_{\theta}^{*}$ is simply the ratio of the $\mathrm{H}_{2} \mathrm{~S}$ concentration in reactor exit gas to the $\mathrm{H}_{2} \mathrm{~S}$ concentration of reactor inlet gas and hence represents the fraction of $\mathrm{H}_{2} \mathrm{~S}$ remaining in the gas stream.

Expressing $t$ in terms of dimensionless time $t$ by dividing it by a characteristic time, $T$, which is defined as

$$
T=\frac{G Y_{\mathrm{H}_{2} \text { S, inlet }}}{W_{0} \lambda_{0}}
$$

This characteristic time, $T$, simply represents the ratio of the inlet molar flow of $\mathrm{H}_{2} \mathrm{~S}$ to the reactor 
to the total mols of zinc oxide present. In other words, theoretically, if a residence time of $T$ is given to the gas, all the zinc oxide present in the sorbent will convert to $\mathrm{ZnS}$. Therefore, this parameter will determine the sorbent inventory needed for a given $\mathrm{H}_{2} \mathrm{~S}$ removal duty or vice versa. This dimensionless time $t^{\star}$ essentially represents the sorbent capacity utilization.

Equation (8-18) can be expressed as

$$
\frac{d x}{d t^{*}}=\left(1-y_{\theta}^{*}\right)
$$

Substituting the expression for $y^{*}$ from Equation (8-16)

$$
\begin{aligned}
& y_{\theta}^{*}=\exp [-\alpha(1-x)] \text { because } z^{*}=1 \text { for } y=y_{\theta}^{*} \\
& \text { or } \frac{d x}{d t^{*}}=[1-\exp -\alpha(1-x)] .
\end{aligned}
$$

This equation can be integrated analytically with an initial condition: at $t^{*}=0, x=0$, to obtain

$$
x+\frac{1}{\alpha} \ln \left(\frac{1-e^{-\alpha}}{1-e^{-\alpha(1-\alpha)}}\right)=t^{*} .
$$

This equation can be used to calculate the conversion of ZnO at any time t. Since Equation (823 ) is implicit in $x$, a plot between $x$ and $t$ for various values of $\alpha$ can be constructed. Such a plot is shown in Figure 8-2, which has been generated using a spectrum of $\alpha$ values.

Now, in order to establish the validity of the foregoing analysis, one can compare the experimentally observed breakthrough behavior of $\mathrm{H}_{2} \mathrm{~S}$ with that of model predictions. Again using the relationship, Equation (8-21), one can express

$$
y_{\theta}^{*}=\exp [-\alpha(1-x)]
$$

This equation gives a direct relationship between the conversion of zinc oxide and the fraction of $\mathrm{H}_{2} \mathrm{~S}$ unreacted.

Before digressing into the calculations of $\alpha$ and $T^{*}$ for the semi-batch reactor system used in this study, it may be worthwhile to examine the $\mathrm{H}_{2} \mathrm{~S}$ breakthrough behavior as a function of $\alpha$, based on Equations (8-23) and (8-24). Figure 8-3 shows the $y_{0}^{*}$ as a function of dimensionless time $t$ for various values of $\alpha$. It is very clear from this figure that for a satisfactory performance, a minimum value of $\alpha$ that is needed is 10 . Below $\alpha=10$, the prebreakthrough $\mathrm{H}_{2} \mathrm{~S}$ levels are not acceptable and also the sorbent capacity utilization, which is incidentally approximately equal to the dimensionless time $t$ shown on the abscissa in Figure $8-3$, will be less than 40 percent, which may not be acceptable from an economic standpoint. Hence for an efficient operation of the reactor, an $\alpha$ value of $>10$ is recommended.

Looking into the components that constitute $\alpha$, i.e.,according to Equation (8-14), 


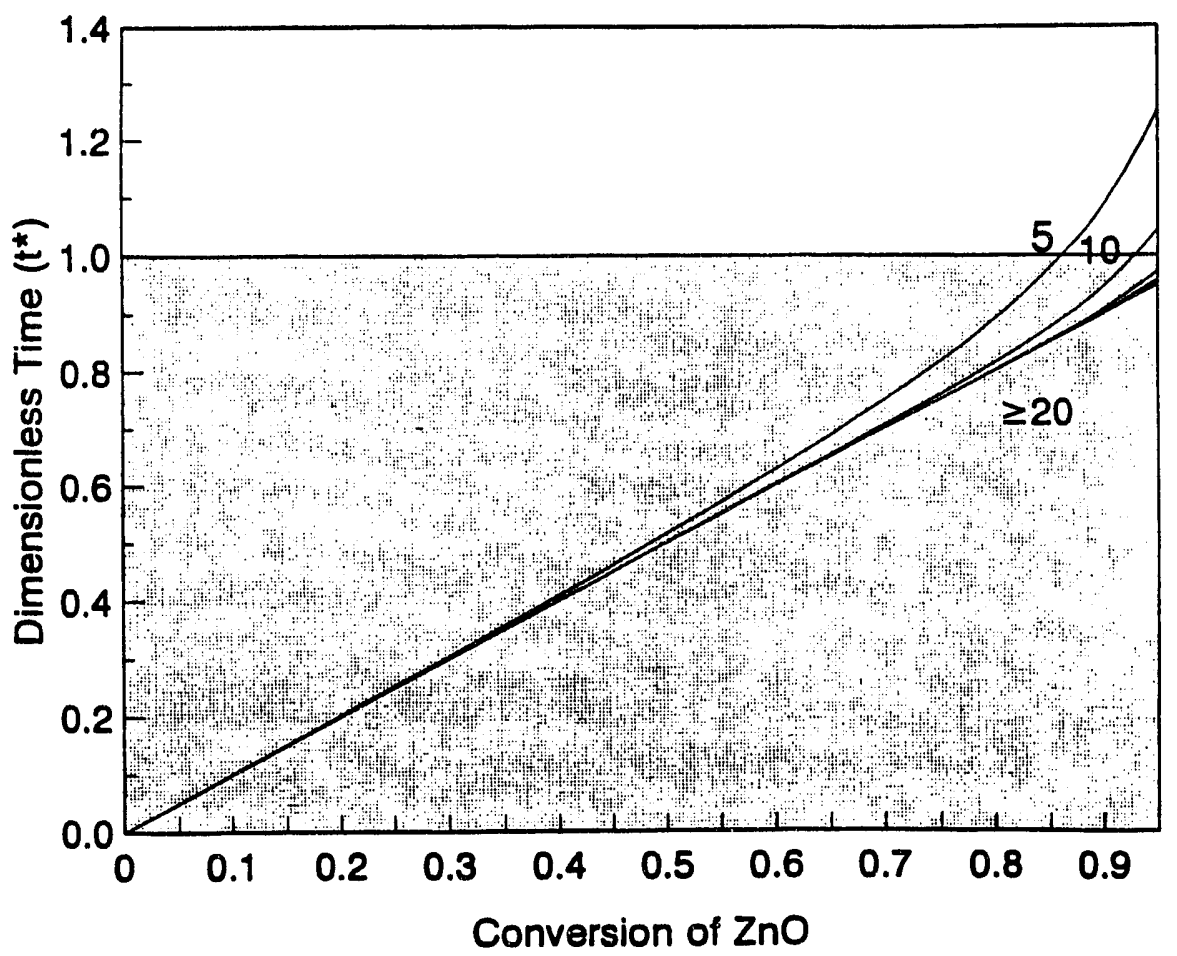

Figure 8-2. ZnO conversion as a function of dimensionless time $\left(t^{*}\right)$ for various values of $\alpha$.

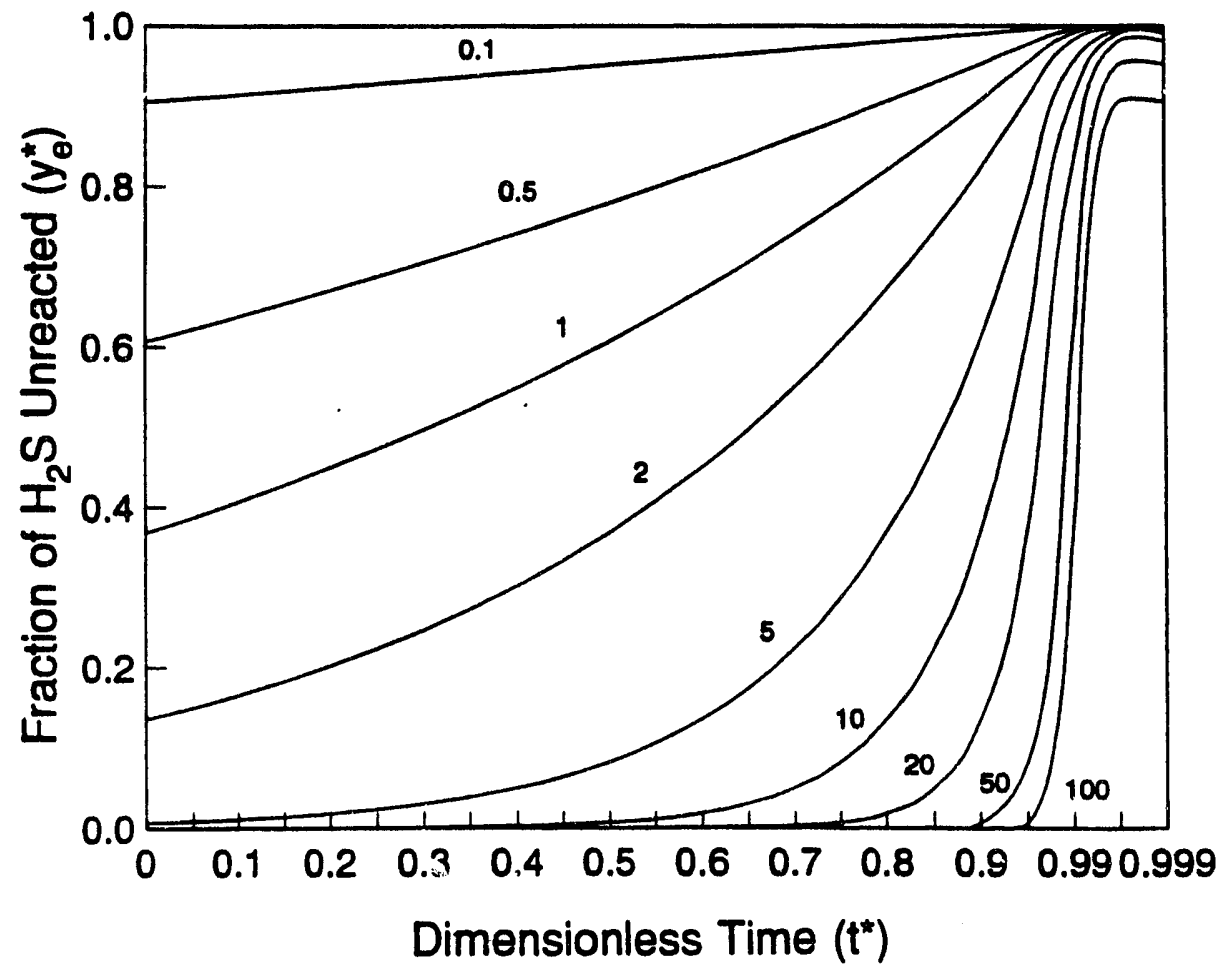

Figure 8-3. Fraction of $\mathrm{H}_{2} \mathrm{~S}$ unreacted as a function of dimensionless time ( $\left(^{*}\right)$ for varlous values of $\alpha$. 


$$
\alpha=\left(\left.W_{0} k C_{Z n O}\right|_{t=0} P_{T}\right) / G
$$

qualitatively, the value of $\alpha$ can be increased by

- Increasing the sorbent inventory,

- Increasing the reaction rate constant,

- Increasing the zinc oxide content of the sorbent,

- Increasing the total pressure, or

- Decreasing the molar flow rate of coai gas.

All these trends are observed experimentally. Therefore, this analysis at least qualitatively predicts the system behavior.

For $350 \mathrm{~g}$ of the sorbent typically used in the bench runs, at $15 \mathrm{~atm}$ total pressure and a coal gas flow rate of $35 \mathrm{slpm}$, the value of the rate constant $k$ that will be needed for $\alpha=10$ can be estimated. This value comes out to be $4.16 \mathrm{cc}$ gas $/ \mathrm{g}$ sorbent/s, which appears to be reasonable.

Based on the rate data collected in the TGR, estimates of the global rate constant $k$, are between 2 to $8 \mathrm{cc}$ gas/g sorbent/s as discussed in Section 7.2.1 of Chapter 7. A value of $k=5$ will result in an $\alpha$ value of 12 which seems reasonable.

Using the K-L model, as shown in the previous topical report (Gupta and Gangwal, 1991), a value of $1 \times 10^{7} \mathrm{~cm}^{3} /\left(\mathrm{mol} / \mathrm{cm}^{3}\right) / \mathrm{h} / \mathrm{g}$ of sorbent was estimated for the global rate constant. Converting, this value comes out to be $0.5642 \mathrm{cc}$ gas $/ \mathrm{g}$ sorbent/s. This value is about an order of magnitude lower than the value estimated using the present model. This will be expected as the fluidized-bed reactors are known to have faster kinetics than the fixed-bed reactors.

Since $k$ is a first order rate constant, its per-s value is about 5 . This value is at least an order of magnitude higher than the value in a fixed-bed reactor $(k-0.1)$ due to the elimination of mass transfer resistance.

Figure 8-3 showed the dependence of $y_{\theta}^{*}$ as a function of $t^{*}$ for various values of $\alpha$. In a real system, the $y_{\theta}^{*}$ values are expected to range between 0 and 0.1 because at least 95 percent of the $\mathrm{H}_{2} \mathrm{~S}$ from the coal gas must be removed. Hence, the $y$ scale on Figure 8-3 was amplified to show the operating range. Figure 8-4 shows the modified chart. For example, most of the bench runs were conducted using the Texaco gas that contained 12,000 ppm of $\mathrm{H}_{2} \mathrm{~S}\left(\mathrm{Y}_{\mathrm{H}_{2} \mathrm{~S} \text {, inlet }}\right.$ $=1.2$ percent) and the desulfurization process was carried out until the $\mathrm{H}_{2} \mathrm{~S}$ concentration $2 n^{\prime}$ the exit gas became 500 ppmv, thus giving a $y^{*}=0.0417$.

As shown in Figure $8-4$, for $a y^{\circ}=0.0417$, one needs to operate the reactor at a position where $\alpha$ is between 10 and 20 to optain reasonable sorbent utilization and low pre-breakthrough levels. A computation of $\alpha$ for $y^{\prime}=0.0417$ is shown in Figure 8-5, which gives a value of breakthrough time needed at any given $\alpha$. The breakthrough time is expressed as a dimensionless time that was defined earlier.

\subsection{COMPARISON WITH EXPERIMENTAL DATA}

The next logical step to determine the credibility of this analysis is to compare it with the experimental data taken on breakthrough. Since the value of the rate constant $k$ is not known with reasonable certainty, the best way to compare the experimental data with the model was to extract a value of $k$ which will make the model fit these data. 


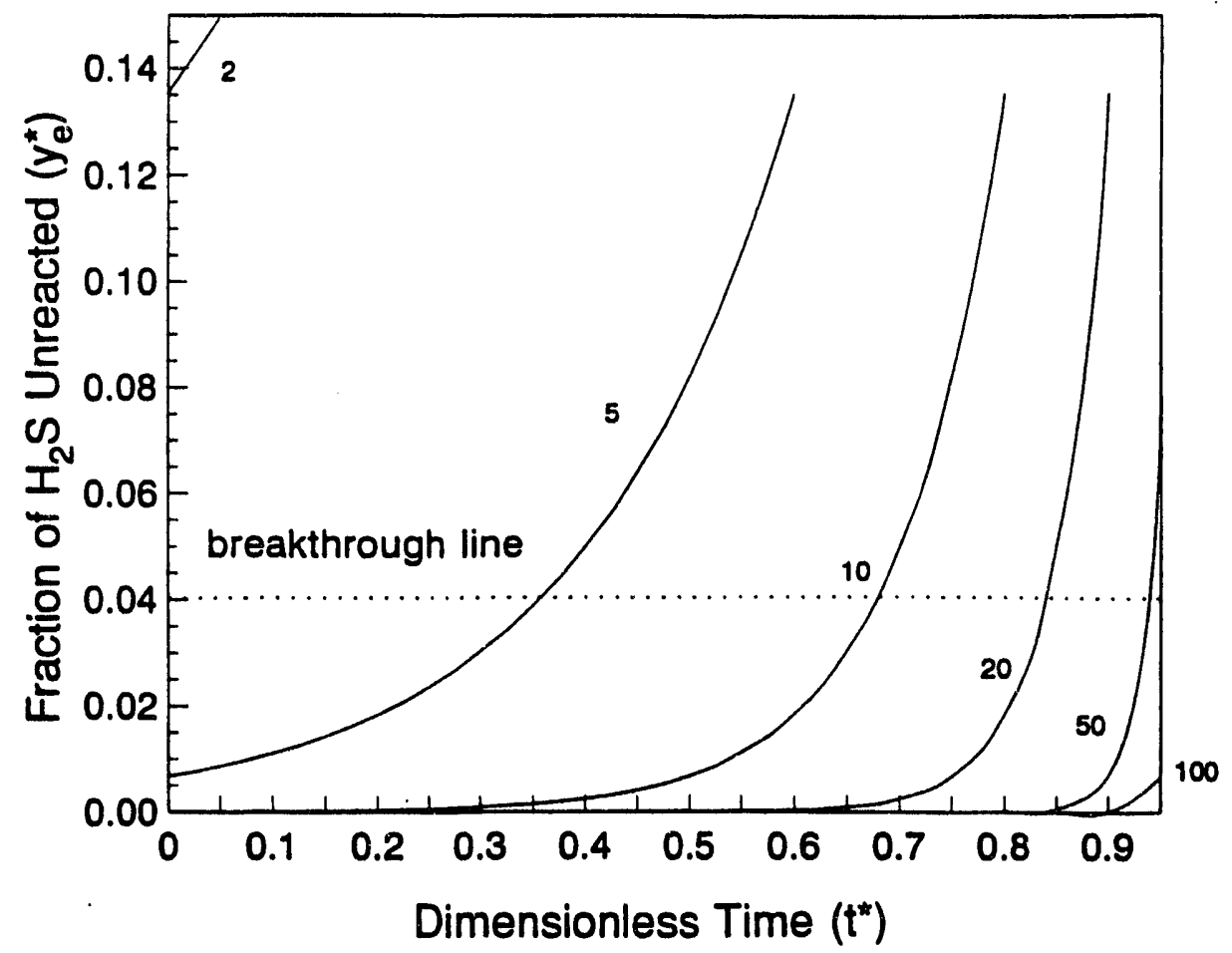

Figure 8-4. Fraction of $\mathrm{H}_{2} \mathrm{~S}$ unreacted $\left(\mathrm{y}_{0}^{*}\right)$ as a function of dimensionless time for various vales of $\alpha$ for $a y_{0}^{*}$ range of 0 to 0.14 .

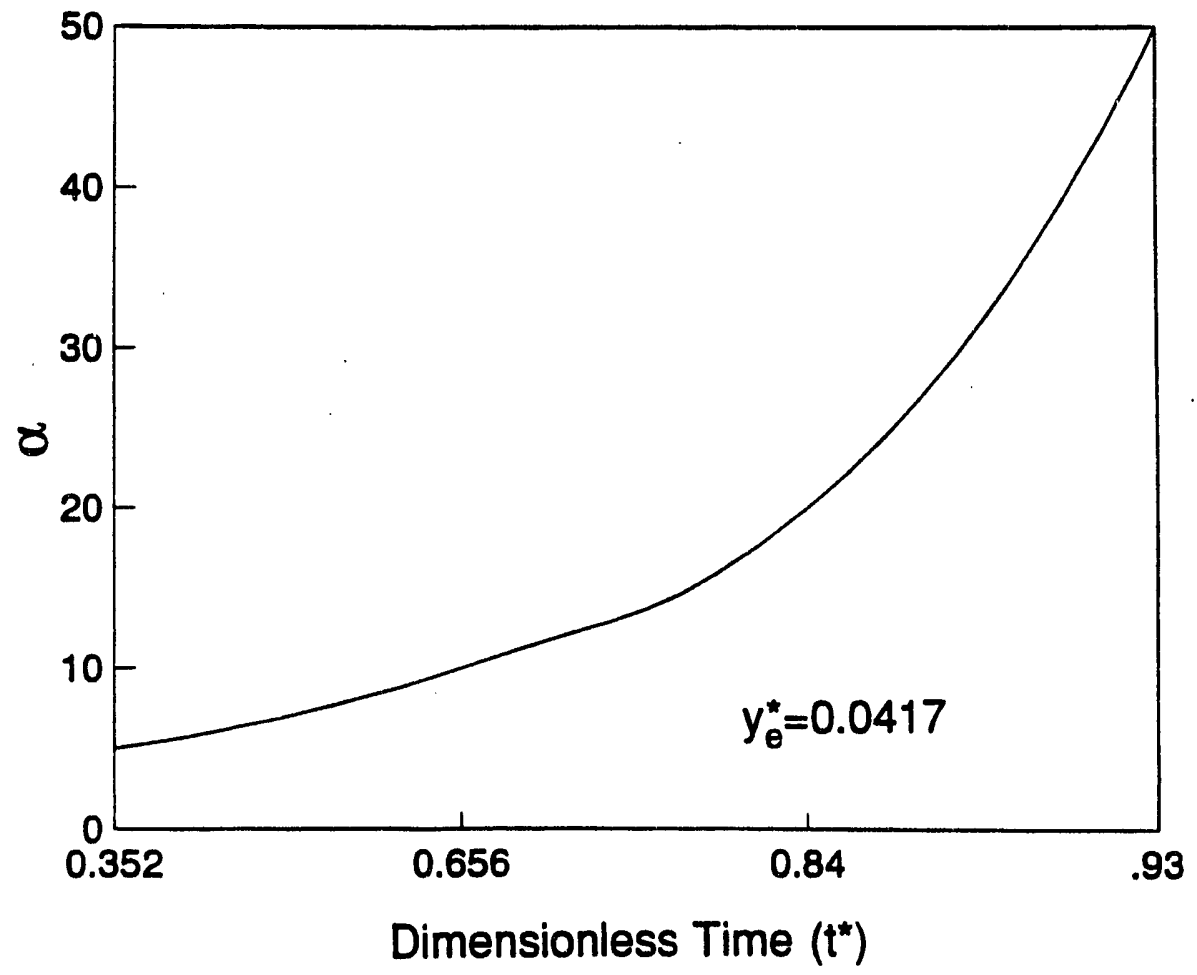

Figure 8-5. Dimensionless parameter, $\alpha$, as a function of dimensionless time for $y_{0}^{*}=0.417$. 
Figure 8-6 shows a comparison of experimental data with the model predictions. The two curves in the figure are for two values of $\alpha$, namely 7.7 and 8.4. The experimental data here are taken from Run No. 9, Cycle No. 1, that was made at $750^{\circ} \mathrm{C}, 15 \mathrm{~atm}$ and in Texaco gas at a 35 slpm gas flow rate. Further run details can be found in Section 6.10.

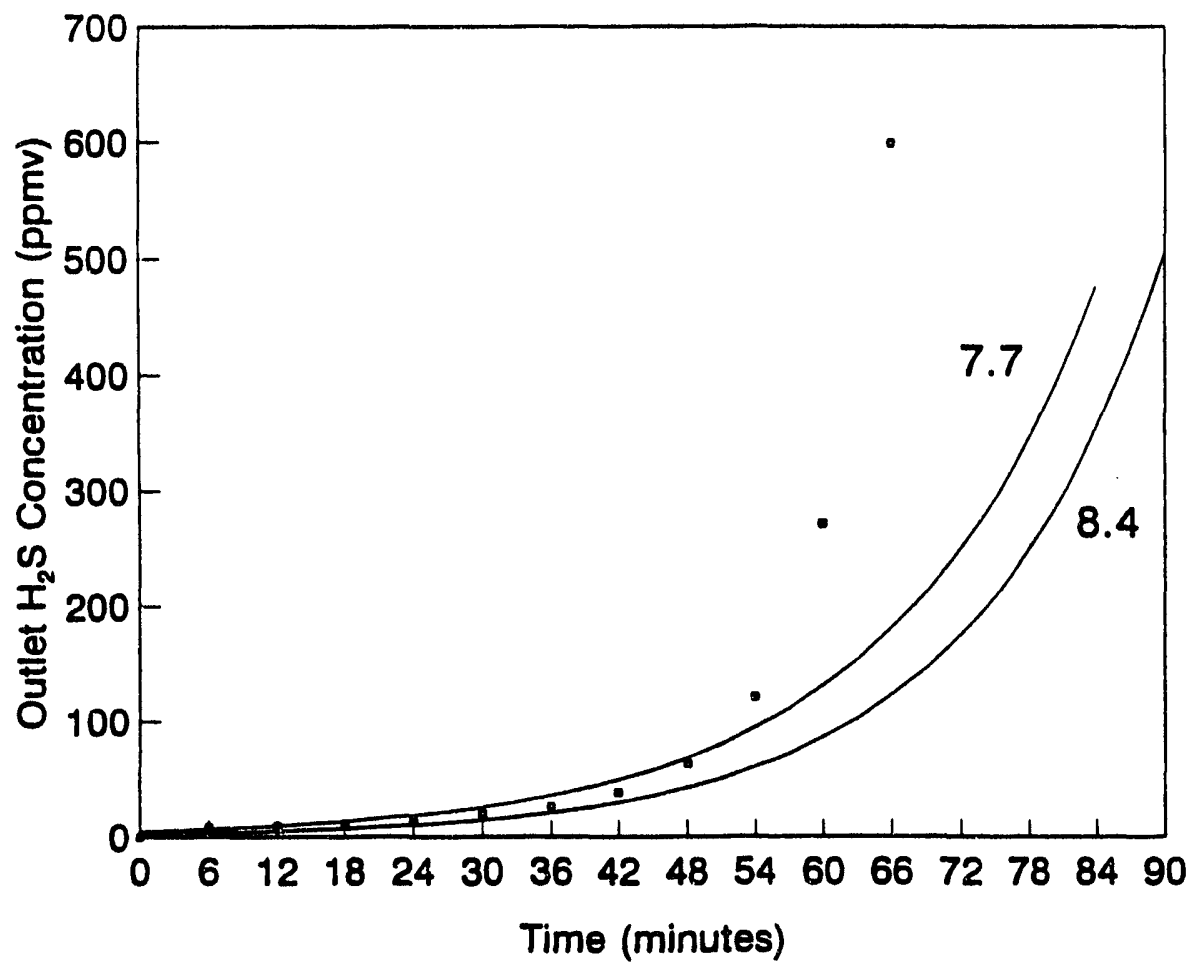

Figure 8-6. A comparison of experimental data (Run No. 9) with model predictions $(k=7.7$ and 8.4$)$.

At first glance, the comparison between experimental data and model appears to be very good, particularly in the prebreakthrough portion. However, experimental data indicate a sharp rise in $\mathrm{H}_{2} \mathrm{~S}$ concentration similar to a fixed bed, while the model predicts a more gradual rise in this case. Since the model does not take into account any mass transfer effects, both external and internal to the sorbent particles, the sharp breakthrough may be due to the diffusional effects.

To further determine the importance of diffusional effects, the second comparison between the experimental data and model prediction was made for the high velocity run (Run No. 10). Figure 8-7 shows the comparison. It is to be noted here that the superficial velocity used in this run was about 2.2 times that of Run No. 9 for which the earlier comparison was shown. Here it is found that the comparison between the data and model is better than in the previous case. High velocity in the reactor will lead to a significantly lower diffusional resistance, or higher mass transfer rates; as a result, the breakthrough curve is more diffused and gradual compared to the previous case.

Both runs compared here were carried out at $750^{\circ} \mathrm{C}$, and in both cases a value of $\alpha$ between 8 and 9 was obtained. Since in the high velocity case, the sorbent inventory was 1.43 times ( $500 \mathrm{~g}$ vs. $350 \mathrm{~g}$ ) greater and the gas flow was increased by 2.05 times, there is a net increase in the value of global reaction rate constant $k$ by 58 percent just due to the increase in gas velocity. The low velocity case indicated a superficial gas velocity that was about four times 


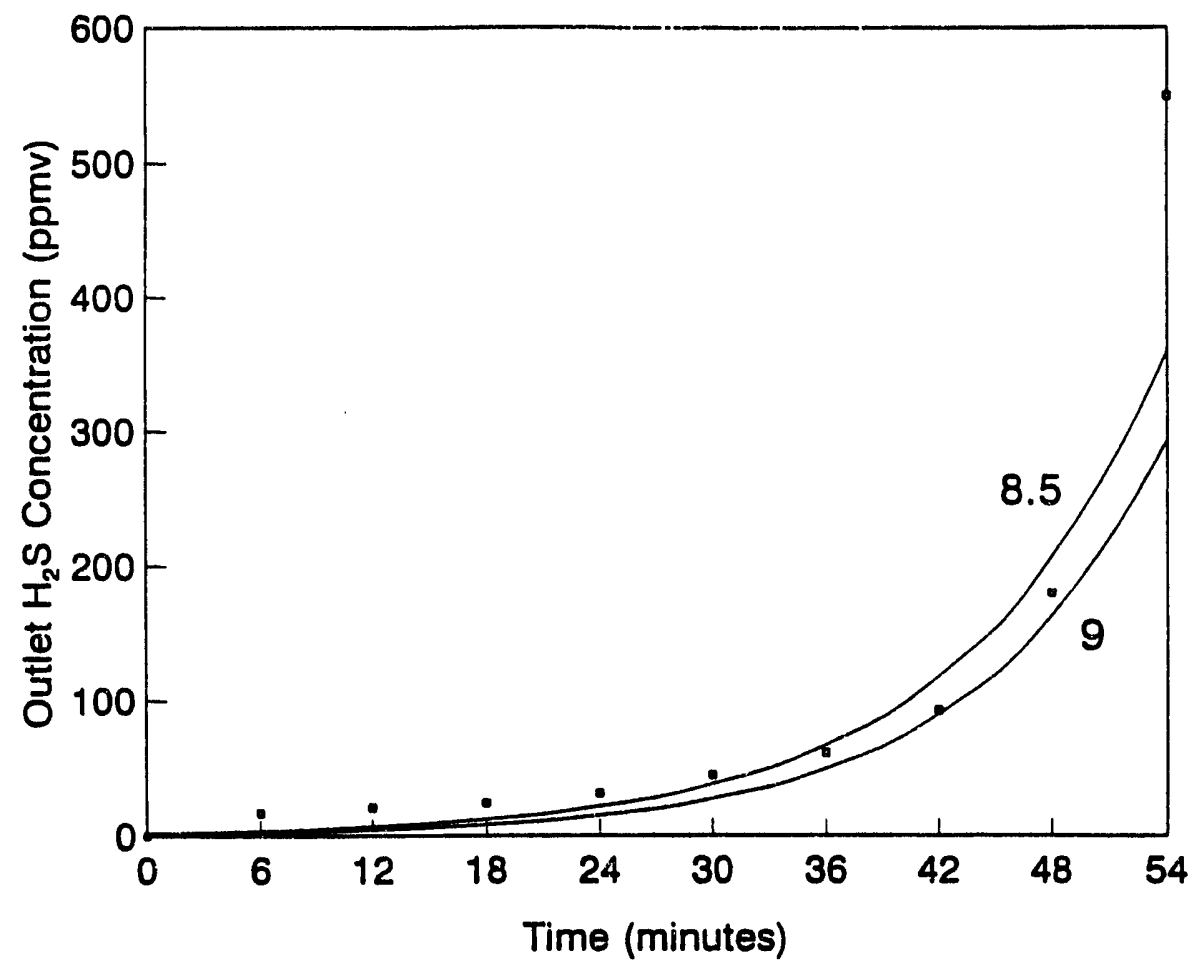

Figure 8-7. A comparison of experimental data (Run No. 10) for high velocity case with model predictions ( $k=8.5$ and 9$)$.

that of the minimum fluidization velocity $\left(U_{\mathrm{mf}}\right)$ calculated on the basis of the mean particle size.

In the case of the high velocity run, the bed was vigorously bubbling and the velocity was about $8.4 \mathrm{U}_{\mathrm{mf}}$. The contact between solids and gas in this case was extremely good. Most industrial bubbling fluidized-bed reactors are operated at a $U / U_{m f}$ of about 8 to 12. Due to high velocity and hence better gas-solid contacting, mass transfer rates between the coal gas and sorbent particles will be significantly faster than in the low velocity case. This perhaps explains the 58 percent increase in the global reaction rate constant. Thus, the model fairly well simulates the experimental data with low diffusional effects.

\subsection{POSSIBLE IMPROVEMENTS TO MODEL}

Since the model described in this chapter is based on a number of very simplified assumptions such as perfect mixing of solids and plug-flow of gas, there is a lot of room for improvement. Also, the mass transfer effects cannot be completely neglected. The next version of the model should incorporate diffusional resistances to predict the sharp breakthrough behavior observed in the low velocity case.

Regarding the application of fluidized bed models, a number of codes are presently available. Most of these codes are extremely complex and require a supercomputer to run them. Also, a number of fuzz factors that are built into these codes need to be specified during the execution. Therefore, at this point, it does not appear worthwhile to invest the resources in adapting one of those multiphase flow codes for this application.

Unfortunately, the global reaction rate constant that is needed to design a reactor cannot 
be determined a priori. As is shown, $k$ depends not only on the temperature but also on the hydrodynamics (gas-solid contacting). The rate constants determined from laboratory data, for example from a TGA, cannot be used in reactor design as such. The rate data taken on a TGA have a big mass transfer component which is generally not present in a bench test. Therefore, a carefully controlled run must be carried out in the bench reactor under the conditions of operation of a commercial system to get some realistic estinates of reaction rate constant. These issues should be addressed in the next study. 


\section{CHAPTER 9}

\section{CONCLUSIONS AND RECOMMENDATIONS}

This study investigated the feasibility of using zinc titanate sorbents in a fluidized-bed reactor for desulfurization of hot coal-derived gases. Attempts were made to prepare a series of zinc titanate sorbent formulations with high chemical reactivity and, in particular, high attrition resistance suitable for application in a fluidized-bed reactor using a number of techniques. Selected sorbent formulations were tested in the HTHP bench-unit.

Significant accomplishments and major conclusions of this study are the following:

- Ten HTHP runs were carried out, each involving 10 sulfidation-regeneration cycles in the bench-scale unit that was designed in the base program, and is capable of operation at up to $871^{\circ} \mathrm{C}$ at $20 \mathrm{~atm}$.

- Granulation and spray drying techniques were investigated to prepare durable sorbents in the $\mathbf{5 0}$ to $\mathbf{3 0 0 \mu \mathrm { m }}$ size range for circulating and bubbling fluidized-bed applications.

- Sorbent formulations prepared by DuPont and UCl using spray drying exhibited poor overall performance as measured by attrition resistance and chemical reactivity.

- Granulation proved to be the superior technique for manufacture of zinc titanate. A number of sorbent formulations prepared using this technique exhibited excellent durability, attrition resistance, and sulfur capacity during multicycle testing. However, the process parameters for the granulation process need to be optimized.

- Three promising sorbents designated as $Z T-2, Z T-5$, and $Z T-4$ were identified using screening tests. ZT-2 and ZT-5 were prepared with 2 percent binder using zinc to titanium mol ratios of 0.8 and 1.5, respectively. ZT-4 was prepared with 5 percent binder and a zinc to titanium ratio of 1.5. ZT-4 was found to have the best overall performance of all the sorbents tested in terms of attrition resistance, long-term chemical reactivity, and sulfur capacity.

- It was found that partially sulfided $Z T-4$ exhibited significantly higher attrition resistance than both fresh and regenerated $Z T-4$. The attrition resistance of sulfided ZT-4 was comparable to an equilibrium FCC catalyst (US260) prepared by Englehard Corporation. Equilibrium FCC catalysts are known to have significantly higher attrition resistance than the fresh catalyst because they have undergone a toughness process during the circulation between riser and regenerator.

- The fact that partially sulfided zinc titanate has significantly higher attrition resistance than fully regenerated or fresh zinc titanate suggests that a commercial desulfurization system should be operated in such a mode that zinc titanate is maintained in a partially sulfided state at all times. This mode of operation is expected to have additional advantages which include prevention of sulfate formation in the regenerator and nearly zero oxygen partial pressure in the regeneration off-gas. 
- Another very significant finding of the project was that ZT-4 did not undergo a measurable zinc loss over 10 cycles of bench-scale testing at temperatures as high as $750^{\circ} \mathrm{C}$ and high superficial fluidizing velocities up to $15 \mathrm{~cm} / \mathrm{s}\left(U / U_{\mathrm{mf}}>8\right)$ in the presence of Texaco gasifier gas. This is attributed to a very highly uniform distribution of zinc and titanium in the sorbent matrix.

- Unlike zinc ferrite sorbents, which show a decline in sulfur capture capacity with cycling, the sulfur capacity for zinc titanate sorbents at breakthrough remained fairly constant over 10 cycles at about 40 to 60 percent of their theoretical capacity in all the 10 multicycle tests.

- Commercial potential of the granulation method for zinc titanate manufacture was demonstrated by producing $1 \mathrm{ft}^{3}$ batch of $\mathrm{ZT}-5$ and $\mathrm{ZT-2}$ sorbents.

- It was demonstrated that sulfided sorbent can be completely regenerated with 1 to 5 percent $\mathrm{O}_{2}$ in $\mathrm{N}_{2}$. Sulfate formation was not found to occur at $760^{\circ} \mathrm{C}$ and $1.5 \mathrm{MPa}$. The inlet temperature could be controlled to reach the required $760^{\circ} \mathrm{C}$ with any of the oxygen contents tested.

- Regeneration of the zinc titanate sorbent demonstrated stoichiometric formation of an $\mathrm{SO}_{2}$ containing off-gas with potentially no oxygen according to $\mathrm{ZnS}+(3 / 2) \mathrm{O}_{2} \rightarrow \mathrm{ZnO}$ $+\mathrm{SO}_{2}$. A quasi-steady-state generation of $\mathrm{SO}_{2}$-containing off-gas vas demonstrated indicating that a constant steady-state $\mathrm{SO}_{2}$ content in the regeneration off-gas of a commercial fluidized-bed system can be obtained. The consistency of $\mathrm{SO}_{2}$ concentration is believed to be important for economical processing downstream to elemental sulfur or sulfuric acid.

- The sulfidation reaction was found to be controlled by intrinsic chemical reaction rather than external diffusion or pore diffusion. The apparent activation energy for the sulfidation reaction ranged from 15 to $20 \mathrm{kcal} / \mathrm{mol}$ depending on the sorbent composition. This indicates that significant reduction in size of the desulfurization system can be achieved by increasing the operating temperature. A simple mathematical model which assumed a well-mixed solid phase and plug flow of gas made a reasonable prediction of the breakthrough behavior in the batch HTHP reactor using a rate constant based on TGA measurements.

\section{RECOMMENDATIONS FOR FUTURE WORK}

Recommendations for future work are as follows:

- A 100 cycle test should be conducted with the $Z T-4$ sorbent at its expected operating limit of $750^{\circ} \mathrm{C}$ to evaluate long-term durability.

- Transfer of the zinc titanate sorbent production technology to the private sector should be conducted. This could involve detailed discussions with major catalyst manufacturers and presentation of results at national meetings. 
- To assist in the technology transfer, a large 500-kg batch of the sorbent should be prepared, thereby demonstrating the technology at a semi-commercial scale. Also, the sorbent cost for a commercial operation (i.e., in tonnage quantity) should be investigated by designing and costing a sorbent production plant. Some realistic projections of annualized cost and future sorbent demand should be carried out.

- The optimum particle size needed for commercial fluid-bed reactors should be determined. The suitability of the 100 to $30,00 \mathrm{~m}$ particle size that is currently being used should be reassessed for commercial systems taking into consideration the mode of fluidization, circulation between absorber and regenerator, etc.

- $\quad$ ZT-4 should be tested with actual coal-derived gases in the field. Potential sites include Dow Chemical's LGTI plant and Allision Gas Turbine's bench-scale two-stage direct coal-fired turbine system.

- Mathematical models should be developed for continuous hot-gas desulfurization systems using various configurations of fluidized beds (e.g., bubbling, circulating, and transport). Using these models, a semi-pilot scale continuous absorber-regenerator system with continuous sorbent circulation should be designed, built, and tested to serve as a prototype of a commercial system. 


\section{CHAPTER 10}

\section{REFERENCES}

ASTM. 1981. Attrition and Abrasion of Catalysts and Catalyst Carriers. American Society for Testing Materials D-4058.

Anderson, R.R., and K.C. Pratt. 1985. Introduction to Characterization and Testing of Catalysts. Academic Press, Orlando, pp. 190-196.

Bagajewicz, M.J. 1992. "Propagation of Reaction Fronts in Noncatalytic Nonisothermal GasSolid Fixed Bed Reactors." Chem. Eng. Comm. 112:145-164.

Bajura, R.A., and R.C. Bedick. 1991. "Update on DOE's IGCC Programs." In Proceedings of the 8th Annual International Pittsburgh Coal Conference, M.J. Maytield and A.B. Flowers (eds.), October.

Bartram, S.F., and R.A. Slepetys. 1961. "Compound Formation and Crystal Structure in the System ZnO-TiO ${ }_{2}$ " J. Am. Ceram. Soc. 44(10):493-499.

Bemrose, C.R., and J. Bridgwater. 1987. "A Review of Attrition and Attrition Test Methods." Powder Technology. 49:97-126.

Brunauer, S., P.H. Emmet, and E. Teller. 1938. "Adsorption of Gases in Multimolecular Layers." J. Am. Chem. Soc. 60:309-318.

Chemrys, W.L. 1992. Private Communications, United Catalysts, Inc., Louisville, KY.

Cockrill, D.E., F.R. Groves, and D.P. Harrison. 1988. "Modeling of a High-Temperature Fluidized-Bed Desulfurization Reactor." Presented at 1988 AlChE Spring National Meeting, Paper 9b, New Orleans, LA, March 6-10.

Contractor, R.M., H.E. Bergna, H.S. Horowitz, C.M. Blackstone, B. Malone, C.C. Torardi, B. Griffiths, U. Chowdbry, and A.W. Sleight. 1987. "Butane Oxidation to Maleic Anhydride Over Vanadium Phosphate Catalysts." Catalysis Today. 1:49-58.

Contractor, R.M., and A.W. Sleight. 1987. "Maleic Anhydride from C-4 Feedstocks Using Fluidized Bed Reactors." Catalysis Today. 1:587-607.

Cole, S.S., and W.K. Nelson. 1938. "The System Zinc Oxide - Titanium Dioxide. Zinc Orthotitanate and Solid Solutions with Titanium Dioxide." J. Phys. Chem. 42:245-251.

Cook, C.S., B. Parekh, E. Gal, and A.H. Furman. 1989. "Integrated Operation of a Pressurized Fixed-Bed Gasifier and Hot Gas Desulfurization Systems." In Proceedings of the Ninth Annual Gasification and Gas Stream Cleanup Systems Contractors' Review Meeting, DOE/METC-89/6107, Vol. I, NTIS/DE89011706, June, pp. 37-46.

Courty, P., H. Ajot, C. Marcilly, B. Delmon. 1973. "Oxydes Mixtes ou en Solution Solide sous Forme Tres Divisee Obtenus per Decomposition Thermique de Precurseurs Amorphes." Powder Diffraction. 7:21-38. 
Datta, R. 1992. Private Communications. Virginia Polytechnic Institute and State University, Blacksburg, VA.

Dulin, F.H., and D.E. Rase. 1960. "Phase Equilibria in the System ZnO-TiO ." J. Am. Ceram. Soc. $43(1): 125-131$.

Flytzani-Stephanopoulos, M., and K. Jothimurugesan. 1990. "Preparation of Extrusions of Bulk Mixed Oxide Compounds with High Macroporosity and Mechanical Strength." U.S. Patent No. 4,977,123, December 11.

Forsythe, W.L., and W.R. Hertwig. 1949. "Attrition Characteristics of Fluid Cracking Catalysts." Ind. Eng. Chem. 41:1200-1206.

Gal, E.M., S.C. Cook, A.H. Furman, and D.P. Smith. 1987. "Design Studies for Hot Gas Cleanup System in a Load Following Mode." In Proceedings of the VIIth Annual Gasification and Gas Stream Cleanup Systems Contractors' Review Meeting, DOE/METC87/6079, Vol. 2 (DE87006496), pp. 668-677.

Gangwal, S.K., S.M. Harkins, M.C. Woods, and S.J. Bossart. 1989. "Bench-Scale Testing of Novel High-Temperature Desulfurization Sorbents." Environmental Progress. 8(4):265.

Gangwal, S.K., S.M. Harkins, M.C. Woods, and T.N. Rogers. 1988. "Bench-Scale Testing of Novel High-Temperature Desulfurization Sobents." Report No. DOE/MC/23126-2662 (DE89000935), Morgantown Energy Technology Center, U.S. Department of Energy, Morgantown, WV.

Gangwal, S.K., and W.J. McMichael. 1991. "Direct Sulfur Recovery Process." In Proceedings of the Eleventh Annual Gasification and Gas Stream Cleanup Systems Contractors' Review Meeting.

Gray, N.B, et al., 1973. "Roasting o! Sulfides in Theory and Practice." In Proc. Richardson Conf. Phys. Chem. Process Metallurgy. Imperial College, London.

Grindley, T. 1991. "Study of Fluidized-Bed Desulfurization with Zinc Ferrite." Technical Note, DOE/METC, January.

Grindley, T., and H. Goldsmith. 1987. "Development of Zinc Ferrite Desulfurization Sorbents for Large Scale Testing." Presented at the AIChE Annual Meeting, Session 114d, New York, November 15-20.

Grindley, T., and G. Steinfeld. 1981. "Development and Testing of Regenerable Hot Coal-Gas Desulfurization Sorbents." DOE/MC/16545-1125.

Gupta, R. 1991. "Evaluation of Zinc Loss from Zinc Titanate Sorbents During Hot-Gas Desulfurization," Technical Progress Report to Texaco, Inc., August 1.

Gupta, R., and S.K. Gangwal. 1991. "Enhanced Durability of Desulfurization Sorbents for Fluidized Bed Applications," Topical Report to DOE/METC, Report No. DOE/IMC/250063011, Morgantown Energy Technology Center, U.S. Department of Energy, Morgantown, WV, NTIS/DE91002090, June.

Gupta, R., S.K. Gangwal, and S.C. Jain. 1992. "Development of Zinc Ferrite Sorbents for Desulfurization of Hot Coal Gass in a Fluid-Bed Reactor." Energy and Fuels 6:21-27. 
Gwyn, J.E. 1969. "On the Particle Size Distribution Function and the Attrition of Cracking Catalysts." AIChE Journal. (1):35-39.

Ingraham, T.R., and H.H. Kellogg. 1963. "Thermodynamic Properties of Zinc Sulfate, Zinc Basic Sulfate and the System Zn-5-0." Trans. Amer. Inst. Min. Eng. 227:1419-1426.

Haldipur, G.B., et al. 1987. "KRW Process Development Coal Gasification Hot-Gas Cleanup." In Proceedings of the Seventh Annual Gasification and Gas Stream Cleanup Systems Contractors' Review Meeting, DOE/METC-87/6079, Vol. 2, NTIS/DE87006496, pp. 668677.

Jalan, V., M. Desai, F. Brown, and B. Chamberland. 1990. "Copper-Based Sorbents for Hot Gas Cleanup." ACS Preprints, Division of Fuel Chemistry. 35(1):87-94.

Knacke, O., O. Kubaschewski, and K. Hesselmann. 1991. Thermochemical Properties of Inorganic Substances, 2nd Edition, Springer-Verlag.

Kubaschewski, O. 1972. "The Thermodynamic Properties of Double Oxides (A Review)." HighTemp.-High Pressures. 4:1-12.

Kunii, D., and O. Levenspiel. 1969. Fluidization Engineering. Wiley, New York.

Kunii, D., and O. Levenspiel. 1990. Fluidization Engineering. 2nd ed. Buttenworth-Heinemann, Boston, MA.

Lercher, J.A., H. Vinek, H. Noller. 1984. " $\mathrm{TiO}_{2} / \mathrm{ZnO}$ Mixed Oxide Catalysts, Characterization by $X$-ray Photoelectron and Infrared-Spectroscopy and Reactions with Propanol and Butanol." Appl. Catal. 12:293-307.

Lew, S. 1990. "High Temperature Sulfidation and Reduction of Zinc Titanate and Zinc Oxide Sorbents." Ph.D. Dissertation, Massachusetts Institute of Technology, October.

Lew, S., K. Jothimurugesan, M. Flytzani-Stephanopoulos. 1989 . "High-Temperature $\mathrm{H}_{2} \mathrm{~S}$ Removal from Fuel Gases by Regenerable Zinc Oxide-Titanium Dioxide Sorbents." Ind. Eng. Chem. Process Des. Dev. 28:535-541.

Lew, S., A.F. Sarofim, and, M. Flytzani-Stephanopoulos. 1992. "The Reduction of Zinc Titanate and Zinc Oxide Solids." Chem. Eng. Sci. 47(6):1421-31.

Marcilly, C., P. Courty, B. Delmon. 1970. "Preparation of Highly Dispersed Mixed Oxides and Oxide Solid Solutions by Pyrolysis of Amorphous Organic Precursors." J. Am. Ceram. Soc. 53(1): 56-57.

PSRI. 1991. "Hardgrove Grindability Index of Various Materials." Private communication.

Reddy, V.B., S.P. Goel, P.N. Mehrotra. 1984. "Investigations on Formation of Zinc Titanates via Thermal Decomposition of Zinc Titanyl Oxalate Hydrate." Mater. Chem. Phys. 10:365373.

Robin, A.M., et al. 1992. "Integration and Testing of Hot Desulfurization and Entrained Flow Gasification for Power Generation Systems." Paper presented at the Twelfth DOE/METC Gasification and Gas Stream Cleanup Contractors' Review Meeting, Morgantown, September. 
Satterfield, C.N. 1980. Heterogeneous Catalysis in Practice, McGraw-Hill, New York.

Schrodt, J.T. 1981. "Hot Gas Desulfurization: Use of Gasifier Ash in a Fluidized-Bed Process. DOE/ET/10463, Vol. 2.

Sheinkman, R.D., F.P. Sheinkman, I.P. Dobrovol'skii, G.R. Zvyagina. 1977. Phase Formation Sequence in the Reaction of Zinc Oxide with Titanium Dioxiae. IzV. Akad. Nauk SSSR, Neorg. Mater 13(8): 1447-1450.

Sugitani, T., et al. 1987. "Fundamental Studies and Present Status of IHI HOt Gas Desulfurization Process." Intl. Conf. Coal Sci., J.A. Moulgyn, et al. (eds), Elsevier Science Publishers B.V., Amsterdam, pp. 915-919.

Sugitani, T. 1990. Private Communications. Ishikawajima-Harima Heavy Industries Co, Ltd., Japan.

Vosen, J. 1958. Doctoral thesis, Rheinisch-Westfaellische Technische Hochschule, Aachen, Germany.

Wang, J., et al. 1988. "Dynamic Simulation Models for High-Temperature Desulfurization Processes." Final Report to DOE/METC. DOE/MC/23089-2601.

Watanabe, Akio, Hajime Haneda, Yusuke Moriyoshi, and Schin-Ichi Schiraski. 1989. "Preparation of $\mathrm{Zn}_{2} \mathrm{TiO}_{4}$ by Co-precipitation Method and Hot-isostatic Pressing. Journal of Materials Science. 24:2281-84.

Westmoreland, P.R., and D.P. Harrison. 1976. "Evaluation of Candidate Solids for HighTemperature Desulfurization of Low Btu Gases." Environmental Science and Technology. 10:659.

Woods, M.C., et al. 1989. "Reaction Kinetics and Simulation Models for Novel High Temperature Desulfurization Sorbents." Final Report to DOE/METC, DOE/MC/24160-2671.

WU, J.C., A.M. Robin, and J.S. Kassman. 1989. "Integration and Testing of Hot Gas Desulfurization and Entrained Flow Gasification for Power Generation Systems." In Proceedings of the Ninth Annual Gasification and Gas Stream Cleanup Systems Contractors' Review Meeting, Volume 1, DOE/METC-89/6106, Vol. I (DE89011706), June.

Yamaguchi, O., M. Morimi, H. Kawabata, K. Shimizu. 1987. Formation and Transformation of $\mathrm{ZnTiO}_{3}$. J. Am. Ceram. Soc. 70(5), C-97 - C-98. 


\section{LIST OF ACRONYMS}

\begin{tabular}{|c|c|}
\hline Abbreviation & Description \\
\hline APS & average particle size \\
\hline ASME & American Society of Mechanical Engineers \\
\hline atm & atmosphere \\
\hline Btu & British thermal units \\
\hline COR & Contracting Officer's Representative \\
\hline $\cos$ & Carbonyl sulfide \\
\hline CP & centipoise \\
\hline CSTR & continuous stirred-tank reactor \\
\hline DOE & Department of Energy \\
\hline DTA & differential thermal analysis \\
\hline EDS & energy dispersive scan \\
\hline FCC & fluid catalytic cracking \\
\hline FPD & flame photometric detector \\
\hline GC & gas chromatograph \\
\hline GC/MS & gas chromatograph/mass spectrometer \\
\hline GE & General Electric \\
\hline h & hour \\
\hline HGI & Hardgrove Grindability Index \\
\hline HRSG & heat recovery steam generator \\
\hline HTHP & high temperature, high pressure \\
\hline ICP & inductively coupled plasma \\
\hline IGCC & integrated gasification combined cycle \\
\hline IGFC & integrated gasification fuel cell \\
\hline IHI & Ishikawajima-Harima Heavy Industries \\
\hline K & degrees Kelvin \\
\hline$K-L$ & Kunii and Levenspiel \\
\hline KRW & Kellogg-Rust-Westinghouse \\
\hline $\mathrm{m}^{2} / \mathrm{g}$ & square meters/gram \\
\hline
\end{tabular}


LIST OF ACRONYMS (continued)

\begin{tabular}{|c|c|}
\hline Abbreviation & Description \\
\hline MCFC & molten carbonate fuel cell \\
\hline $\mathrm{Me}$ & metal \\
\hline $\mathrm{MeO}$ & metal oxide \\
\hline Mes & metal sulfide \\
\hline METC & Morgantown Energy Technology Center \\
\hline MIT & Massachusetts Institute of Technology \\
\hline $\mathrm{mL}$ & milliliter \\
\hline $\mathrm{mm}$ & milimeter \\
\hline MPa & mega Pascal \\
\hline MPD & median pore diameter \\
\hline MPV & mercury pore volume \\
\hline MW & molecular weight \\
\hline NASA & National Aeronautics and Space Administration \\
\hline NIST & National Institute of Standards and Technology \\
\hline $\mathrm{nm}$ & nanometer \\
\hline ppm & parts per million \\
\hline ppmv & parts per million by volume \\
\hline psia & pounds per square inch (absolute) \\
\hline QA & quality assurance \\
\hline QF & quality factor \\
\hline RTI & Research Triangle Institute \\
\hline $\mathbf{s}$ & second \\
\hline SEM & scanning electron microscopy \\
\hline Si-Al & silica-alumina \\
\hline slpm & standard liter per minute \\
\hline TA & thermal analysis \\
\hline TC & temperature controller \\
\hline TCD & thermal conductivity detector \\
\hline TGA & thermogravimetric analysis \\
\hline
\end{tabular}


LIST OF ACRONYMS (continued)

$\begin{array}{ll}\text { Abbrevlation } & \text { Descriptlon } \\ \mathrm{TGR} & \text { thermogravimetric reactor } \\ \mathrm{TiO}_{2} & \text { titanium dioxide } \\ \mathrm{UCl} & \text { United Catalysts, Inc. } \\ \mathrm{V}_{2} \mathrm{O}_{3} & \text { vanadium trioxide } \\ \mathrm{wt} & \text { weight } \\ \mathrm{XRD} & \text { X-ray diffraction } \\ \mathrm{ZnTiO} & \text { zinc meta-titanate } \\ \mathrm{Zn} \mathrm{Ti}_{3} \mathrm{O}_{8} & \text { zinc sesquit-titanate } \\ \mathrm{Zn} \mathrm{TiO}_{4} & \text { zinc ortho-titanate } \\ \mathrm{ZnFe} \mathrm{O}_{4} & \text { zinc ferrite } \\ \mathrm{ZnO} & \text { zinc oxide } \\ \mathrm{ZnS} & \text { zinc sulfide } \\ \mathrm{ZT} & \text { zinc titanate } \\ { }^{\circ} \mathrm{C} & \text { degrees Centigrade } \\ { }^{\circ} \mathrm{F} & \text { degrees Fahrenheit }\end{array}$




\section{LIST OF SYMBOLS}

\section{Abbreviation}

A

A

$A_{R}$

$B$

$\bar{C}_{p}$

$\mathrm{C}_{\mathrm{ZnO}}$

$F_{A O}$

$\dot{M}_{g}$

G

H

k

$\mathrm{K}_{1}$

$\mathrm{k}_{\mathrm{p}}$

m

$M$

$\mathrm{P}_{\mathrm{H}_{2} \mathrm{~S}}$

$P_{T}$

R

$\dot{M}_{\mathrm{s}}$

$S$

t

$t^{*}$

T

$T$

$v_{0}$

$w_{0}$

$x$

$x_{A}$

\section{Term}

Lumped parameter defined by Equation (7-17)

Cross-sectional area

Attrition resistance in single-hole attrition tester

Lumped parameter defined by Equation (7-17)

Mean heat capacity of gas during regeneration

Concentration of $\mathrm{ZnO}$ in the sorbent

$\mathrm{Mol}$ of $\mathrm{H}_{2} \mathrm{~S}$ per $\mathrm{s}$ at reactor inlet

Gas phase mass flow rate

Molar flow rate of coal gas

Reactor height used by the sorbent

Reaction rate constant

Pseudo first-order rate constant defined by Equation (7-8)

Attrition rate constant defined by Equation (5-1)

Exponent in attrition rate in Equation (5-1)

Gas molecular weight

Partial pressure of $\mathrm{H}_{2} \mathrm{~S}$ in coal gas

Total system pressure

Gas law constant

Solid phase mass flow rate

Solid phase specific heat

Time

Dimensionless time

Temperature

Characteristic time defined by Equation (8-19)

Volumetric flow rate at reactor inlet defined by Equation (7-12)

Sorbent inventory

Conversion of $\mathrm{ZnO}$ into $\mathrm{ZnS}$

Fractional conversion of $\mathrm{H}_{2} \mathrm{~S}$ 


\section{LIST OF SYMBOLS (continued)}

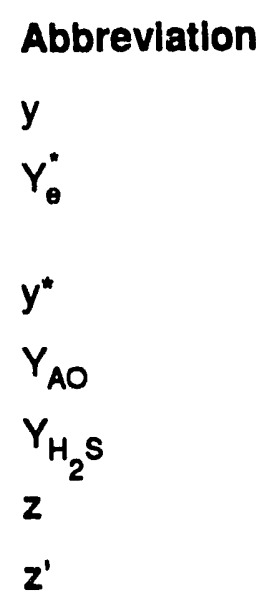

Greek Letters

$\alpha$

$\Delta \mathrm{G}$

$\Delta \mathrm{H}_{\mathrm{r}}$

$\Delta T$

$\mathrm{rH}_{2} \mathrm{~S}$

$\lambda_{0}$

$\partial$

$\rho$

$\rho_{B}$

$\theta$
Term

Axial concentration of $\mathrm{H}_{2} \mathrm{~S}$ in the reactor

Ratio of $\mathrm{H}_{2} \mathrm{~S}$ concentration in reactor exit gas to the $\mathrm{H}_{2} \mathrm{~S}$ concentration in reactor inlet gas

Dimensionless axial concentration of $\mathrm{H}_{2} \mathrm{~S}$

Mol fraction of $\mathrm{O}_{2}$ in the regeneration inlet gas

Mol fraction of $\mathrm{H}_{2} \mathrm{~S}$

Axial coordinate

Dimensionless axial coordinate

Dimensionless parameter defined by Equation (8-14)

Gibbs free energy

Heat of regeneration reaction

Temperature rise

Rate of $\mathrm{H}_{2} \mathrm{~S}$ removal from the coal gas

mol of ZnO initially present per $\mathrm{g}$ of sorbent

Partial derivative

density

Bulk density

theta 


\section{APPENDIX A}

SAMPLES OF PORE SIZE DISTRIBUTION REPORTS GENERATED BY MICROMERITICS AUTOPORE 922011 MERCURY POROSIMETER 
SAMPLE DIRECTORY/NUMBER: DISKS /95 OPERATOR: EWJ

SAMPLE ID: ZT-4 FRESH

SUBMITTER: 4274

PENETROMETER NUMBER: E-3CCPWDR PENETROMETER CONSTANT: $10.79 \mu \mathrm{L} / \mathrm{PF}$ PENETROMETER WEIGHT: STEM VOLUME: MAXIMUM HEAD PRESSURE:

PENETROMETER VOLUME:
69.4884 $0.4120 \mathrm{~mL}$ 4.6800 peia $3.1790 \mathrm{~mL}$
ADVANCING CONTACT ANGLE: 130.0 deg RECEDING CONTACT ANGLE: $130.0 \mathrm{deg}$ MERCURY SURFACE TENSION: $485.0 \mathrm{dYn} / \mathrm{cm}$ MERCURY DENSITY: $\quad 13.5335 \mathrm{~g} / \mathrm{mL}$ SAMPLE WEIGHT:

$0.6189 \mathrm{~g}$ SAMPLE+PEN+Hg WEIGHT: $105.4054 \mathrm{~g}$

LOW PRESSURE:

EVACUATION PRESSURE:

EVACUATION TIME:

MERCURY FILLING PRESSURE:

EQUILIBRATION TIME:

$\begin{array}{rl}50 & \mu m H g \\ 5 & \mathrm{~min} \\ 0.4788 & \text { peia } \\ 10 & \text { eec }\end{array}$

HIGH PRESSURE:

EOUILIBRATION TIME:

10 eec

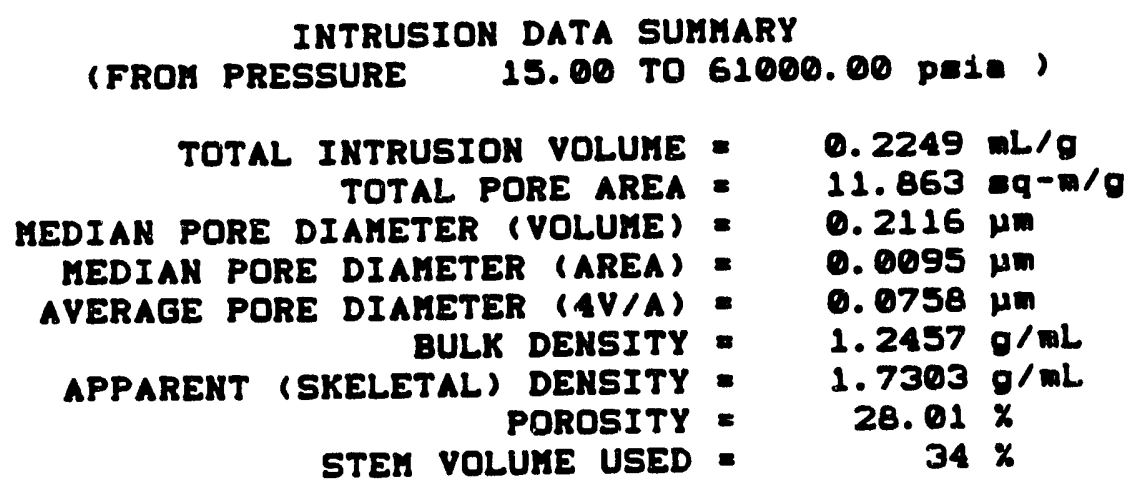


SAMPLE DIRECTORY/NUMBER: DISKS /95 OPERATOR: EWJ

SAMPLE ID: ZT-4 FRESH

SUBMITTER: 4274 $\begin{array}{lll}\text { LP } & 15: 23: 18 & 08 / 10 / F 2 \\ \text { HP } & 16: 57: 10 & 08 / 10 / F 2 \\ \text { REP } & 15: 55: 45 & 11 / 24 / 91\end{array}$

\begin{tabular}{|c|c|c|c|c|c|}
\hline $\begin{array}{l}\text { PRESSURE } \\
\text { PEIa }\end{array}$ & $\begin{array}{c}\text { PORE } \\
\text { DIAMETER } \\
\mu \mathrm{m}\end{array}$ & $\begin{array}{c}\text { MEAN } \\
\text { DIAMETER } \\
\mu m\end{array}$ & $\begin{array}{c}\text { CUMULATIVE } \\
\text { VOLUME } \\
\mathrm{mL} / \mathrm{g}\end{array}$ & $\begin{array}{c}\text { INCREMENTAL } \\
\text { VOLUME } \\
\mathrm{mL} / \mathrm{g}\end{array}$ & $\begin{array}{c}\text { DIFFEREN. } \\
V D L d V / d D \\
m L / g-\mu m\end{array}$ \\
\hline $\begin{array}{r}15.00 \\
15.91 \\
17.90 \\
19.91 \\
21.90 \\
23.98 \\
25.96 \\
27.96 \\
29.97 \\
34.84 \\
40.03 \\
44.91 \\
49.81 \\
59.77 \\
69.90 \\
79.94 \\
89.96 \\
100.90 \\
119.89 \\
139.93 \\
159.93 \\
179.29 \\
200.05 \\
224.35 \\
249.04 \\
274.29 \\
299.24 \\
323.50 \\
348.74 \\
374.43 \\
399.25 \\
448.60 \\
498.37 \\
547.99 \\
597.44 \\
649.74 \\
697.98 \\
750.55 \\
800.56 \\
848.19 \\
899.21 \\
947.19 \\
1002.89 \\
1106.91 \\
1202.76\end{array}$ & $\begin{array}{r}12.0576 \\
11.3714 \\
10.1029 \\
9.0846 \\
8.2577 \\
7.5423 \\
6.9668 \\
6.4677 \\
6.0350 \\
5.1910 \\
4.5182 \\
4.0270 \\
3.6309 \\
3.0260 \\
2.5875 \\
2.2626 \\
2.0105 \\
1.8087 \\
1.5086 \\
1.2925 \\
1.1309 \\
1.0088 \\
0.9041 \\
0.8062 \\
0.7263 \\
0.6594 \\
0.6044 \\
0.5591 \\
0.5186 \\
0.4830 \\
0.4530 \\
0.4032 \\
0.3629 \\
0.3300 \\
0.3027 \\
0.2784 \\
0.2591 \\
0.2410 \\
0.2259 \\
0.2132 \\
0.2011 \\
0.1909 \\
0.1803 \\
0.1634 \\
0.1504\end{array}$ & $\begin{array}{r}12.0576 \\
11.7145 \\
10.7371 . \\
9.5933 \\
8.6711 \\
7.9000 \\
7.2546 \\
6.7173 \\
6.2513 \\
5.6130 \\
4.8546 \\
4.2726 \\
3.8289 \\
3.3285 \\
2.8067 \\
2.4250 \\
2.1365 \\
1.9096 \\
1.6586 \\
1.4006 \\
1.2117 \\
1.0698 \\
0.9564 \\
0.8551 \\
0.7662 \\
0.6928 \\
0.6319 \\
0.5817 \\
0.5389 \\
0.5008 \\
0.4680 \\
0.4281 \\
0.3830 \\
0.3465 \\
0.3164 \\
0.2905 \\
0.2687 \\
0.2500 \\
0.2334 \\
0.2196 \\
0.2072 \\
0.1960 \\
0.1856 \\
0.1719 \\
0.1569\end{array}$ & $\begin{array}{l}0.0000 \\
0.0008 \\
0.0025 \\
0.0036 \\
0.0044 \\
0.0059 \\
0.0059 \\
0.0066 \\
0.0073 \\
0.0087 \\
0.0088 \\
0.0088 \\
0.0090 \\
0.0096 \\
0.0104 \\
0.0110 \\
0.0117 \\
0.0120 \\
0.0138 \\
0.0154 \\
0.0154 \\
0.0174 \\
0.0174 \\
0.0183 \\
0.0193 \\
0.0203 \\
0.0211 \\
0.0221 \\
0.0229 \\
0.0252 \\
0.0257 \\
0.0270 \\
0.0291 \\
0.0326 \\
0.0373 \\
0.0482 \\
0.0646 \\
0.0835 \\
0.0996 \\
0.1110 \\
0.1213 \\
0.1287 \\
0.1363 \\
0.1486 \\
0.1572\end{array}$ & $\begin{array}{l}0.0000 \\
0.0008 \\
0.0017 \\
0.0011 \\
0.0009 \\
0.0015 \\
0.0000 \\
0.0006 \\
0.0007 \\
0.0014 \\
0.0001 \\
0.0000 \\
0.0002 \\
0.0006 \\
0.0007 \\
0.0006 \\
0.0006 \\
0.0003 \\
0.0018 \\
0.0016 \\
0.0000 \\
0.0020 \\
0.0000 \\
0.0009 \\
0.0011 \\
0.0010 \\
0.0009 \\
0.0010 \\
0.0009 \\
0.0022 \\
0.0005 \\
0.0013 \\
0.0021 \\
0.0035 \\
0.0047 \\
0.0109 \\
0.0164 \\
0.0189 \\
0.0161 \\
0.0114 \\
0.0103 \\
0.0075 \\
0.0076 \\
0.0123 \\
0.0085\end{array}$ & 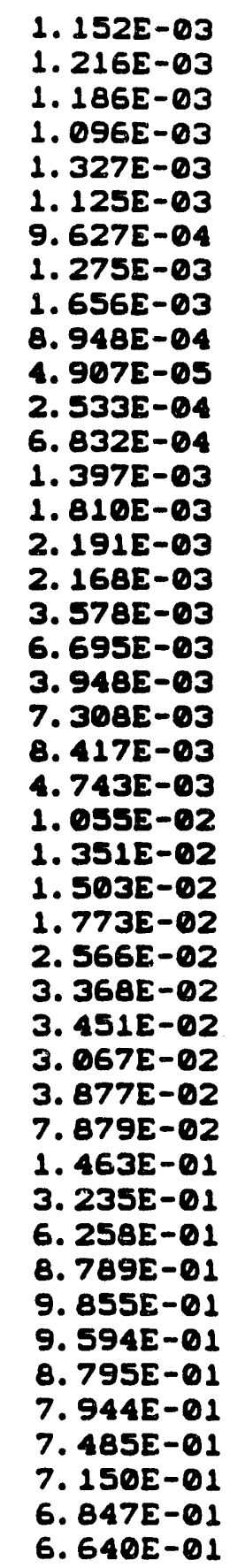 \\
\hline
\end{tabular}


SAMPLE DIRECTORY/NUMBER: DISKS /95 OPERATOR: EWJ

SAMPLE ID: $2 T-4$ FRESH

SUBMITTER: 4274
LP $\quad 15: 23: 18 \quad 08 / 10 / F 2$

HP $16: 57: 10 \quad 08 / 10 / F 2$

REP 15:55:45 11/24/91

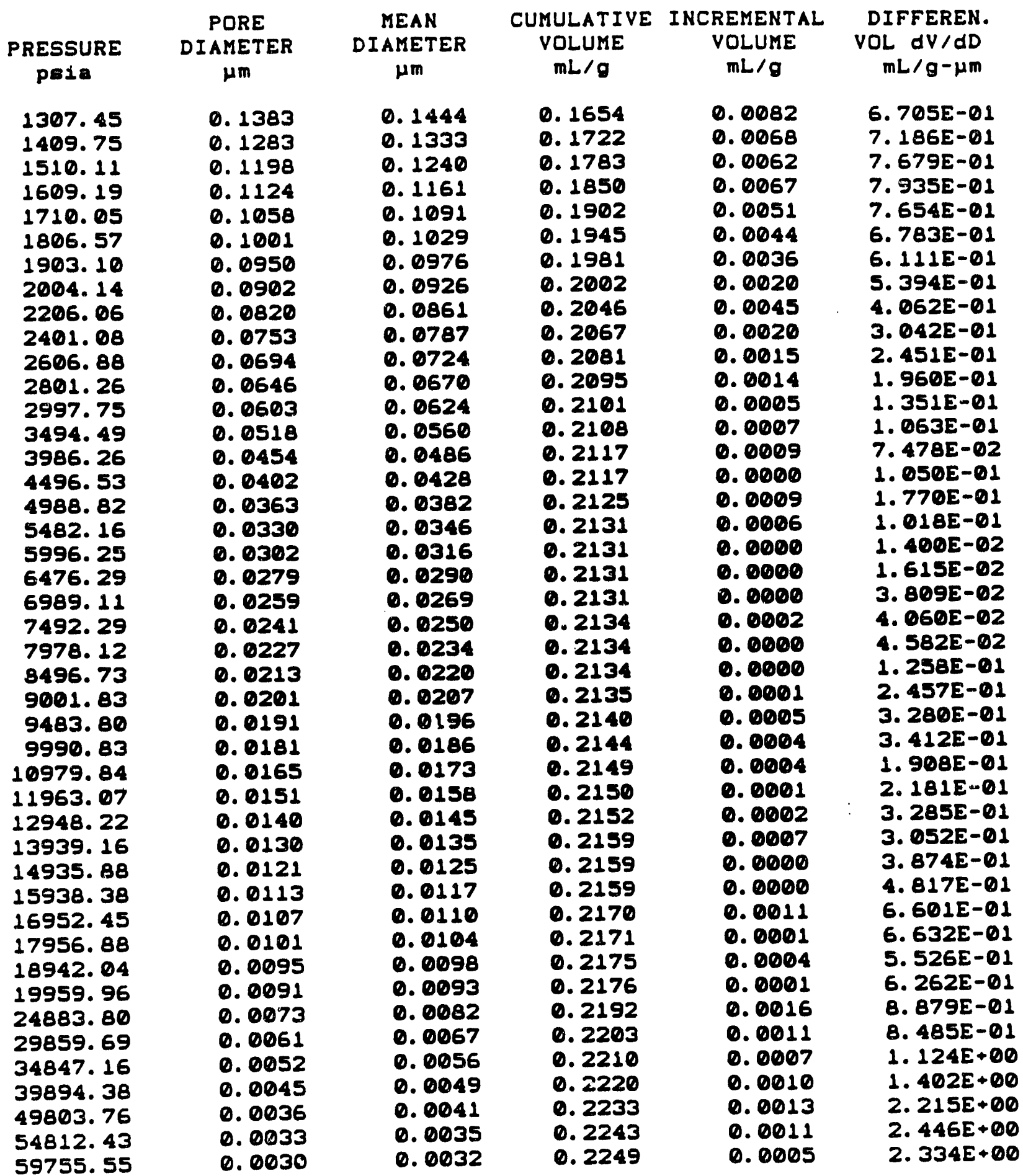


AUTOPORE II 9220 v3.01

SAMPLE DIRECTORY/NUMBER: DISKS /95

OPERATOR: EWJ

SAMPLE ID: $2 T-4$ FRESH

SUBMITTER: 4274

LP $15: 23: 1808 / 10 / F 2$

HP $16: 57: 10 \quad 08 / 10 / F 2$

REP 15:55:45 11/24/91

CUMULATIVE INTRIJEION VE IIOMETER

+ intrusior, * extruejon

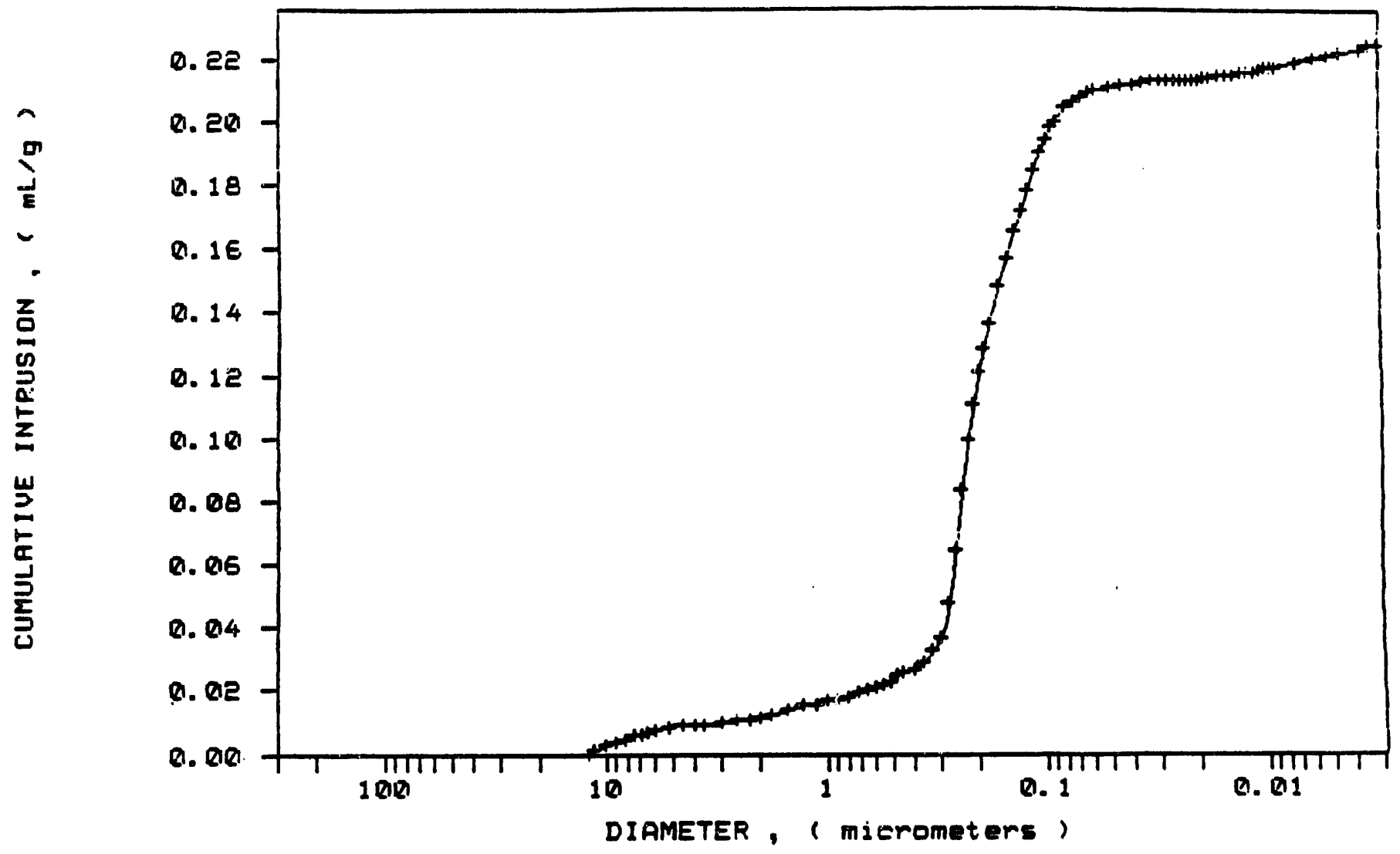

A-6 
SAMPLE DIRECTORY/NUMBER: DISKS /95

OPERATOR: EWJ

SAMPLE ID: $2 T-4$ FRESH

SUBMITTER : 4274

LP $15: 23: 18 \quad 08 / 10 / F 2$

HP $16: 57: 10 \quad 08 / 10 / F 2$

REP 15:55:45 11/24/91

INCREMENTAL INTRUSION VS DIAMETER

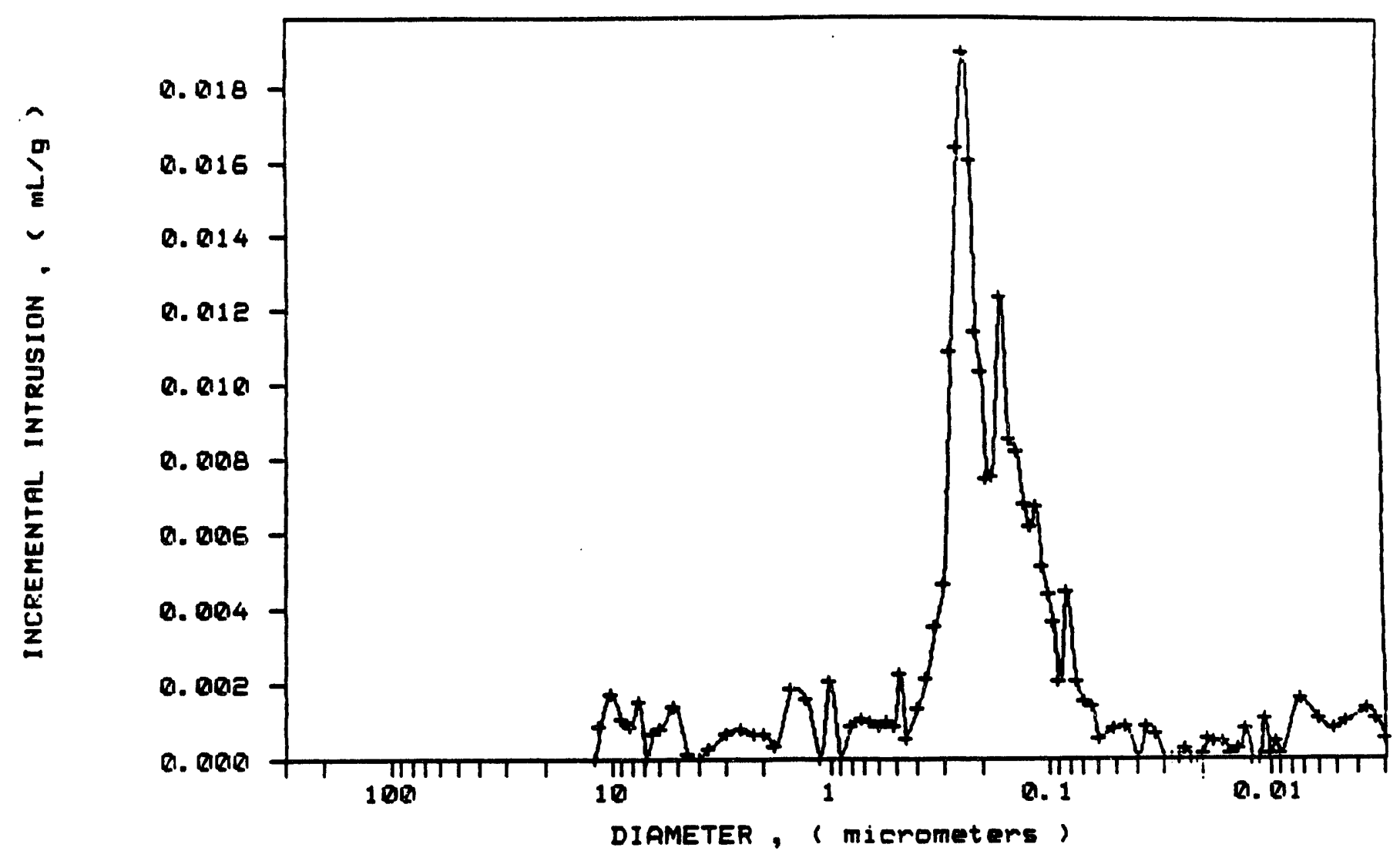


SAMFLE DIRECTORY/NUMAER: DISKS $19 \Xi$ OFERATOR: $t$ IP

SAIMFLE ID: $2 T-4$ SUlfided

SURMITTER: $4 \Xi 74$

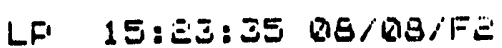

HF $19: 48: \Xi 4$ BIS/RS/FE

REF $18: 01: 1911 / E 4 / Y 1$
FIENETROMETER NUMBER: C-3̄CC FWDR

FENETROMETER CONSTANT: $12.79 \mu \mathrm{L} / \mathrm{PF}$

F'EINETROMETER WEIGHT: 68.7 3 : $\mathrm{g}$

STEM VULUME:

MIAXIMUM HEAD FIRESSURE: 4. GBRIR FSIE

FENETROMETER VOLUME:
ADUANCING CONTACT ANGLE: $130 . Q$ dEg RECEDING CUNTACT ANGLE: $130 . \Omega$ deg MERCURY SURFACE TENSIOTS 485.07 dynicm MERCURY DENSITY: $13.5335 \mathrm{~g} / \mathrm{mL}$ SAMFLE WEIGHT: Q. $5308 \mathrm{~g}$

LOW F'RESSURE:
EVACUATION F'RESSURE: EVACUATION TIME: MERCURY FILLING F'RESSURE: EQUILIBRATION TIME:
50 $\mu \mathrm{mHg}$
5 in in
a. 4868 psia
10 sec

HIGH F'RESSURE:
EQUILIERATION TIME:
$10 \sec$

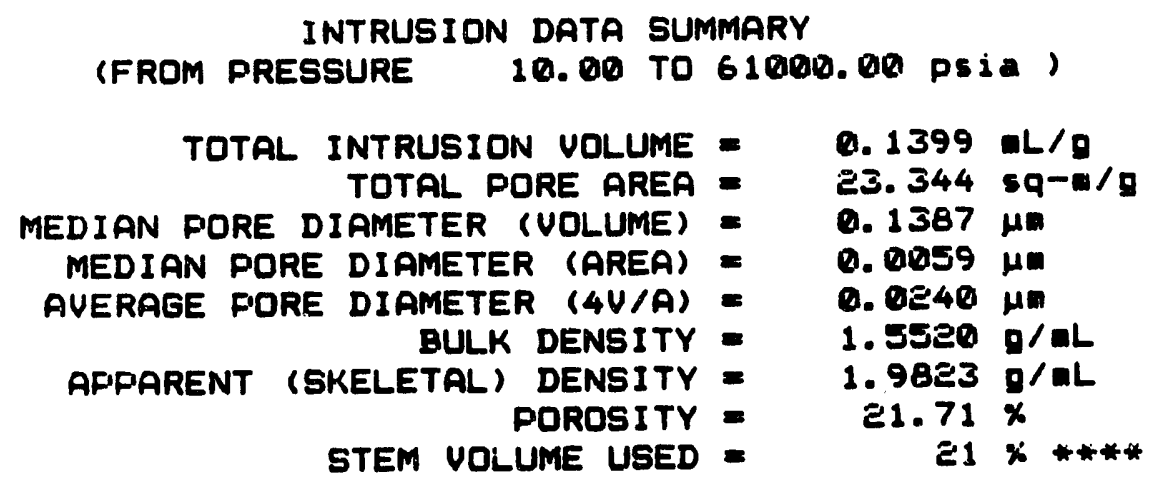


SAMFLLE DIRECTORY/INUMBER: DISKS /9E' OFERATOR: $t \mathrm{mP}$ SAMF'LE ID: $2 T-4$ Sulfided SUBMITTER: $4: 74$
LF $15: \Xi \Xi: 35$ Q18/R日/FE

HF $19: 48: \Xi 4$ R8/Q8/FE

REF $16: 07: 19 \quad 11 /: 4 / 91$

\begin{tabular}{|c|c|c|c|c|c|}
\hline $\begin{array}{c}\text { F'RESSURE } \\
\text { Psia }\end{array}$ & $\begin{array}{c}\text { F'ORE } \\
\text { DIAMETER } \\
\text { HM }\end{array}$ & $\begin{array}{c}\text { MEAIN } \\
\text { DIAMETER } \\
\mu m\end{array}$ & $\begin{array}{c}\text { CUMULAT I VE } \\
\text { WDLUME } \\
\mathrm{mL} / \mathrm{g}\end{array}$ & $\begin{array}{c}\text { INCREMENTAL } \\
\text { VOLUMIE } \\
m L / g\end{array}$ & $\begin{array}{c}\text { DIFFEREN. } \\
\text { UOL } d U / d D \\
m L / g-\mu \text { m }\end{array}$ \\
\hline $\begin{array}{l}10.810 \\
11.93 \\
13.93 \\
15.91 \\
17.90 \\
20.00 \\
21.97 \\
23.94 \\
25.97 \\
27.97 \\
29.98 \\
34.85 \\
39.88 \\
44.86 \\
49.82 \\
59.84 \\
70.41 \\
79.68 \\
89.84 \\
99.72 \\
120.38 \\
139.59 \\
159.25 \\
179.81 \\
199.41 \\
254.02 \\
249.06 \\
274.36 \\
299.07 \\
324.08 \\
350.71 \\
373.51 \\
4010.39 \\
452.86 \\
498.93 \\
551.78 \\
603.19 \\
646.39 \\
700.37 \\
748.55 \\
8010.74 \\
849.88 \\
895.65 \\
947.19 \\
998.89\end{array}$ & 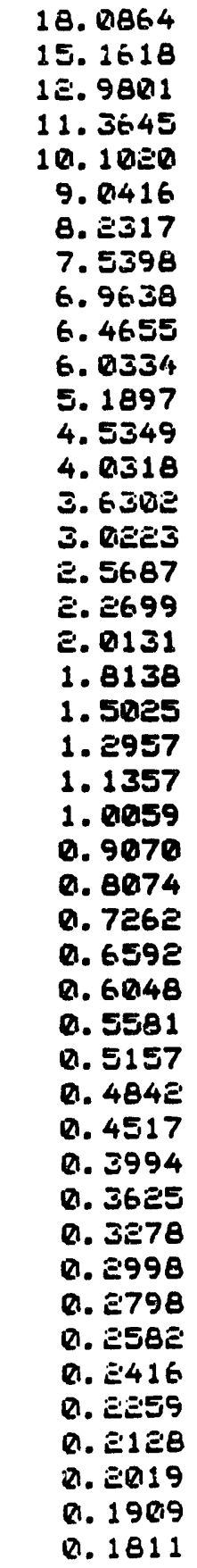 & $\begin{array}{l}18.0864 \\
16.6341 \\
14.0710 \\
13.1723 \\
10.733 \pm \\
9.5718 \\
8.6366 \\
7.8857 \\
7.3518 \\
6.7146 \\
6.2494 \\
5.6115 \\
4.8623 \\
4.3834 \\
3.8310 \\
3.3562 \\
2.7955 \\
2.4193 \\
2.1415 \\
1.9134 \\
1.6581 \\
1.3991 \\
1.2157 \\
1.0708 \\
0.9564 \\
0.8572 \\
0.7668 \\
0.6927 \\
0.6320 \\
0.5814 \\
0.5369 \\
0.5000 \\
0.4680 \\
0.4256 \\
0.3809 \\
0.3451 \\
0.3138 \\
0.3898 \\
0.3690 \\
0.3499 \\
0.31337 \\
0.3193 \\
0.3074 \\
0.1964 \\
0.1860\end{array}$ & 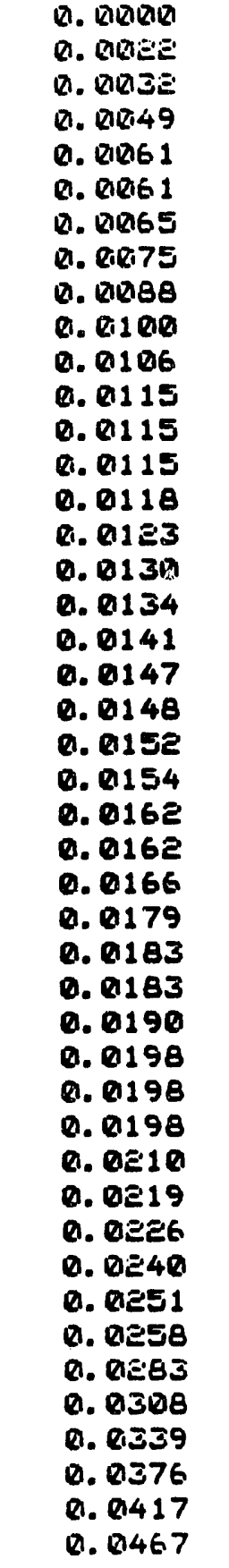 & 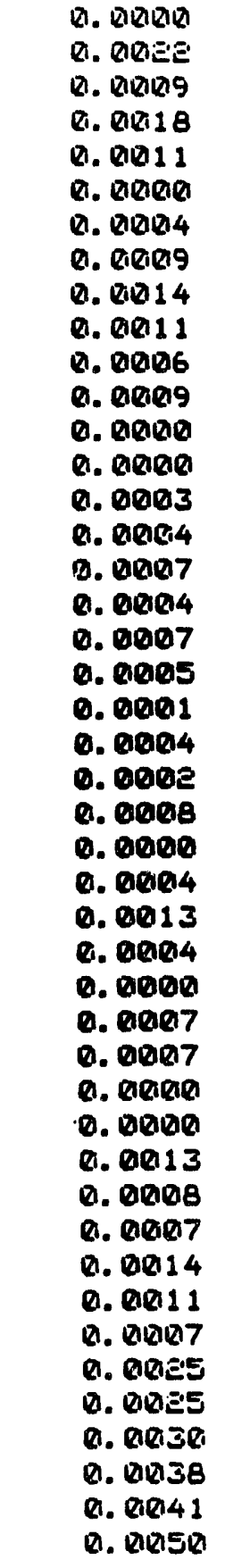 & 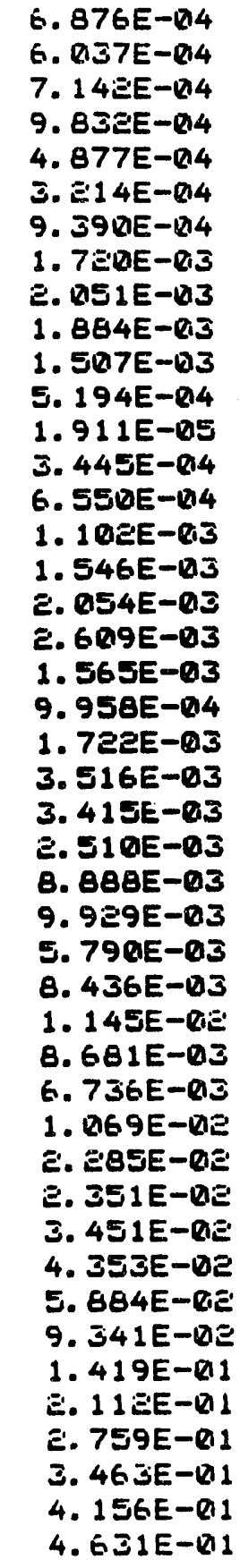 \\
\hline
\end{tabular}


SAMFLE DIRECTORY/NUMBER: DISKS /9E OFERATOR: $t m p$

SAMFILE ID: $2 T-4$ sulfided

SUBMITTER: $4: 74$
LF $15: \Xi 3: 55$ Q8/R8/FE

HF 19:48:E4 DS/08/FE

REF $16: 07: 19 \quad 11 /: 4 / 91$

\begin{tabular}{|c|c|c|c|c|c|}
\hline $\begin{array}{c}\text { F'RESSURE } \\
\text { psia }\end{array}$ & $\begin{array}{c}\text { FOORE } \\
\text { DIAMETER } \\
\mu m\end{array}$ & $\begin{array}{c}\text { MEAN } \\
\text { DIAMETER } \\
\mu m\end{array}$ & $\begin{array}{c}\text { CUMILAT I VE } \\
\text { UOLUME } \\
m L / g\end{array}$ & $\begin{array}{c}\text { INCREMENTAL } \\
\text { VOLUME } \\
m: / g\end{array}$ & $\begin{array}{c}\text { DIFFEREN. } \\
\text { VL } d U / d D \\
m L / g-\mu n\end{array}$ \\
\hline 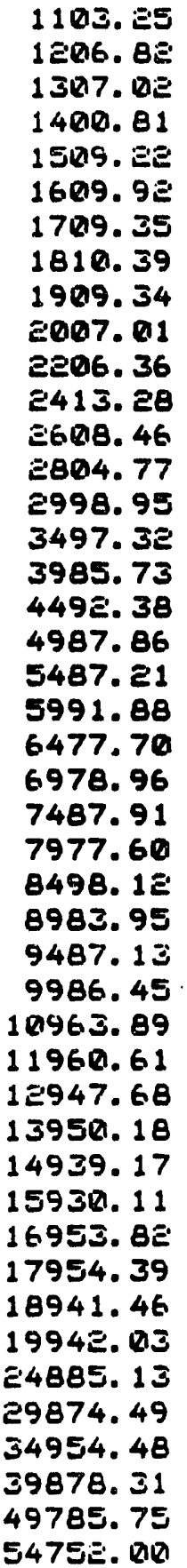 & $\begin{array}{l}0.1639 \\
0.1499 \\
0.1384 \\
0.1291 \\
0.1198 \\
0.1123 \\
0.1058 \\
0.0999 \\
0.0947 \\
0.0901 \\
0.0820 \\
0.0749 \\
0.0693 \\
0.0645 \\
0.0603 \\
0.0517 \\
0.0454 \\
0.0403 \\
0.0363 \\
0.0330 \\
0.0302 \\
0.0279 \\
0.0259 \\
0.0242 \\
0.0227 \\
0.0213 \\
0.0201 \\
0.0191 \\
0.0181 \\
0.0165 \\
0.0151 \\
0.0140 \\
0.0130 \\
0.0131 \\
0.0114 \\
0.0107 \\
0.0101 \\
0.0095 \\
0.0091 \\
0.0073 \\
0.01061 \\
0.0053 \\
0.01245 \\
0.0036 \\
0.01033\end{array}$ & $\begin{array}{l}0.1725 \\
0.1569 \\
0.1441 \\
0.1337 \\
0.1245 \\
0.1161 \\
0.1091 \\
0.10129 \\
0.0973 \\
0.0924 \\
0.0860 \\
0.0785 \\
0.0721 \\
0.0669 \\
0.0624 \\
0.0560 \\
0.0485 \\
0.0428 \\
0.0383 \\
0.0346 \\
0.0316 \\
0.0291 \\
0.0269 \\
0.0250 \\
0.0234 \\
0.0220 \\
0.0207 \\
0.0196 \\
0.0186 \\
0.0173 \\
0.0158 \\
0.0145 \\
0.0135 \\
0.0125 \\
0.0117 \\
0.0110 \\
0.0104 \\
0.0098 \\
0.0093 \\
0.0083 \\
0.0067 \\
0.0056 \\
0.0049 \\
0.0041 \\
0.01035\end{array}$ & $\begin{array}{l}0.1955 \\
0.0635 \\
0.0701 \\
0.0749 \\
0.0792 \\
0.0839 \\
0.10862 \\
0.1881 \\
0.0908 \\
0.0927 \\
0.0950 \\
0.0975 \\
0.0992 \\
0.1006 \\
0.1013 \\
0.1027 \\
0.1043 \\
0.1050 \\
0.1051 \\
0.1056 \\
0.1056 \\
0.1066 \\
0.1066 \\
0.1073 \\
0.1073 \\
0.1079 \\
0.1079 \\
0.1090 \\
0.1091 \\
0.1096 \\
0.1101 \\
0.1110 \\
0.1128 \\
0.1146 \\
0.1146 \\
0.1153 \\
0.1172 \\
0.1183 \\
0.1196 \\
0.1233 \\
0.1275 \\
0.1305 \\
0.1355 \\
0.1354 \\
0.1372\end{array}$ & 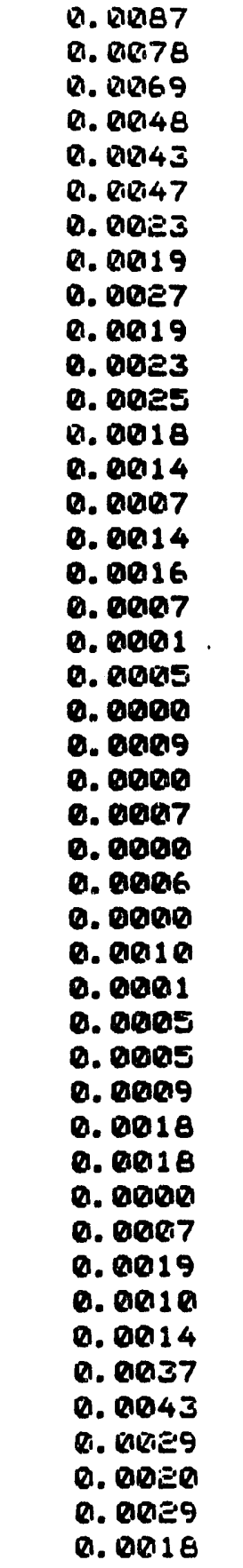 & 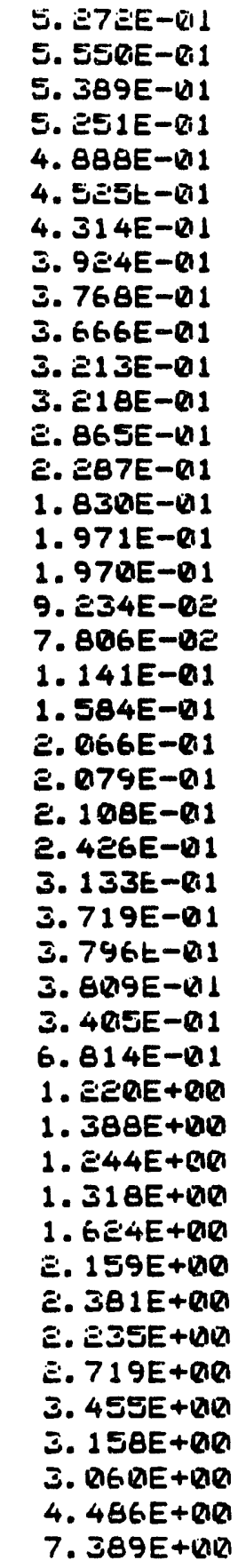 \\
\hline
\end{tabular}


AUTOPORE II 9E:0 V3. Q1

SAMFLE DIRECTORY/NUMBER: DISKS $19 \Xi$ OFERATOR: $t m P$

SAMFLE ID: $2 T-4$ sulfided

SURMITTER: $4 \Xi 74$

\begin{tabular}{|c|c|c|c|c|c|}
\hline GRESSURE & $\begin{array}{c}\text { FORE } \\
\text { DIAMETER } \\
\mu m\end{array}$ & $\begin{array}{c}\text { MEAN } \\
\text { DIAMETER } \\
\mu \pi\end{array}$ & $\begin{array}{l}\text { CUMUULAT I VE } \\
\text { VOLUME } \\
m L / g\end{array}$ & $\begin{array}{c}\text { INCREMENTAL } \\
\text { VOLUME } \\
\mathrm{mL} / \mathrm{g}\end{array}$ & $\begin{array}{l}\text { DIFFEREN. } \\
V O L \quad d V / d D \\
m L / g-\mu m\end{array}$ \\
\hline & Q. $\operatorname{an}=0$ & Q. & Q. 1399 & Q. Que7 & $9.416 E+210$ \\
\hline
\end{tabular}


SAMFLE DIRECTORY/NUMEER: DISKS /9E

\section{OPERATOR: $t m p$}

SAMFLE ID: $2 T-4$ sulfided

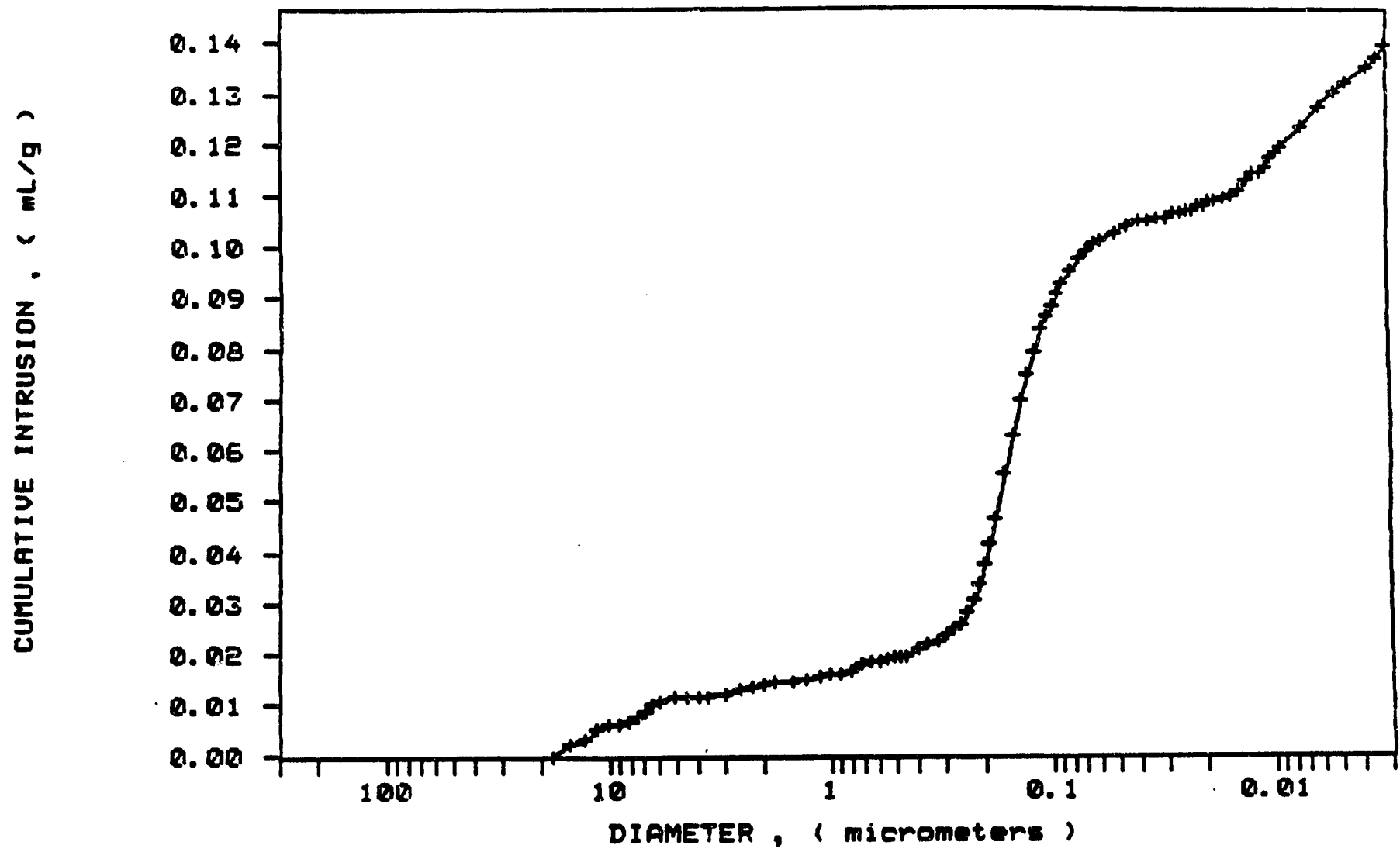


AUTOPORE II 9EEQR U3.Q1

SAMFLE DIRECTORY/NUMBER: CISKS $19 \Xi$

OFERATOR: $t m P$

SAMFLE ID: $2 T-4$ Sulfided

SUBMITTER: $4 \Xi 74$

LF. 15:Eउ:35 R8/208/FE

HF $19: 48: \Xi 4$ Q88/B8/FE

REF $16: 07: 19$ 11/:4/91

INCREMENTAL INTRUSION VS DIAMETER

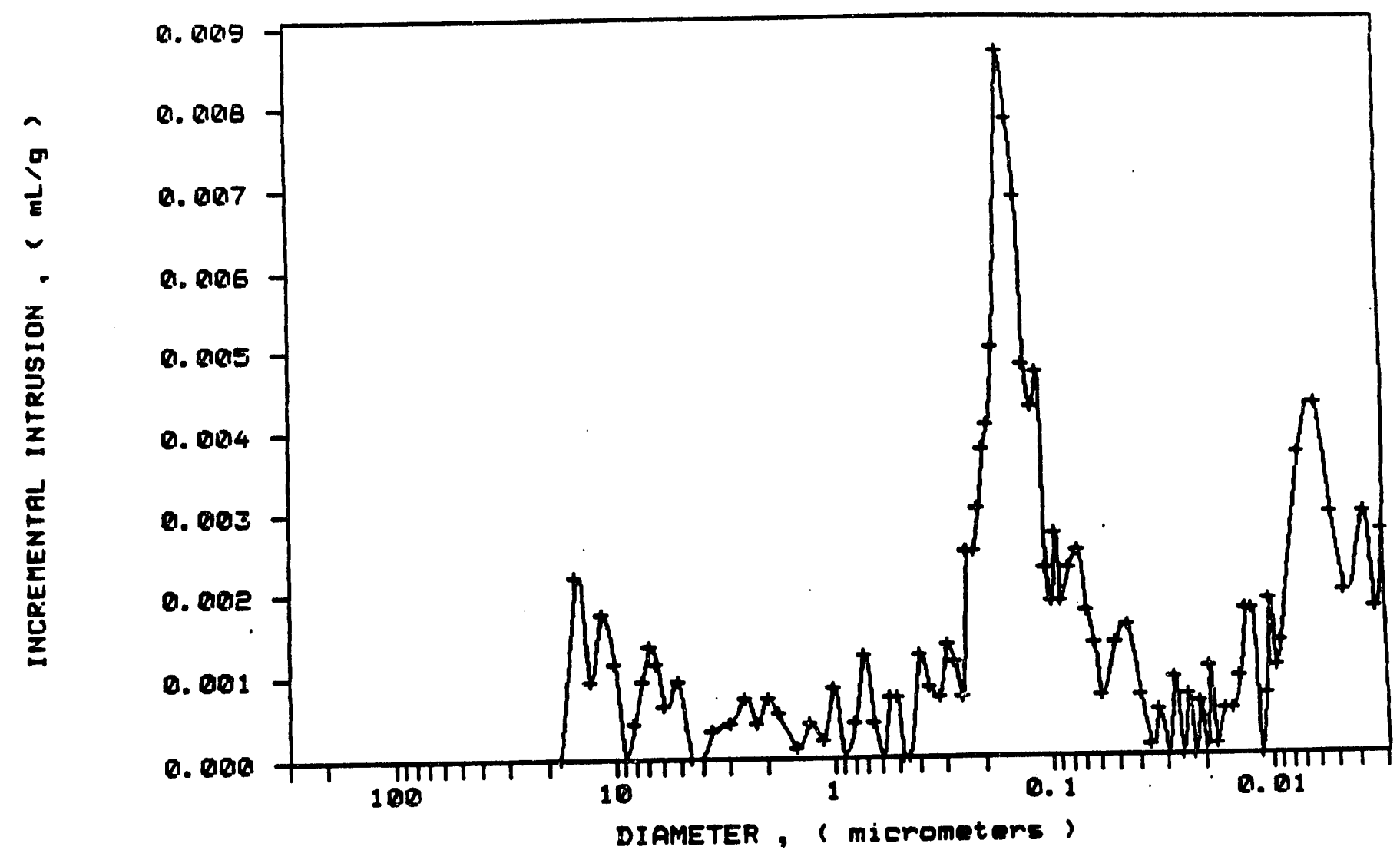




\section{APPENDIX B}

A SAMPLE X-RAY DIFFRACTION REPORT

AND

SCANNING ELECTRON MICROGRAPHS

FOR A ZINC TITANATE SPECIMEN

DONE BY

WEST VIRGINIA UNIVERSITY 


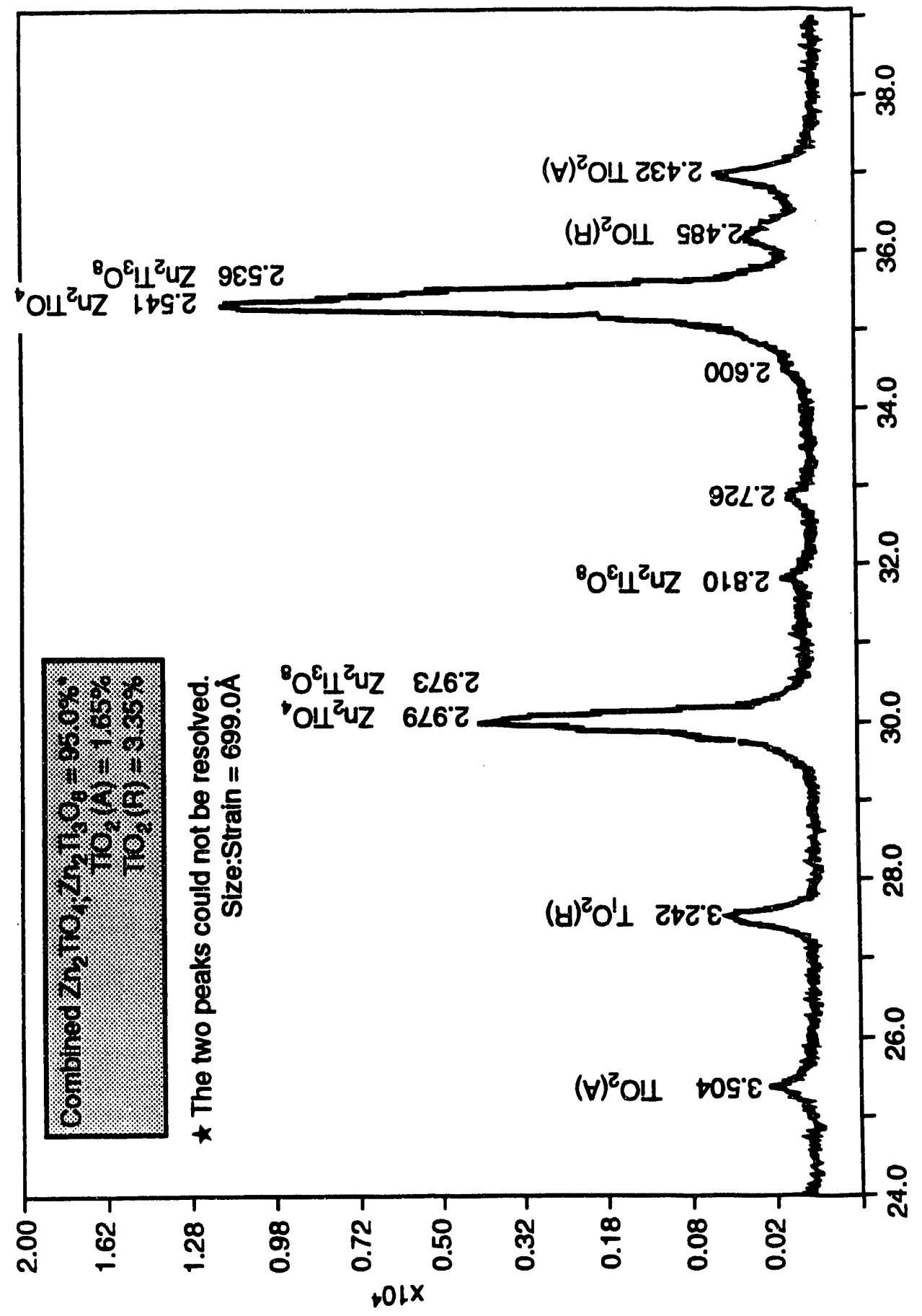

B-3 


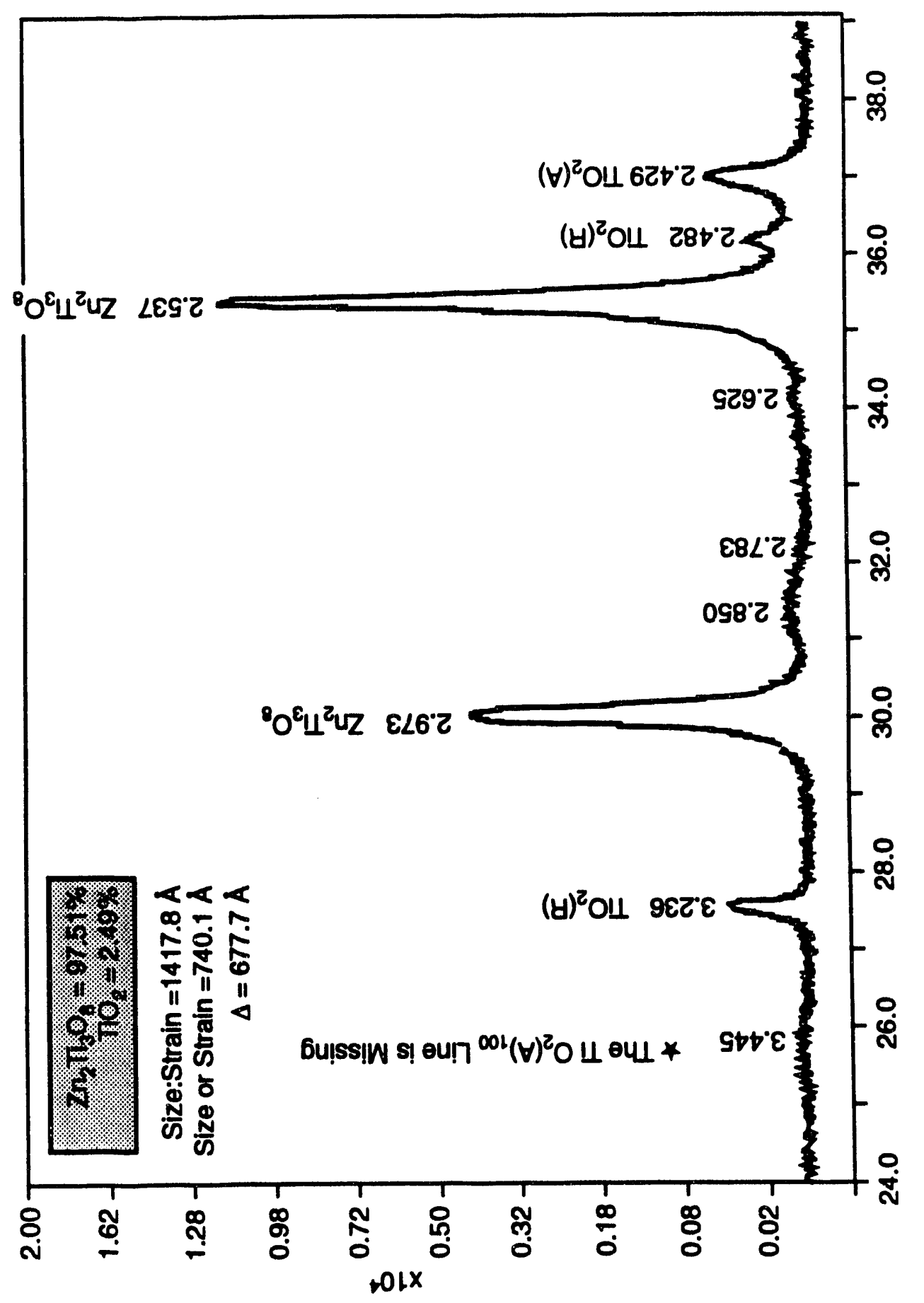

B-4 
APL1700 Automated Fowder [liffractometer Systen 1

Fiaw data file riame

Sample ideritification

Measumement date/time

Gerierator settirigs

Cu alpha1,2 wavelengths

Step size, count time

Moriochromator used

livergence slit

File angle range

Fiarige in II spacing

Maximum intensity

Peak information from

Fit angle range

Fit range in ll spacing

Fit step size

Convergence criterion

Number of iterations

Firial sum of squares

Flot files produced

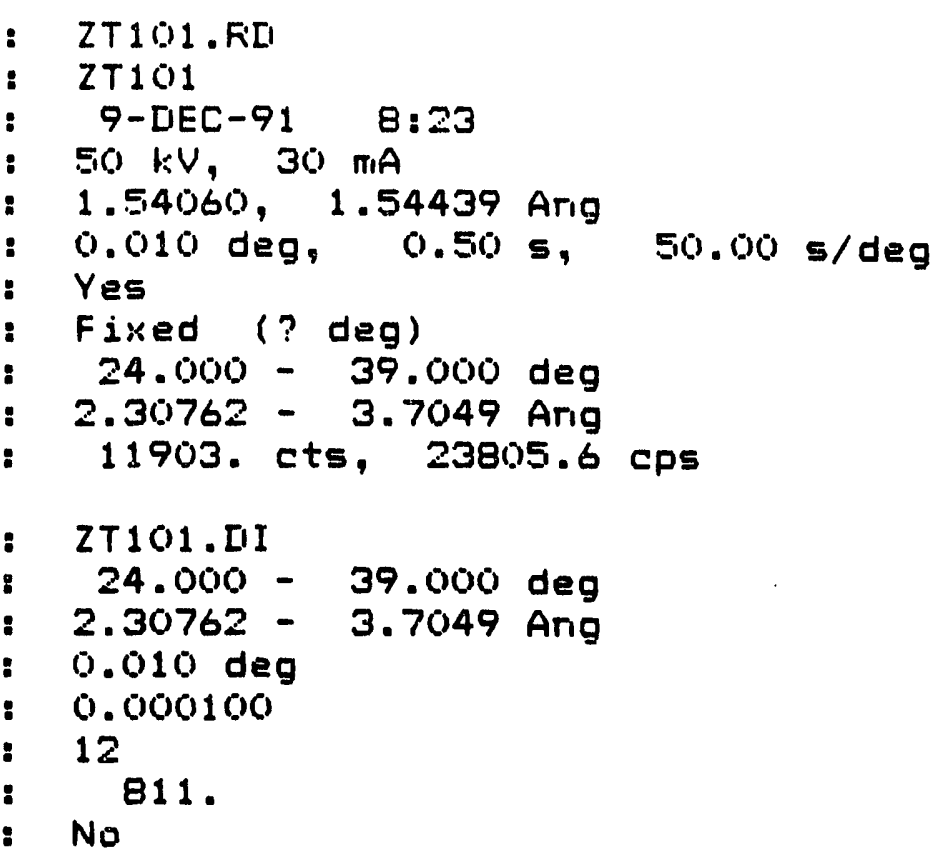

\begin{tabular}{|c|c|c|c|c|c|c|c|}
\hline $\begin{array}{l}\text { Peak } \\
\text { no. }\end{array}$ & $\begin{array}{l}\text { Angle } \\
\text { (deg) }\end{array}$ & $\begin{array}{l}\text { Alphal peak } \\
\text { int (ets) }\end{array}$ & $\begin{array}{l}\text { FWHM } \\
\text { (deg) }\end{array}$ & $\begin{array}{l}\text { Alphal backg } \\
\text { int (ets) }\end{array}$ & $\begin{array}{l}\text { Delta } \\
\text { int }\end{array}$ & $\begin{array}{l}\text { Integrated } \\
\text { area (cts) }\end{array}$ & $\begin{array}{l}\text { Average } \\
\text { sigma }\end{array}$ \\
\hline $\begin{array}{l}1 \\
2 \\
3 \\
4 \\
5 \\
6 \\
7 \\
8 \\
9\end{array}$ & $\begin{array}{l}26.1553 \\
27.5166 \\
30.0167 \\
31.3104 \\
32.0980 \\
35.0614 \\
35.3 .397 \\
36.1142 \\
36.9436\end{array}$ & $\begin{array}{r}15 . \\
347 . \\
3963 . \\
52 . \\
4 . \\
63 . \\
11126 . \\
130 . \\
465 .\end{array}$ & $\begin{array}{l}0.4823 \\
0.1259 \\
0.1443 \\
1.1673 \\
0.0561 \\
2.4957 \\
0.1480 \\
0.3913 \\
0.1803\end{array}$ & $\begin{array}{l}51.0 \\
51.4 \\
52.0 \\
52.3 \\
52.5 \\
53.3 \\
53.3 \\
53.4 \\
53.7\end{array}$ & $\begin{array}{r}-4.9 \\
31.2 \\
11.0 \\
9.1 \\
-3.7 \\
275.5 \\
-312.1 \\
-36.7 \\
-17.8\end{array}$ & $\begin{array}{r}8534 . \\
7062 . \\
92456 . \\
7261 . \\
46 . \\
18910 . \\
276495 . \\
7005 . \\
13504 .\end{array}$ & $\begin{array}{l}0.889 \\
0.753 \\
1.429 \\
0.953 \\
0.738 \\
1.028 \\
2.049 \\
2.024 \\
1.045\end{array}$ \\
\hline
\end{tabular}

$2=\mathrm{TiO}_{2}(\mathrm{R})$
$3=\mathrm{Zn}_{2} \mathrm{Ti}_{3} \mathrm{O}_{8}$
$7=\mathrm{Zn}_{2} \mathrm{Ti}_{3} \mathrm{O}_{8}$ 
APD1700 Automated Fowder [liffractometer System 1

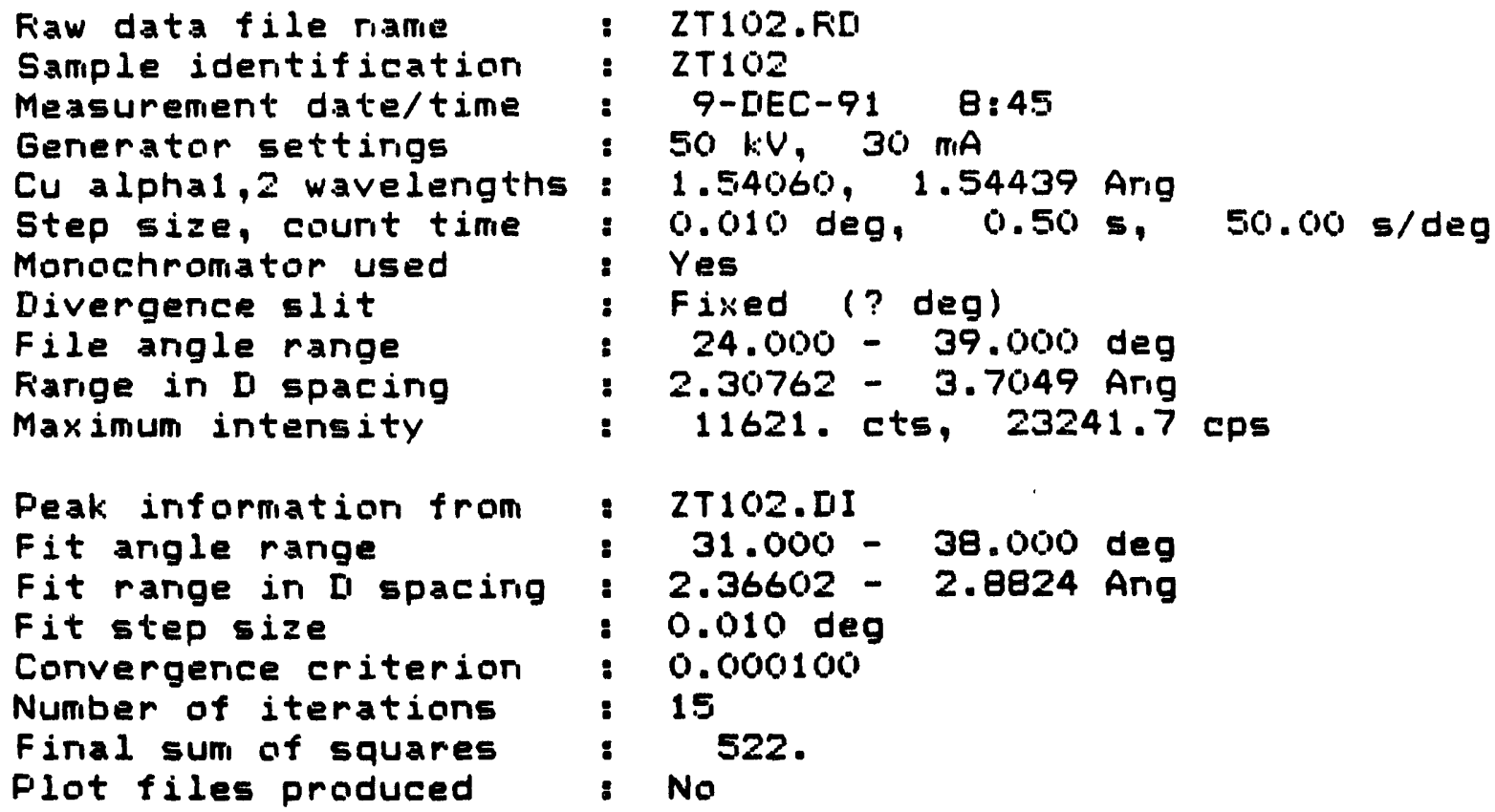

\begin{tabular}{|c|c|c|c|c|c|c|c|}
\hline $\begin{array}{l}\text { Peak } \\
\text { rio. }\end{array}$ & $\begin{array}{l}\text { Angle } \\
\text { (deg) }\end{array}$ & $\begin{array}{l}\text { Alphal peak } \\
\text { int (cts) }\end{array}$ & $\begin{array}{l}\text { FWHM } \\
\text { (deg) }\end{array}$ & $\begin{array}{l}\text { Alphal backg } \\
\text { int (cts) }\end{array}$ & $\begin{array}{c}\text { Delta } \\
\text { int }\end{array}$ & $\begin{array}{l}\text { Integrated } \\
\text { area (cts) }\end{array}$ & $\begin{array}{l}\text { Average } \\
\text { sigma }\end{array}$ \\
\hline $\begin{array}{l}1 \\
2 \\
3 \\
4 \\
5 \\
6 \\
7\end{array}$ & $\begin{array}{l}31.7730 \\
32.8090 \\
34.6551 \\
35.2820 \\
35.2375 \\
36.1123 \\
36.8948\end{array}$ & $\begin{array}{r}53 . \\
60 \\
62 \\
10960 \\
0 \\
222 \\
476\end{array}$ & $\begin{array}{l}0 . \\
0 . \\
0 . \\
0 . \\
0.1 \\
0 . \\
0 .\end{array}$ & $\begin{array}{l}75.1 \\
72.4 \\
67.6 \\
66.0 \\
66.1 \\
63.8 \\
61.8\end{array}$ & $\begin{array}{r}-9.8 \\
-4.8 \\
23.8 \\
-144.4 \\
-214.7 \\
-55.6 \\
7.6\end{array}$ & $\begin{array}{r}2388 . \\
1053 . \\
4736 . \\
274399 . \\
0 . \\
16521 . \\
13654 .\end{array}$ & $\begin{array}{l}1.22 \\
0.86 \\
0.95 \\
1.69 \\
1.43 \\
1.64 \\
1.10\end{array}$ \\
\hline
\end{tabular}

$$
4=\mathrm{Zn}_{2} \mathrm{TiO}_{4}
$$


AFI1700 Automated Fowder [liffractometer System 1

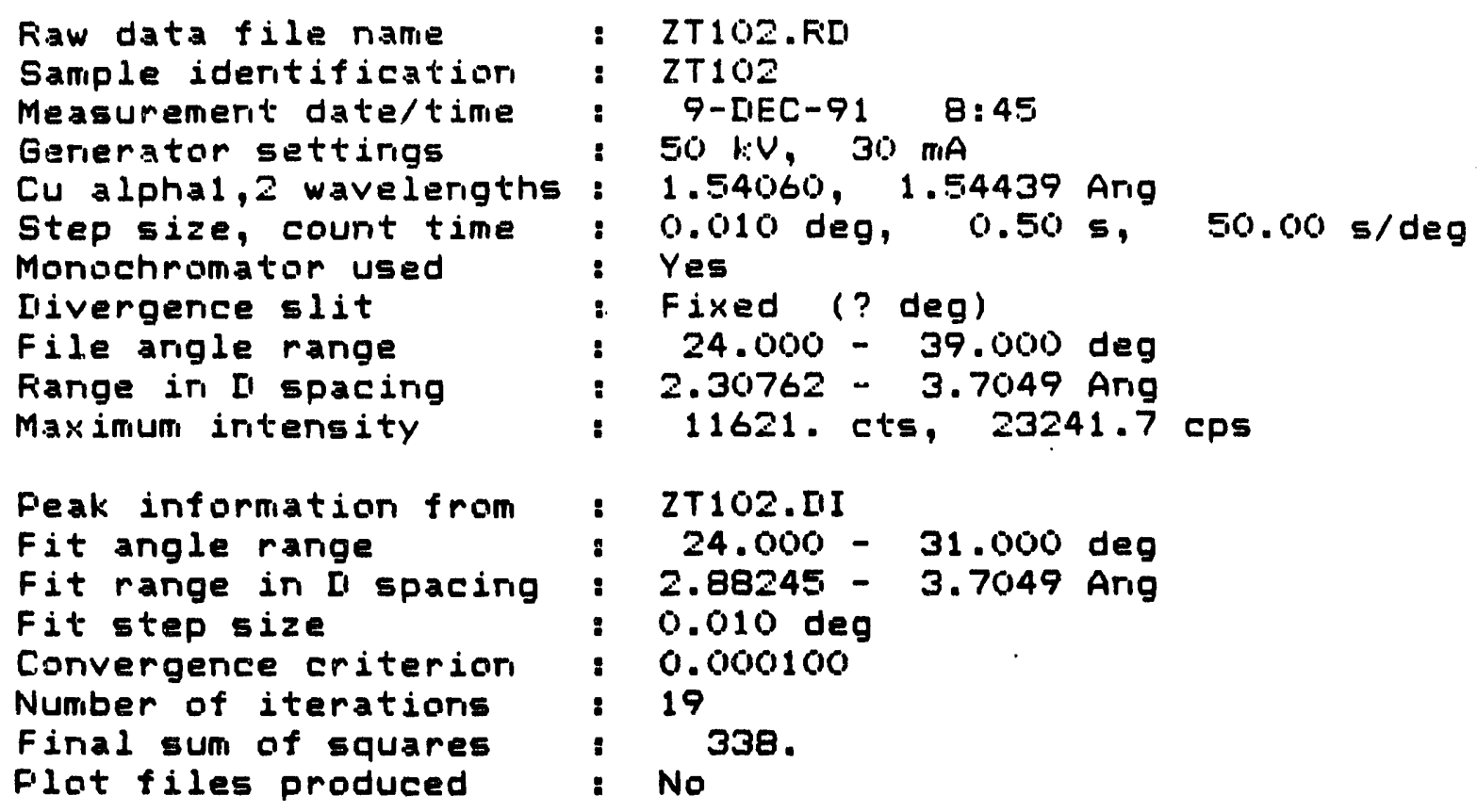

\begin{tabular}{|c|c|c|c|c|c|c|c|}
\hline $\begin{array}{l}\text { Peak } \\
\text { no. }\end{array}$ & $\begin{array}{l}\text { Angle } \\
\text { (deg) }\end{array}$ & $\begin{array}{l}\text { Alphal peak: } \\
\text { int (cts) }\end{array}$ & $\begin{array}{l}\text { FWHM } \\
\text { (deg) }\end{array}$ & $\begin{array}{l}\text { Alpha1 backg } \\
\text { int (cts) }\end{array}$ & $\begin{array}{l}\text { Delta } \\
\text { int }\end{array}$ & $\begin{array}{l}\text { Iritegrated } \\
\text { area (cts) }\end{array}$ & $\begin{array}{l}\text { Average } \\
\text { sigma }\end{array}$ \\
\hline $\begin{array}{l}1 \\
2 \\
3 \\
4\end{array}$ & $\begin{array}{l}25.3708 \\
27.4753 \\
29.9619 \\
30.6045\end{array}$ & $\begin{array}{r}96 . \\
420 \\
3771 . \\
0 .\end{array}$ & $\begin{array}{l}0.24 \\
0.13 \\
0.14 \\
2.00\end{array}$ & $\begin{array}{l}59.0 \\
59.0 \\
59.0 \\
59.0\end{array}$ & $\begin{array}{r}-2 \\
1 \\
5 . \\
-24\end{array}$ & $\begin{array}{r}4771 . \\
9665 . \\
92741 . \\
209 .\end{array}$ & \\
\hline
\end{tabular}

$1=\mathrm{TiO}_{2}(\mathrm{~A})$

$2=\mathrm{TiO}_{2}(\mathrm{R})$

$3=\mathrm{Zn}_{2} \mathrm{TiO}_{4}$ 


\section{Standard profile \\ File name \\ Identification \\ Arialysed profile \\ File riame \\ Identification}

QTZ9.FIE

: QTZ9

: ZT101.FILI

: ZT101

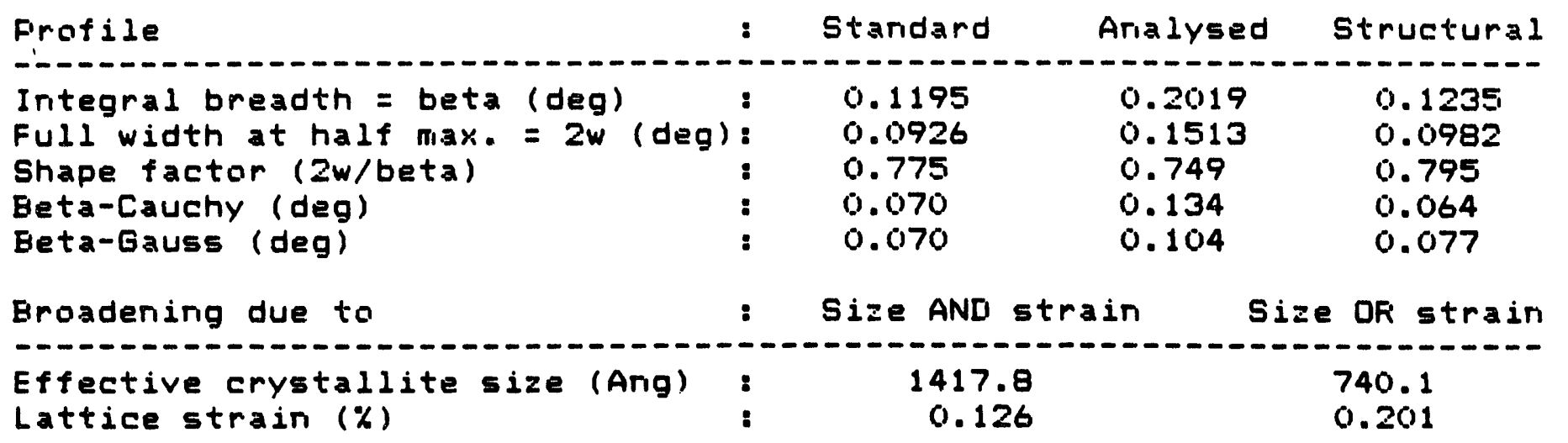


standard profile

File riame

: QTZ9.FII

Identification

: QTZ9

Arialysed profile

File riame

Identification

: ZT102.FII

: $2 T 102$

\begin{tabular}{|c|c|c|c|c|}
\hline Profile & : & Standard & Arialysed & Structural \\
\hline $\begin{array}{l}\text { Integral breadth = beta (deg) } \\
\text { Full width at half max. = } 2 w \text { (deg) } \\
\text { Shape factor ( } 2 w / \text { beta) } \\
\text { Eeta-cauchy (deg) } \\
\text { Beta-Gauss (deg) }\end{array}$ & $\begin{array}{l}: \\
:\end{array}$ & $\begin{array}{l}0.1195 \\
0.0926 \\
0.775 \\
0.070 \\
0.070\end{array}$ & $\begin{array}{l}0.2176 \\
0.1444 \\
0.663 \\
0.200 \\
0.051\end{array}$ & 0.131 \\
\hline
\end{tabular}

$\begin{array}{lcc}\text { Eroadening due to } & \text { Size AND strain Size OR strain } \\ \text { Effective crystallite size (Ang) : } & 699.0 & - \\ \text { Lattice strain (\%) } & : & -0\end{array}$



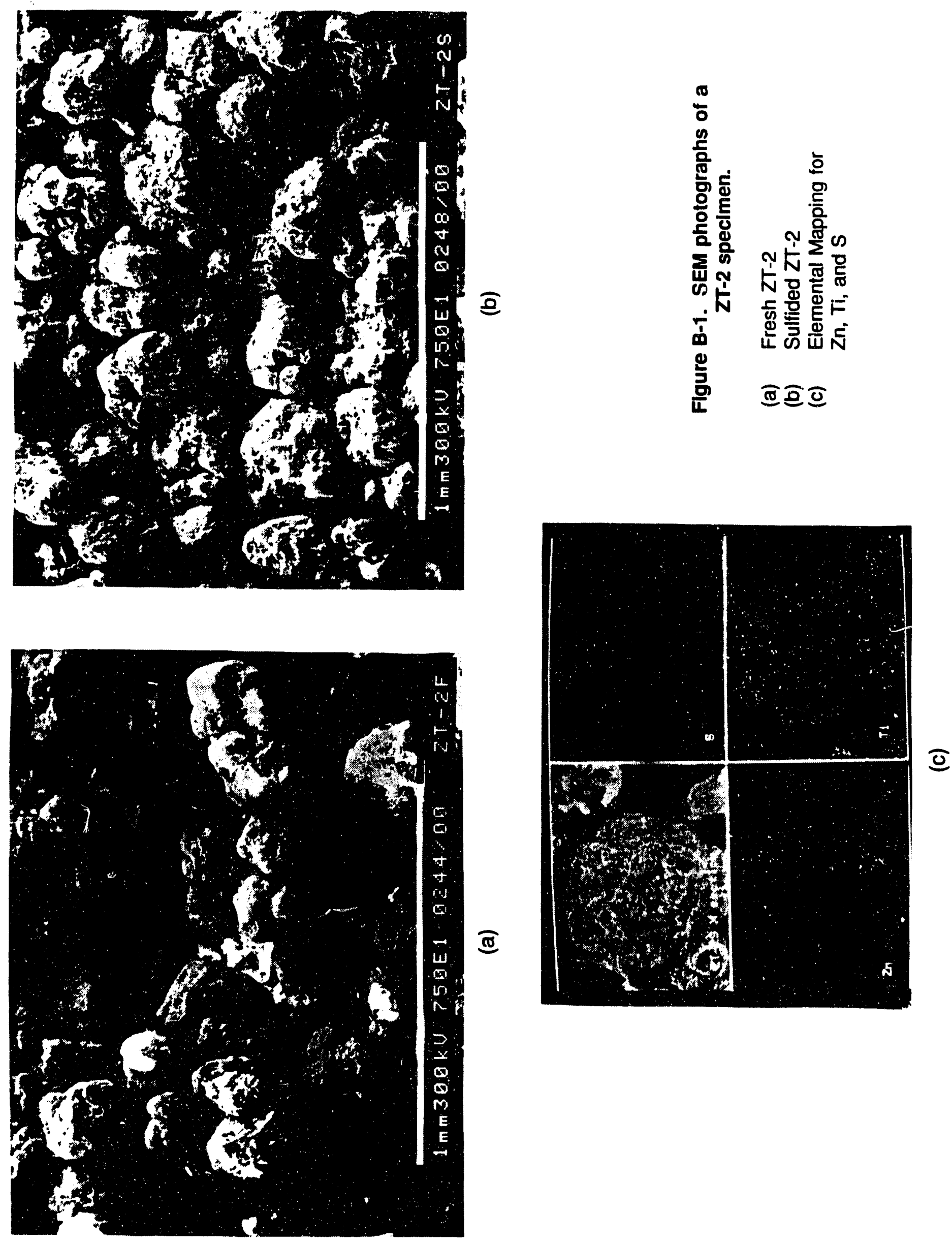


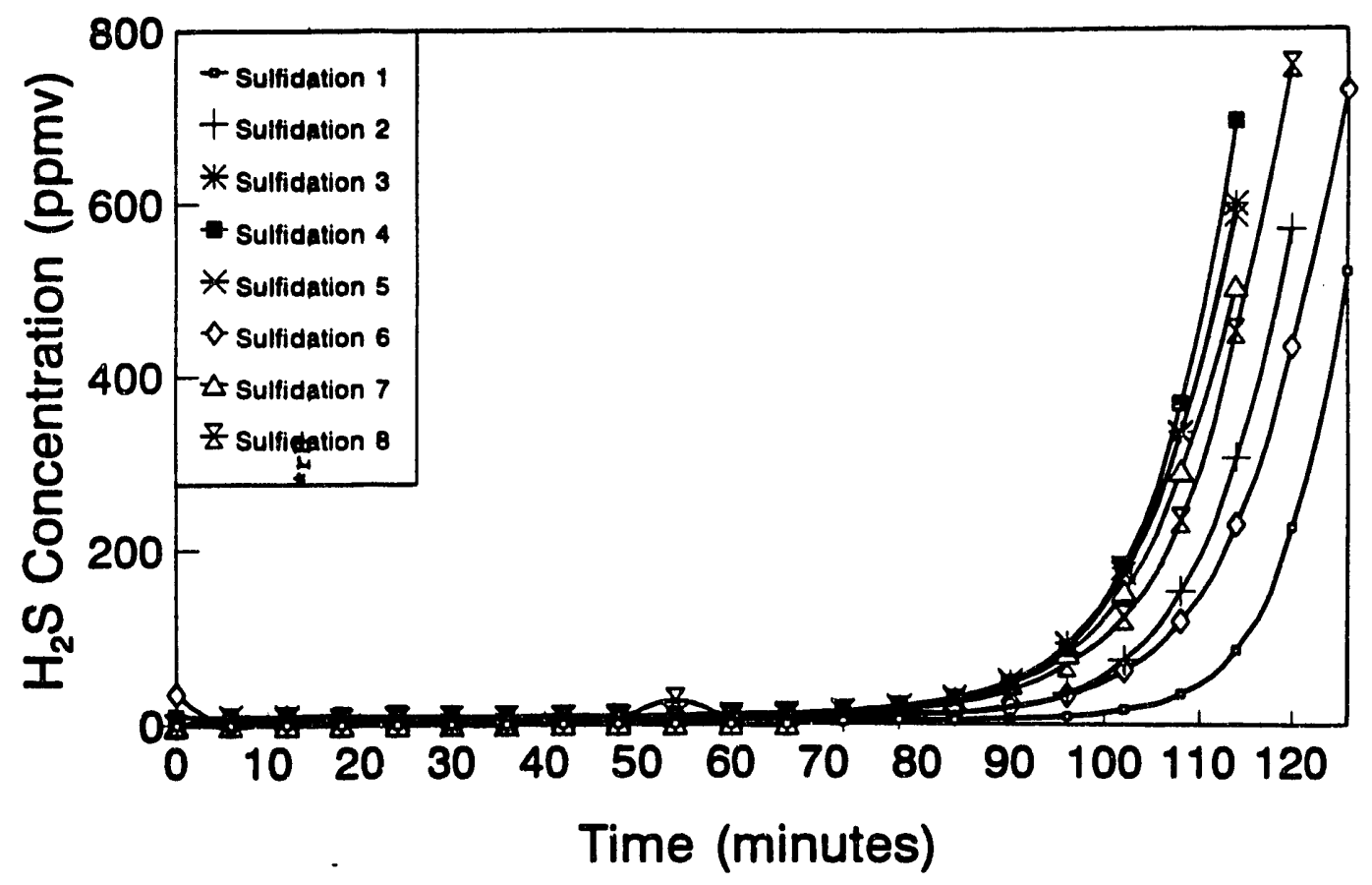

Run \#1

Figure C-1. Breakthrough curves for L-3758, KRW sulfidation gas at $650^{\circ} \mathrm{C}$.

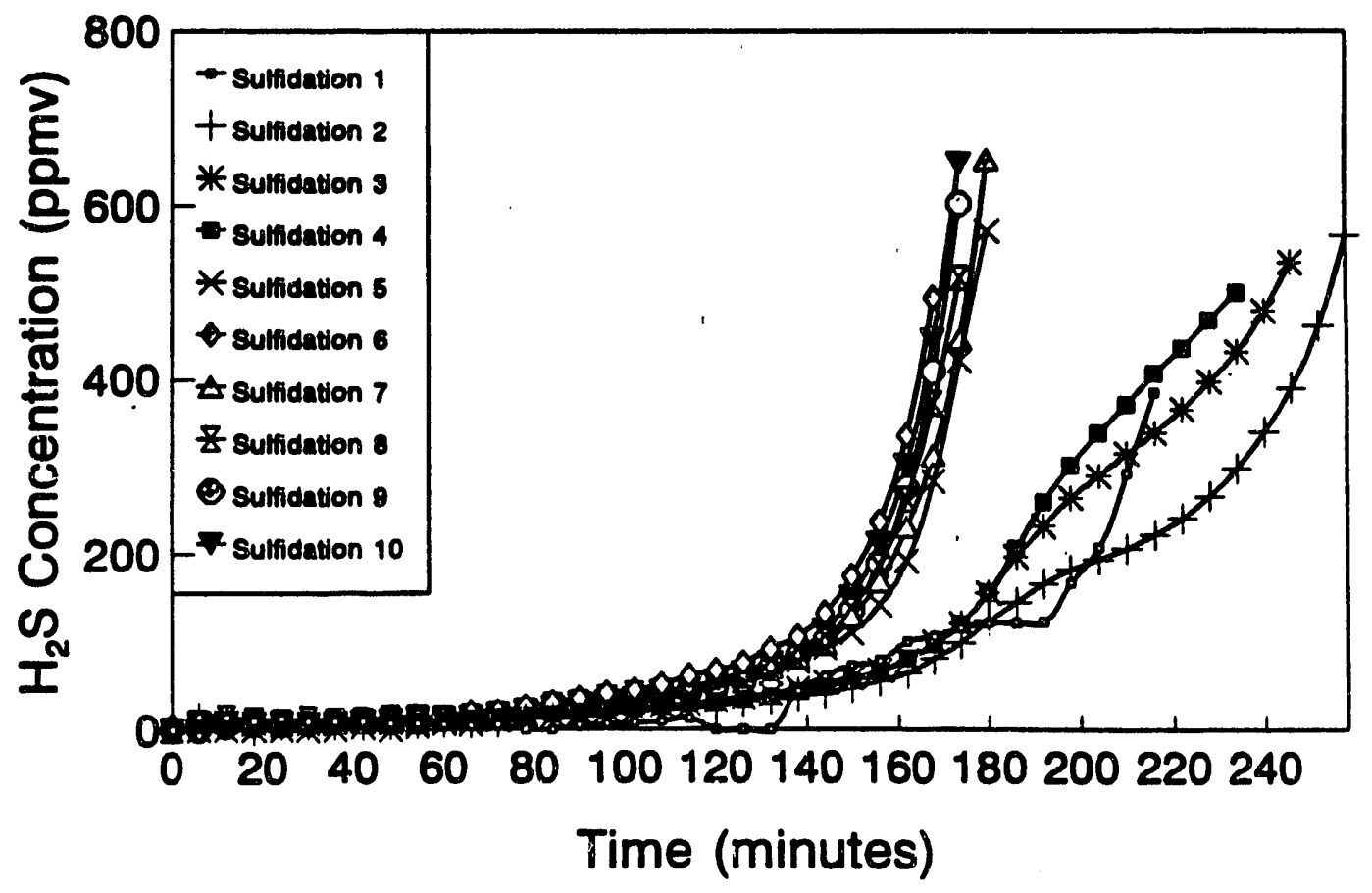

Run \#2

Figure C-2. Breakthrough curves for ZT-5, KRW sulfidation gas at $650^{\circ} \mathrm{C}$. 


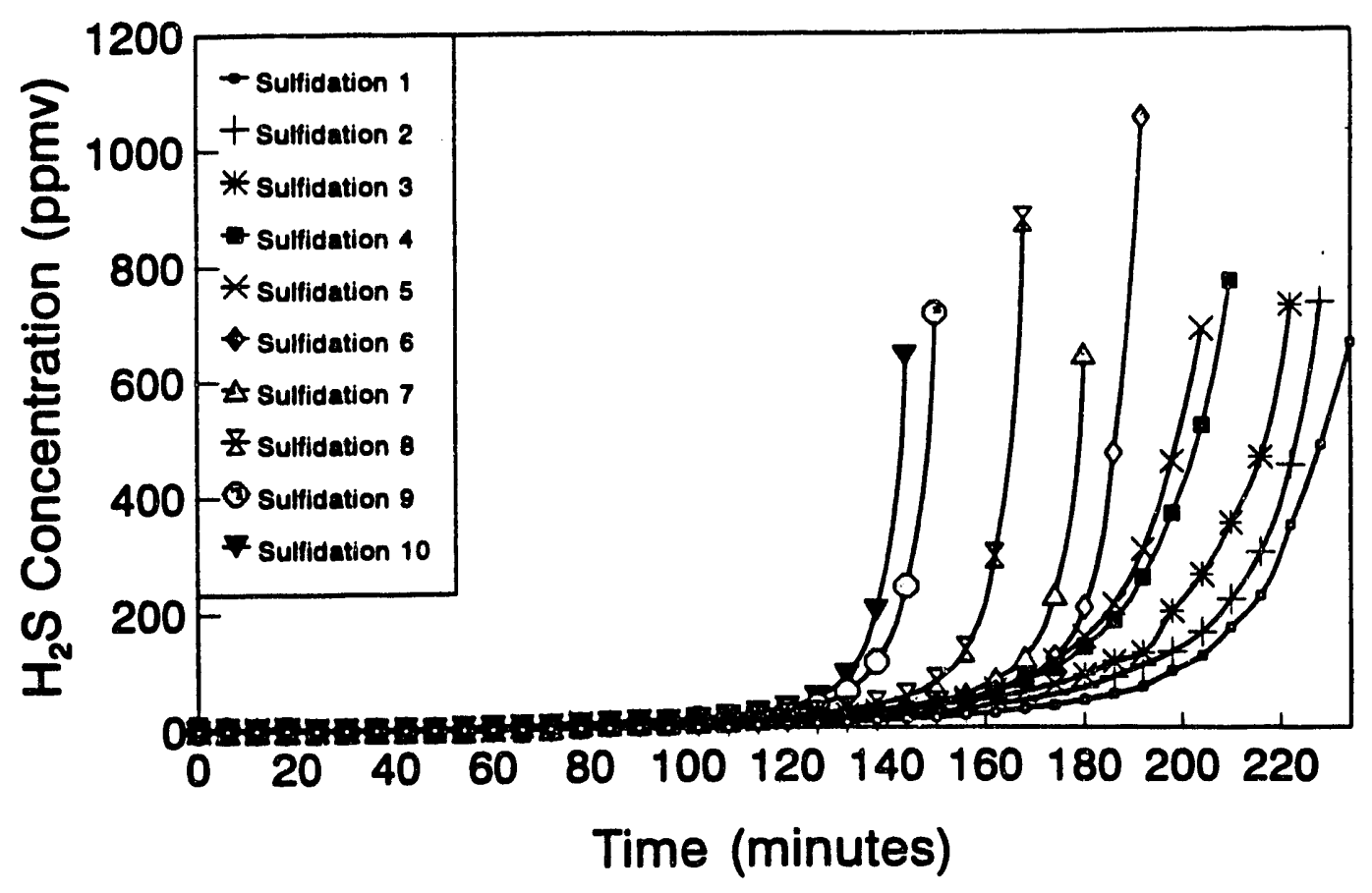

Run \#3

Figure C-3. Breakthrough curves for $\mathrm{ZT-5}, \mathrm{KRW}$ sulfidation gas at $650^{\circ} \mathrm{C}$.

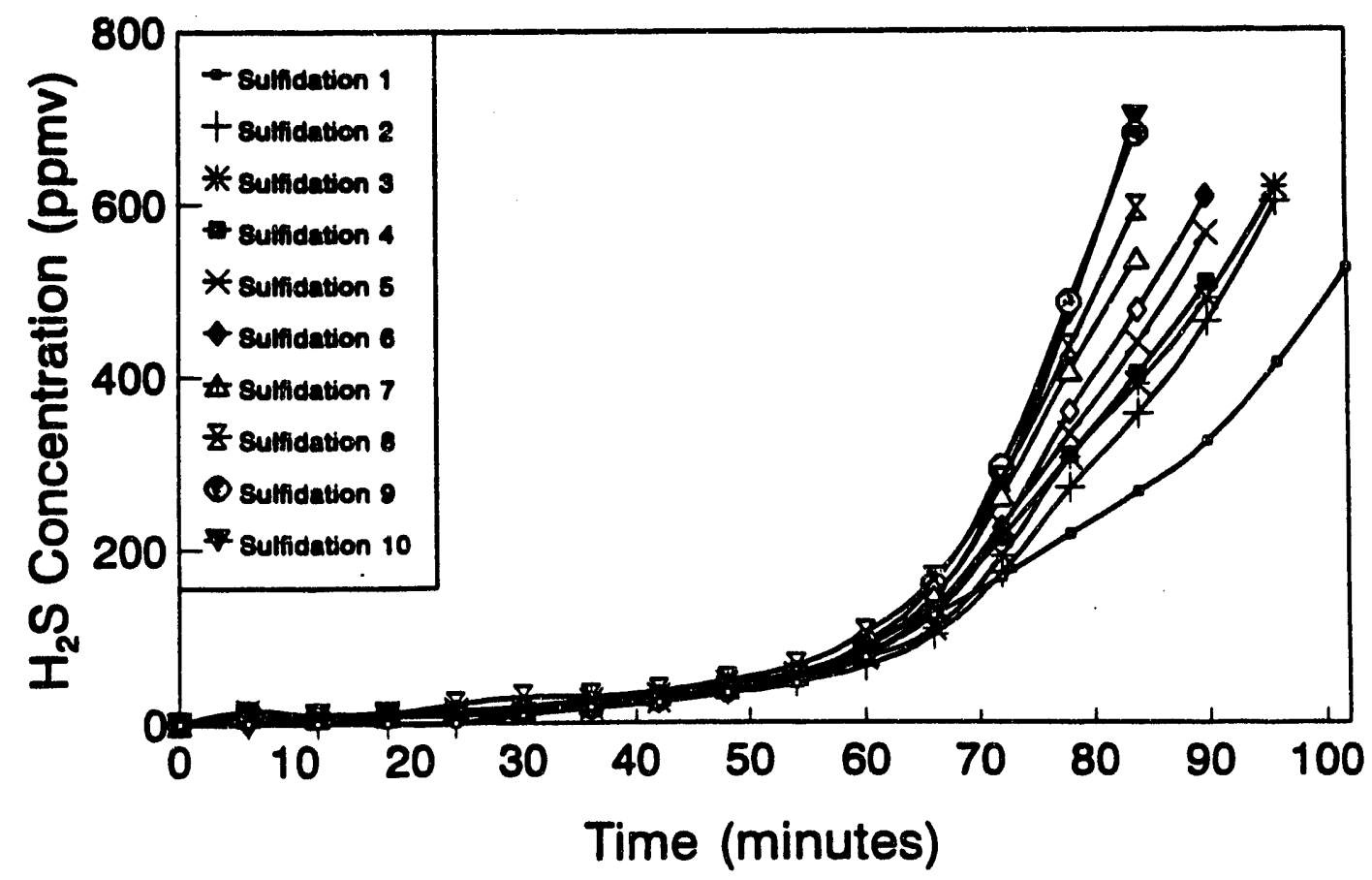

Run \#4

Figure C-4. Breakthrough curves for $\mathrm{ZT-5}$, Texaco sulfidation gas at $650^{\circ} \mathrm{C}$. 


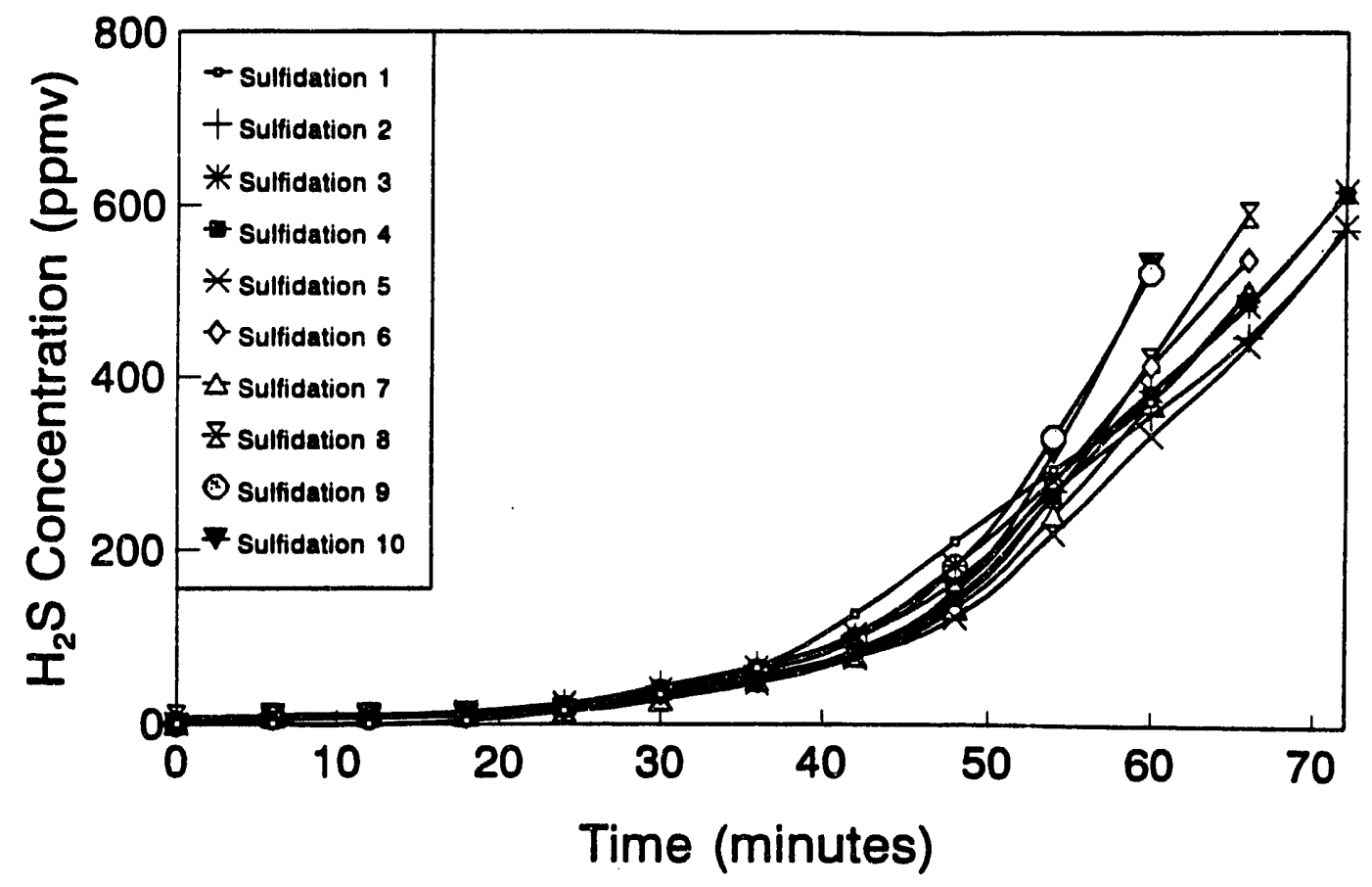

Run \#5

Figure C-5. Breakthrough curves for $Z \mathbf{Z}-2$, Texaco sulfidation gas at $650{ }^{\circ} \mathrm{C}$.

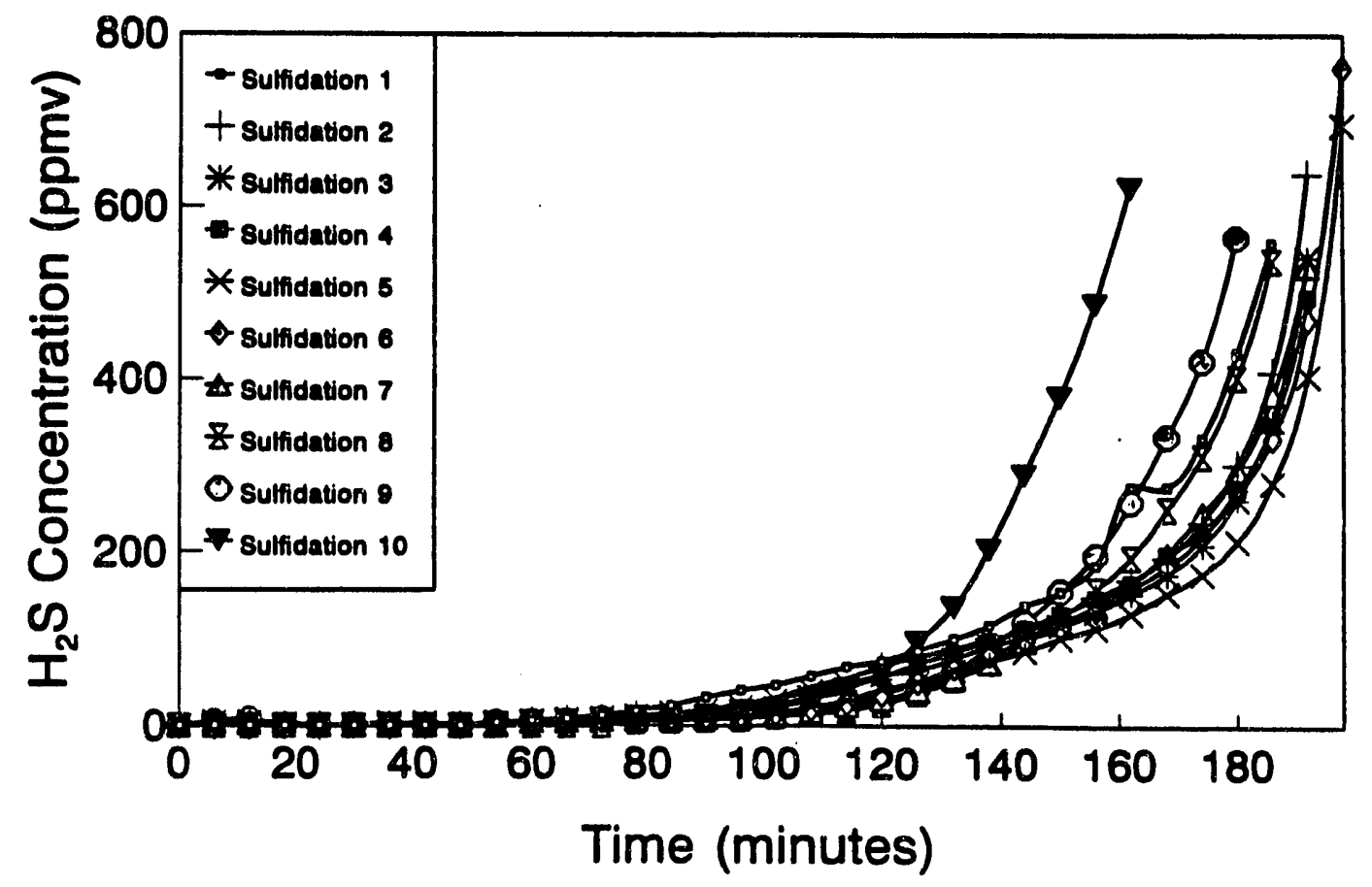

Run \#6

Figure C-6. Breakthrough curves for ZT-2, KRW sulfidation gas at $650^{\circ} \mathrm{C}$. 


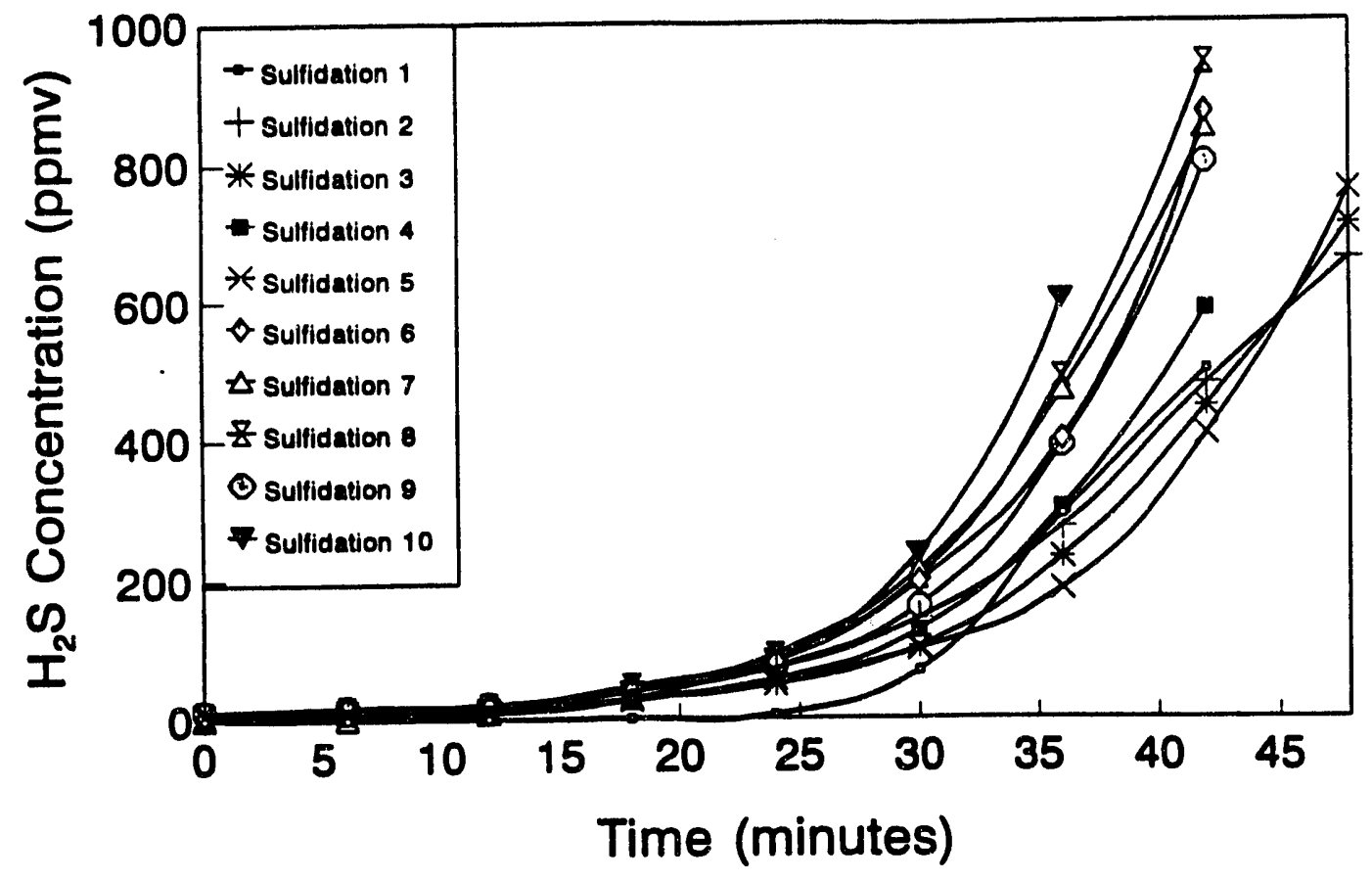

Run \#7

Figure C-7. Breakthrough curves for $\mathrm{ZT-7}$, Texaco sulfidation gas at $650^{\circ} \mathrm{C}$.

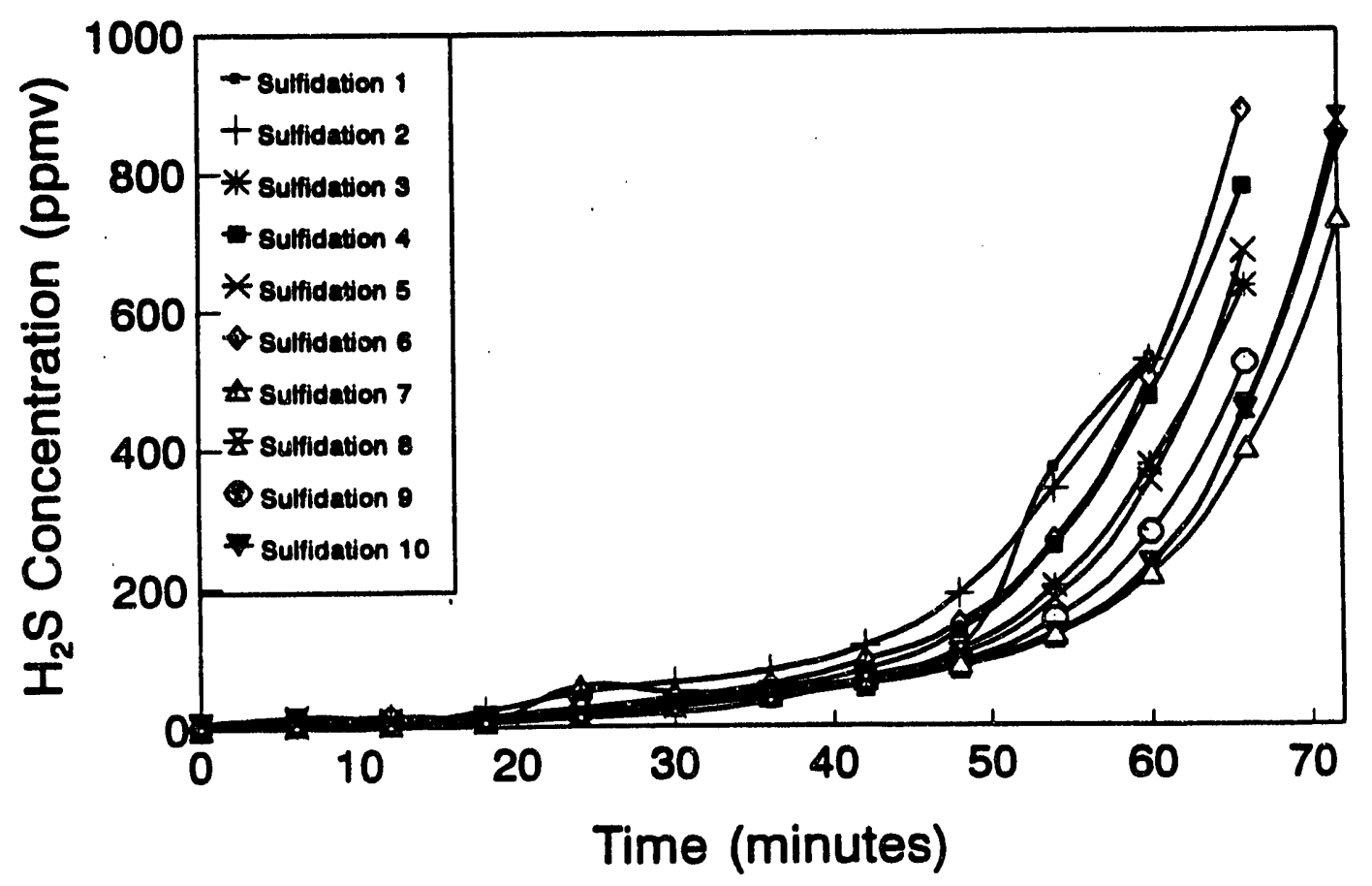

Run *8

Figure C-8. Breakthrough curves for $Z \mathbf{Z}-4$, Texaco sulfidation gas at $650^{\circ} \mathrm{C}$. 


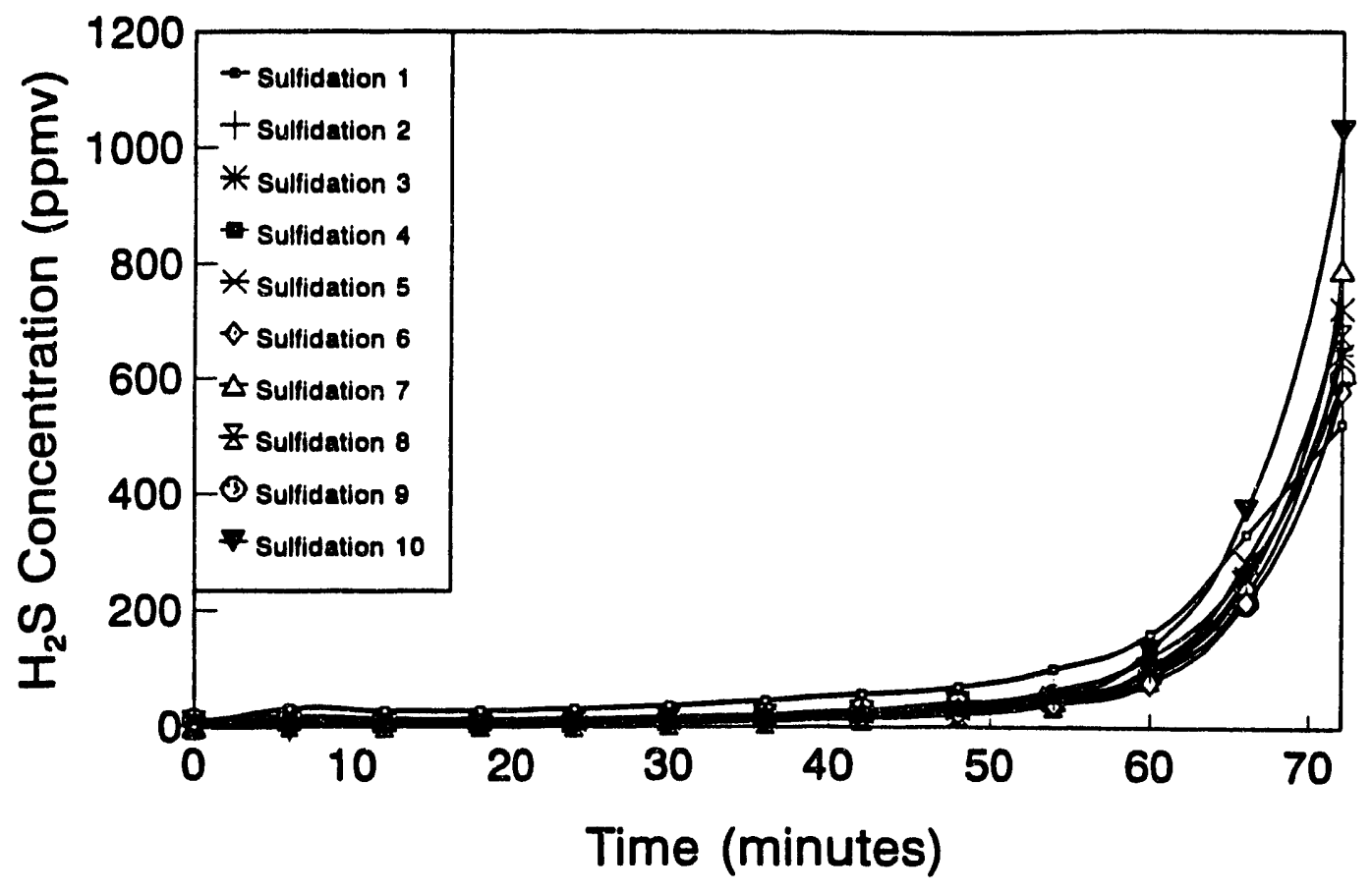

Run \#9

Figure C-9. Breakthrough curves for $\mathbf{Z T}-4$, Texaco sulfidation gas at $750{ }^{\circ} \mathrm{C}$.

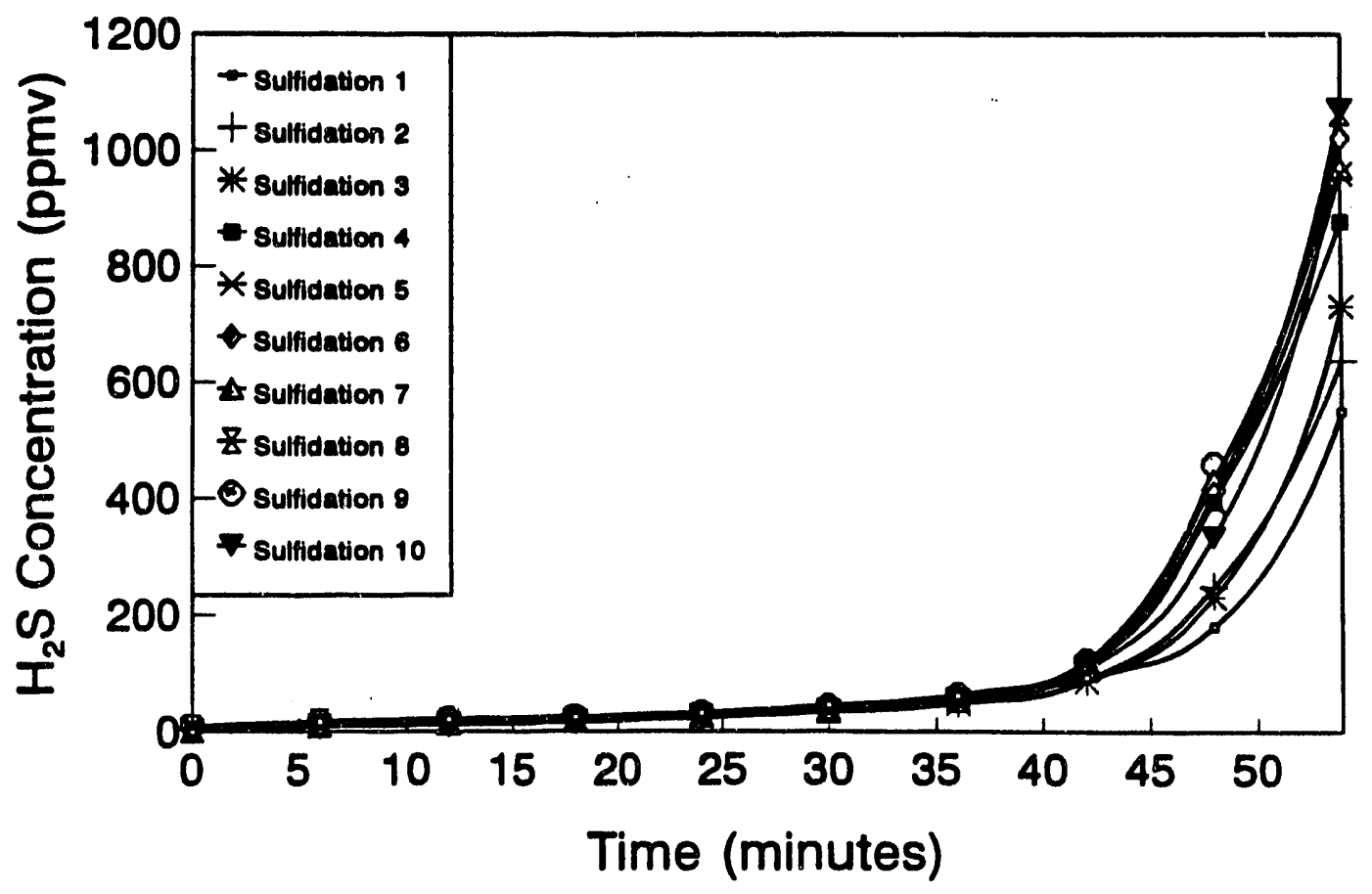

Run \#10

Figure C-10. Breakthrough curves for $\mathrm{ZT}-4$, Texaco sulfidation gas at $750^{\circ} \mathrm{C}$. 


\section{APPENDIX D}

COS BREAKTHROUGH CURVES FOR RUNS 1 TO 10 


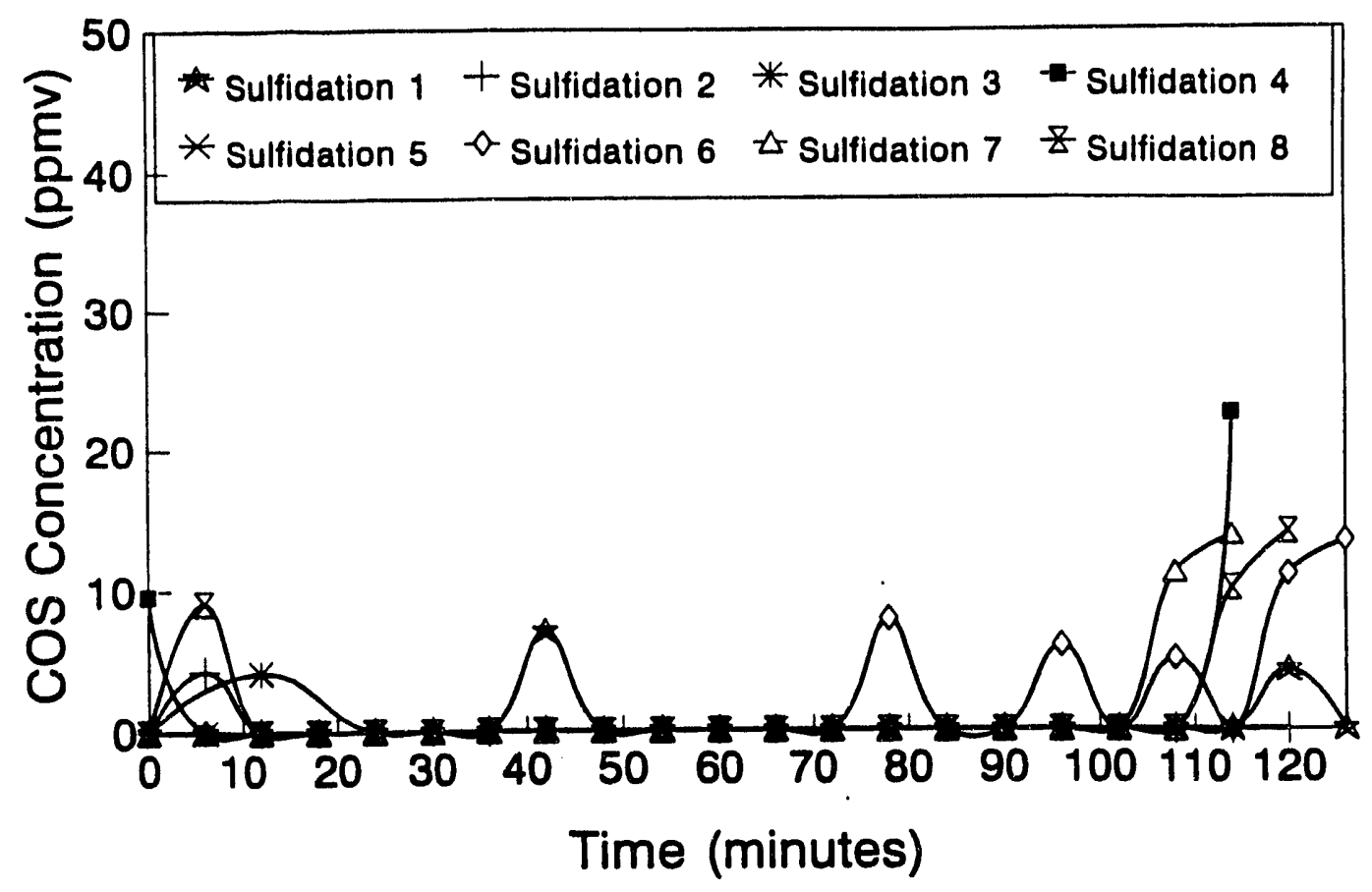

Run \#1

Figure D-1. Cos breakthrough curves for L-3758, KRW sulfidation gas at $650^{\circ} \mathrm{C}$.

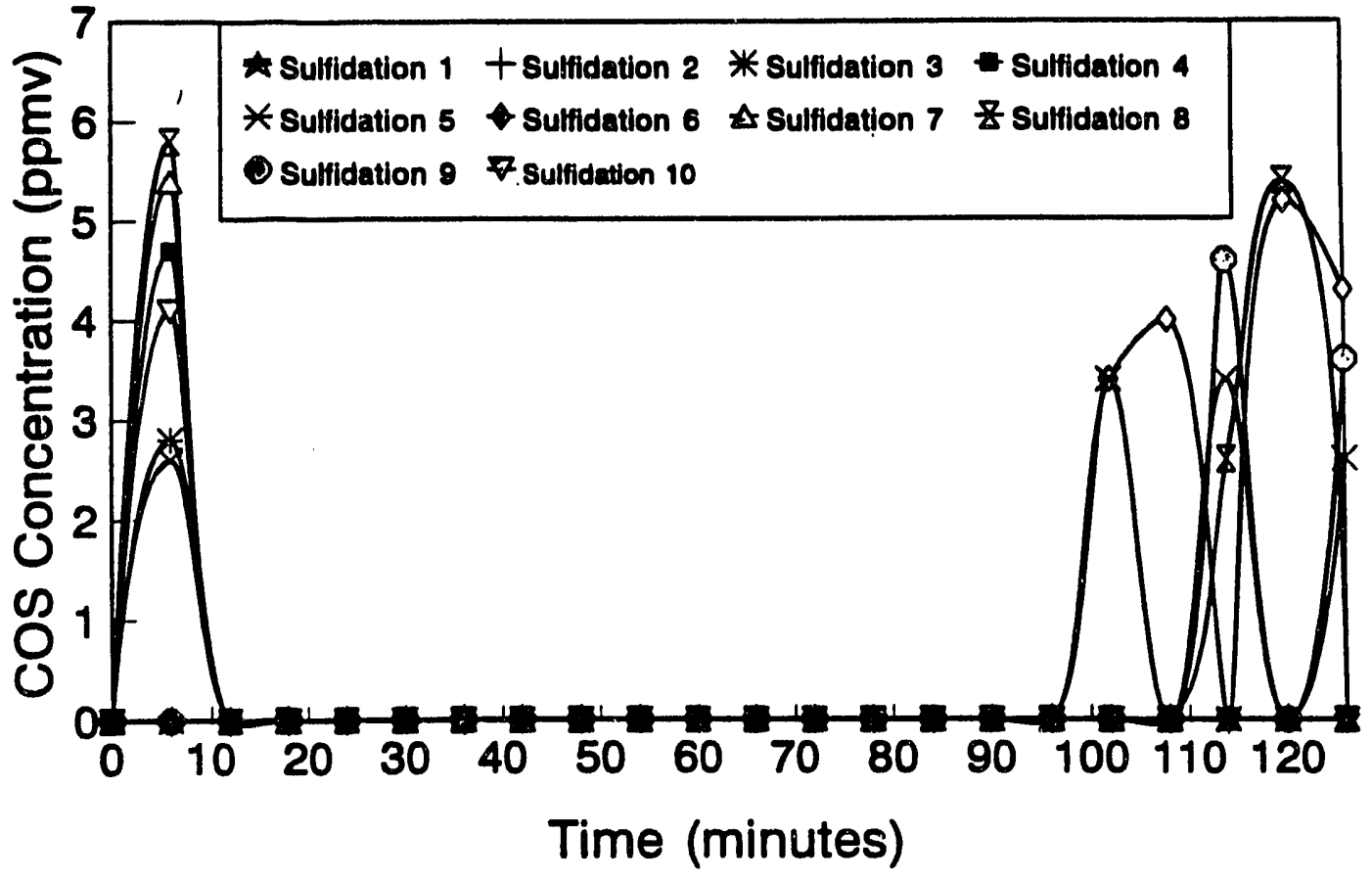

Run \#2

Figure D-2. Cos breakthrough curves for ZT-5, KRW sulfidation gas at $650^{\circ} \mathrm{C}$. 


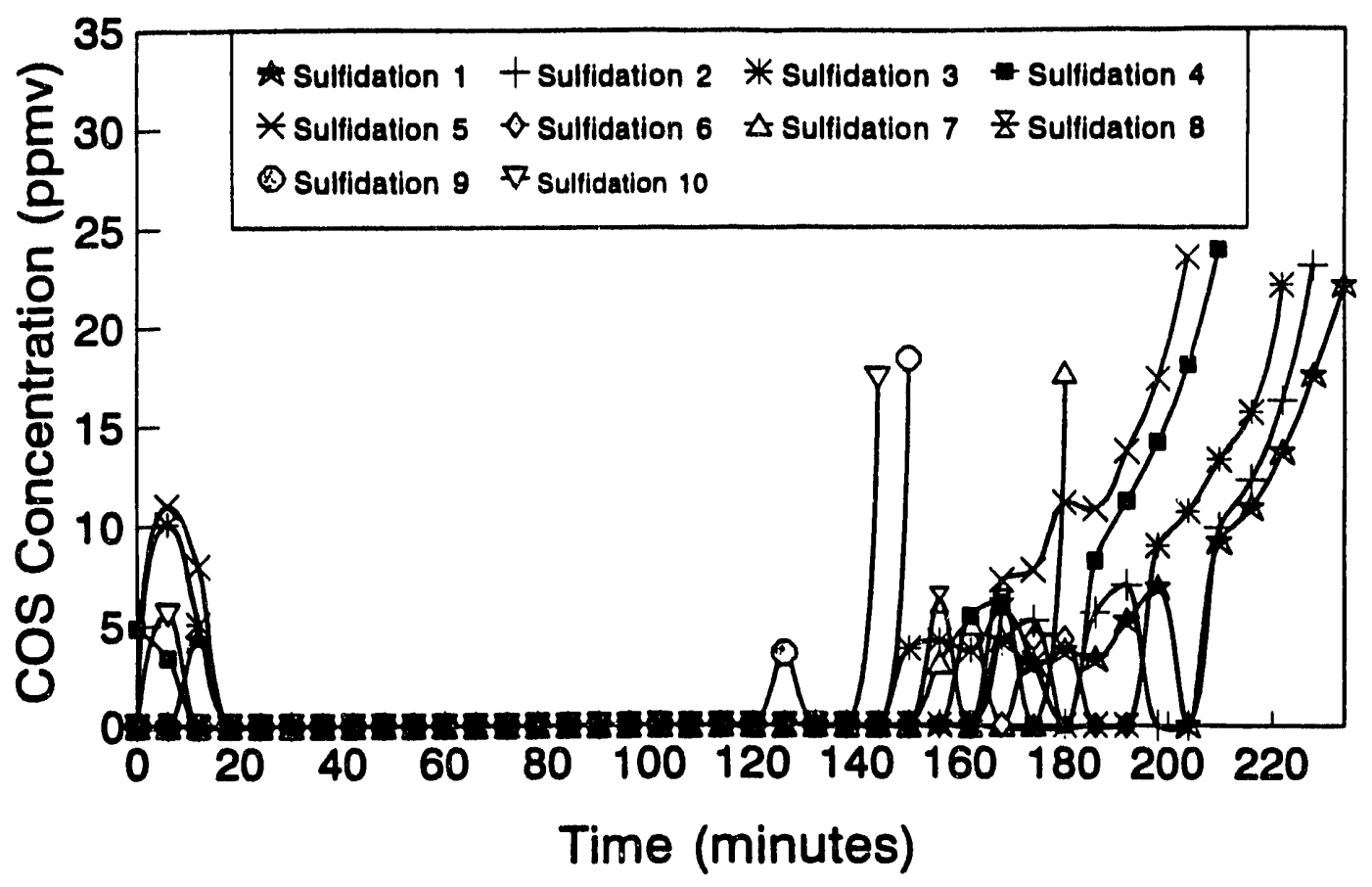

Run *3

Figure D-3. COS breakthrough curves for ZT-5, KRW sulfidation gas at $650^{\circ} \mathrm{C}$.

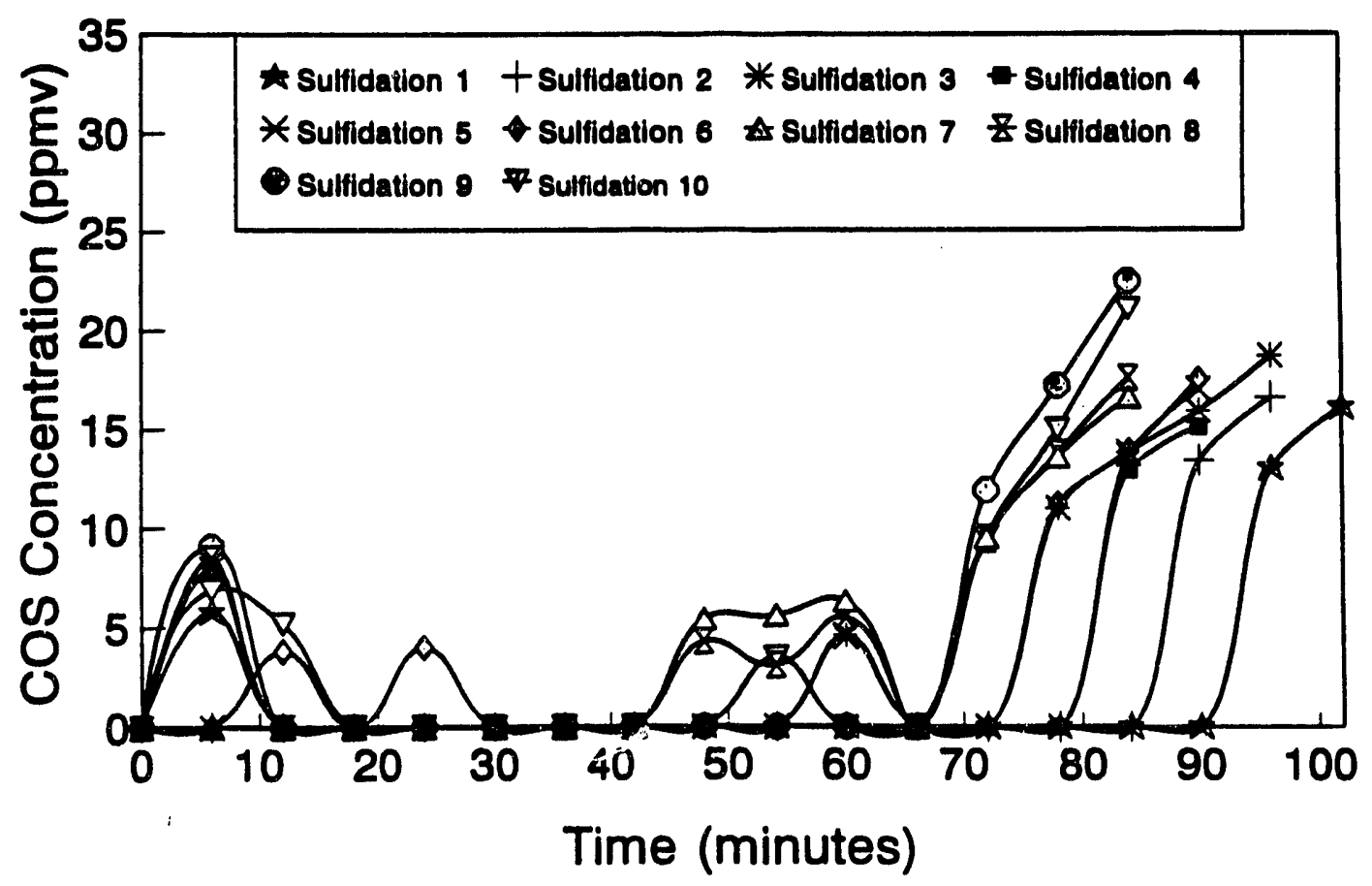

Pun \#4

Figure D-4. COS breakthrough curves for ZT-5, Texaco sulfidation gas at $650^{\circ} \mathrm{C}$. 


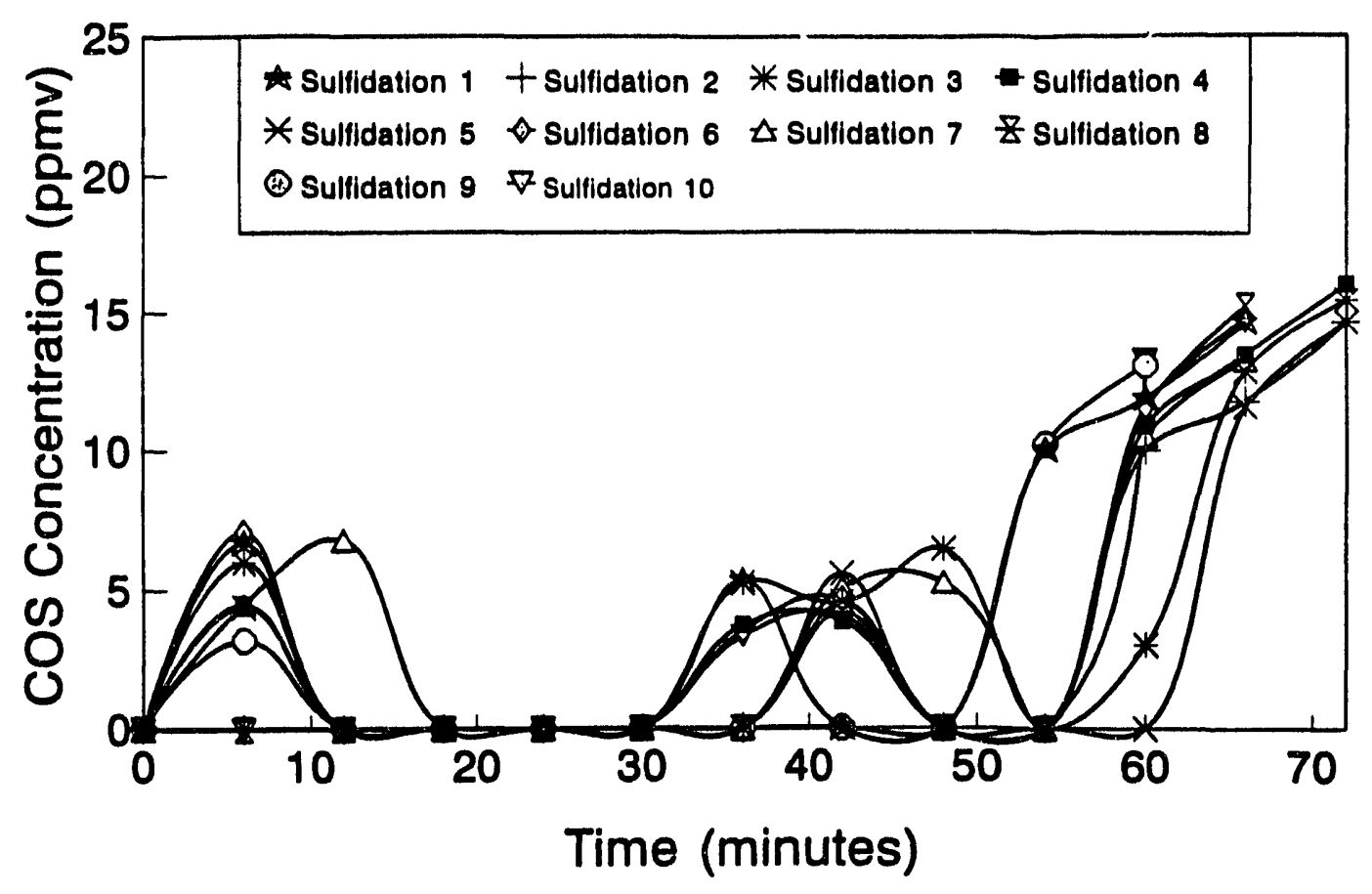

Run \#5

Figure D-5. COS breakthrough curves for ZT-2, Texaco sulfidation gas at $650^{\circ} \mathrm{C}$.

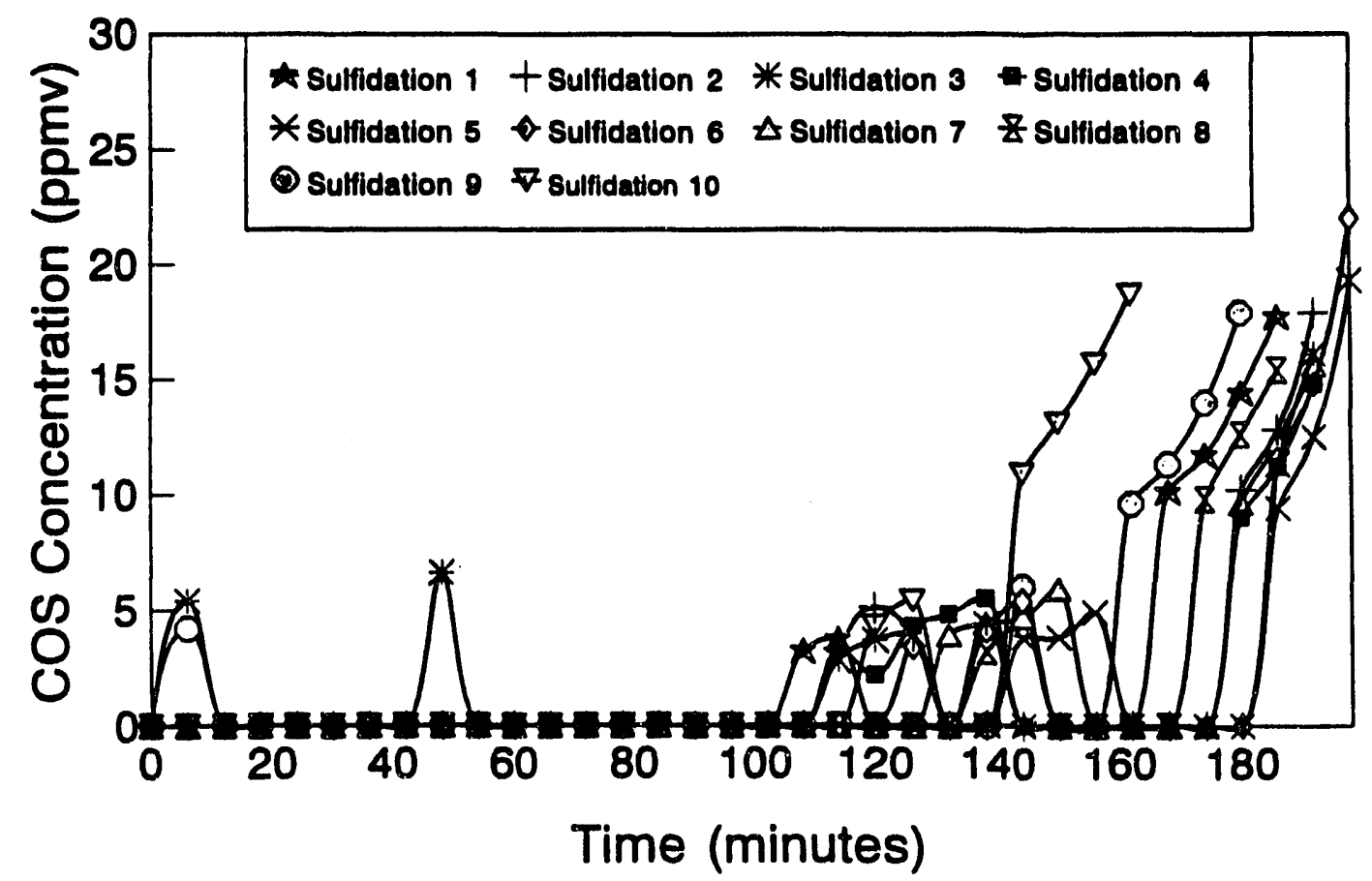

Pun \#6

Figure D-6. COS breakthrough curves for ZT-2, KRW sulfidation gas at $650{ }^{\circ} \mathrm{C}$. 


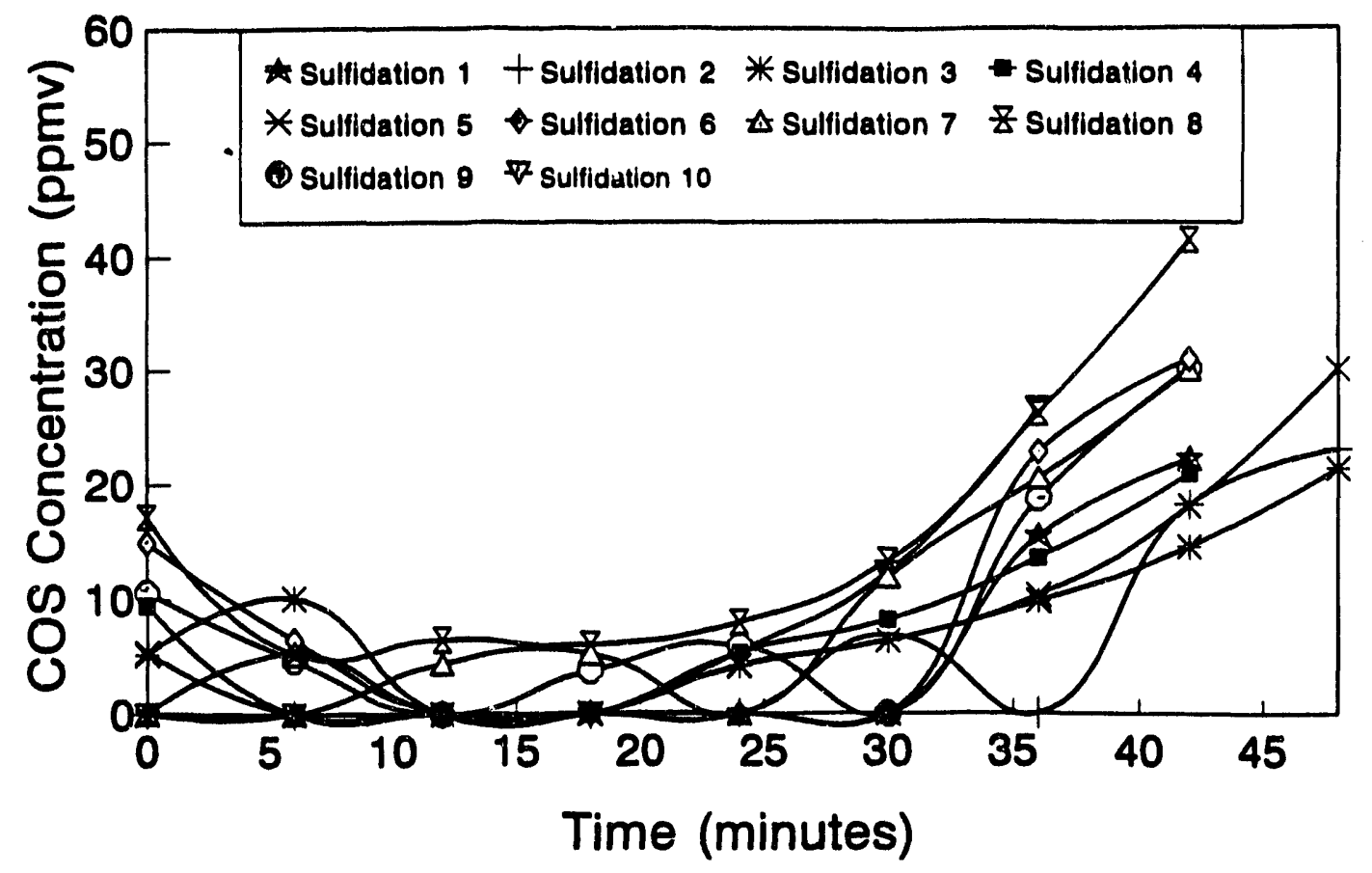

Run \#7

Figure D-7. Cos breakthrough curves for ZT-7, Texaco sulfidation gas at $650^{\circ} \mathrm{C}$.

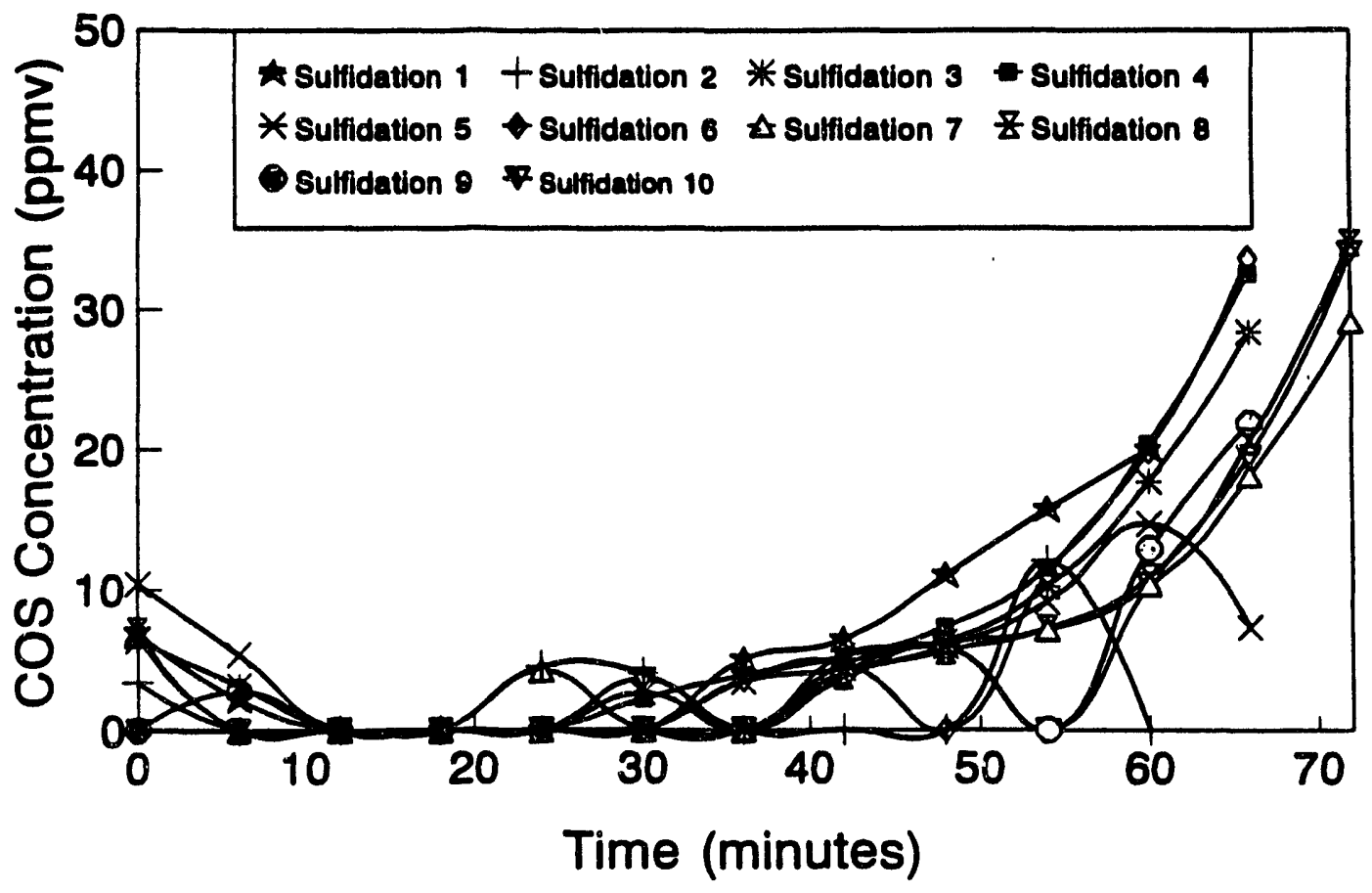

Run \#8

Figure D-8. COS breakthrough curves for $\mathrm{ZT}-4$, Texaco sulfidation gas at $650^{\circ} \mathrm{C}$. 


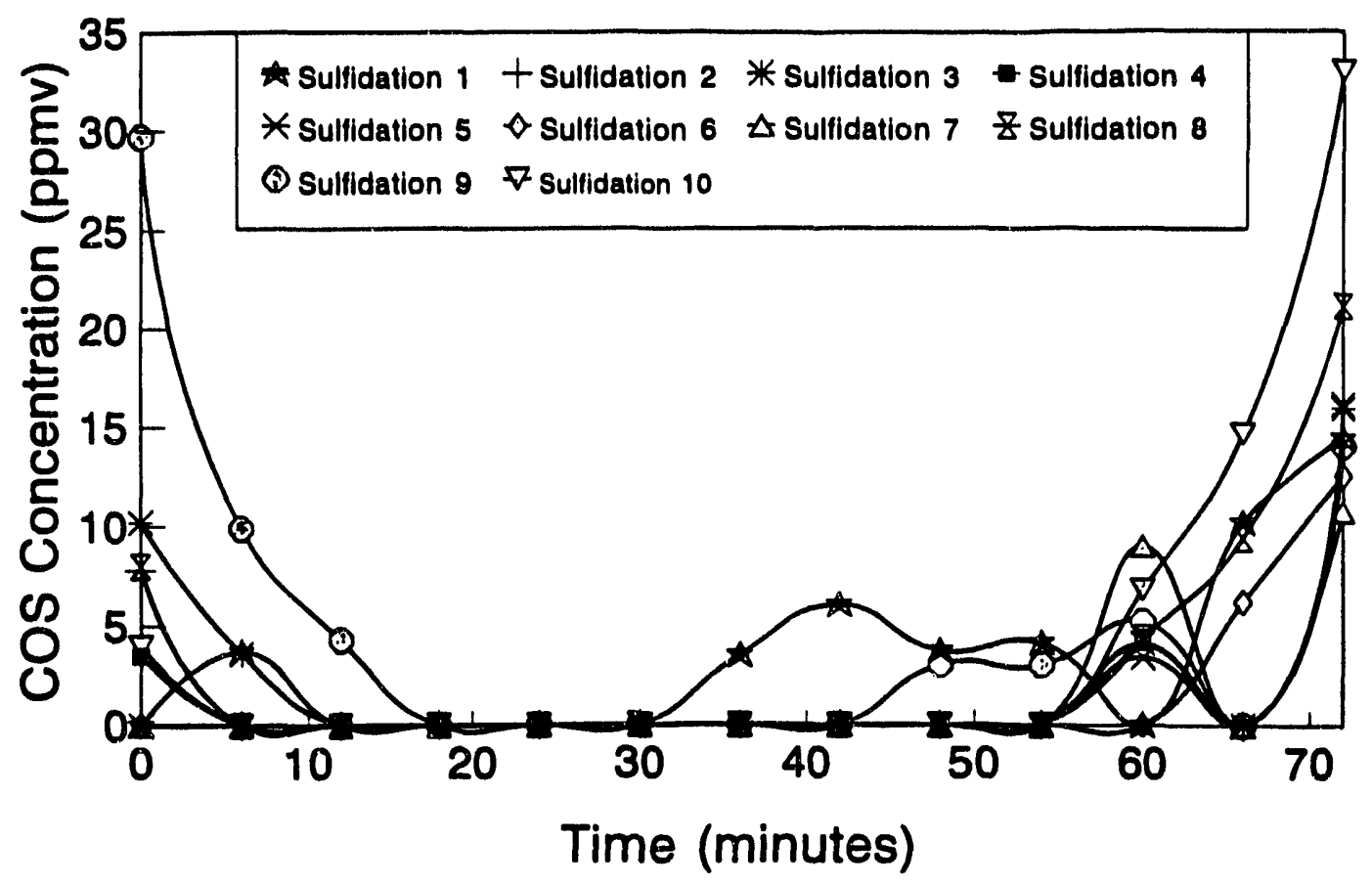

Run *9

Figure D-9. COS breakthrough curves for $Z T-4$, Texaco sulfidation gas at $750^{\circ} \mathrm{C}$.

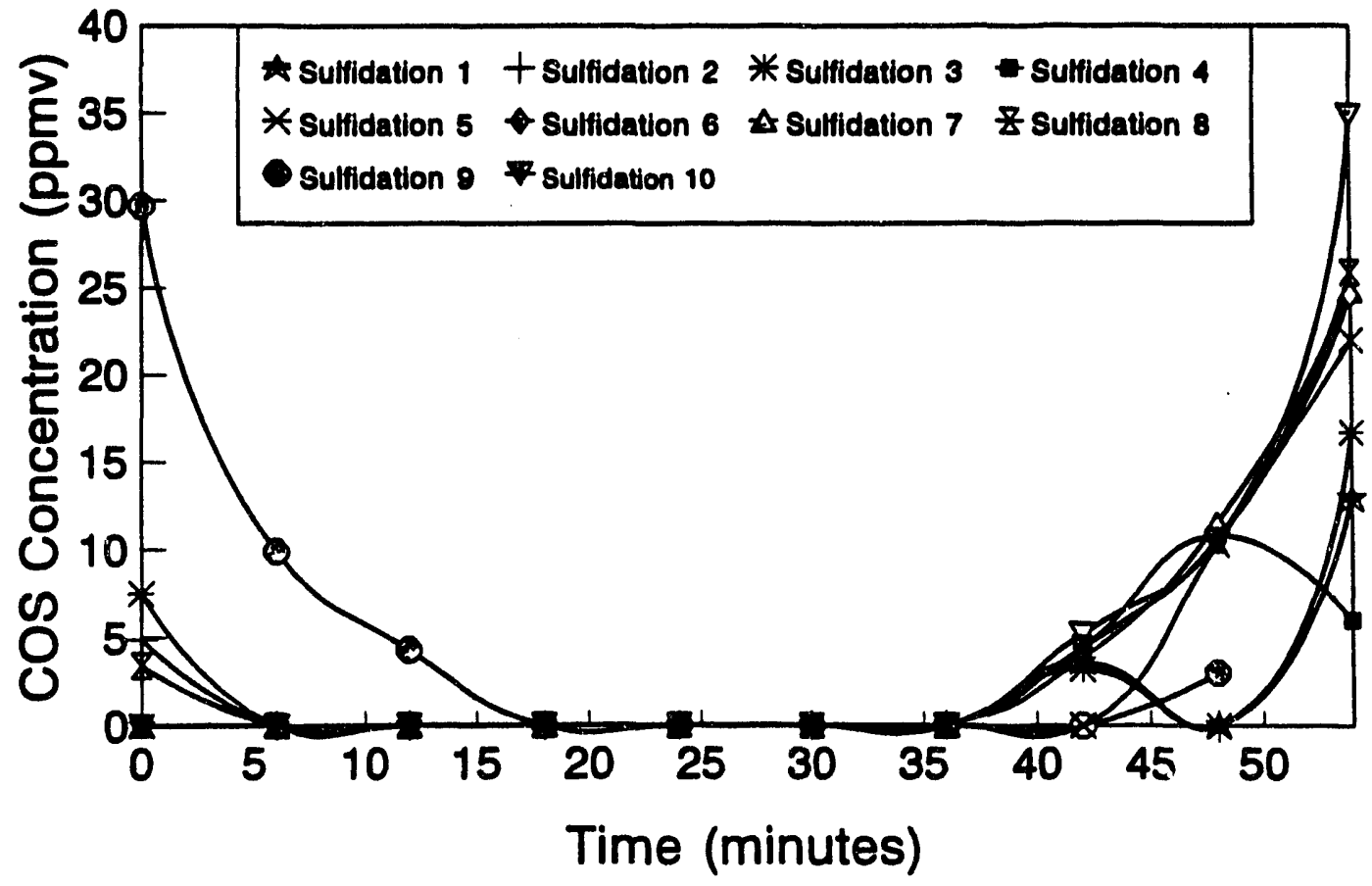

Run \#10

Figure D-10. COS breakthrough curves for $\mathbf{Z T - 4}$, Texaco sulfidation gas at $750^{\circ} \mathrm{C}$. 


\section{APPENDIX E}

SULFUR CAPACITIES CURVES FOR

RUNS 1 TO 10 


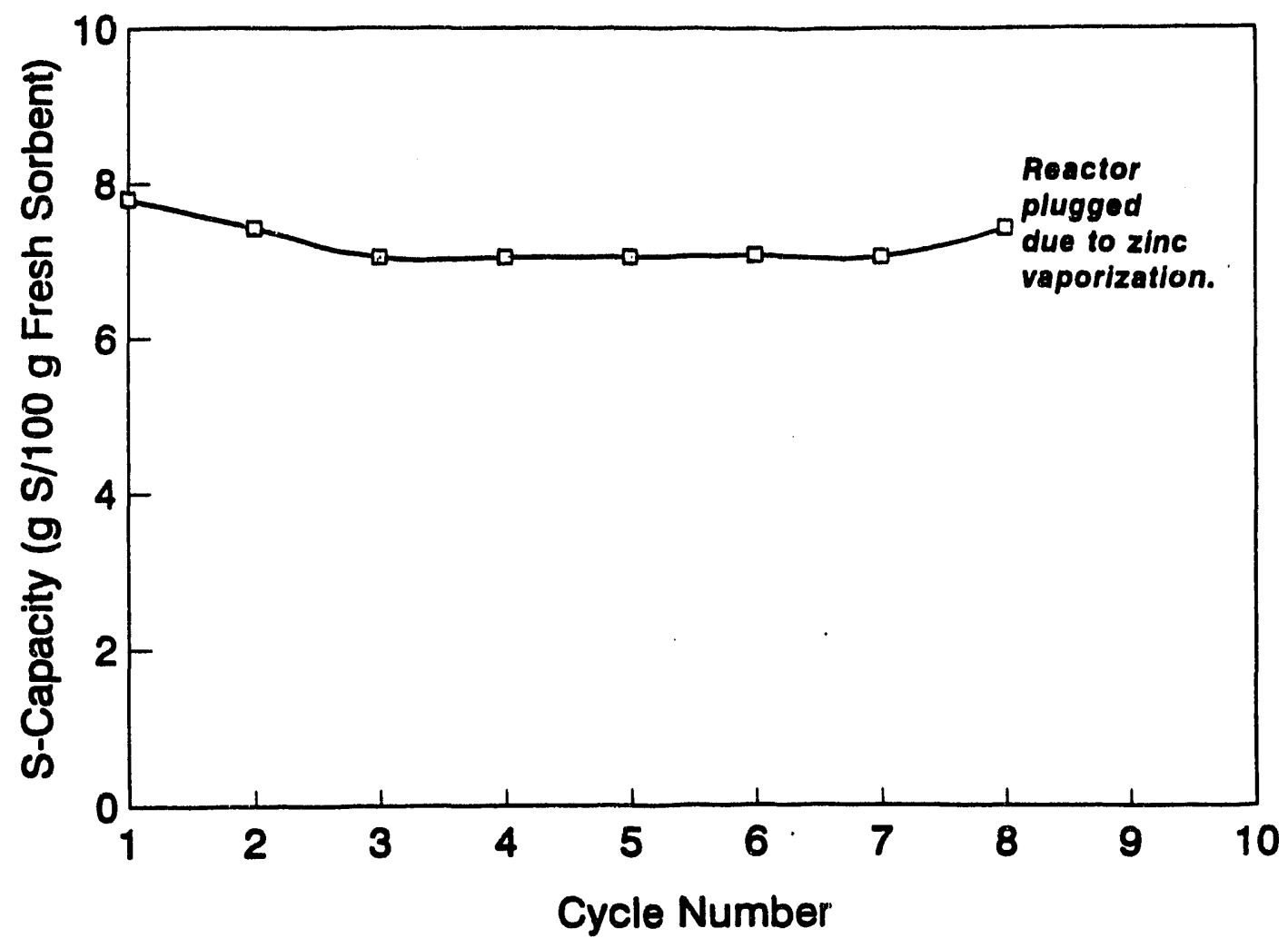

Figure E-1. S-capacity of L-3758 in KRW gas at $650{ }^{\circ} \mathrm{C}$.

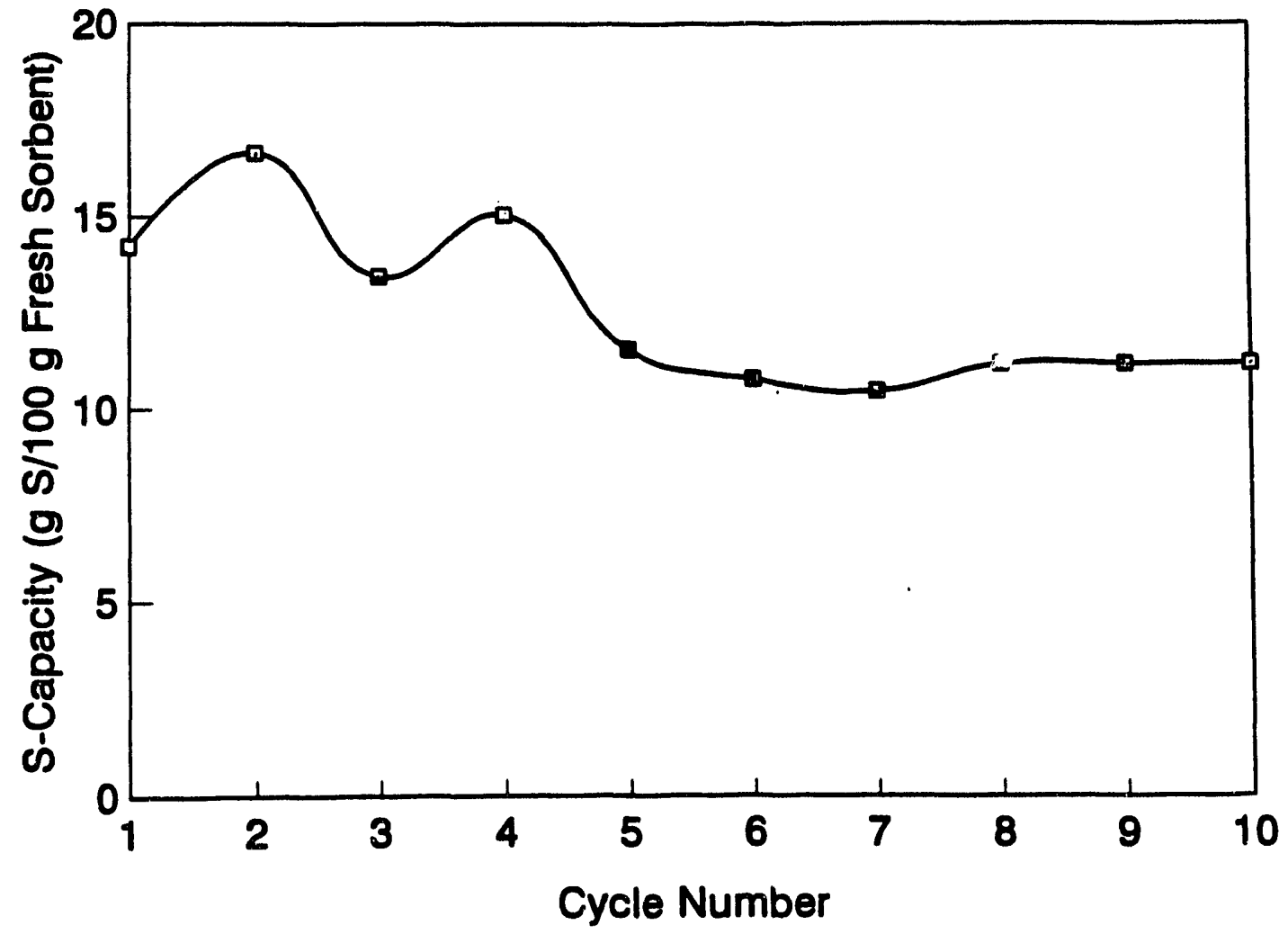

Figure E-2. S-capacity of ZT-5 in KRW gas at $650^{\circ} \mathrm{C}$. 


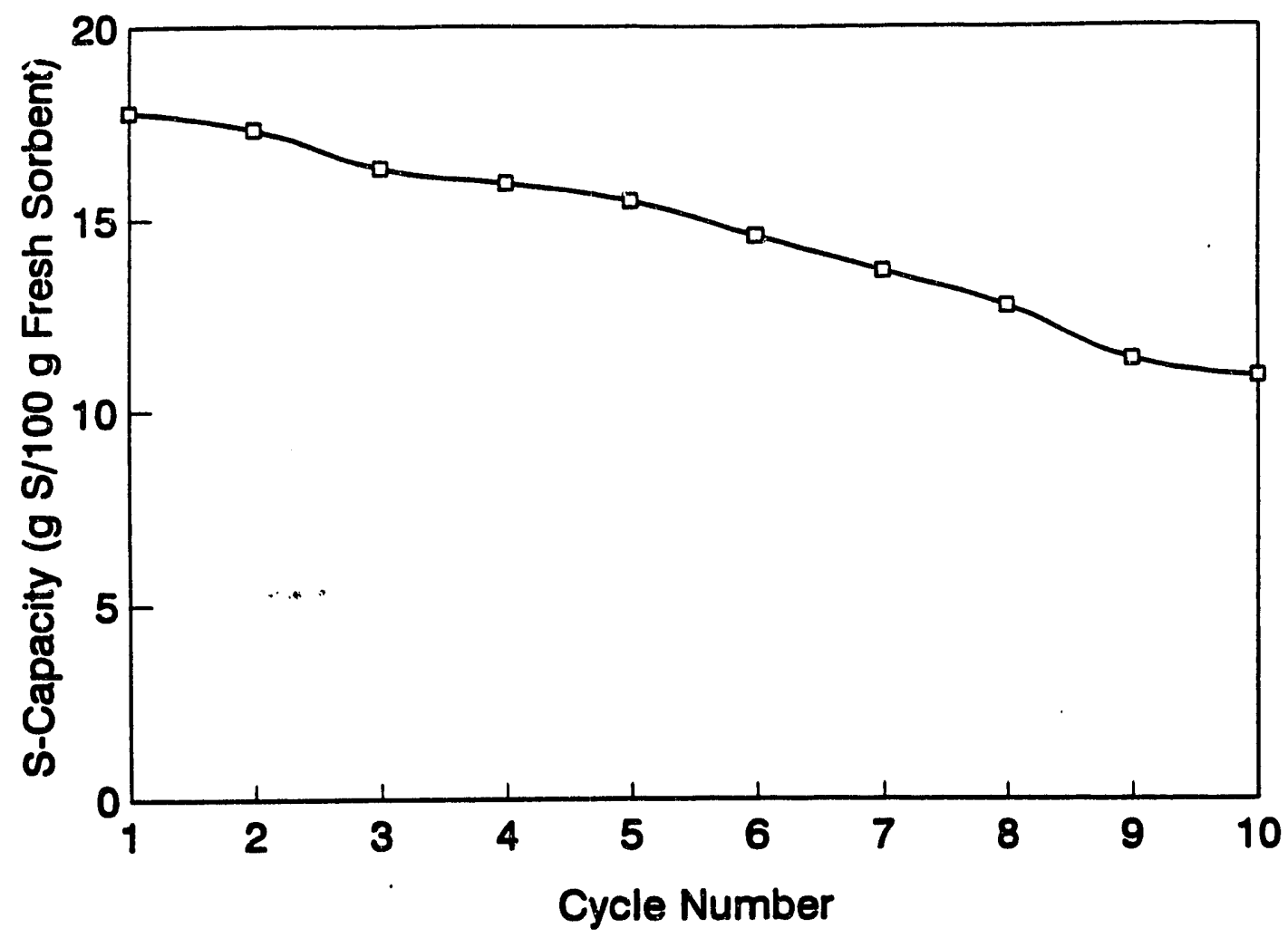

Figure E-3. S-capacity of ZT-5 in KRW gas at $650^{\circ} \mathrm{C}$.

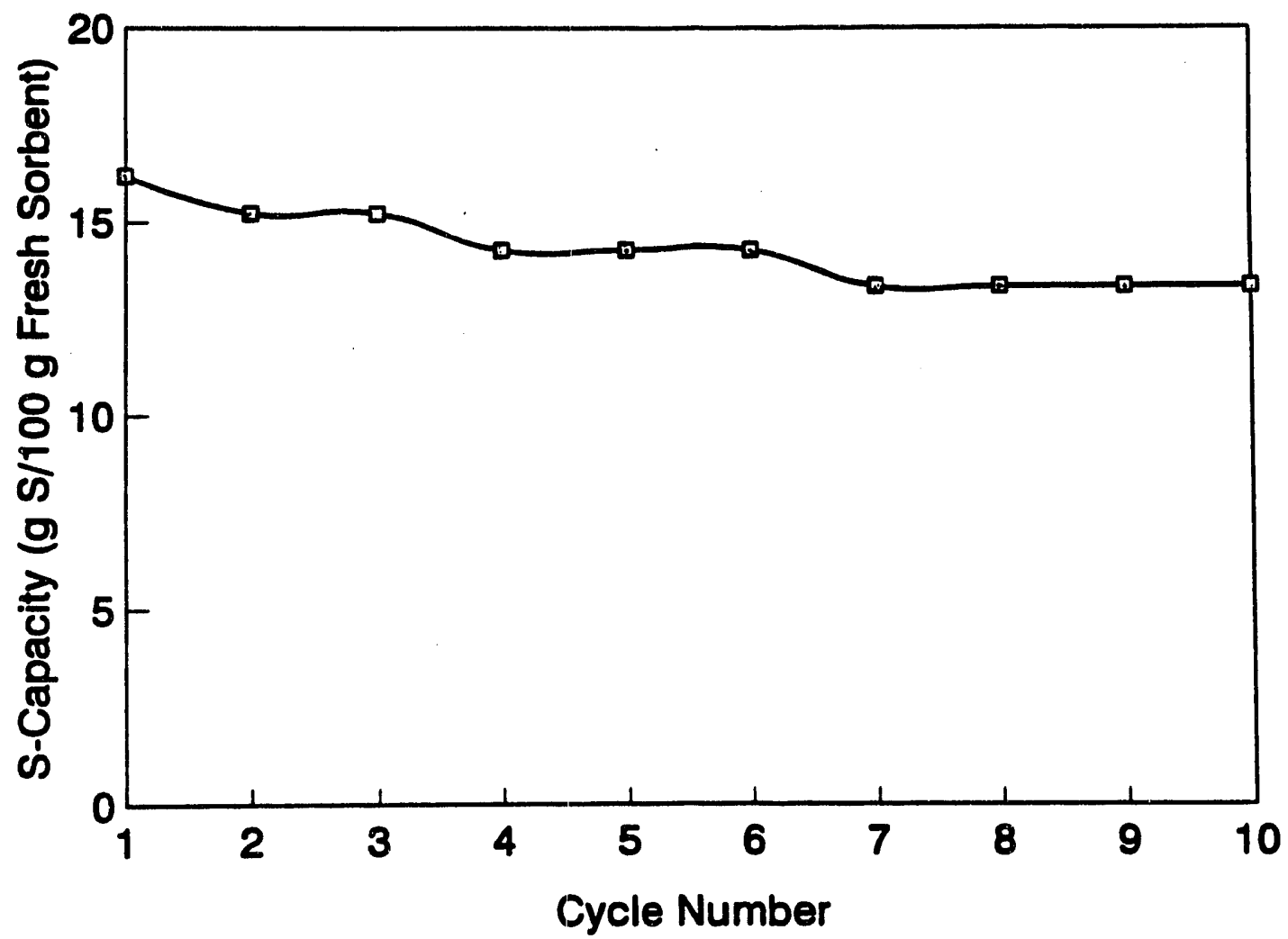

Figure E-4. S-capacity of ZT-5 in Texaco gas at $650^{\circ} \mathrm{C}$. 


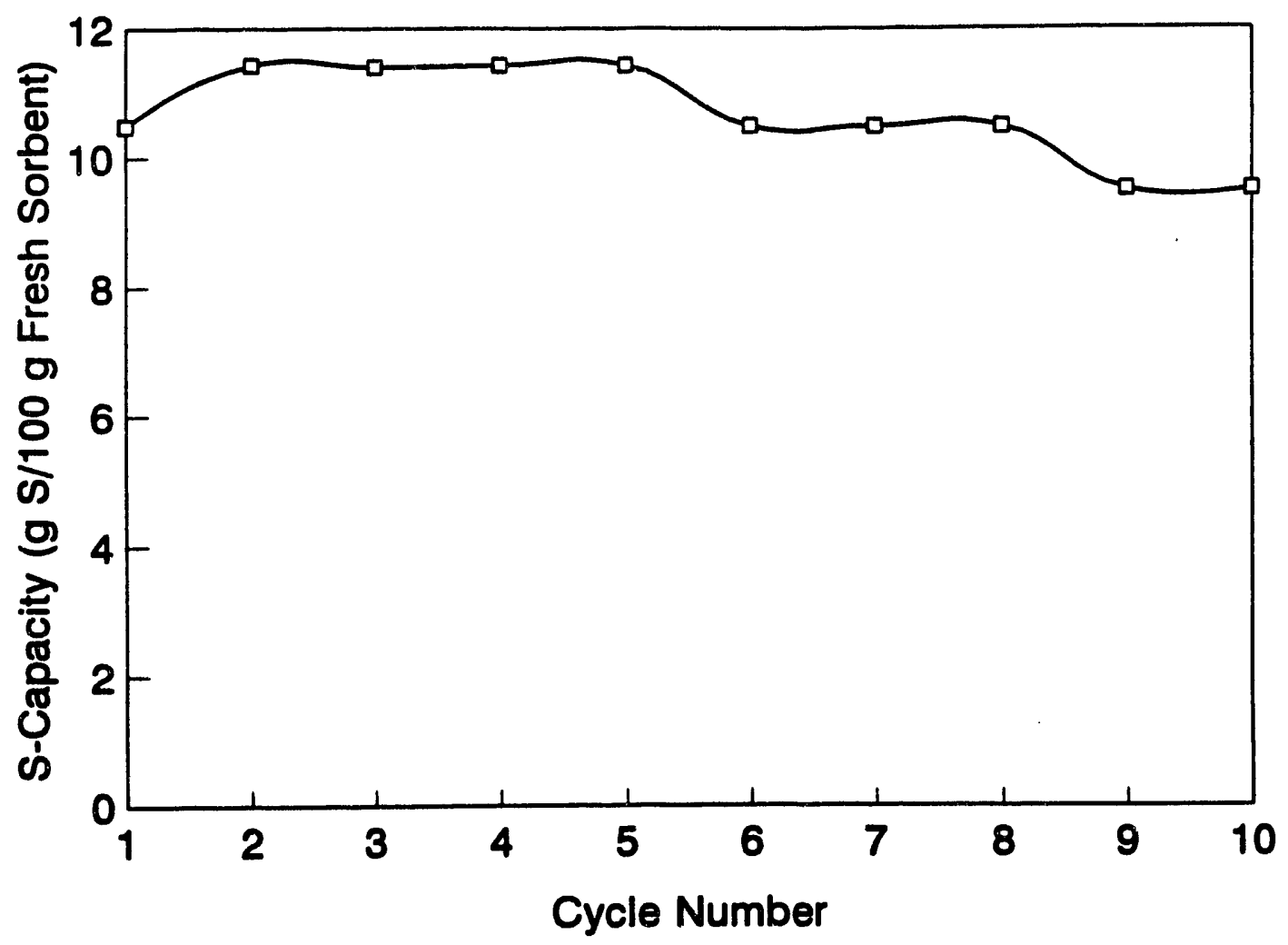

Figure E-5. S-capacity of ZT-2 in Texaco gas at $650^{\circ} \mathrm{C}$.

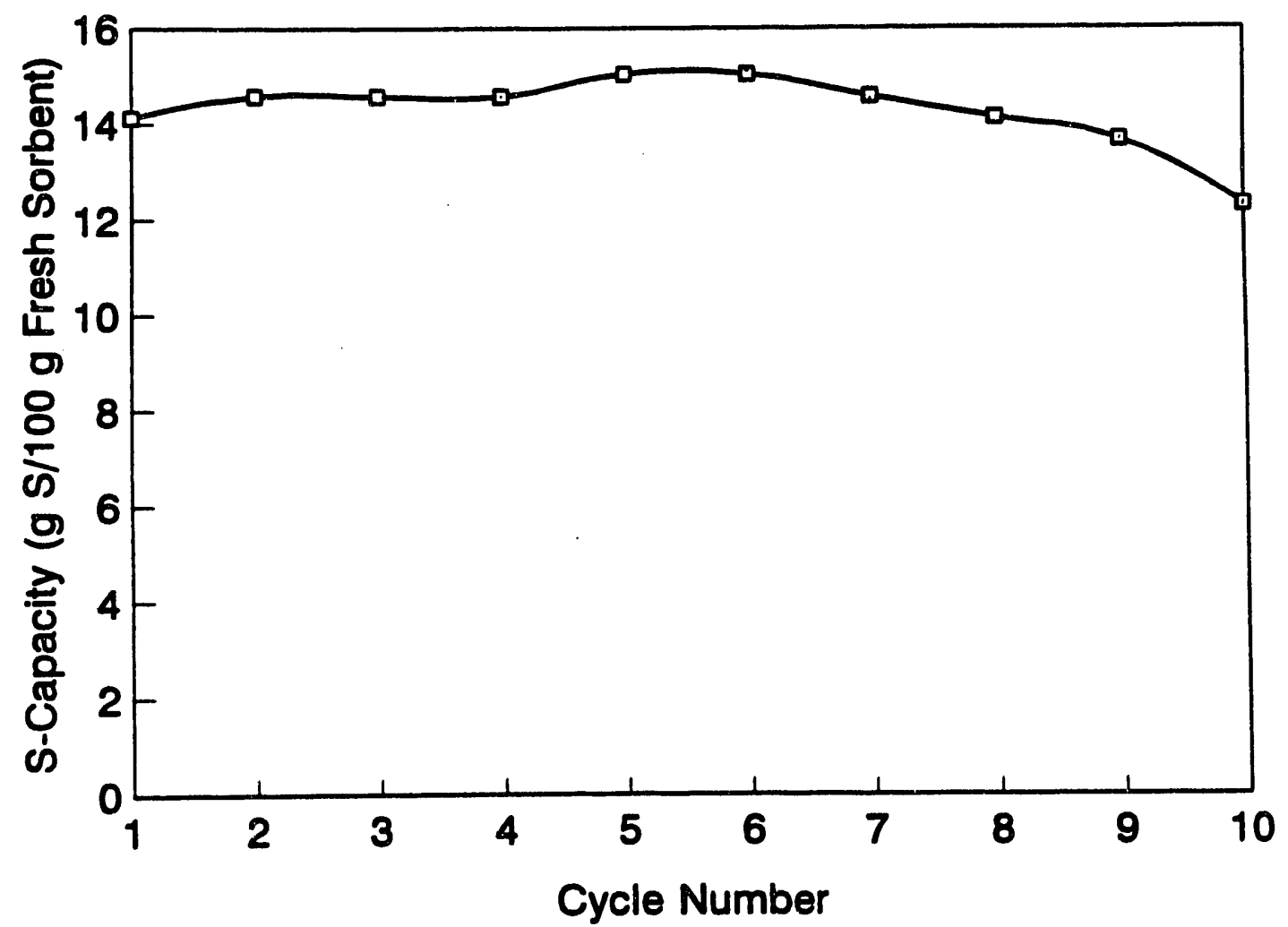

Figure E-6. S-capacity of ZT-2 in KRW gas at $650^{\circ} \mathrm{C}$. 


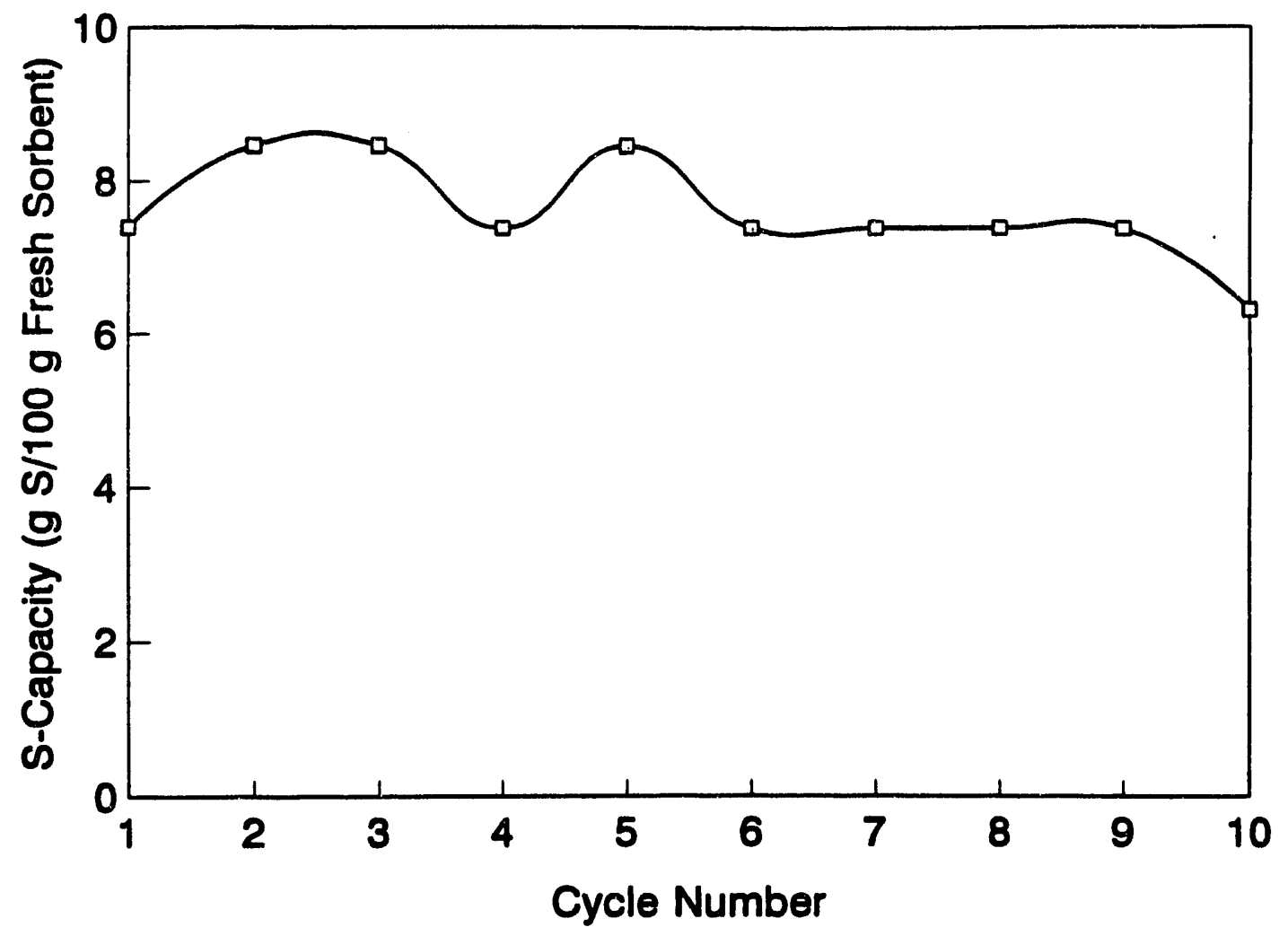

Figure E-7. S-capacity of ZT-7 in Texaco gas at $650^{\circ} \mathrm{C}$.

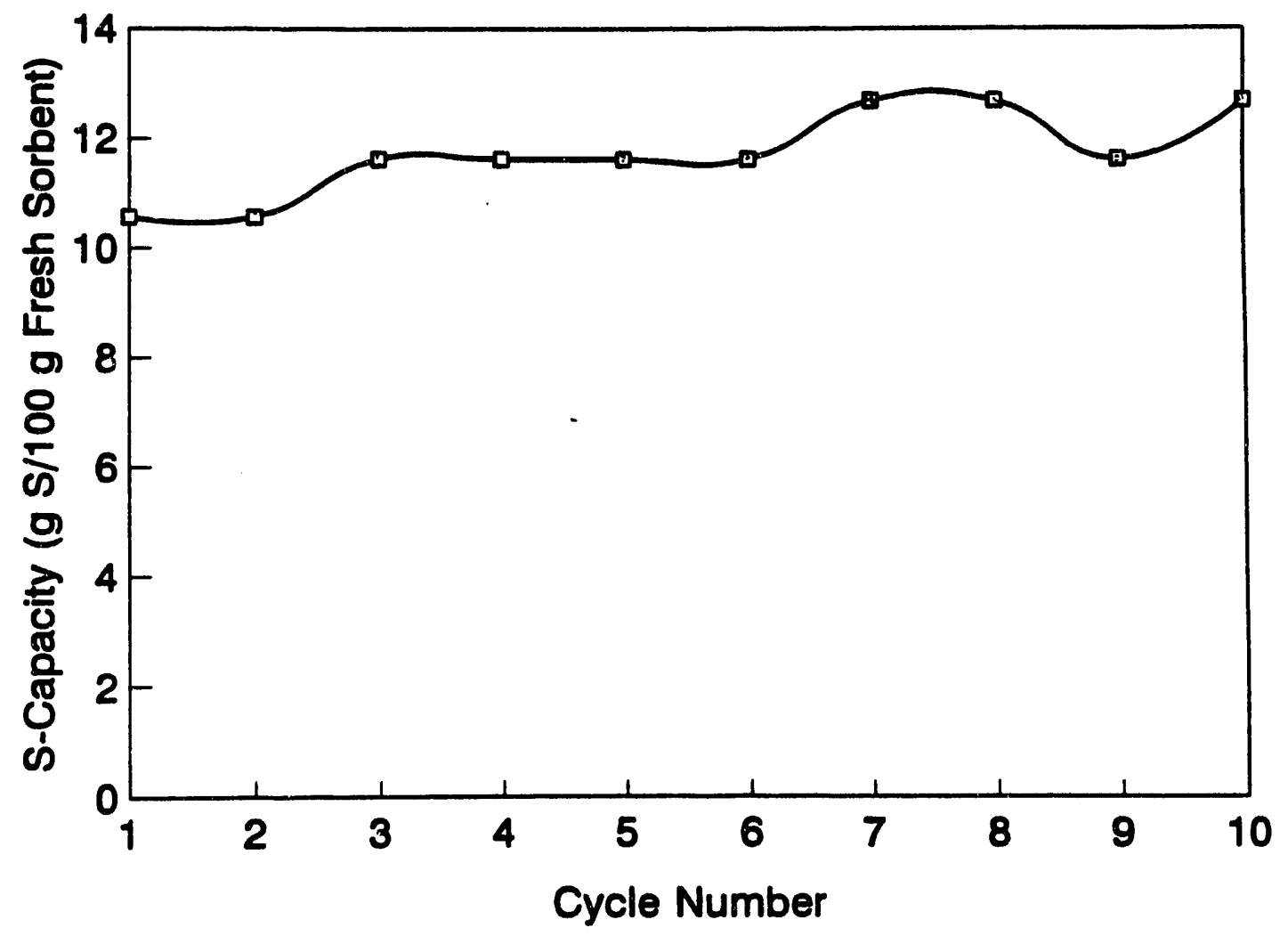

Figure E-8. S-capacity of $2 T-4$ in Texaco gas at $650^{\circ} \mathrm{C}$. 


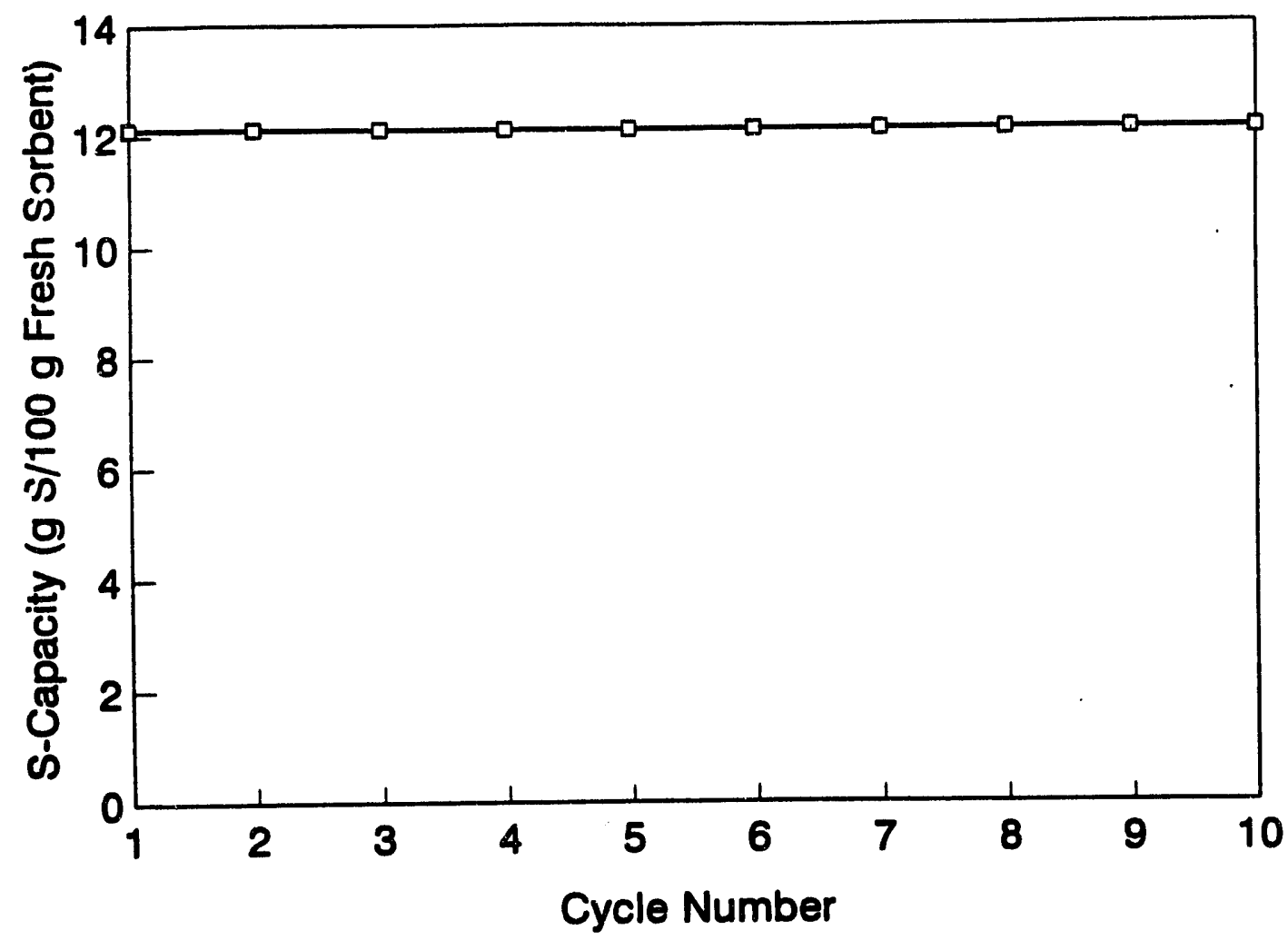

Figure E-9. S-capacity of $\mathrm{ZT-4}$ in Texaco gas at $750^{\circ} \mathrm{C}$.

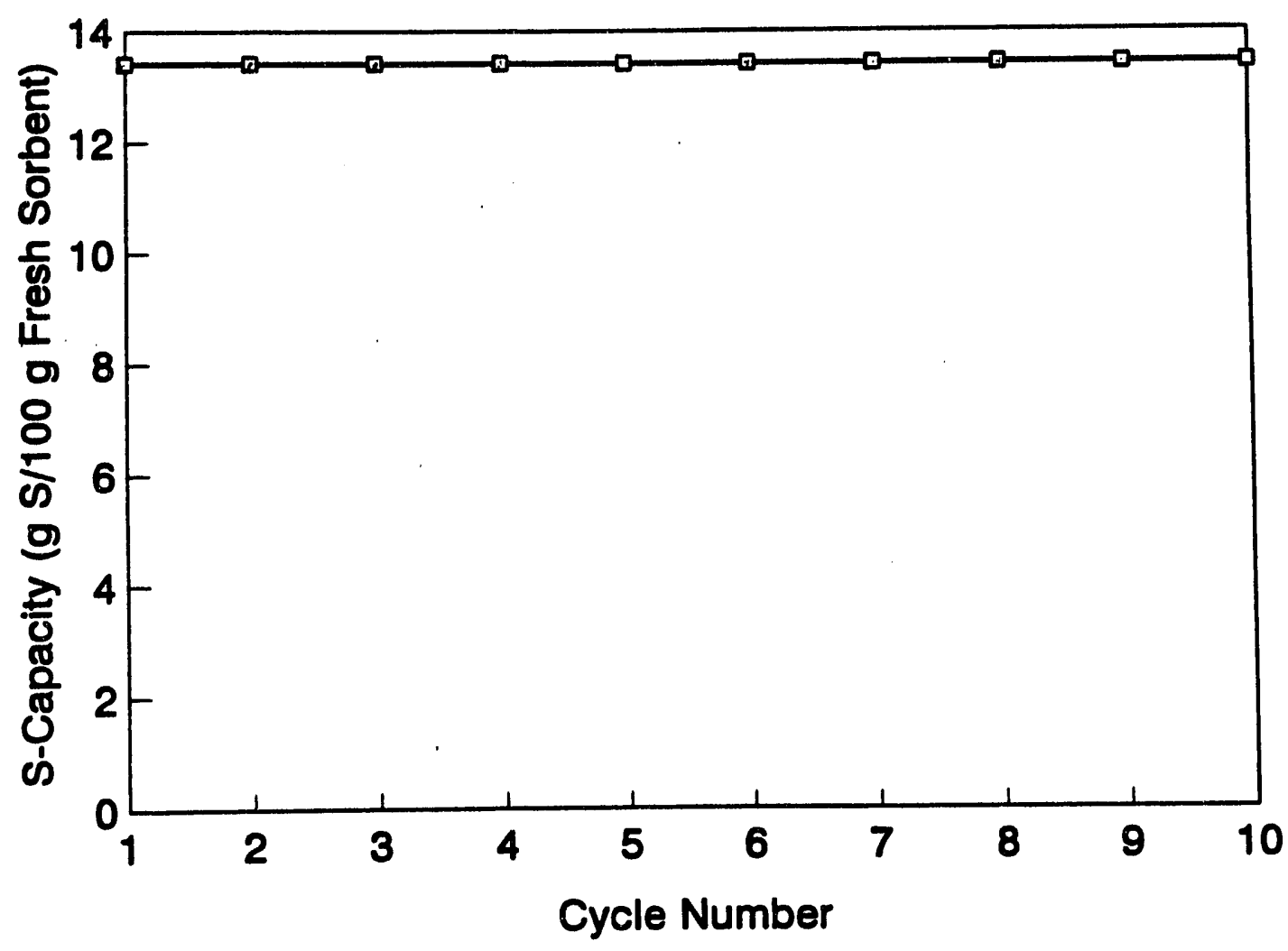

Figure E-10. S-capacity of ZT-4 in Texaco gas at $750^{\circ} \mathrm{C}$. 
PARTICLE SIZE DISTRIBUTION OF FRESH AND REACTED SORBENTS FOR RUNS 1 TO 10 


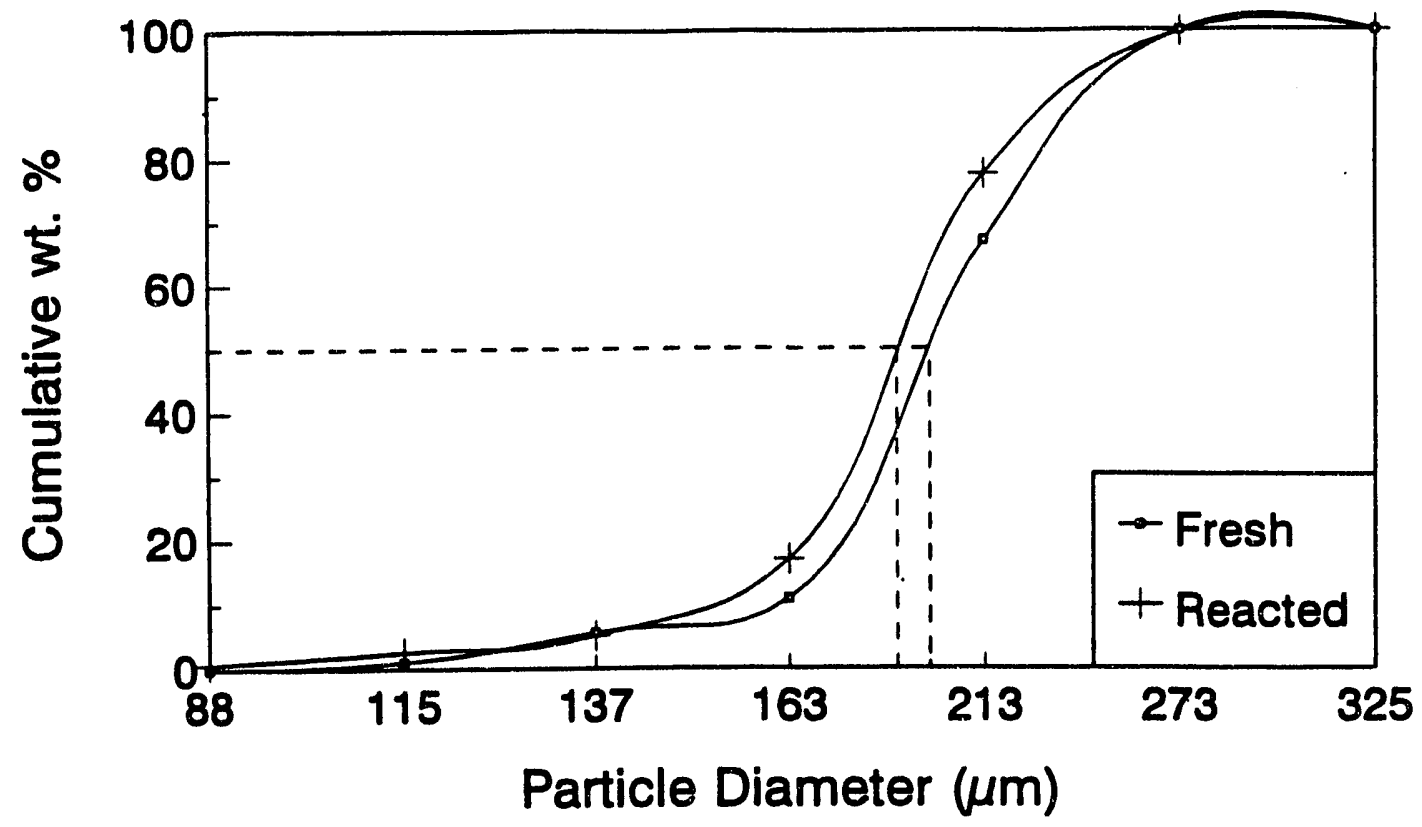

Run *1

Figure F-1. Particle size distribution, fresh and reacted L-3758 run at $650^{\circ} \mathrm{C}$ in KRW gas.

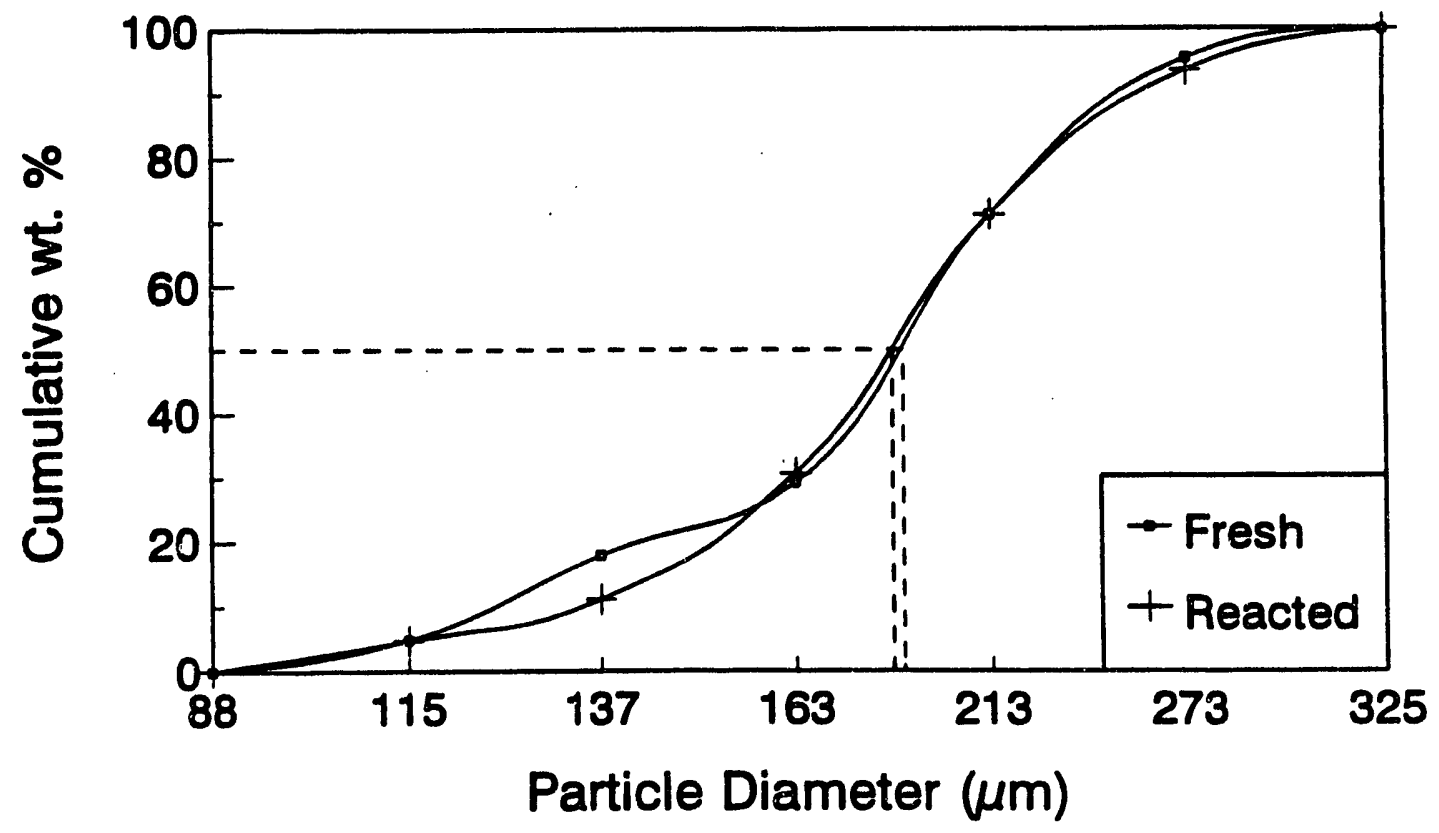

Run \#2

Figure F-2. Particle size distribution, fresh and reacted $\mathrm{ZT}-5$ run at $650^{\circ} \mathrm{C}$ in KRW gas. 


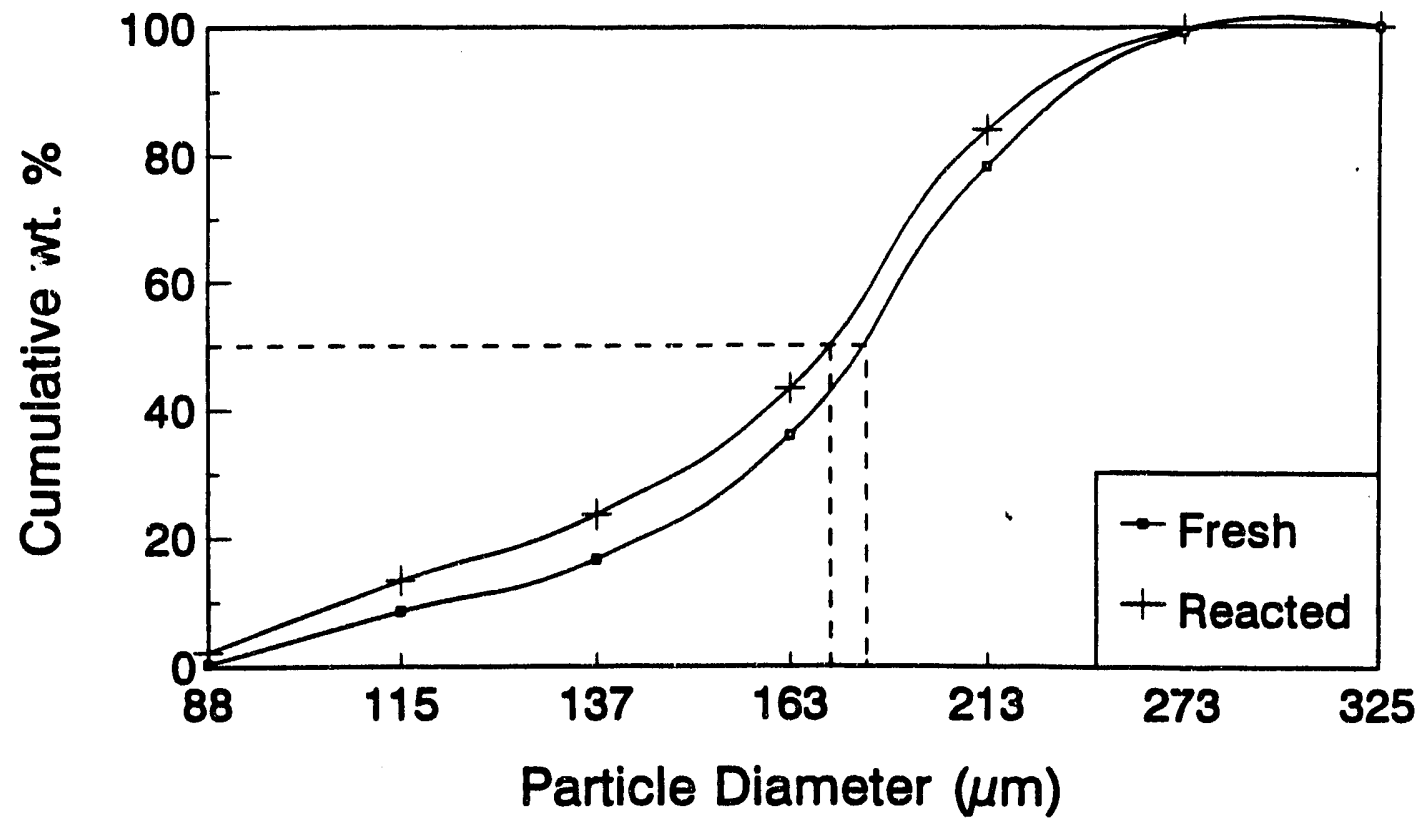

Run \#3

Figure F-3. Particle size distribution, fresh and reacted ZT-5 run at $650{ }^{\circ} \mathrm{C}$ in KRW gas.

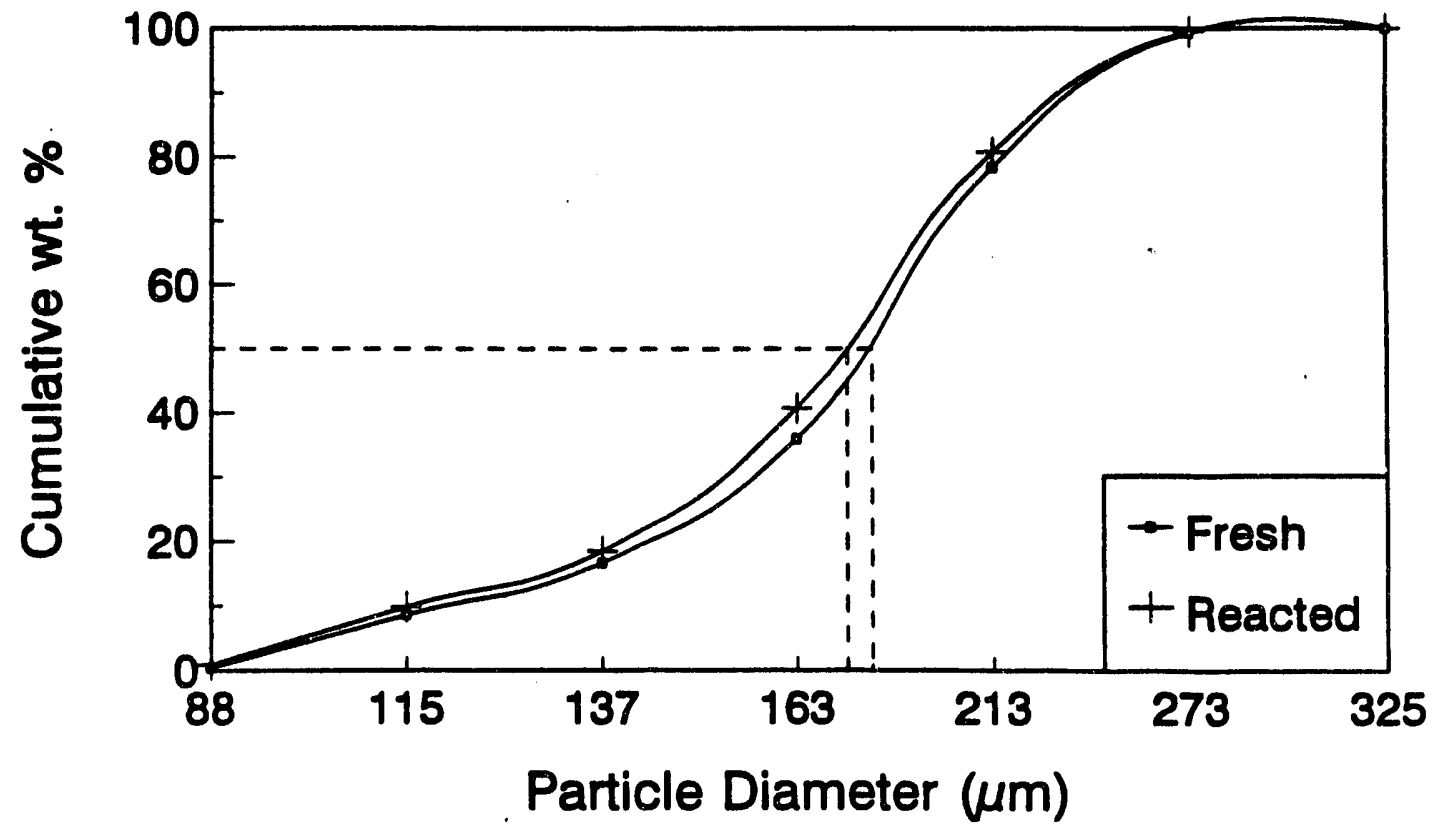

Run \#4

Figure F-4. Particle size distribution, fresh and reacted $\mathrm{ZT}-5$ run at $650{ }^{\circ} \mathrm{C}$ in Texaco gas. 


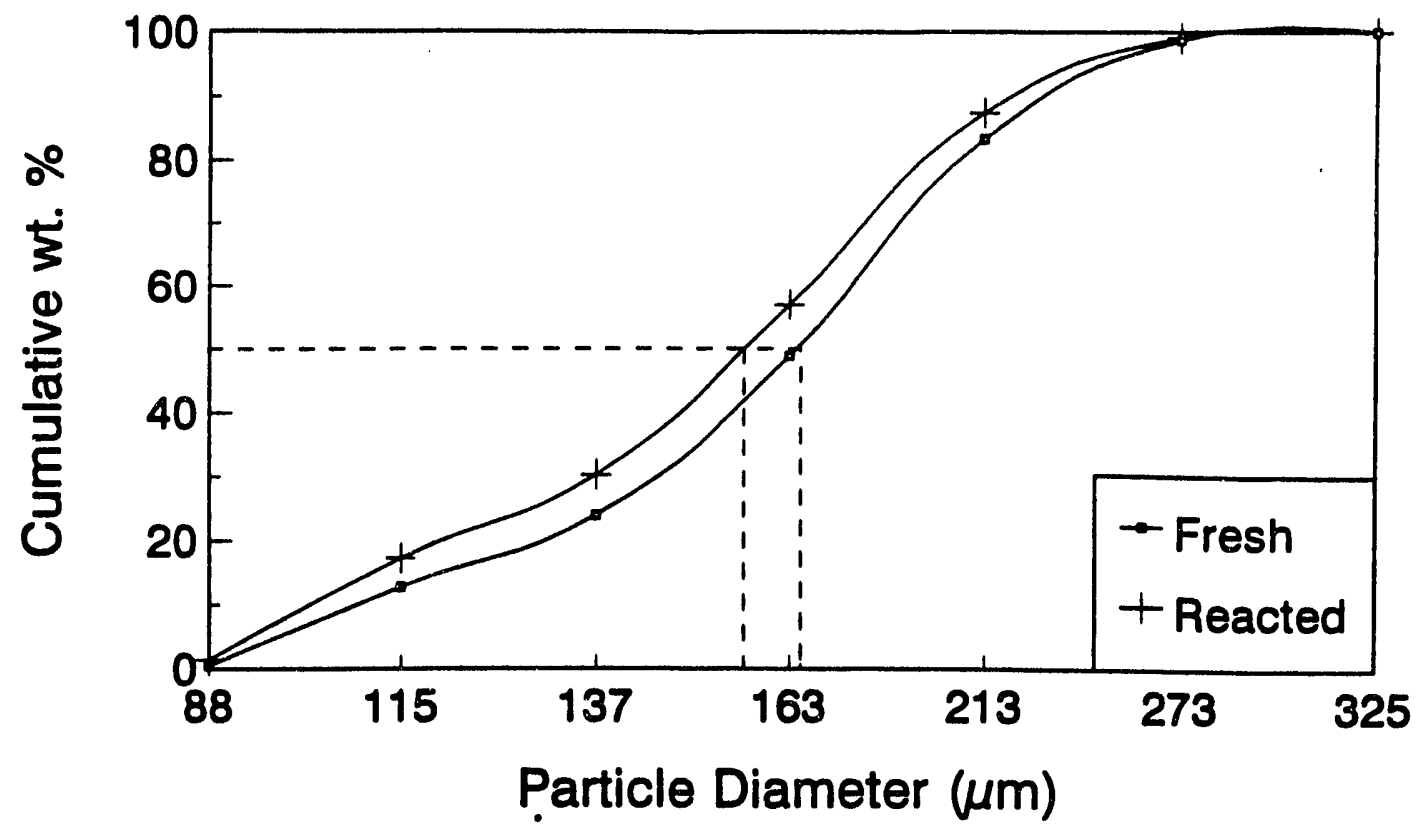

Run \#5

Figure F-5. Particle size distribution, fresh and reacted $\mathrm{ZT-2}$ run at $650^{\circ} \mathrm{C}$ in Texaco gas.

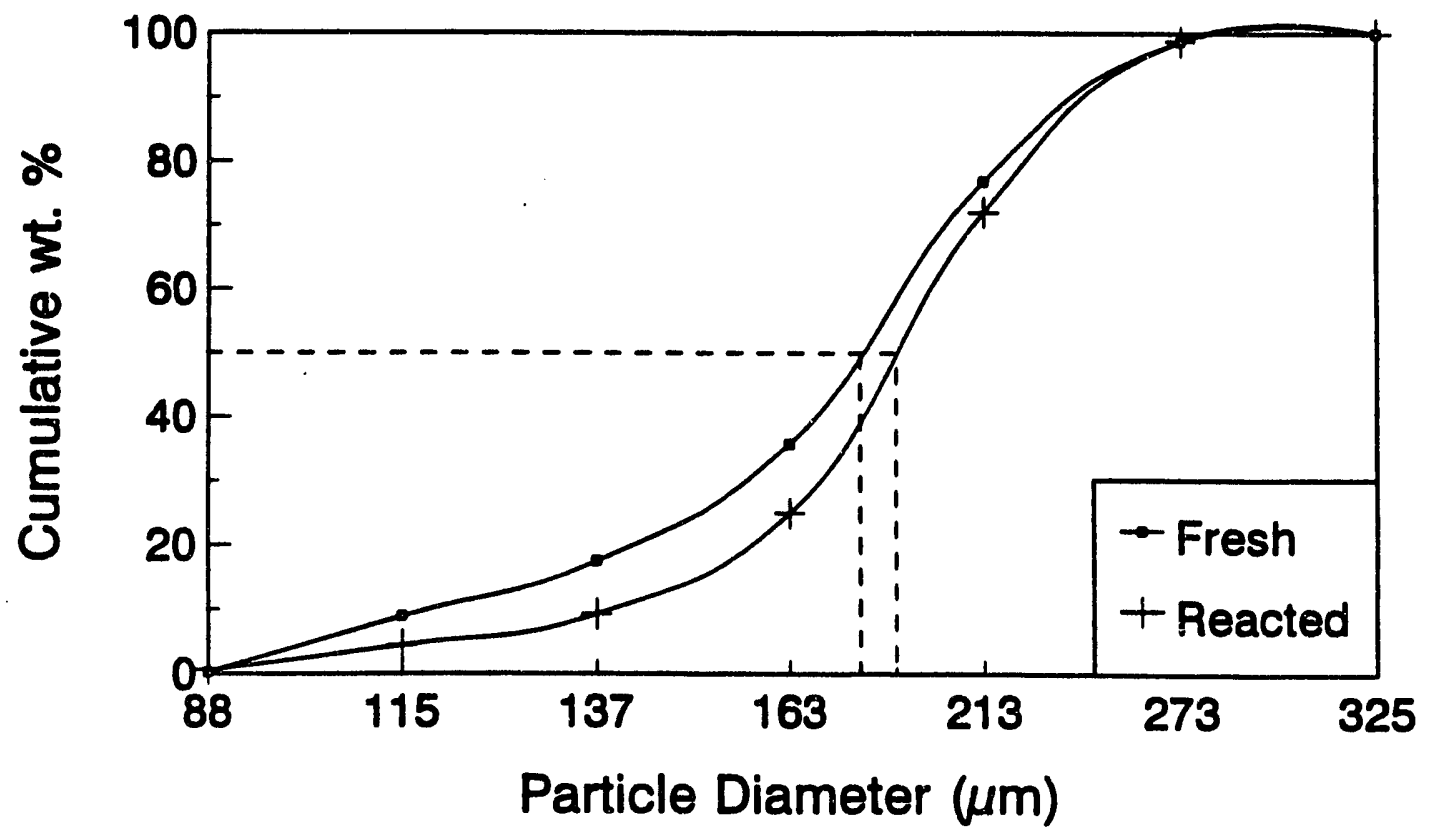

Run \#6

Figure F-6. Particle size distribution, fresh and reacted $\mathrm{ZT-2}$ run at $650^{\circ} \mathrm{C}$ in KRW gas. 


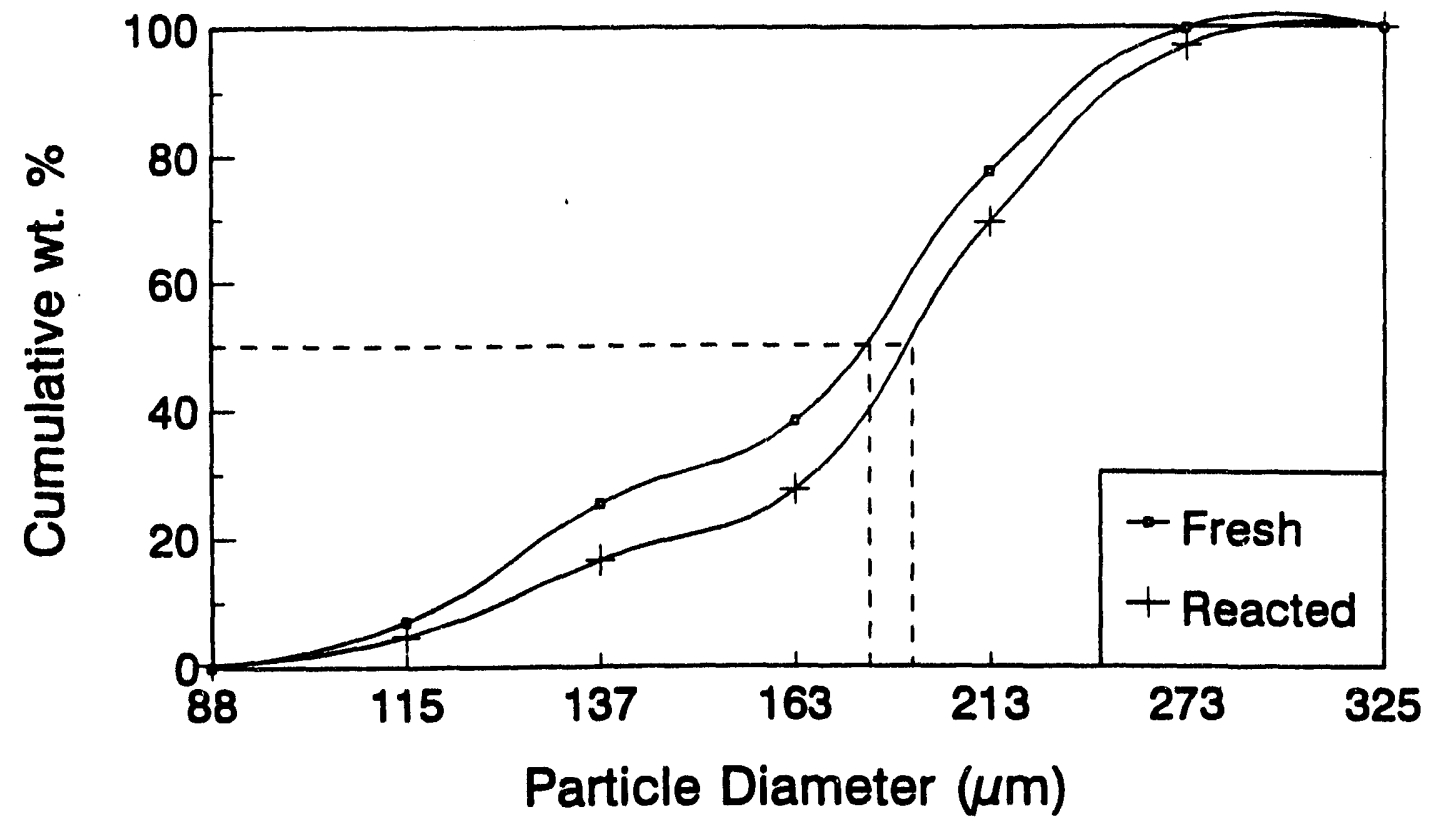

Run \#7

Figure F-7. Particle size distribution, fresh and reacted ZT-7 run at $650{ }^{\circ} \mathrm{C}$ in Texaco gas.

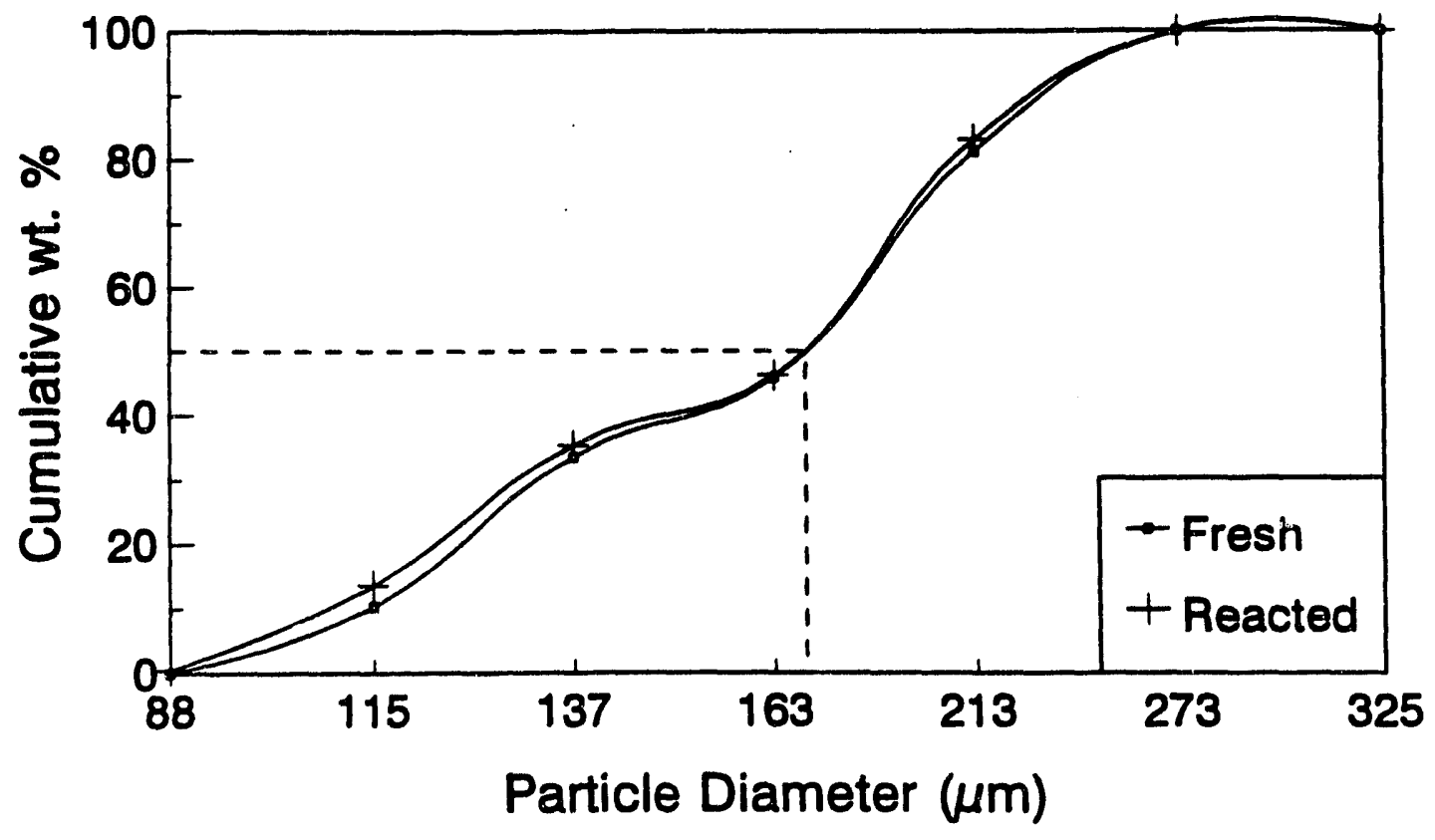

Run \#8

Figure F-8. Particle size distribution, fresh and reacted ZT-4 run at $650^{\circ} \mathrm{C}$ in Texaco gas. 


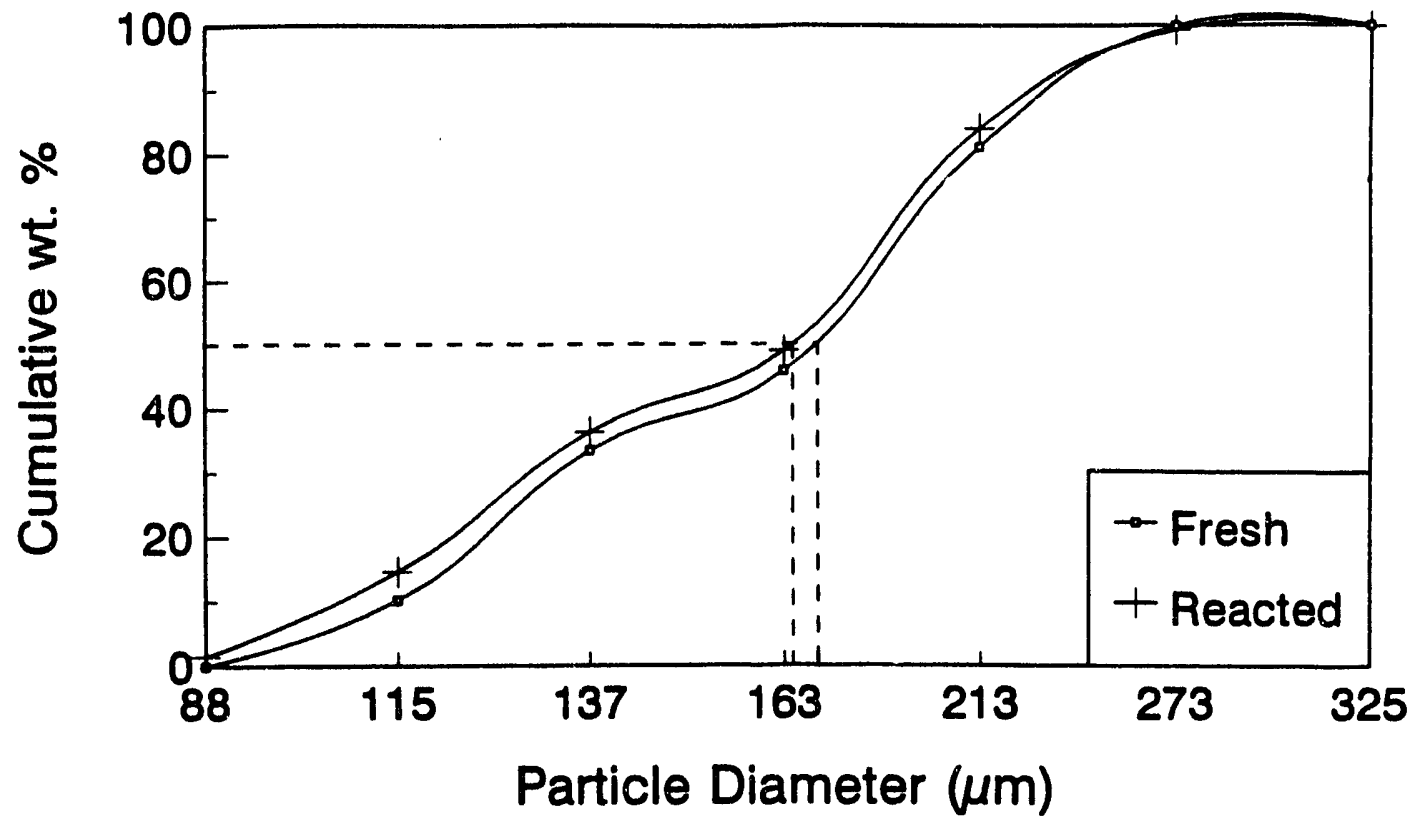

Run \#9

Figure F-9. Particle size distribution, fresh and reacted $\mathrm{ZT}-4$ run at $750{ }^{\circ} \mathrm{C}$ in Texaco gas.

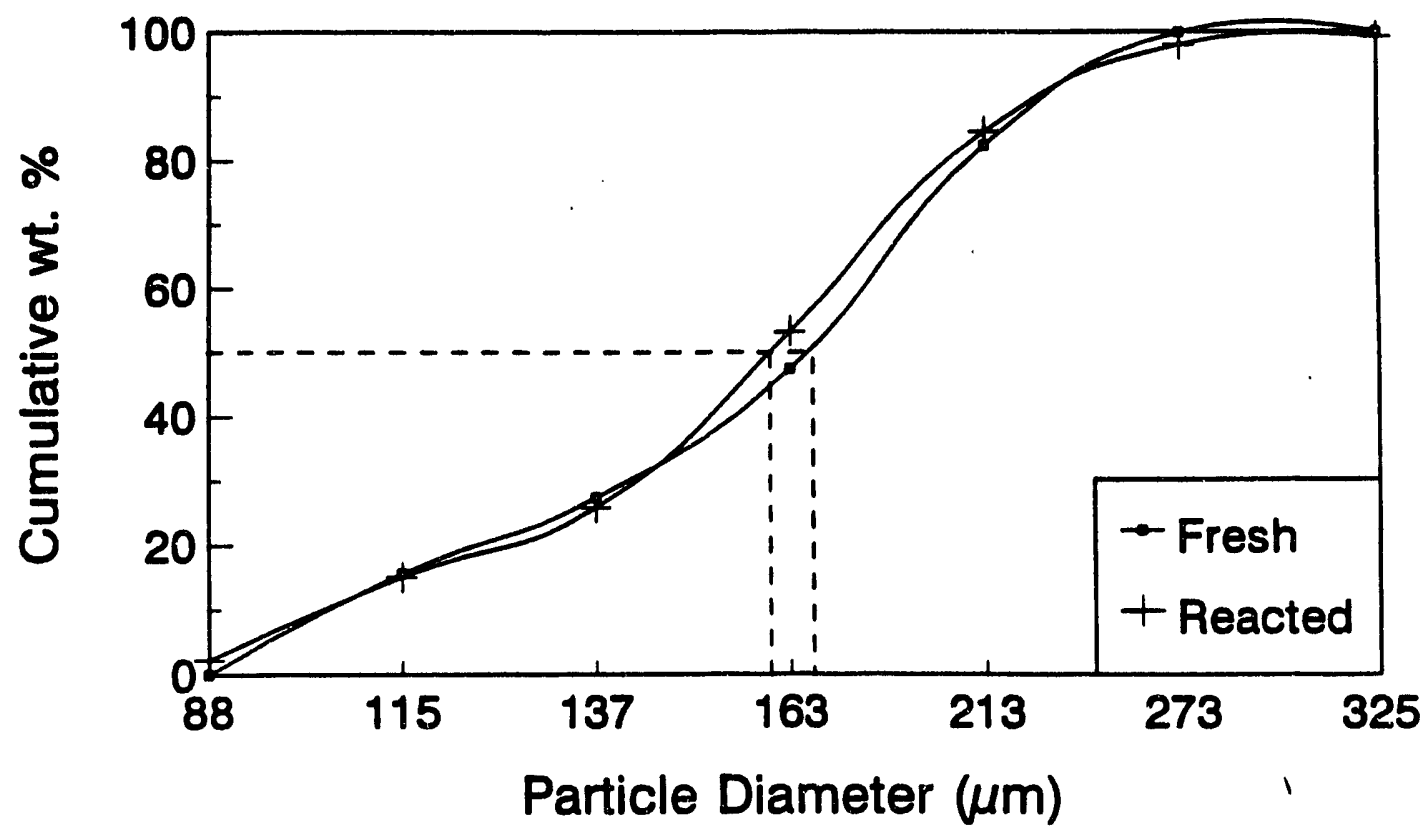

Run \#10

Figure F-10. Particle size distribution, fresh and reacted $\mathrm{ZT}-4$ run at $750{ }^{\circ} \mathrm{C}$ in Texaso gas. 

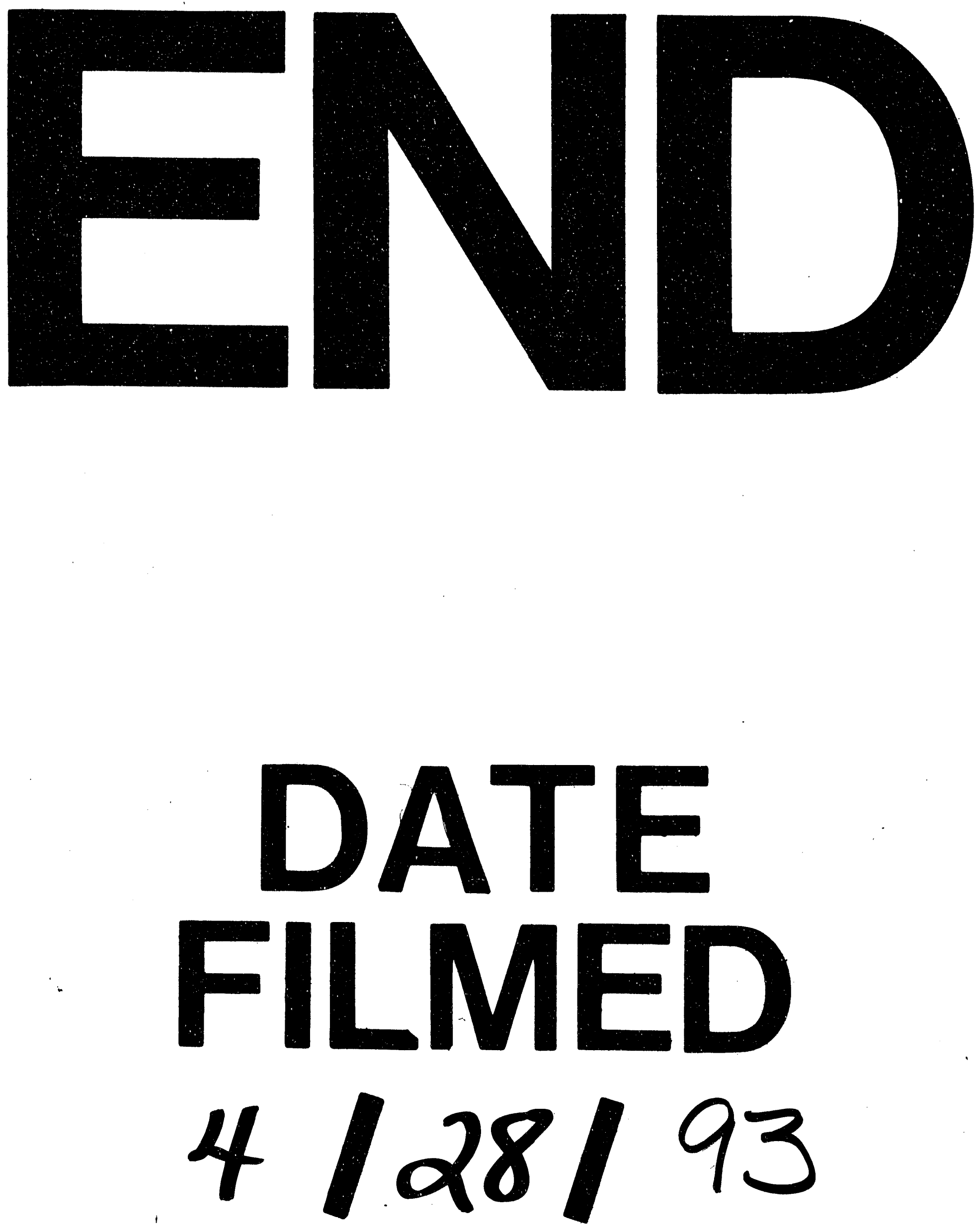


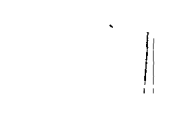

